Argonne

\title{
Irreversible Wash Aid Additive for Cesium Mitigation: Selection and/or Modification of Commercial Off-the-Shelf Field Portable Waste Water Systems
}

Nuclear Engineering Division 


\section{Acknowledgment}

The U.S. Environmental Protection Agency managed and collaborated in the research described in this presentation under Contract CBCM3332. It has been subjected to the Agency's review and has been approved for publication. Note that approval does not signify that the contents necessarily reflect the views of the Agency. Mention of trade names, products, or services does not convey official EPA approval, endorsement, or recommendation.

\section{About Argonne National Laboratory}

Argonne is a U.S. Department of Energy laboratory managed by UChicago Argonne, LLC under contract DE-AC02-06CH11357. The Laboratory's main facility is outside Chicago, at 9700 South Cass Avenue, Argonne, Illinois 60439. For information about Argonne and its pioneering science and technology programs, see www.anl.gov.

\section{DOCUMENT AVAILABILITY}

Online Access: U.S. Department of Energy (DOE) reports produced after 1991 and a growing number of pre-1991 documents are available free via DOE's SciTech Connect (http://Www.osti.gov/scitech/)

Reports not in digital format may be purchased by the public from the National Technical Information Service (NTS):

U.S. Department of Commerce

National Technical Information Service

5301 Shawnee Rd

Alexandria, VA 22312

wuw.ntis.gov

Phone: (800) 553-NTIS (6847) or (703) 605-6000

Fax: (703) 605-6900

Email: orders@ntis.gov

Reports not in digital format are available to DOE and DOE contractors from the Office of Scientific and Technical Information (OSTI):

U.S. Department of Energy

Office of Scientific and Technical Information

P.O. Box 62

Oak Ridge, TN 37831-0062

unw.osti.gov

Phone: (865) 576-8401

Fax: (865) $576-5728$

Email: reports@osti.gov

\section{Disclaimer}

This report was prepared as an account of work sponsored by an agency of the United States Government. Neither the United States Government nor any agency thereof, nor UChicago Argonne, LLC, nor any of their employees or officers, makes any warranty, express or implied, or assumes any legal liability or responsibility for the accuracy, completeness, or usefulness of any information, apparatus, product, or process disclosed, or represents that its use would not infringe privately owned rights. Reference herein to any specific commercial product, process, or service by trade name, trademark, manufacturer, or otherwise, does not necessarily constitute or imply its endorsement, recommendation, or favoring by the United States Government or any agency thereof. The views and opinions of document authors expressed herein do not necessarily state or reflect those of the United States Government or any agency thereof, Argonne National Laboratory, or UChicago Argonne, LLC. 


\section{Irreversible Wash Aid Additive for Cesium Mitigation: Selection and/or Modification of Commercial Off-the-Shelf Field Portable Waste Water Systems}

by

Michael Kaminski, Carol Mertz, and Nadia Kivenas

Nuclear Engineering Division

Argonne National Laboratory

Matthew Magnuson

National Homeland Security Research Center

U.S. Environmental Protection Agency

January 2015 



\section{TABLE OF CONTENTS}

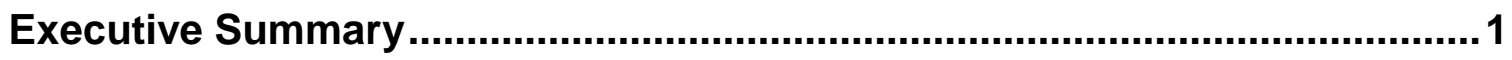

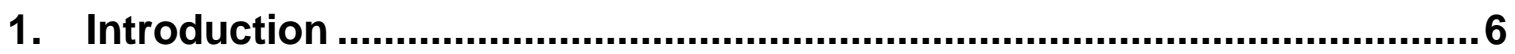

2. Materials, Reagents, and Unit Operations Considered..........................11

2.1 The Wash Solution Composition ............................................................... 11

2.2 Availability and Pricing of Wash Solution Additives....................................... 18

2.3 Creating the Saturated Brine ............................................................. 21

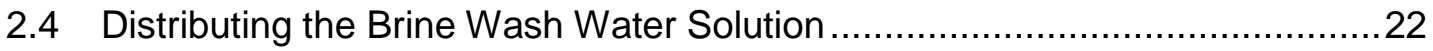

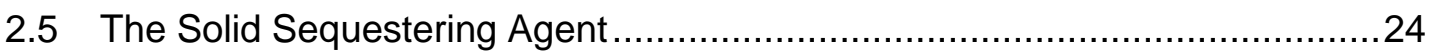

2.5.1 Role and Requirements .......................................................... 24

2.5.2 Candidate Sequestering Materials .................................................25

2.5.3 Sequestering Agent Availability and Pricing .................................40

2.5.4 Choosing the Sequestering Agents......................................... 43

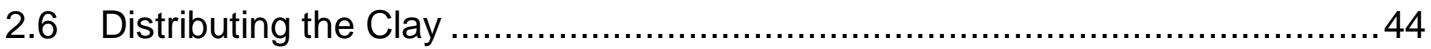

2.7 Containing the Contaminated Water for Filtration and Reuse ........................44

2.7.1 The Network of Sewer Lines as a Reservoir ...................................45

2.7.2 Collapsible Berms .......................................................................4 46

2.7.3 Cost of HESCO Containers..........................................................49

2.7.4 Multi-Stage Separations to Produce Radioactively-Free Wash

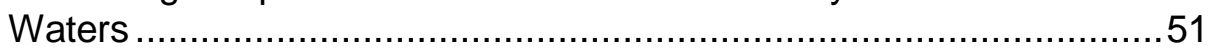

2.8 Prevent/Minimize Infiltration through Manholes and Sewers .........................52

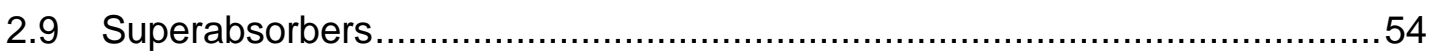

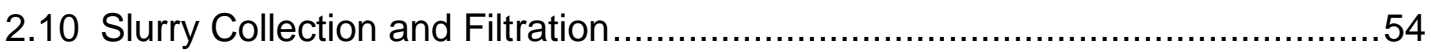

2.11 Filtering the Contaminated Wash Water Slurry ...........................................57

2.11.1 Massive Throughput Filter Devices ............................................58

2.11.2 Sedimentation Operations ...................................................6 60

2.11.3 Continuous Centrifugal Filters ..................................................... 64

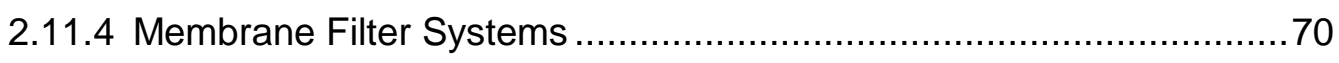

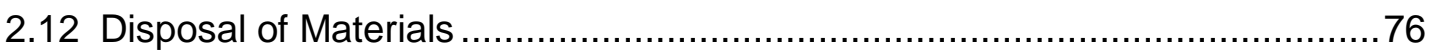

2.12.1 Disposal of the Berm Containers ................................................ 76

2.12.2 Disposal of the Fill Material and Sequestering Agents .....................77

2.12.3 Disposal of the Slurry or Wash Water ........................................ 78

2.13 Summary of COTS Selection Criteria and Recommendations .......................80

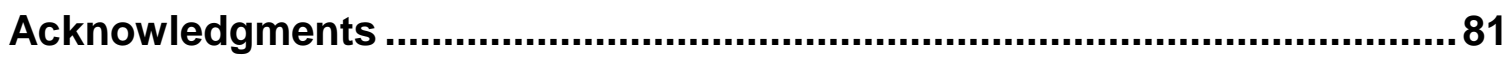

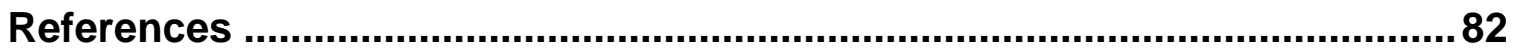

Appendix A. Views of Chicago Financial District........................................85

Appendix B. Summary of Data Gathered on Potential Sequestering Agents for Cesium from Salty Solution ..................................................................97

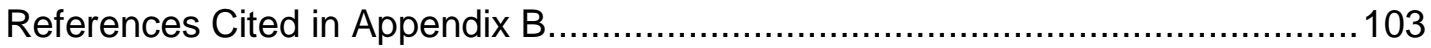


After an accidental or malicious release of radioactivity, large urban areas may be contaminated, compromising response efforts by first responders and law enforcement officials. In addition, some public services (e.g., drinking water and wastewater treatment, electrical power distribution, etc.) may be disrupted. In such an event, it may be important to deploy mitigation efforts in certain areas to restore response activities and public services (Fig. S-1). This report explores the state-of-the-art approach for a system to rapidly return critical infrastructure components to service following a cesium-137 (Cs-137) radiological dispersal device (RDD) release while avoiding the spread of Cs-137 beyond its original deposition area and minimizing the amount of Cs-137-contaminated wastewater. Specifically, we describe a wash system consisting of chemical additives added to fire hydrant water and irreversible solid sequestering agents added as the water is collected and treated for recycle in situ. The wash system is intended to be a rapidly deployable, cost-effective means of mitigating an urban setting for the purpose of restoring critical infrastructure and operational activities after a radiological release.

In Phase I, Argonne National Laboratory (Argonne) developed the basis for a gross mitigation method for radionuclide contaminations. In summary, the laboratory experiments demonstrated that the application of a suitable wash system has the potential to reduce the level of Cs-137 contamination, thus reducing the exposure of emergency workers, responders, and the general population to radiation in an urban environment. Depending on the impacted urban material, the amount of reduction may be as high as 90-100\%, for non-porous materials and for porous materials where the Cs-137 has not yet penetrated or bound to the porous material (for example, dry deposition of cesium). For porous material, where Cs-137 penetration and binding to components with high affinity such as certain minerals in aggregate used in concrete has occurred, the amount of reduction can also be 30-50\%, which at face value is not as impressive as for nonporous materials. However, when put into the context of the overall response to a Cs-137 $\mathrm{RDD}$, it can make a significant difference in the outcome in several areas, based on lessons learned from exercises involving RDDs, e.g., Liberty RadEx (Philadelphia) and TOPOFF 2 (Seattle). First, it may allow emergency responders to conduct response activities for longer periods of time by reducing their cumulative doses of radiation due to being in the "hot" zone. This is critical in the early phases of an RDD when the number of responders will be limited. A 50\% reduction in Cs-137 and a related reduction in exposure may allow the workers to remain on the job twice as long, performing twice as much life-saving activity. Second, the lower exposure would also be of benefit to workers involved in restoring the area to its original condition during late-phase recovery activities. Although a greater number may be available, qualified workers will represent a scarce resource. Third, reducing the contamination level by even $30 \%$ at the beginning of the clean-up may result in significant savings later, because the longer the Cs-137 is in contact with some common materials, a more aggressive approach may be needed to decontaminate them - for instance grinding off the surface may be necessary, which can be logistically more challenging and destructive with a higher aggregate radiation dose exposure to the workforce than a wash-aid application. 
Fourth, even lower reductions in Cs-137 via a wash system correlates to potentially significant reductions in the volumes of radiologically-impacted wastewater. Namely, the wash aid removes Cs-137 which may be mobile and capable of being spread to other locations. Experiments demonstrate that for non-porous surfaces such as sealed asphalt, most of the radiological contaminant is mobile, and that depending on the urban material, $\sim 25 \%$ to $90 \%$ is mobile. Thus, by providing another binding material, the mobility of Cs-137 is lessened as a whole. That which is mobile is sequestered by the wash aid, and the bound Cs-137 can be removed relatively easily from the wash water, leading directly to a reduction in the amount of radiologically-impacted wastewater being discharged to the environment. It will also result in a reduction of contamination released to sensitive and economically-important receiving waters (e.g., Puget Sound, with its large fisheries industry, was a concern in TOPOFF 2).

The contaminated runoff can be dramatically reduced by deploying artificial reservoirs around the contaminated zone. This system of berms serves to contain the contaminated material where it can be separated and treated; the sequestering agents are removed, dewatered, and transferred into transport containers for disposal, and the wash waters can be treated for reuse in mitigation activities, or treated and discharged or disposed.

The whole of the system is described as the "irreversible wash-aid additive" method and it is being further developed and demonstrated under Phase II of the project. Phase II of this project addressed several interrelated requirements related to the clean-up of Cs-137-RDD contamination.

- The need for rapid return to service of critical infrastructure, buildings, and public services.

- An approach to deal with enormous volumes (potentially billions of gallons) of wash-down water.

- A safe and effective means to apply existing technologies to RDD decontamination.

- The tools for use by the local response community.

- An assessment and selection of commercial, off-the-shelf (COTS) technologies and equipment that can be implemented for immediate availability.

This first report addresses these five requirements while the follow-up reports describe the field testing that was completed to demonstrate the wash-aid system and its deployment, and to develop the lessons learned.

Mitigation of a contaminated area can be accomplished with the use of many different approaches. Of those available (see full report for a summary), we chose to develop the technique of 1) washing down the contamination zone, 2) introducing sequestering agents into the wash water to bind the radionuclides, 3) containing the wash water locally, 4) treating the wash water to permit free release or reuse, and 5) disposing of the sequestering agents. Therefore, we completed a study of commercial vendors and suppliers to determine the COTS equipment that can be purchased, stockpiled, or that is immediately available either locally, regionally, or nationally, to deploy the wash-aid system. We supplemented any experimental data or literature data not obtained in Phase I 
with experiments in Phase II. The total system operations will be briefly addressed in turn.

The Wash Solution consists of a salt solution with a surfactant additive to improve the wettability of asphalt and other hydrophobic surfaces. The salts that we found that work the best are potassium and ammonium. These are supplied worldwide as potassium chloride, potassium nitrate, ammonium nitrate, and ammonium chloride. The surfactant that we tested was sodium dodecyl sulfate, also supplied in bulk with regional supplies. A saturated, surfactant brine can be created in smaller tanks and drawn into the fire hose by the eductor system already employed by firefighting units to achieve the desired salt concentration ( $>0.1$ molarity and preferably $0.5 \mathrm{M}$ molarity). These eductors draw a secondary fluid into the main water line without the need for specialized pumps. In this manner, the need for extra equipment is minimal, since the small tanks (several thousand gallons) and eductors are already available locally.

The Solid Sequestering Agent has the function of binding the mobile radionuclides introduced into the wash waters. Based on Phase I studies and supplemented by Phase II experiments, the sequestering agents of choice are montmorillonite and vermiculite clay with vermiculite being preferred. Both are prevalent regionally, but the purity of the montmorillonite is important and can be a supply chain issue, since the best purity is obtained oversees.

The Clay is Distributed across the ground in the affected zone and within the artificial reservoirs setup downgrade from the wash activities. It can be simply dumped from a truck and spread using shovel trucks of any sort available. The idea is to have the wash waters run down from the buildings and roadways and come in immediate contact with the clay so that the now-mobile radionuclides are quickly bound.

We expect to Contain the Contaminated Water for Filtration and Reuse by deploying a system of berms to create reservoirs at the street level. The COTS system we chose is from HESCO Global (Louisiana office). They are the prime suppliers of berm material for the military and flood zones across the U.S. Their system of accordion-style mesh-fabric containers can be deployed rapidly and in hazardous conditions. The containers are filled with either the clay material, or any available fill, like rocks, dirt, or sand. By encircling the perimeter of a contaminated zone, the wash waters will be contained. HESCO baskets can be placed atop catch basins, sewer caps, and utility manhole covers to prevent extensive intrusion of contaminated waters into the underground tunnels.

As the wash waters and clay material collect in the reservoirs, we will begin Slurry Collection and Filtration operations. From the experiment, we expect up to $80 \%$ of the cesium to be bound within the clay sequestering agent within the reservoir. To permit the release of the wash water for reuse or disposal, we must remove the remaining fraction of mobile cesium. This can be accomplished in several ways. But first, the original sequestering agent must be separated from the wash water. To do this, we chose a series of COTS filters. The first is a centrifugal filter manufactured by LAKOS (California). The LAKOS units can operate at very high throughput (millions of gallons per day) on high slurry concentrations. There are no moving parts except for the pump that feeds the separator. Centrifugal action forces the solid material into the purge zone while the clarified product is fed to another unit for secondary or final clarification. Final clarification is achieved by a simple membrane filter with purge capacity to collect 
settled solids. We chose the mobile transport design by Separmatic Systems (Wisconsin) because of its high throughput, simple operation, reliability, and reasonable cost. Their system removes all suspended material and can be purged automatically to avoid close contact with radioactive material.

Additional mixing of clarified wash waters with clay to remove the remaining mobile cesium can be accomplished by transferring the product wash waters from either filtration unit to a small reservoir, mixing fresh clay into this reservoir, collecting this material, and separating the solids as before.

Disposal of Materials is a key aspect of the technology. By using the clay and filtration system, we can be reasonably assured that the wash waters will be suitable for direct disposal as treated waters (not low-level radioactive liquid waste). The presence of salt complicates its disposal since the salt would be prohibited from entering the water treatment facilities (based on our interaction with officials at the municipal water treatment facilities across the country). Therefore, a system would be needed to remove the salt. We are exploring options. The sequestering agents can be collected from the purge lines of the centrifugal and membrane filter units directly into inflatable waste bladders provided by several U.S. suppliers and transported to a facility for low-level waste (LLW) treatment. The berms can be wrapped in plastic liners (provided by several U.S. suppliers as part of their container systems) and lifted onto trucks for transport and disposal. Or, if the contents are deemed to be clean, the HESCO container structure itself can be removed for low-level waste disposal, and the fill material can be hauled away separately, to a landfill or other suitable disposal site. 


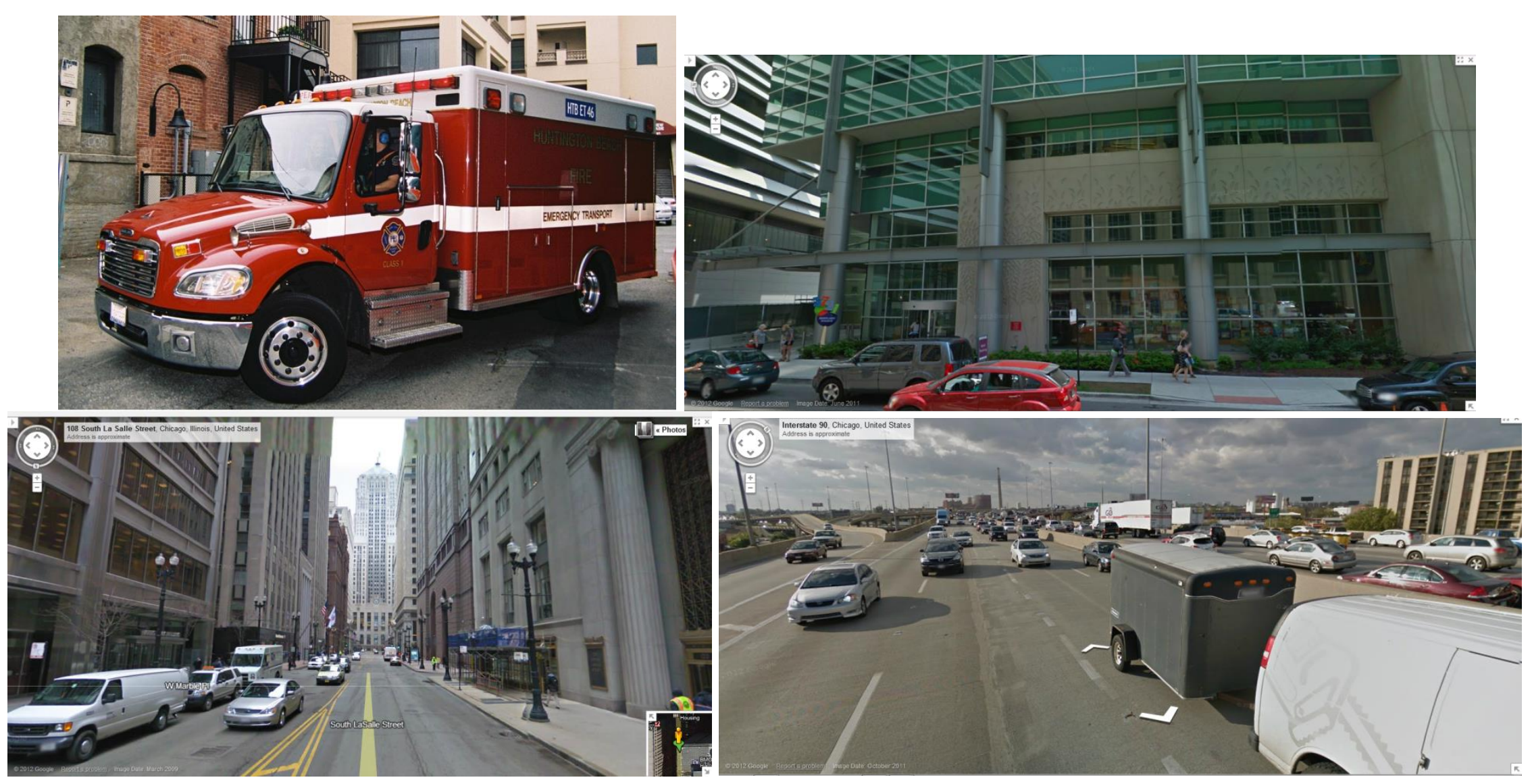

Figure S-1. Radiation mitigation efforts might be required to maintain first-responder operations by decontaminating rescue vehicles leaving the contamination zone (upper left), or re-open critical infrastructure such as hospitals (upper right), financial and business centers (bottom left), and major thoroughfares for access and egress (bottom right). 
After an accidental or malicious release of radioactivity, large urban areas may be contaminated, compromising response efforts by first responders and law enforcement officials. In addition, some public services (e.g., drinking water and wastewater treatment, electrical power distribution, etc.) may be disrupted. In such an event, it may be important to deploy mitigation efforts in certain areas to restore response activities and public services. This report explores the state-of-the-art for a system to rapidly return critical infrastructure components to service following a cesium-137 (Cs-137) radiological dispersal device (RDD) release while avoiding the spread of Cs-137 beyond its original deposition area and minimizing the amount of Cs-137-contaminated wastewater. Specifically, we describe a wash system consisting of chemical additives added to fire hydrant water and irreversible solid sequestering agents added as the water is collected and treated for recycling in situ. The wash system is intended to be a rapidly deployable, cost-effective means of mitigating an urban setting for the purpose of restoring critical infrastructure and operational activities after a radiological release.

Mitigation refers primarily to activities that occur shortly after an attack that restore the infrastructure to a level where it can continue to be utilized, allowing public services to be provided. Note that this is different from decontamination, which is a longer-term activity, designed to cleanup the contaminated infrastructure to acceptable levels. Thus, these mitigation methodologies may not be as effective as those methodologies used for final decontamination. Nevertheless, during mitigation, speed at which methodologies can be deployed and completed may be of equal importance, relative to their effectiveness, and may also impact the effectiveness of decontamination technologies for longer term recovery.

An optimal water-based mitigation technology will be capable of achieving two main goals. The first is the ability to remove radioactive cesium from the surfaces of structures. The second is that once the cesium has been removed from the surfaces of structures, it must be in a form that is conducive to common separation techniques like filtration or sedimentation. There are several operational options that are potentially feasible for implementation of this technology. One option is to introduce chelating agents that bind strongly to cesium into the wash water from a fire hydrant, thus carrying it into the wash water. Another option is to use soluble salts to promote ion exchange replacement reactions with the cesium that is bound to the surfaces. A combination of these two options is also implied. Once desorbed, the radioactive cesium must be removed from the solution so that the water may be reused in decontamination or discharged to eliminate the potential cross-contamination of areas by the runoff. A couple of approaches are permissible. The dissolved or chelated cesium can be bound onto solid supports introduced into the wash water for subsequent sedimentation or filtration operations. Or, the wash water can be collected and passed through an ion-specific filter system such as an ion-exchange column. An overall approach that includes a combination of these options may also be justified.

In Phase I, Argonne developed the basis for a gross mitigation method for radionuclide contaminations. In summary, the laboratory experiments demonstrated that the application of a suitable wash system has the potential to reduce the level of Cs-137 contamination, thus reducing the exposure of emergency workers, responders, and the 
general population to radiation in an urban environment. Depending on the impacted urban material, the amount of reduction may be as high as $90-100 \%$, for non-porous materials and for porous materials where the Cs-137 has not yet penetrated or bound to the porous material (for example, dry deposition of cesium). For porous material where Cs-137 penetration and binding to components with high affinity such as certain minerals in aggregate used in concrete and penetration has occurred, the amount of reduction can also be $30-50 \%$, which at face value, is not as impressive as for non-porous materials. However, when put into the context of the overall response to a Cs-137 RDD, can make a significant difference in the outcome in several areas, based on lessons learned from exercises involving RDDs [USEPA-2012b], e.g., Liberty RadEx (Philadelphia) [USEPA2012c] and TOPOFF 2 (Seattle) [US-DHS-2003].

First, it may allow emergency responders to conduct response activities for longer periods of time by reducing their cumulative doses of radiation due to being in the "hot" zone. This is critical in the early phases of an RDD when the number of responders will be limited. A 50\% reduction in Cs-137 and a related reduction in exposure may allow the worker to remain on the job twice as long, performing twice as much lifesaving activity. Second, the lower exposure would also be of benefit to workers involved in restoring the area to its original condition during late-phase recovery activities. Although a greater number may be available, qualified workers will represent a scarce resource. Third, reducing the contamination level even $30 \%$ at the beginning of the cleanup may result in significant savings later, because the longer the Cs-137 is in contact with some common materials, the more aggressive the approach that may be needed to decontaminate themfor instance, grinding off the surface may be necessary, which can be logistically more challenging and destructive with higher aggregate radiation dose exposure to the workforce than a wash-aid application.

Fourth, even lower reductions in Cs-137 via a wash system correlates to potentially significant reductions in the volumes of radiologically-impacted wastewater. Namely, the wash aid removes Cs-137 which may be mobile and capable of being spread to other locations. Experiments demonstrate that for non-porous surfaces such as sealed asphalt, most of the radiological contaminant is mobile, and that depending on urban material, $\sim 25 \%$ to $90 \%$ is mobile. Thus, by providing another binding material, the mobility of Cs-137 is lessened as a whole. That which is mobile is sequestered by the wash aid, and the bound Cs-137 can be removed relatively easily from the wash water, leading directly to a reduction in the amount of radiologically impacted water being discharged to the environment. It will also result in a reduction of contamination released to sensitive and economically-important receiving waters (e.g., Puget Sound with its large fisheries industry, was a concern in TOPOFF 2).

This irreversible wash-aid system was further developed and demonstrated under Phase II of the program. Phase II addressed several inter-related requirements related to clean-up of cesium-RDD contamination.

- The need for rapid return to service of critical infrastructure, buildings, and public services.

- An approach to deal with enormous volumes (potentially billions of gallons) of wash-down water. 
- Safe and effective means to apply existing technologies to RDD decontamination.

- The tools for the local response community.

The technical objective of Phase I was to demonstrate the irreversible wash-aid system for rapid return to service of critical infrastructures, buildings, and public services and to develop procedures that enable the removal of radiologically-bound particles from the wash water. The demonstration will include an evaluation of the technology for removal of cesium from urban surfaces and capture of the bound radionuclide via a modified portable wastewater treatment system. Demonstrating the irreversible wash aid system will involve application of the wash aid to the appropriate infrastructure, building component, or vehicle. It will culminate with the collection of the bound radionuclides, demonstrating the ability of the approach to reduce the millions of gallons of wash water reasonably expected from an RDD event.

This report describes the technologies reviewed and tested under the program that led to the selection and/or modification of commercial-off-the-shelf (COTS) fieldportable wastewater systems that might be suitable for immediate and large-scale deployment and can be demonstrated at the pilot scale.

Based on the Phase I study, Argonne, in partnership with the U.S. Environmental Protection Agency (EPA), defined an approach to perform an initial decontamination activity on critical infrastructure that included buildings, roadways, and vehicles, that may be deployed in the immediate aftermath of an RDD event [USEPA-2012a]. The exact timeline for deployment was not part of this study, although the consensus is that decontamination is most effective as soon as possible in the aftermath to avoid the spread of contamination and irreversible bonding of the radionuclides to environmental substrates.

We start with the assumption that a release of radioactivity has occurred and lifesaving operations have completed in the area to the point that first responders can implement radiological mitigation activities without compromising their mission. The mitigation efforts may assume any of the goals outlined below.

- Cover contamination zone with agent (e.g., film) to control resuspension and perform decontamination operations at later date.

- Wash down contamination zone and divert water and dilute in local, natural reservoir.

- Wash down contamination zone and allow water to travel through sewer system and treat at downstream location.

- Wash down contamination zone and introduce sequestering agents and allow water to travel through sewers and treat downstream.

- Wash down contamination zone and contain water locally and dispose.

- Wash down contamination zone and introduce sequestering agents and contain water locally and dispose.

- Wash down contamination zone and introduce sequestering agents and contain water locally and treat water to free release or reuse and dispose of sequestering agents. 
Localized and wide-area mitigation operations will create tremendous volumes of potentially-contaminated waters, thousands to millions, or even billions of gallons. Because operations will occur outside, in an uncontrolled environment (i.e., unable to entirely contain the reagent wash waters and contaminated wash), we avoided the use of hazardous chemical agents and recognized that our ability to control the temperature would be severely limited. With this limitation, our previous studies highlighted several key reagents to any such radioactive decontamination operation and these are: 1) salts dissolved in the water will promote the release of radioactivity from the contaminated substrates (e.g., roof tile, bricks, concretes, asphalts, cars) without the need for corrosive acids and 2) clay will bind the dissolved radioactivity in the wash water to prevent downstream contamination and facile filtration and discharge of the massive volumes of clean water. Argonne has designed a system of specific salts and clays to meet this challenge.

Ideally, the contaminated waters would be contained and treated to reduce the spread of contamination to the environment, water transport systems, and the downstream facilities. Based on worldwide experience in large-scale disaster response, private industry has off-the-shelf capabilities that can be utilized and/or modified for use. Argonne proposed to EPA the construction of temporary berms that hold contaminated waters and selectively remove the contamination while portable systems draw water from the reservoir, remove the radioactivity, and then pump these waters into reservoirs for reuse in decontamination activities or into the sewer system for treatment by the municipal water treatment facilities. Smaller scale operations can be operated similarly with small berms set up to capture flow from individual household mitigation and/or decontamination operations (such as from washing exterior walls, roofs, gutters, and downspouts).

The system we proposed employs commercial, off-the-shelf technology, available around the country and it is designed to prevent the need to dispose of the large quantity of radiologically-contaminated water. Ideally, in this approach, we would set up temporary and collapsible berms around the contamination zone first. However, we recognize that lifesaving operations are likely already in progress and may include firefighting operations, so berm emplacement may be occurring during initial and unintentional decontamination operations. The berms are filled with stone, rock, earth, sand, or ideally vermiculite or montmorillonite clay, which are highly selective toward sorption of cesium. Then, water permeating the berm will have no radiological consequence. Light, interwoven coir fabric logs may be placed around sewer inlets and catch basins outside the berm to prevent contamination from entering the sewer system. Another approach to protect the sewers from incoming waters is to place berm containers filled with clay over the sewer caps. Berms with impermeable membranes filled with any available solid such as dirt, gravel, or sand would be effective in preventing water invasion. The same clay is spread across the ground within the bermed zone to interact with incoming wash waters and bind cesium.

Critical infrastructure and buildings within the contaminated zone are thoroughly rinsed with the wash water - a combination of fire hydrant water mixed in-line with concentrated potassium or ammonium salts in a surfactant that help to promote the removal of fixed contaminants within the contamination zone. The in-line mixing uses conventional eductor systems and collapsible tanks common within the firefighter 
services. The copious amounts of salt water will carry radioactive cesium from the contamination zone and collect it within a temporary reservoir created by the berm zone. As the water collects, it is pumped from the reservoir to portable water purification trucks designed to rapidly filter suspensions. The capacity for each of these filter trucks is $>1 \mathrm{M}$ gallons per day for potable water. We will assess its capacity for our applications since we do not need to meet drinking water standards, but must remove the radioactive ions. The concentrated, radioactive clay solids are purged from this unit periodically into waste drums or bladders for further settling and decanting, before transporting to a staging area for treatment. We can send the cleaned water from the purification trucks to the sewer after assaying the water for radiological purity.

Based on the previous research and current knowledge, we summarize here the down selection process for each of the unit operations considered in this study. 


\section{MATERIALS, REAGENTS, AND UNIT Operations CONSIDERED}

\subsection{The Wash Solution Composition}

An important consideration in developing a wash solution for mitigation is to avoid introducing additional chemical hazards. Not only would a large volume of mixed waste be produced, which is extremely expensive and difficult to dispose of, the outdoor environment of the mitigation operations would preclude worker safety. Our previous work in the development of non-hazardous wash solutions [Kaminski-2008, Kaminski2013, USEPA-2012a] was based on the ability of common salts in high concentration to readily exchange with sorbed cesium [Nisbet-2009]. We employed commonly available salts distributed in large quantities locally and regionally.

The decontamination testing procedure differed slightly between fine and crushed, coarse aggregate of concrete, and the tile and brick samples because of the smaller mass of tile and brick materials available for testing. In all, a near-neutral solution of Cs-137 was mixed with the solid for at least 10 minutes before the supernatant was removed and the solids were washed with deionized water. The fine aggregate of concrete was tested in duplicate while the crushed, coarse aggregate was tested with single samples unless stated otherwise ( $5 \mathrm{~g}$ of material and $5 \mathrm{~mL}$ of the various wash solution). The crushed brick samples were tested in duplicate $(0.5 \mathrm{~g}$ of material and $0.5 \mathrm{~mL}$ of solution) and the crushed tile samples were tested in duplicate $(0.25 \mathrm{~g}$ of material and $0.25 \mathrm{~mL}$ of the various wash solutions).

Kinetic experiments (not shown in this document) showed that equilibrium was reached with gentle mixing after $<20$ minutes. To decontaminate, test samples were centrifuged for several minutes and aliquots $(20 \mu \mathrm{L})$ were withdrawn after 60 minutes. At the end of the contamination period, the remaining supernatant was removed and discarded. A second decontamination of the samples was performed by adding fresh wash solution (same volumes as used in first decontamination) and vortexing periodically during the decontamination period. Test samples were centrifuged for several minutes (depending upon the dispersibility of the material) and an aliquot $(20 \mu \mathrm{L})$ was withdrawn. The remaining solution was removed and discarded. Sample aliquots were diluted to $1 \mathrm{~mL}$ with deionized water and were gamma counted for 10 minutes to quantify the Cs-137 photopeak. Our work in this area showed that ammonium and potassium salts were equally effective in desorbing cesium from porous building materials, such as the aggregates from concrete (Fig. 1), crushed tiles (Figs. 2), and crushed brick (Figs. 3) and we obtained somewhat more consistently better results than the other monovalent salts. 


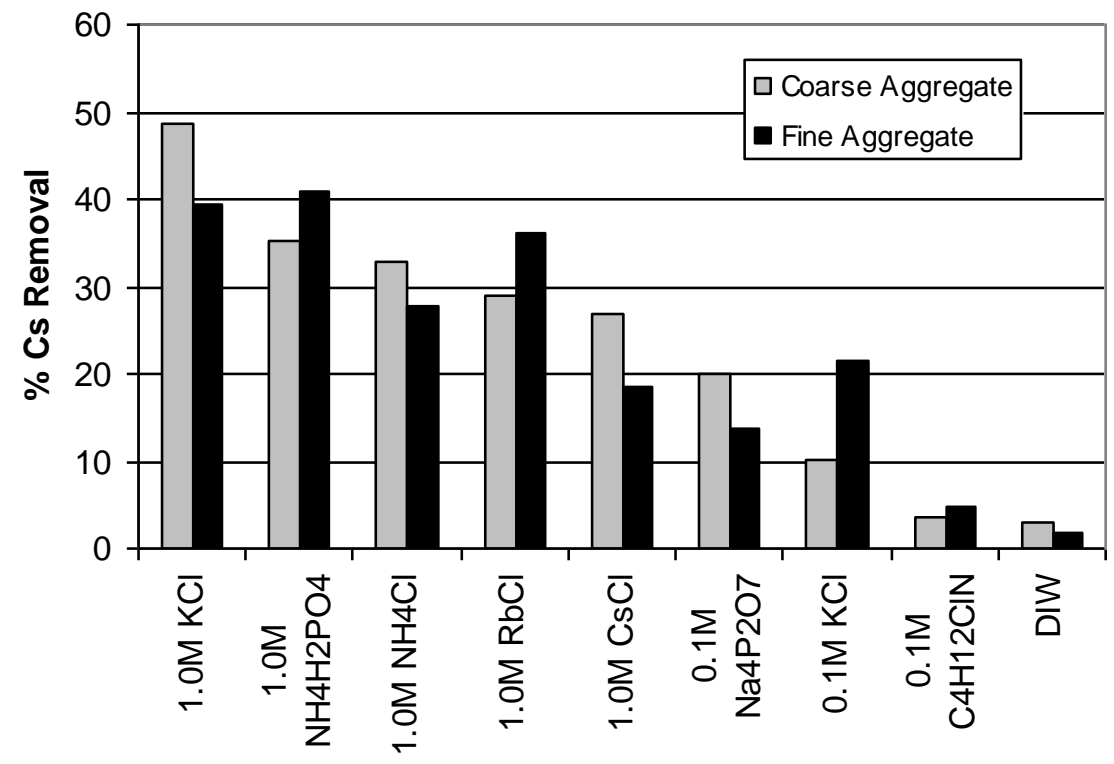

Wash Solution

Figure 1. Decontamination results using various wash solutions for cesium removal from the aggregate material of concrete. $1.0 \mathrm{M} \mathrm{KCl}$ in coarse aggregate is the average of duplicate tests. Similar tests run in triplicate at a later date showed that the decontamination of cesium using $1.0 \mathrm{NH}_{4} \mathrm{Cl}$ resulted in $50 \pm 2 \%$ and $29.0 \pm 0.4 \%$ removal from coarse aggregate and fine aggregate, respectively. The fine aggregate of $1.0 \mathrm{M}$ $\mathrm{NH}_{4} \mathrm{Cl}$ was done as a single sample. Data shows that non-ammonium-based solutions may perform as well as ammonium chloride.

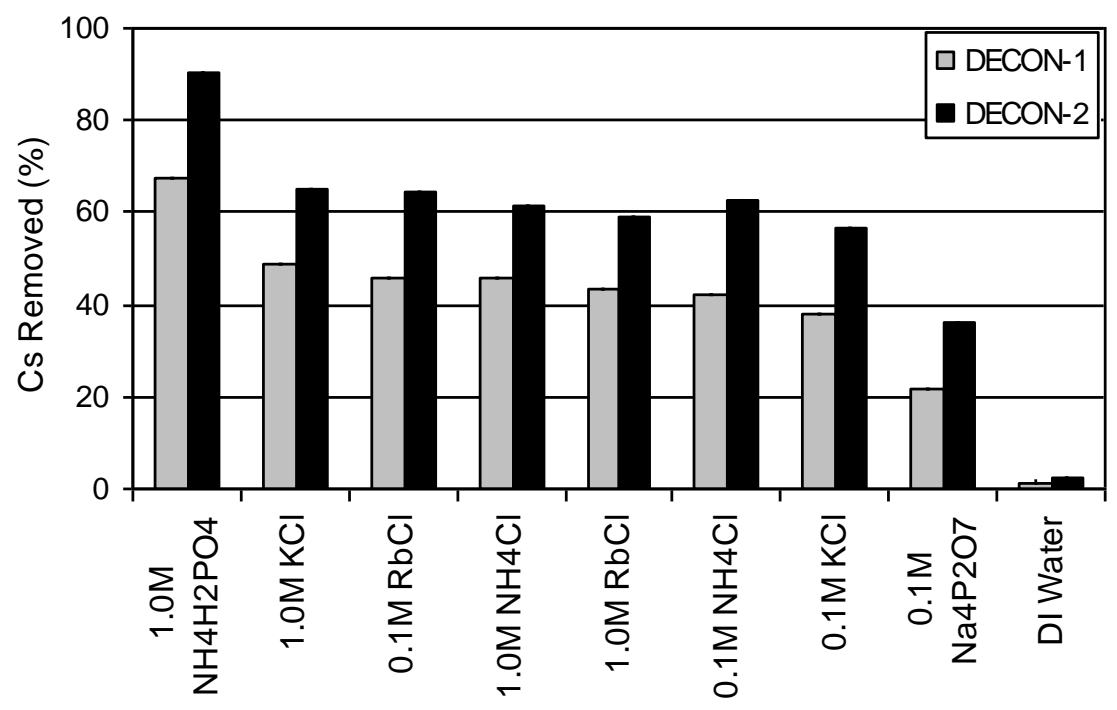

Figure 2. Decontamination results using various wash solutions for cesium removal from crushed tile. Data shows that ammonium dihydrogen phosphate can remove $90 \%$ of the cesium in two applications. Other non-ammonium based solutions perform as well as ammonium chloride (RSD was $<11 \%$ for all salt samples). 


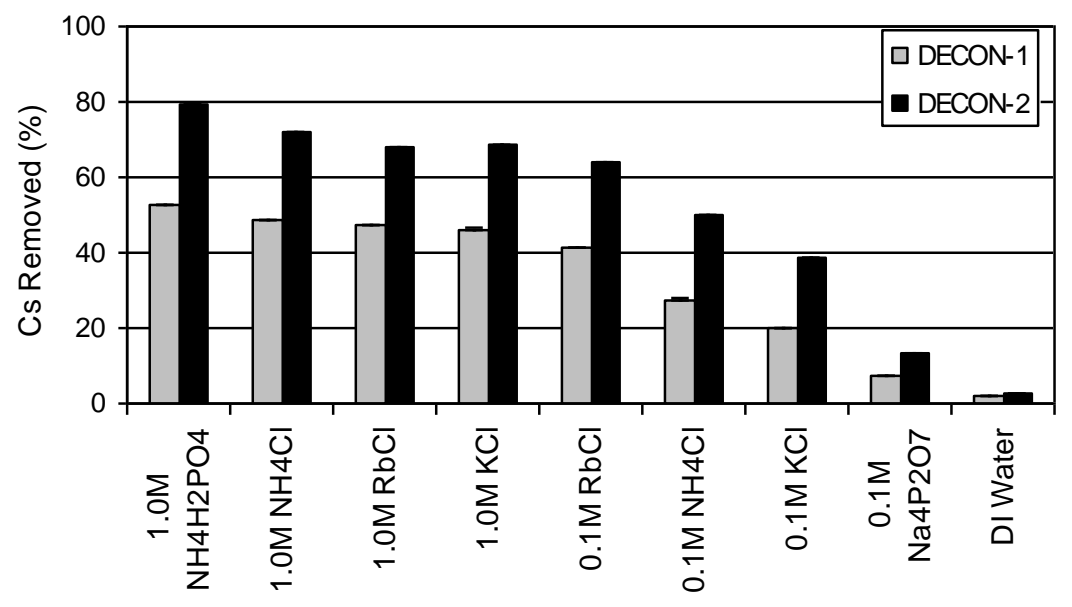

Figure 3. Decontamination results using various wash solutions for cesium removal from crushed brick (RSD $<6 \%$ for all trials except for the second decontamination of $1 \mathrm{M} \mathrm{KCl}$ with $\mathrm{RSD}=12 \%$ ). Data shows that ammonium dihydrogen phosphate can remove $80 \%$ of the cesium in two applications. Other non-ammonium based solutions perform as well as ammonium chloride.

From these data, we assumed that the same salts would be effective toward asphalt (Figs. 4-6). Interestingly, the effect of salt did not significantly improve decontamination from the asphalt over deionized water, but we suspect that sample coverage by the solution was poor (Fig. 4). Once we added a surfactant to the decontamination solution (sodium dodecyl sulfate), decontamination significantly improved to $\sim 40 \%$.

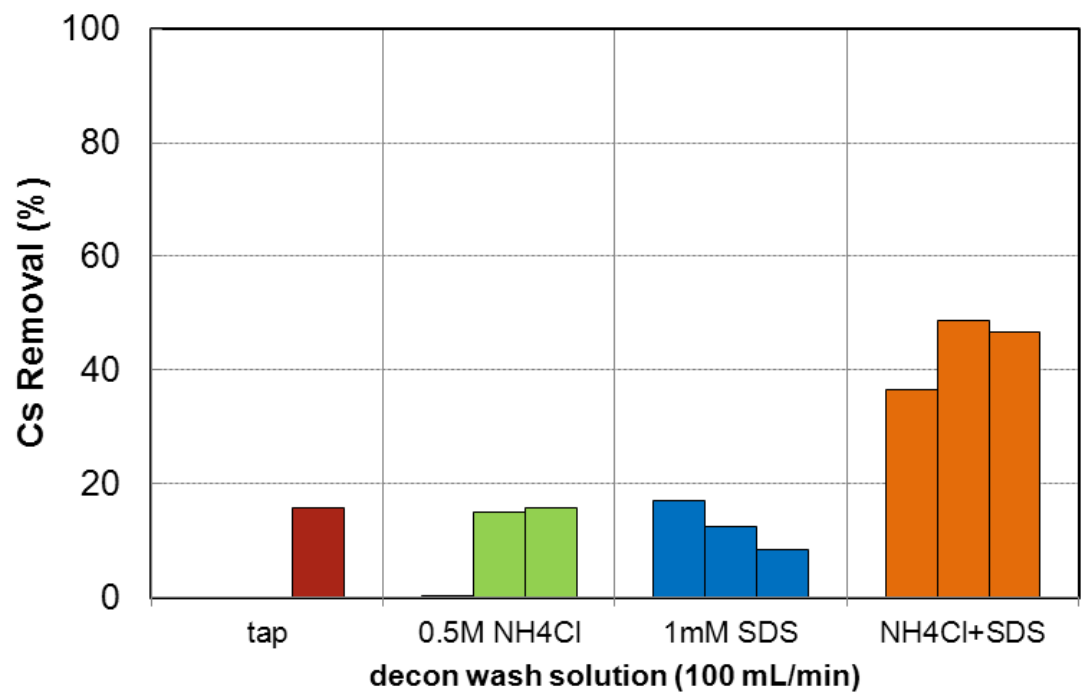

Figure 4. Decontamination of cesium from asphalt coupons. Samples were rinsed by pipetting $5 \mathrm{~mL}$ of tap water, $0.5 \mathrm{M} \mathrm{NH}_{4} \mathrm{Cl}$, or $1 \mathrm{mM}$ SDS in scoping tests across the coupon face. Flow tests used $100 \mathrm{~mL}$ of $0.5 \mathrm{M} \mathrm{NH}_{4} \mathrm{Cl}+1 \mathrm{mM}$ SDS passed over the face of the coupon at a rate of $100 \mathrm{~mL} / \mathrm{min}$ (triplicate samples shown). 
We tested the effect of the physical form of the cesium contamination, either deposited on the monolithic samples as a dissolved ("wet") substance in deionized water or as a dry powder $(\mathrm{CsCl})$. We see a clear benefit to performing a decontamination on dry material over decontamination of cesium originating from solution, as the decontamination using tap water removes $90 \%$ of the cesium from the asphalt sample. Of note, multiple decontaminations of the same coupon (Fig. 5) shows that once the powder has been rendered soluble, there is no added benefit; the second and third decontamination using tap water failed to reduce contamination levels.

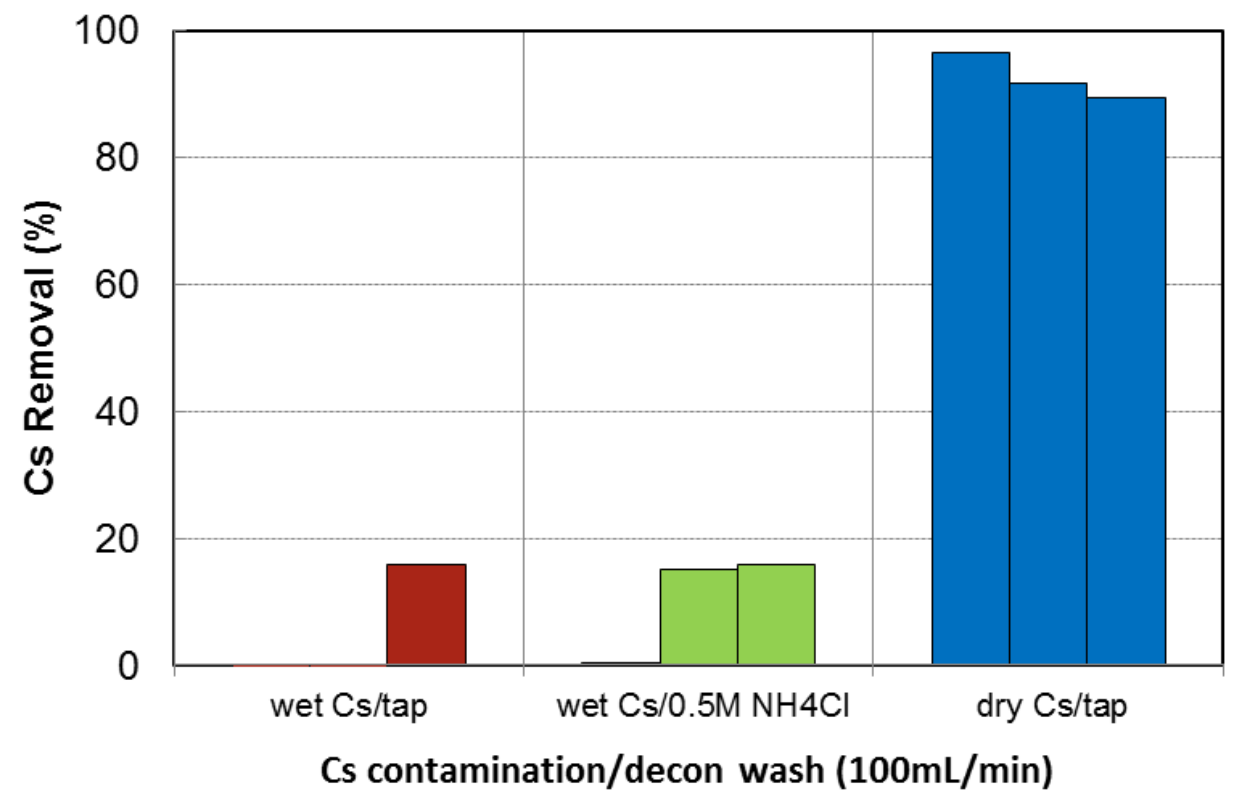

Figure 5. Decontamination of cesium from asphalt coupons when cesium was deposited as a dissolved solution ("wet") or as a powder ("dry"). Samples were rinsed by pipetting $5 \mathrm{~mL}$ of tap water or $0.5 \mathrm{M} \mathrm{NH}_{4} \mathrm{Cl}$ in scoping tests across the coupon face. Flow tests used $100 \mathrm{~mL}$ of tap water passed over the face of the coupon at a rate of $100 \mathrm{~mL} / \mathrm{min}$. (triplicate samples shown).

Similar tests were completed on concrete monoliths (Fig. 6) and the trend identified with the asphalt tests persisted, although decontamination of the dry cesium chloride powder using salt did improve over the use of tap water alone. Again, once the cesium was rendered soluble, little could be removed by additional treatments with salt. 


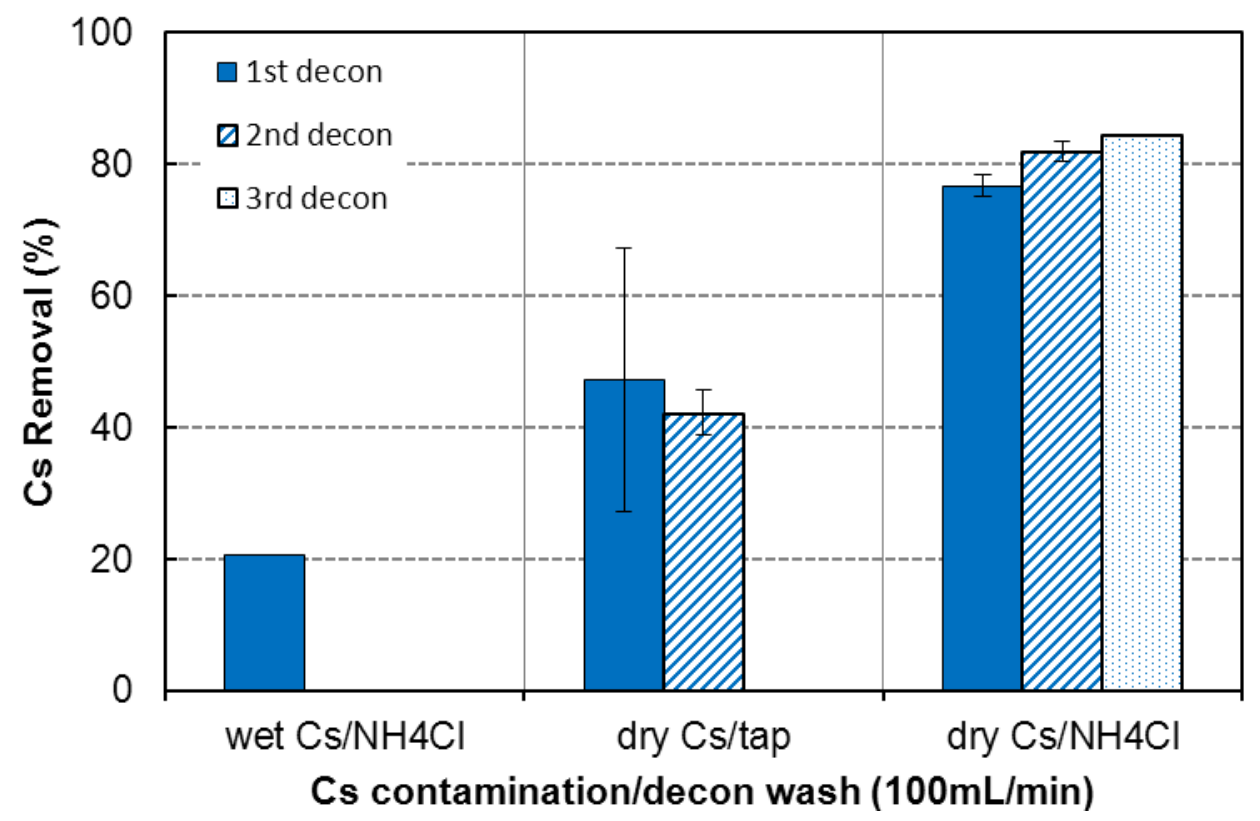

Figure 6. Decontamination of cesium from concrete coupons when cesium was deposited as a dissolved solution ("wet") or as a powder ("dry"). Flow tests used $100 \mathrm{~mL}$ of $0.5 \mathrm{M}$ $\mathrm{NH}_{4} \mathrm{Cl}$ or tap water passed over the face of the coupon at a rate of $100 \mathrm{~mL} / \mathrm{min}$ (triplicate samples shown).

From the data of Figs. 1-3 and the data consolidated in Fig. 7, the concentration of the salt should be at least $\sim 0.05 \mathrm{M}$ to provide additional benefits over tap water, but should be preferably $0.5-1.0 \mathrm{M}$, noting the large error bars. Clearly, a larger data set would be beneficial. Tests above $1.0 \mathrm{M}$ were not conducted, but higher concentrations are more difficult to generate in the field in large quantities. Since large volumes of salt water are needed at this concentration, we do not expect to draw from a reservoir of solution at this concentration. Instead, we expect that preparing concentrated brine from which to draw and dilute with hydrant water directly in the firehose would be a preferred method. In this way, a much smaller concentrated brine tank would be required. In the upcoming section "Creating the Saturated Brine" we describe the logistics of preparing the brine and distributing the wash solution using conventional firefighter equipment. 


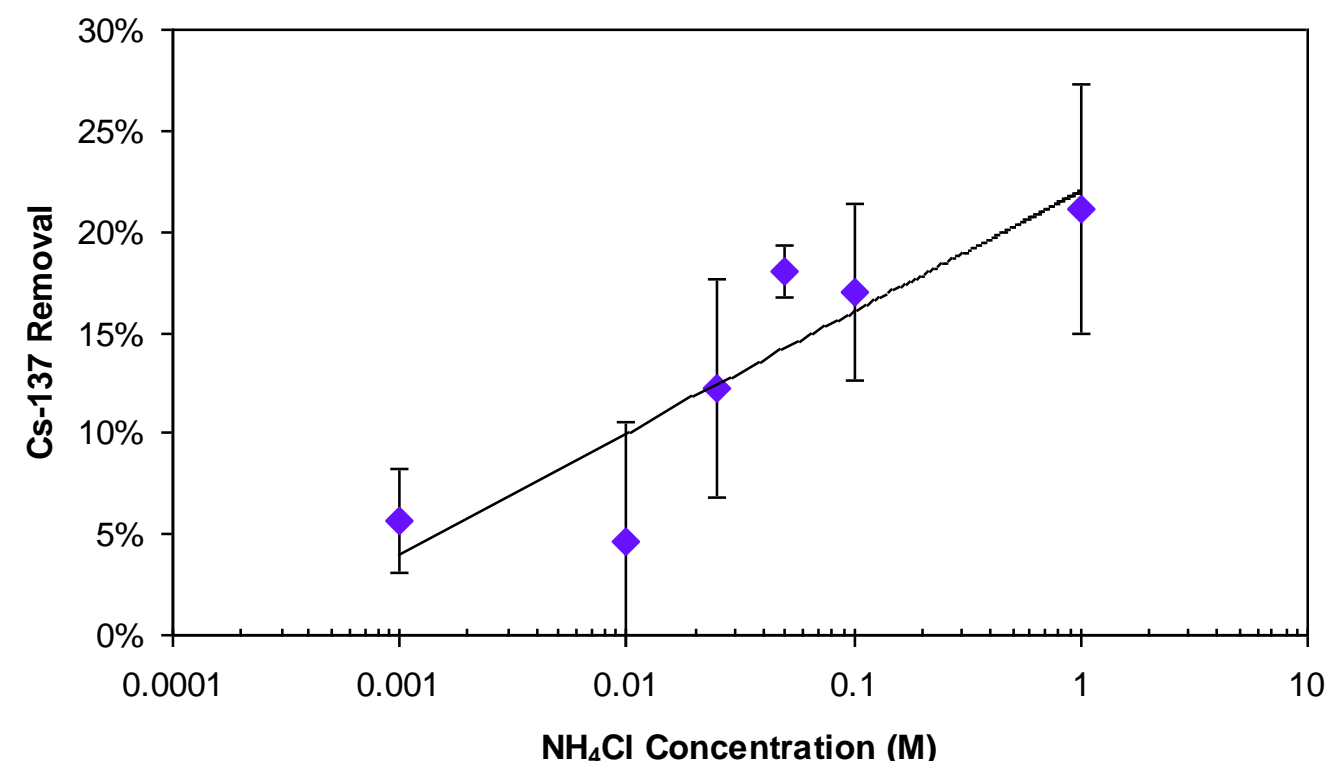

Figure 7. Decontamination of Cs-137 (in \% removed) from coarse aggregate of concrete derived from river rock as a function of ammonium chloride concentration.

Additional tests were completed to quantify decontamination of cesium from vehicles coatings. We received five Army Chemical Agent Resistant Coating (CARC) coupons used on military vehicles (Fig. 8). We cut the as-received coupons into 1.25 inch squares and epoxied the sides and back surfaces (Devcon 5 Minute ${ }^{\circledR}$ Epoxy). Then, each coupon was washed with mild soap (Clorox Green), and dried. They were immersed in isopropyl alcohol (Sigma) to remove any surfactant and set onto a paper towel to dry. To contaminate each, we pipetted $100 \mu \mathrm{L}$ of neutral solution containing Cs-137 as the chloride $(\sim 4.8 \mu \mathrm{Ci}$ per $100 \mu \mathrm{L})$ and allowed this to dry at the ambient temperature. When dried, the samples (control samples in duplicate and contaminated samples in triplicate) were transferred to a small plastic bag $\left(\right.$ Ziploc $\left.^{\circledR}\right)$ and counted at $10 \mathrm{~cm}$ from the face of a gamma-ray detector (HPGe, EG\&G Ortec) for 600 seconds (live time). After counting, the coupons were allowed to age for 7 days in the plastic bags. Then, each was removed and placed in turn on an inclined holder. We sprayed the surface (small salon-style spray bottle, $0.94 \mathrm{~mL}$ per spray) at a distance of approximately $1.5 \mathrm{in}$. (at this distance the conical spray pattern could cover the entire coupon surface) with either deionized water (control) or $0.5 \mathrm{M} \mathrm{KCl}$ in $1 \mathrm{mM}$ sodium dodecyl sulfate (SDS). Each trial used five sprays $\left(4.7 \mathrm{~mL}\right.$ or $\left.3.0 \mathrm{~mL} / \mathrm{in}^{2}{ }^{2}\right)$. After each trial, the coupons were held upright to drain the excess solution and were blotted dry at the bottom end onto an absorbent paper towel. After placing the coupons into a new plastic bag, they were recounted at the gamma-ray detector to quantify the decontamination. The trials were repeated, as needed, to produce $>99 \%$ decontamination. 

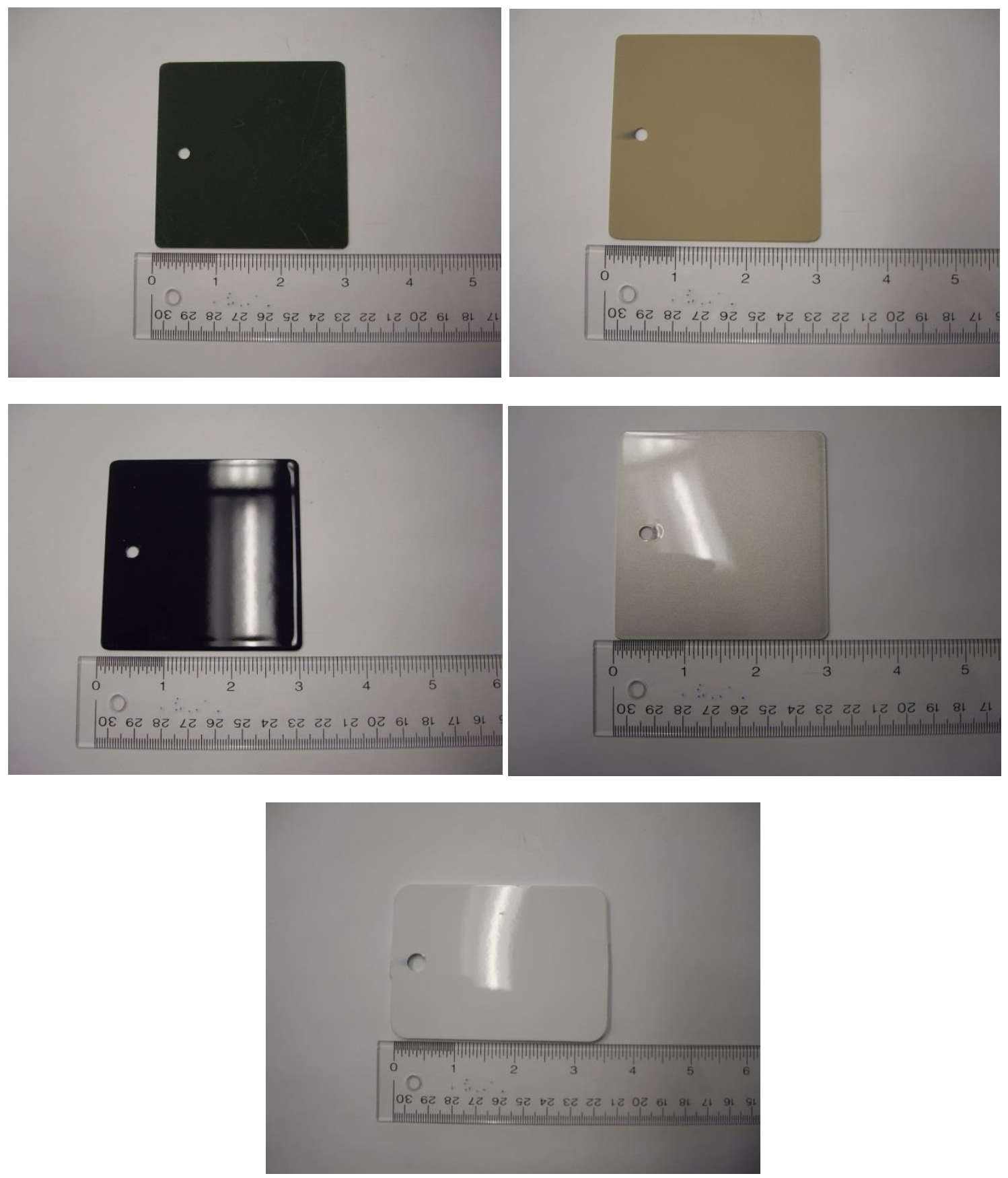

Figure 8. Vehicle coatings tested for decontamination of cesium using salt wash. Top left: Metal (aluminum) with green paint/no clear topcoat (dull.). Top right: Metal (aluminum) with tan paint/no clear topcoat (dull). Middle left: Metal (aluminum) with black paint/clear topcoat (shiny). Middle right: Metal (aluminum) with grey paint/clear topcoat (shiny). Bottom: White plastic/topcoat, super white (shiny).

The results (Table 1) show the efficacy of using deionized water (or tap water by extension) in decontaminating the surfaces of vehicles composed of the test materials. The green samples without the topcoat were the only samples that could not be cleaned to 
$>98 \%$ by using deionized water. The use of the $\mathrm{KCl} / \mathrm{SDS}$ solution produced a small increase in the decontamination factors.

Table 1. Spray decontamination of CARC materials using deionized water (Control) and $0.5 \mathrm{M} \mathrm{KCl} / 1 \mathrm{mM} \mathrm{SDS}$. DF=(initial activity)/(activity after decontamination). \%RE is the percent of cesium removed from the coupon (standard deviation was $<2 \%$ for contaminated samples and $<6 \%$ for controls).

\begin{tabular}{|c|cc|cc|cc|}
\hline & \multicolumn{2}{|c|}{ Decon 1 } & \multicolumn{2}{c|}{ Decon 2 } & \multicolumn{2}{c|}{ Decon 3 } \\
Sample & DF & \% RE & DF & \% RE & DF & \% RE \\
\hline Green (Control) & 10.7 & 89.4 & 17.9 & 93.4 & 25.1 & 95.75 \\
Green & 9.94 & 89.7 & 27.0 & 96.24 & 38.7 & 97.34 \\
\hline Tan (Control) & 70.7 & 98.58 & 160 & 99.37 & & \\
Tan & 212 & 99.4 & 540 & 99.78 & & \\
\hline Black (Control) & 133 & 99.25 & & & & \\
Black & 432 & 99.73 & & & & \\
\hline Gray (Control) & 115 & 99 & & & & \\
Gray & 244 & 99.59 & & & & \\
\hline White (Control) & 31.1 & 96.52 & 54.0 & 98.15 & & \\
White & 71.1 & 98.59 & 168 & 99.39 & & \\
\hline
\end{tabular}

\subsection{Availability and Pricing of Wash Solution Additives}

For large-scale use, we need to identify locally- and regionally-available supplies while considering several primary concerns: 1) availability of additive in bulk for potential radiological release event, 2) cost, 3) solubility of the concentrated additive so that we are able to produce solution for spraying onto the contaminated structures $(0.5 \mathrm{M}$ in salt and $1 \mathrm{mM}$ in SDS surfactant), 4) potential toxicity of the additive in handling and to downstream treatment plant unit operations (e.g., biological filter beds), and 5) effectiveness of additive toward decontamination.

First, we compiled the solubility of ammonium and potassium salt options for the wash solution [NIST-2013]. In Table 2, we list the chemicals reviewed and their solubility at $0-40{ }^{\circ} \mathrm{C}$ (units of molality, mol per kg of water). Chemicals in bold are those we consider to be the best options with regard to the above five criteria. Of the chemicals in bold, from a solubility standpoint, we prefer ammonium nitrate. However, the high ammonium concentration presents problems to a downstream water treatment plant as could the nitrate, depending on the total load to the reclamation plant [MWRD-2012]. Of the potassium salts, potassium hydroxide is the most soluble, but caustic, with a strong ammonia odor. Potassium carbonate would be the next choice as the chloride and nitrate salts have the lowest solubility, but it, too, has a strong ammonia odor. 
Table 2. Solubility of ammonium and potassium salts as a function of temperature.

\begin{tabular}{|c|c|c|c|c|c|c|c|}
\hline \multirow[b]{2}{*}{ Substance } & \multirow[b]{2}{*}{ Formula } & \multicolumn{6}{|c|}{ Solubility in Water [Molality, mol/kg water] } \\
\hline & & MW & $\mathbf{0}^{\circ} \mathbf{C}$ & $10^{\circ} \mathrm{C}$ & $20^{\circ} \mathrm{C}$ & $30^{\circ} \mathrm{C}$ & $40^{\circ} \mathrm{C}$ \\
\hline $\begin{array}{l}\text { Ammonium } \\
\text { bicarbonate }\end{array}$ & $\mathrm{NH}_{4} \mathrm{HCO}_{3}$ & 79.06 & 1.51 & 2.04 & 2.74 & 3.59 & 4.63 \\
\hline $\begin{array}{l}\text { Ammonium } \\
\text { carbonate }\end{array}$ & $\left(\mathrm{NH}_{4}\right)_{2} \mathrm{CO}_{3} \cdot \mathrm{H}_{2} \mathrm{O}$ & 96.09 & 5.81 & 0.00 & 10.41 & 0.00 & 0.00 \\
\hline $\begin{array}{c}\text { Ammonium } \\
\text { chloride }\end{array}$ & $\mathrm{NH}_{4} \mathrm{Cl}$ & 53.49 & 5.50 & 6.21 & 6.95 & 7.74 & 8.56 \\
\hline $\begin{array}{l}\text { Ammonium } \\
\text { dihydrogen } \\
\text { phosphate }\end{array}$ & $\mathrm{NH}_{4} \mathrm{H}_{2} \mathrm{PO}_{4}$ & 115.03 & 1.97 & 3.43 & 3.25 & 4.03 & 4.93 \\
\hline $\begin{array}{l}\text { Ammonium } \\
\text { fluoride }\end{array}$ & $\mathrm{NH}_{4} \mathrm{~F}$ & & & & & & \\
\hline $\begin{array}{l}\text { Ammonium } \\
\text { fluorosilicate }\end{array}$ & $\left(\mathrm{NH}_{4}\right)_{2} \mathrm{SiF}_{6}$ & & & & & & \\
\hline $\begin{array}{l}\text { Ammonium } \\
\text { hydrogen } \\
\text { phosphate }\end{array}$ & $\left(\mathrm{NH}_{4}\right)_{2} \mathrm{HPO}_{4}$ & 132.07 & 3.25 & 4.76 & 5.22 & 5.69 & 6.19 \\
\hline $\begin{array}{c}\text { Ammonium } \\
\text { nitrate }\end{array}$ & $\mathrm{NH}_{4} \mathrm{NO}_{3}$ & 80.05 & 14.74 & 18.74 & 23.98 & 30.23 & 37.10 \\
\hline $\begin{array}{l}\text { Ammonium } \\
\text { perchlorate }\end{array}$ & $\mathrm{NH}_{4} \mathrm{ClO}_{4}$ & & & & & & \\
\hline $\begin{array}{l}\text { Potassium } \\
\text { carbonate }\end{array}$ & $\mathrm{K}_{2} \mathrm{CO}_{3}$ & 138.21 & 7.60 & 7.89 & 8.03 & 8.25 & 8.47 \\
\hline Potassium chlorate & $\mathrm{KClO}_{3}$ & & & & & & \\
\hline $\begin{array}{l}\text { Potassium } \\
\text { chloride }\end{array}$ & KCl & 74.55 & 3.76 & 4.19 & 4.59 & 4.99 & 5.38 \\
\hline $\begin{array}{l}\text { Potassium } \\
\text { dihydrogen } \\
\text { phosphate }\end{array}$ & $\mathrm{KH}_{2} \mathrm{PO}_{4}$ & & & & & & \\
\hline Potassium fluoride & $\mathrm{KF}$ & & & & & & \\
\hline $\begin{array}{l}\text { Potassium } \\
\text { hydrogen } \\
\text { carbonate }\end{array}$ & $\mathrm{KHCO}_{3}$ & 100.12 & 2.25 & 2.74 & 3.37 & 3.99 & 4.74 \\
\hline $\begin{array}{l}\text { Potassium } \\
\text { hydrogen } \\
\text { phosphate }\end{array}$ & $\mathrm{K}_{2} \mathrm{HPO}_{4}$ & & & & & & \\
\hline $\begin{array}{l}\text { Potassium } \\
\text { hydroxide }\end{array}$ & KOH & 56.11 & 17.06 & 18.36 & 19.96 & 22.46 & 23.88 \\
\hline Potassium iodide & $\mathrm{KI}$ & 166.00 & 7.71 & 8.19 & 8.67 & 9.22 & 9.76 \\
\hline Potassium nitrate & $\mathrm{KNO}_{3}$ & 101.10 & 2.22 & 4.65 & 4.65 & 6.09 & 7.62 \\
\hline $\begin{array}{l}\text { Potassium } \\
\text { perchlorate }\end{array}$ & $\mathrm{KClO}_{4}$ & & & & & & \\
\hline $\begin{array}{l}\text { Potassium } \\
\text { phosphate }\end{array}$ & $\mathrm{K}_{3} \mathrm{PO}_{4}$ & 212.27 & 0.00 & 3.84 & 4.35 & 5.09 & 6.27 \\
\hline
\end{tabular}


From these solubility data, we calculated the dilution required to bring the concentrated solution to 0.5 molarity (Table 3 ) in salt out the fire hose nozzle. We report both the dilution factor and \% dilution needed to prepare $0.5,0.25$, and $0.1 \mathrm{M}$ solutions. As a reference, the firefighter eductors (Y-connectors that use the hydrant water pressure to draw an external solution into the clean water before exiting the nozzle) can achieve up to $6 \%$ solutions (6 parts additive to 100 parts clean hydrant water). Therefore, percent values below $6 \%$ in Table 3 can be mixed using the off-the-shelf eductor systems for large volumetric flow rates.

Table 3. Dilution factors and $\%$ dilution of saturated salt solutions to achieve $0.5,0.25$, and $0.1 \mathrm{M}$ out the nozzle.

\begin{tabular}{|l|cc|cc|cc|}
\hline & $\begin{array}{c}\text { dilution } \\
\text { factor to } \\
\text { make } \\
\mathbf{0 . 5} \mathbf{M}\end{array}$ & $\begin{array}{c}\text { \%o of } \\
\text { concentrate } \\
\text { to make } \\
\mathbf{0 . 5} \mathbf{~ M}\end{array}$ & $\begin{array}{c}\text { dilution } \\
\text { factor } \\
\text { to make } \\
\mathbf{0 . 2 5 ~ M}\end{array}$ & $\begin{array}{c}\text { \% of } \\
\text { concentrate } \\
\text { to make } \\
\mathbf{0 . 2 5} \mathbf{M}\end{array}$ & $\begin{array}{c}\text { dilution } \\
\text { factor } \\
\text { to make } \\
\mathbf{0 . 1} \mathbf{M}\end{array}$ & $\begin{array}{c}\text { \% of } \\
\text { concentrate } \\
\text { to make } \\
\mathbf{0 . 1} \mathbf{~ M}\end{array}$ \\
\hline $\mathrm{NH}_{4} \mathrm{NO}_{3}$ & 37 & 2.7 & 75 & 1.3 & 180 & 0.53 \\
$\mathrm{NH}_{4} \mathrm{Cl}$ & 12 & 8.0 & 25 & 4.0 & 62 & 1.6 \\
\hline $\mathrm{KOH}$ & 37 & 2.7 & 73 & 1.4 & 180 & 0.54 \\
$\mathrm{KCl}$ & 8.4 & 11.9 & 17 & 6.0 & 42 & 2.4 \\
\hline
\end{tabular}

Before we report prices, we must caution that salt prices have become volatile over the last decade, due in part to rising fuel costs. Therefore, the prices quoted here are approximate and are intended to be a guide; these prices should be updated with actual quotes before any final decision is made.

Potassium chloride spot prices are $\$ 105-125$ per ton in bulk $(\$ 43 / 100 \mathrm{lb}$. in bags or drums) [ICIS-2006] but have risen dramatically over the past several years. Potassium carbonate is $\$ 800$ per ton in bulk ( $\$ 39-40 / 100 \mathrm{lb}$.) [ICIS-2006] or $\$ 2,100$ per ton in bulk from Armand Products Company [Armand-2013]. Potassium carbonate solutions are basic at pH11.5-12.5 and potassium chloride and nitrate are near neutral. Ammonium nitrate prices are \$169-175 per ton in bulk [ICIS-2006] and their solutions are slightly acidic at $\mathrm{pH}=4.5-6$. However, a representative at H.J. Baker and Brothers, Inc. said that their company no longer sells $\mathrm{NH}_{4} \mathrm{NO}_{3}$ and that it was illegal to sell this chemical to individuals outside the fertilizer industry. Ammonium chloride prices could not be found.

Most sodium dodecyl sulfate (SDS) in inventory at any supplier is in the acidic form, but the most common uses require neutralization [Nease-2013]. In the acidic form, the product is a solid, but in the neutralized form is a liquid, usually $40 \%$ active $(60 \%$ water). Neutralization is often completed with sodium hydroxide but can also be performed with ammonium or triethylolamine. If we required tonnage quantities, it would require about a day to perform the conversion at the plant before shipment and, according to Nease Chemicals, this is true of any bulk supplier. Bulk suppliers exist regionally. For instance, Stepan, is in the Chicago area ([http://www.stepan.com, (847) 501-2117, Northfield, IL] and Henkel is in Scottsdale, AZ [http://www.henkel.com/index.htm, (480) $754-3425])$. The bulk is routinely shipped by rail car $(200,000 \mathrm{lbs}$.) or tanker truck (40- 
45,000 lbs.) as acid or neutralized form. Prices in bulk are $\sim \$ 1 / 1 b$ in acidic form and $\$ 0.60 / \mathrm{lb}$ in neutralized form.

\subsection{Creating the Saturated Brine}

Large volumes of solution likely will be required for a mitigation effort. Equally large reservoirs or tanks would be necessary to prepare the target salt solution concentration ( $0.5 \mathrm{M}$ cation, ideally) and then spray it onto the affected surfaces. In addition, the mitigation site would have to accommodate the footprint of the reservoirs and associated unit operations. To better appreciate the scale, consider that a reservoir along a single city block in downtown Chicago that covers the footprint of the entire street level ( $20 \mathrm{~m}$ x $70 \mathrm{~m}$ ) filled to 1 feet depth contains 116,000 gallons (see Appendix A). A fire hose can deliver up to $250-500 \mathrm{gpm}$ while several trucks can dispense up to $2000 \mathrm{gpm}$ to a single location filling 120,000 gallons in one hour. Such large installations would require their own logistics for procurement, setup, and operation and this would have to be developed.

The requirement for brine storage can be greatly facilitated by concentrating the brine and diluting it with clean water in-line at the point of application to achieve the final brine concentration ( $0.5 \mathrm{M}$ preferred). From Table 2 , we see that a dilution factor of 6-15 is within the range of solubility for the potassium and ammonium salts that will achieve a final concentration of $0.5 \mathrm{M}$ (that is, from a saturated solution a dilution of a factor of 6-15 would bring the concentration down to $0.5 \mathrm{M}$ in the cation). Thus, a reservoir to store the volume of saturated brine needed to produce 100,000 gallons at $0.5 \mathrm{M}$ would be 6700-16,700 gal., within the size of a couple of large tank trucks used to distribute gasoline (cap. 5500-11,600) [Tank Truck-2013]. More common tank trucks are on the order of 1000-3000 gal. (e.g., a cement mixer is typically 2000 gallons). Assuming this approach would obviate the need to occupy additional large areas for equipment, procure specialty equipment, prepare a large reservoir, and train the necessary personnel.

By preparing a saturated brine, smaller tank trucks or portable bladders could be used to mix and store the solution. Some active mixing would need to be employed to dissolve the salt. Trucks with mixing capability would be ideal (e.g., concrete mixers). Similarly, portable mixers can be inserted into an open portable tank to mix the contents. These could be as simple as collapsible tanks (Fig. 9), swimming pools, or an ad hoc reservoir using temporary berms (see "Containing the Contaminated Water for Filtration and Reuse"). 


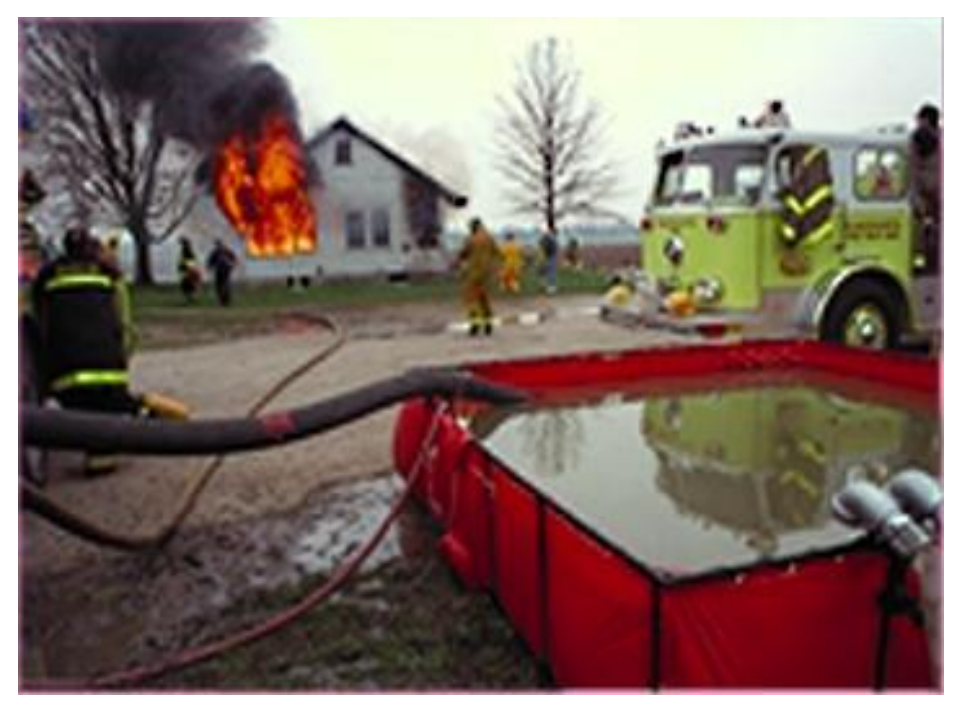

Figure 9. Collapsible tank is used as a holding tank for water in firefighting operations.

\subsection{Distributing the Brine Wash Water Solution}

At the point of application, we prefer a $0.5 \mathrm{M}$ (in potassium or ammonium) salt solution plus $1 \mathrm{mM}$ of SDS surfactant. If the necessary volume for a mitigation operation can be prepared in a tank, then this solution can be pumped directly through a nozzle with great efficiency using a fire truck. Some fire trucks are equipped with on-board high pressure water pumps capable of 200 psi pressure (up from 50-60 psi at the hydrant) and up to $1500 \mathrm{gpm}$, but more typically up to $500 \mathrm{gpm}$ per line, with possibly two lines per truck.

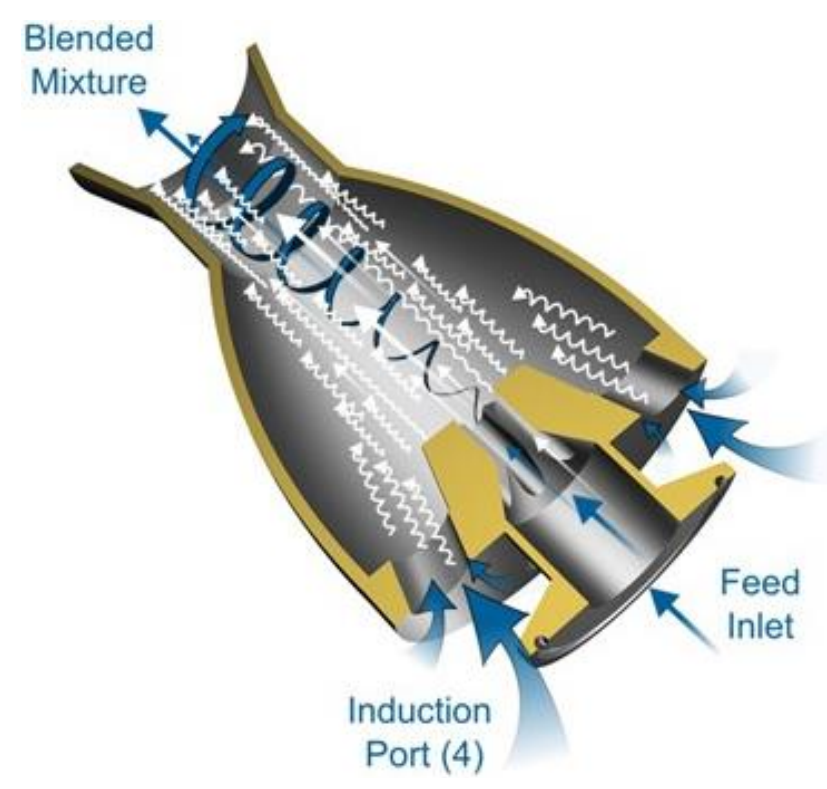

Figure 10. Drawing of an eductor for mixing two liquids. 
If, on the other hand, saturated brine is created in a nearby tank, then eductors can be employed. Eductors are Y-connectors used to draw in foam agents and are common equipment and operations to firefighting units. In an eductor (Figs. 10 and 11), the primary fluid (the hydrant water, in our case) is pumped through a descending nozzle where the constricted flow creates a pressure differential and suction force (Bernoulli Effect) at the nozzle outlet that can draw in a secondary fluid. The velocity of the clean side water line creates the force necessary by the Bernoulli principle to draw the secondary solution. The eductors and nozzles that firefighters use have variable dials to control the amount of secondary fluid (they often draw a foaming agent while we would draw the saturated brine and surfactant). According to a major U.S. supplier of firefighting nozzles, hoses, and fittings, COTS eductors employed by most firehouses can create up to $6 \%$ solutions ( 6 parts secondary solution to 100 parts clean hydrant water). The Y246 has a maximum flow rate of $350 \mathrm{gpm}$ (21,000 gallons per hour) that can be variably set to $6 \%, 3 \%, 1 \%$ or $1 / 2 \%$. The Y247 has a capacity of $500 \mathrm{gpm}$ with a maximum of $3 \%$ proportioning (or $1 \%$ ).

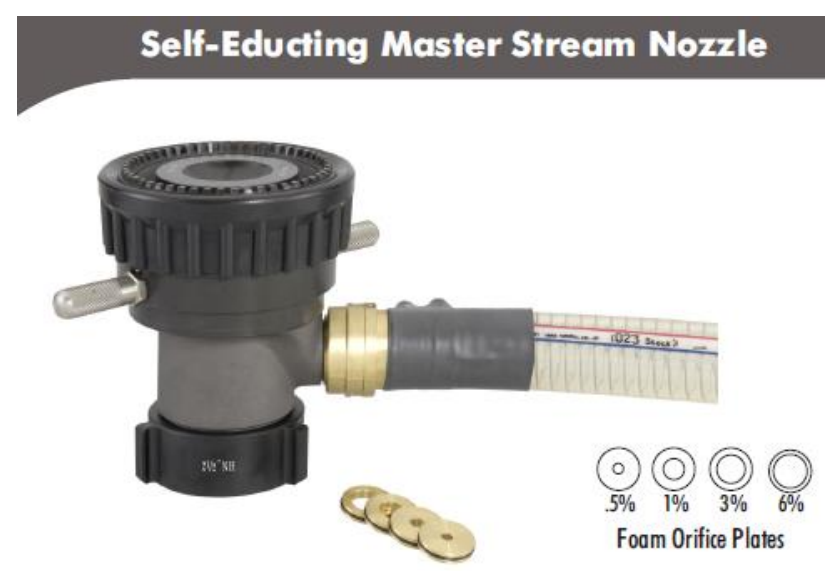

Figure 11. Self-educting nozzles are employed by firefighters for deploying foaming agents. These nozzles are held by a single firefighter or a team of firefighters and the spray is distributed like it is with any common fire hose.

The largest flow eductors are called monitors (Fig. 12) and are premounted on the fire truck or placed on the ground to better control the direction of the spray. For example, the Protek 622 ground monitor can be connected to a Protek self-educting nozzle. This monitor stand permits control of the high velocity stream at $500 \mathrm{gpm}$ and the nozzle has an eductor designed to draw up to a $6 \%$ solution out the nozzle. 


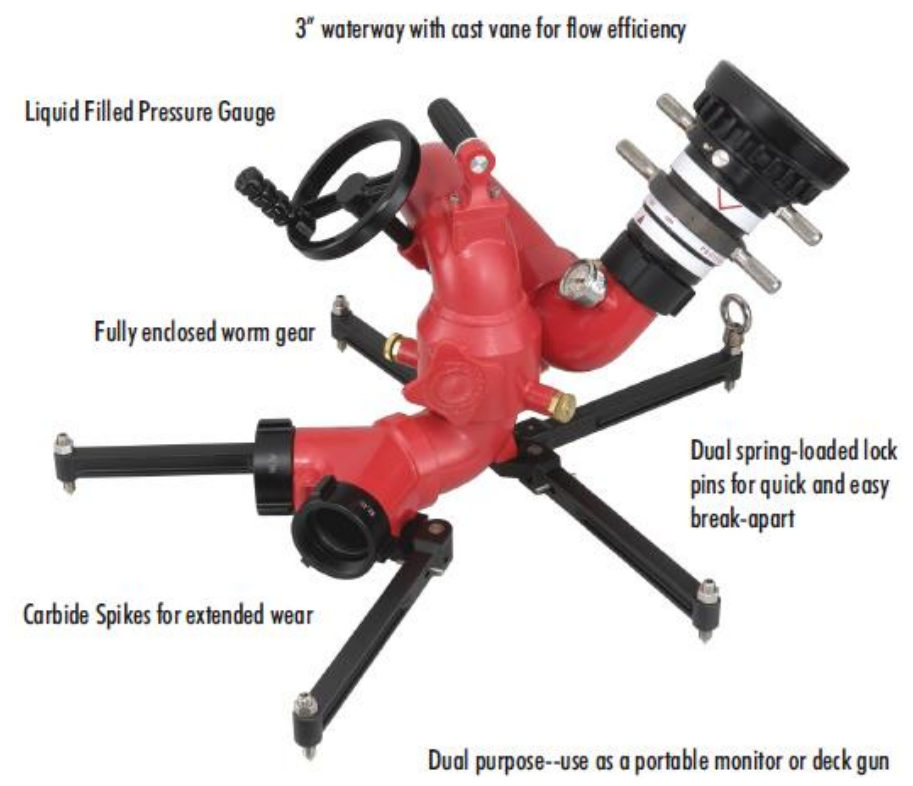

Figure 12. For high volumetric flow rates, the hose becomes too difficult to control, and monitors are used to better control the direction of the spray.

Of note, eductors can be designed to draw enough secondary fluid to create a $10-12 \%$ final concentration, but these would not be COTS technology or within the current inventory of fire houses [C\&S-2013]. The percent educted depends on the metering hole within the eductor. For instance, a $1000 \mathrm{gpm}$ eductor nozzle body (large metering hole) can be attached to a 500 gpm eductor to obtain up to $12 \%$. However, rating such combinations is not part of the calibration process, so special calibrations would be required to ensure the proper percentage of secondary material through the nozzle [C\&S-2013].

\subsection{The Solid Sequestering Agent}

\subsubsection{Role and Requirements}

As the wash waters pass over the contaminated surfaces of the buildings, roadways, and vehicles, the radioactive cesium will accumulate in the wash. We prefer to sequester the radioactivity onto solid substrates as quickly as possible, to limit crosscontamination and facilitate the separation of radioactivity from the wash water for its potential reuse or free discharge. We considered including a solid sequestering agent into the eductor system so that both the salt and the sequestering agent would bathe the contaminated surfaces simultaneously. However, our tests showed that this approach is counterproductive [USEPA-2012a]. The excess salt cations simply overload the sorption sites on the solid sequestering agents rapidly rendering them ineffective against sequestering the radioactive cesium and simultaneously lowering the effective free-salt concentration in the wash water; the lower free-salt concentration translates into a lower decontamination factor for cesium. 
Instead, we proposed that the solid sequestering agent be spread across the ground within the contamination zone and within the area of runoff accumulation. In our system, we will contain the runoff from the contamination zone within a temporary reservoir (see "Containing the Contaminated Water for Filtration and Reuse") and so the solid sequestering agent would be spread across the ground within the footprint of the reservoir. Since it is likely that we will need to contain the contaminated water, the walls of the reservoir should be impermeable to prevent unmitigated runoff. This reservoir provides a means of interacting (mixing) the contaminated runoff immediately with the solid sequestering agent in an enclosure.

We need to decide on the solid sequestering agent to capture the cesium in the wash water. The sequestering agent would serve several purposes, and thus, may require different sequestering agents to meet the differing goals. In all cases, the sequestering agent must have good selectivity for cesium at trace concentrations over 100's of millimolar concentrations of monovalent salt. We propose distributing the sequestering agent within the footprint of the reservoir. Therefore, we prefer a material that is readily available in sufficient quantity regionally or locally. We should also consider the cost, since it is likely that substantial quantities of material will be needed in this function. Next, we may wish to use a sequestering material to create the berms that will form the walls of the reservoir. Even though we would likely require the reservoir walls to be impermeable to water, we may wish to have an engineering backup, in case there is permeation. Filling the berm with the sequestering agent would provide a means of decontaminating the water in situ, to mitigate this potential contamination source.

After collecting the contaminated wash water (contains contaminated salt water and sequestering agent in suspension), we will filter the sequestering agent from the wash water and dispose or reuse the sequestering agent to further load it. It is highly unlikely that this initial water filtration will reduce cesium concentrations in the water to below discharge standards so additional separation or "cleanup" of cesium will be required. "Cleanup" of cesium can be performed in batch or continuous operations, but should be capable of processing very large volumes of water. The sequestering agent should be chosen to maximize selectivity, kinetics, and sorption capacity, while cost should be considered but may not be a significant factor, since the volume of sequestering agent could be orders of magnitude less than that needed to fill the berm. It should be readily available regionally or locally in sufficient quantities or a means to contain the volume of wash water must be provided until a suitable supply of sequestering agent can be procured.

\subsubsection{Candidate Sequestering Materials}

The sorption behavior of cesium onto many types of natural and synthetic materials has been a constant area of study over many years. Google Scholar search of the keywords "cesium sorption" returns 17,000 related articles, with most articles describing cesium sorption onto natural materials like rock and soil compounds and minerals and synthetic materials discussed to a lesser extent. Some more recent reviews include [Pashow-2013, Shoumkova-2014, Misaelides-2011, Abe-1995]. However, many materials are not suitable for decontamination activities because 1) the salt concentration 
is too high, overloading the sorption sites of the sequestering agent, 2) the cost of large scale production is too high, and 3) the materials are in early stage development and not available in the market.

To begin, we summarize the general types of materials that we considered in our evaluation. Much of this work was already reported by us [USEPA-2012a] so we focus, instead, on a general discussion. Many earth materials have affinity for radionuclides. These include mineral oxides, organic matter, clays, and zeolites. Mineral oxides play an important role in radionuclide adsorption. These are generally transition metal oxyhydroxides (e.g., $\mathrm{FeOOH}$ or generically as $\mathrm{S}_{s} \mathrm{OH}$ where $S_{s}$ denotes a surface site) and they have been modeled to quantify the sorption of cations onto the surface. The electrostatic interaction to cationic radionuclides $\left(\mathrm{M}^{n+}\right)$ is caused by the loss of protons creating negatively-charged mineral surfaces:

$$
M^{n+}+>S_{S} O H \leftrightarrow>S_{S} O M^{(n-1)+}+H^{+}
$$

These interactions tend to be non-selective between elements within the alkali and alkaliearth metal groups and the bonds less strong than those on clay minerals.

Organic matter can play an important role in the sequestration of radionuclides. The breakdown of natural organic matter in soils leads to the formation of humic and fulvic acids that are modeled to account for radionuclide transport in the subsurface. These organic acids are alkyl/aromatic units cross-linked mainly by oxygen and nitrogen groups with the major functional groups being carboxylic acid, phenolic and alcoholic hydroxyls, ketone, and quinone groups [Livens-1991]. In radionuclide transport studies, the carboxylate groups are believed to be primarily responsible for sorption under most natural conditions [Choppin-1985] and are modeled similarly to Eqn. 1. However, these materials also have extremely small dimensions and are often found in the colloidal state. Larger organic matter does not appear to be a good sequestering material because of low sorption capacity and lack of selectivity. This includes activated sludge from municipal sewage treatment plants where the partitioning coefficient for cesium from simulated sewage water containing low concentrations ( $<50 \mathrm{mM}$ ) of competing salts is $<100 \mathrm{~mL} / \mathrm{g}$ [Maresova-2010, Koyama-1997].

Clay minerals are hydrous aluminum silicates arranged in the form of layered sheets (phyllosilicates) with variable amounts of cations such as iron, magnesium, alkali metals, and alkaline earths. There are several groups of clays: kaolinite, montmorillonitesmectite, illite, and chlorites, although chlorites are often categorized as a separate type of phyllosilicate material (Fig. 13). Clay minerals are further classified as 1:1 or 2:1 to describe the types of tetrahedral silicate sheets and octahedral hydroxide sheets they are composed from. A 1:1 clay would consist of one tetrahedral sheet and one octahedral sheet like those of the kaolinite clays. A 2:1 clay consists of an octahedral sheet between two tetrahedral sheets as in the vermiculites and montmorillonites (Fig. 14). Depending on the composition of the tetrahedral and octahedral sheets, the layer will have either a neutral charge or a net negative charge. A net negative charge is caused by replacement of higher oxidation state cations with lower oxidation states during clay formation. The excess charge is balanced by the sorption of interlayer cations, commonly the alkali metals and alkali earth metals. The interlayers will also contain water that leads to the common property of swelling in clays (Figs. 13 and 14). 

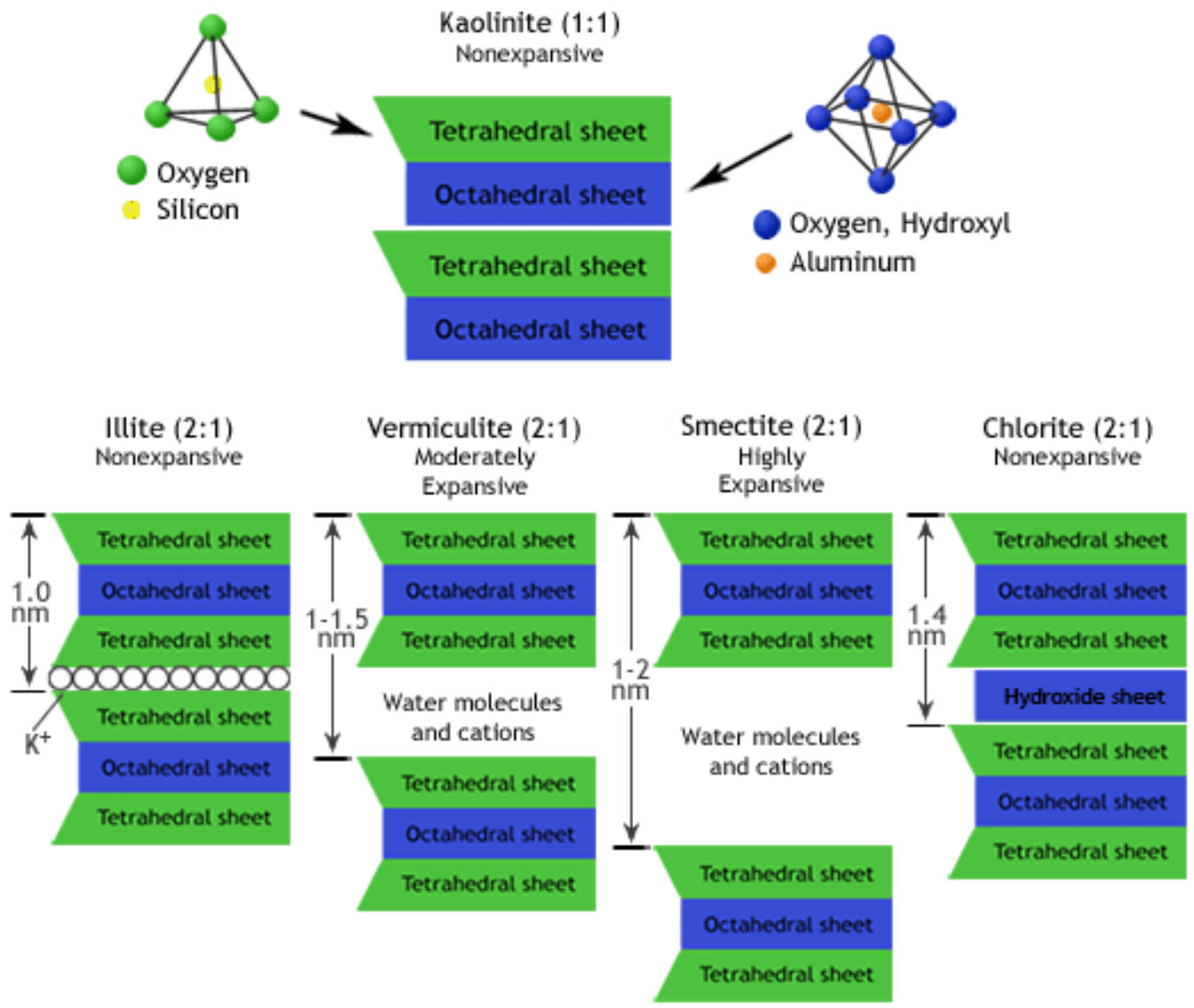

Figure 13. Explanation of the structure of different clay types. Illite, vermiculite, and smectite are candidates for radionuclide sequestration because the spacing between the sheets allows penetration of radionuclide cations (www.soilsurvey.org). 


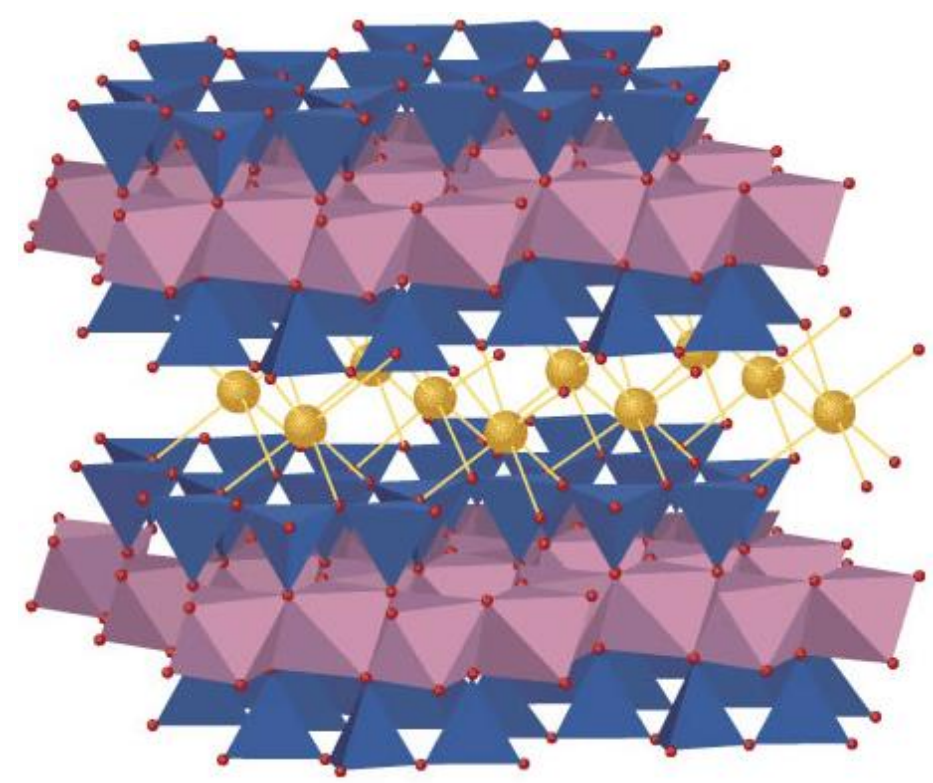

Figure 14. Crystal structure of a smectite clay representative of montmorillonite. Notice the octahedral sheet of aluminum oxide (pink) sandwiched between two tetrahedral sheets (blue) of silicate. Two such layers contain an interlayer of water and cations to balance excess negative charge.

The excess charge of clays can be quite large and the dimensions of the interlayer between sheets discriminates between different sized ions, thus allowing selectivity for sorption of metals. With their worldwide abundance and low cost, clays are very good candidates for radionuclide sequesterring materials. In fact, it has been long recognized [Hatch-1953] that clays make ideal materials to confine the mobility of radionuclides. They are used extensively in the design of nuclear waste repositories for this ability and other engineering characteristics (Fig. 15). 


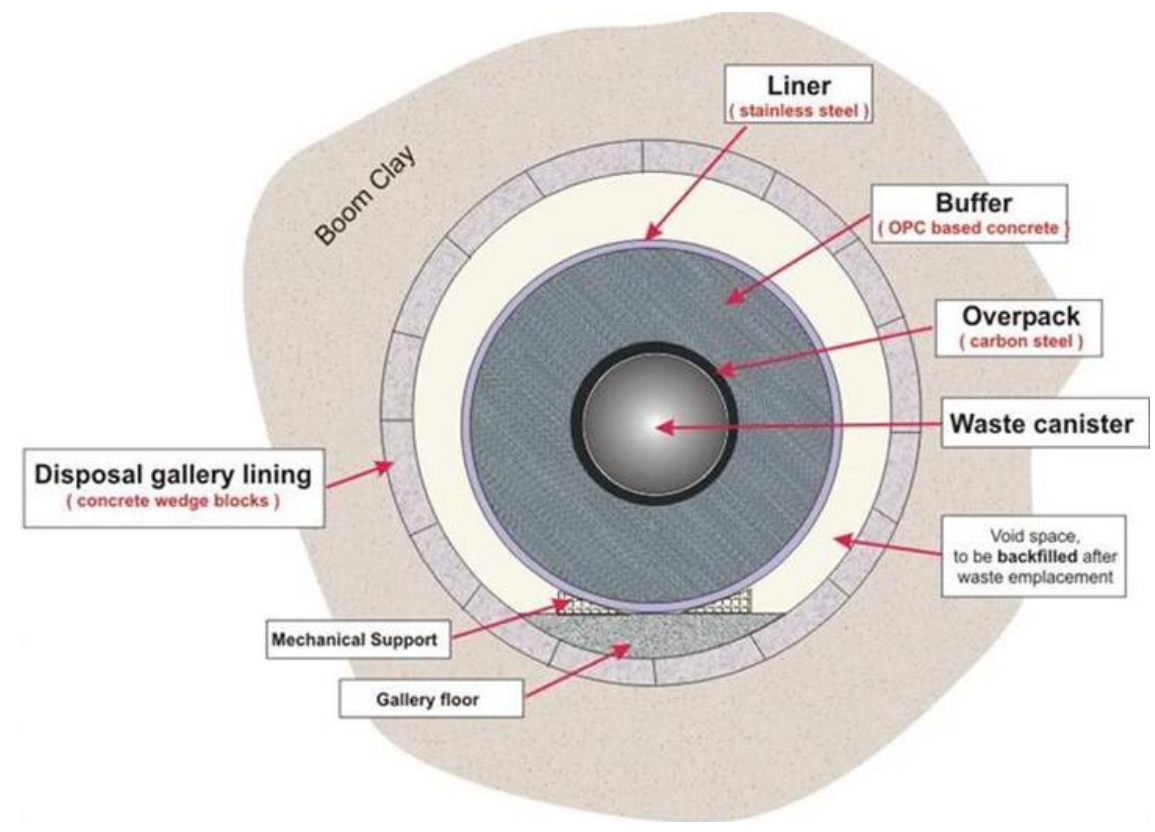

Figure 15. Configuration of radioactive waste repository emplacement design in Belgium utlizes Boom clay as a natural engineered barrier to retard the migration of dissolved radionuclides (from Belgian Nuclear Research Centre, www.sckcen.be/en/OurResearch/Research-domains/Disposal-of-radioactive-waste).

Zeolites are microporous aluminosilicate minerals. There are over 100 types of zeolites that occur naturally. The distinct feature of zeolites is the regular pore structure (Fig. 16) that only permits the adsorption of ions with dimensions smaller than the pore openings lending the term "molecular sieve" to these materials. The most abundant natural zeolite is clinoptilolite $(\mathrm{Na}, \mathrm{K}, \mathrm{Ca})_{2-3} \mathrm{Al}_{3}\left(\mathrm{Al}, \mathrm{Si}_{2}\right)_{2} \mathrm{Si}_{13} \mathrm{O}_{36} \cdot 12\left(\mathrm{H}_{2} \mathrm{O}\right)$ but others like mordenite, erionite, and chabazite have been considered in radioactive waste studies [Song-1997, Mimura-1985, El-Kamash-2008, Borai-2009]. Of these, chabazite was found to have the highest selectivity and capacity for cesium from low-potassium solutions. As synthetic methods have developed, scientists have designed zeolites with very specific pore structures to tailor their sorption selective toward certain cations making them superior materials in terms of sorption capacity and selectivity. Both natural and synthetic zeolites are candidates for sequestration agents in our proposed mitigation technology. 


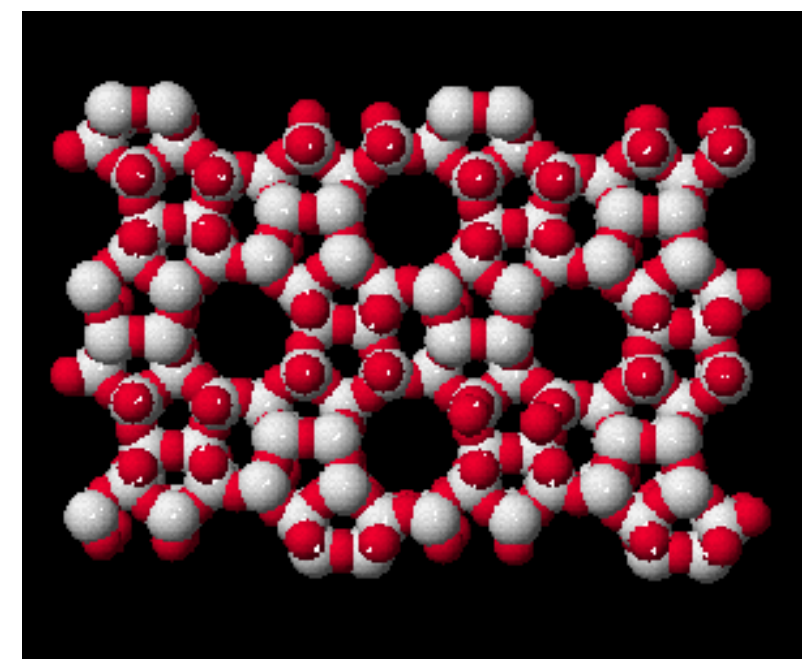

Figure 16. Zeolite structure differs markedly from the layered sheets of the clays. The zeolites are fixed crystal structures with regular channels to accept water and charged ions (from materials.binghamton.edu/labs/zeolite/zeolite.html).

Another interesting sequestering material is the hexacyanoferrates. Known more commonly as Prussian Blue, it is used to sequester internal contaminations of cesium and variations have been studied for many years [reviewed initially by Pekarek-1972] to remove cesium from radioactive waste solutions. Improvements by Mimura et al. [Mimura-1997] produced a highly selective media even in high potassium and ammonium solutions for the potassium nickel form $\mathrm{K}_{0.87} \mathrm{Ni}_{0.57}\left[\mathrm{NiFe}(\mathrm{CN})_{6}\right] \bullet n \mathrm{H}_{2} \mathrm{O}$ or simply KNiFC.

Of the materials mentioned, certain clays and zeolites demonstrate significant selectivity for cesium over other monovalent cations that would be present in the wash waters. Different clays and zeolites work better than others for a given salt and concentration (see Appendix B for a consolidated summary of sequestration agents considered in our studies). From this list, many were not available in bulk and have only been used in research studies. This provided a shortened list of sequestration agents to include in our laboratory screening.

These materials include: crystalline silicotitanate, $\mathrm{Na}_{2}\left(\mathrm{H}_{2} \mathrm{O}\right)_{2} \mathrm{Ti}_{4} \mathrm{O}_{5}(\mathrm{OH})\left(\mathrm{SiO}_{4}\right)_{2} \mathrm{Na}\left(\mathrm{H}_{2} \mathrm{O}\right)_{1.7}$, a synthetic zeolite sold under the trade name IONSIV ${ }^{\circledR} \mathrm{IE}-911$ (UOP), with properties tailored toward cesium sorption in high sodium solutions; montmorillonite clay, $(\mathrm{Na}, \mathrm{Ca})_{0.33}(\mathrm{Al}, \mathrm{Mg})_{2}\left(\mathrm{Si}_{4} \mathrm{O}_{10}\right)(\mathrm{OH})_{2} \cdot n \mathrm{H}_{2} \mathrm{O}$, the most common clay material studied and implemented in the industry for radionuclide sequestration (Fischer Scientific USA as K-10, American Colloid Co., Hoffman Estates, IL, as Volclay ${ }^{\circledR}$ SPV200, and a Wyoming clay from Bentonite Performance Minerals, Houston, TX, as $\quad$ BARA-KADE $\left.^{\circledR}\right) ; \quad$ vermiculite clay, $\left(\mathrm{Mg}, \mathrm{Fe}^{2+}, \mathrm{Al}\right)_{3}(\mathrm{Al}, \mathrm{Si})_{4} \mathrm{O}_{10}(\mathrm{OH})_{2} \bullet 4\left(\mathrm{H}_{2} \mathrm{O}\right)$, a clay with perhaps the most selectivity for cesium over competing alkali metal cations (from W.R. Grace \& Co., Cambridge, MA, as VCX $^{\mathrm{TM}}$ Vermiculite Ore Concentrate; The Strong Co. Inc., Pine Bluff, AR, as Micron Vermiculite); illite, $\left(\mathrm{K}, \mathrm{H}_{3} \mathrm{O}\right)(\mathrm{Al}, \mathrm{Mg}, \mathrm{Fe})_{2}(\mathrm{Si}, \mathrm{Al})_{4} \mathrm{O}_{10}\left[(\mathrm{OH})_{2},\left(\mathrm{H}_{2} \mathrm{O}\right)\right]$, a high-capacity clay available in bulk only from China (Xuzhou Zhonglian Chemical Technology Co., Ltd.); 
and chabazite, $\left(\mathrm{Sr}, \mathrm{Ca}, \mathrm{K}_{2}, \mathrm{Na}_{2}\right)\left[\mathrm{Al}_{2} \mathrm{Si}_{4} \mathrm{O}_{12}\right] \cdot 6\left(\mathrm{H}_{2} \mathrm{O}\right)$, a natural zeolite (St. Cloud Mining Co., Winston, NM). We added an additional novel material because of its interesting properties, KMS-1, $\mathrm{K}_{2 \mathrm{x}} \mathrm{Mn}_{\mathrm{x}} \mathrm{Sn}_{3-\mathrm{x}} \mathrm{S}_{6}(x=0.5-0.95)$ a layered sulfide not available in the market but a facile synthesis method that may be very cost-effective in the long-term (Northwestern University). KNiFC is also a candidate and has been characterized by others [Mimura-1997] for conditions of high salt and so we report their data. The negative control was silica in the form of diatomaceous earth (Celite Corporation).

We completed experiments to determine the kinetics for sorption and the percent of Cs removed as a function of slurry concentration (mass of solid/volume of Cs solution) and salt concentration. Usually, this involved mixing 1-10 mg of solid with $1 \mathrm{~mL}$ of solution for 60 minutes (rotary mixer) before centrifuging the sample and withdrawing aliquots for gamma counting of the Cs-137 tracer (Minaxi $\gamma$ Auto-Gamma 5000 Series Gamma Counter, United Technologies Packard, Model A5550 using 12 x 75 polypropylene tubes). Solutions of ammonium chloride $\left(\mathrm{NH}_{4} \mathrm{Cl}, 99.5+\%\right.$, A.C.S. reagent, Sigma-Aldrich), potassium chloride (KCl, Analytical AR Reagent, Mallinckrodt), and sodium carbonate $\left(\mathrm{Na}_{2} \mathrm{CO}_{3}\right.$, anhydrous, granular AR (ACS) Primary Standard, Mallinckrodt), and Etidronic acid (HEDPA, Aldrich) were prepared with deionized $\mathrm{H}_{2} \mathrm{O}\left(\sim 18 \mathrm{M} \Omega \bullet \mathrm{cm}\right.$ resistivity at $\left.25^{\circ} \mathrm{C}\right)$ or Chicago tap water. Standard buffer solutions $(\mathrm{pH}=4.01,7.01$, and 10.01) were used to calibrate the $\mathrm{pH}$ meter from Hanna Instruments. Material was weighed into $1.5 \mathrm{~mL}$ microcentrifuge tubes (Ambion). Illite and vermiculite were washed with deionized $\mathrm{H}_{2} \mathrm{O}$ and centrifuged four times to remove any dust or water-soluble impurities. The supernatant was removed with a disposable transfer pipette after each centrifugation and replaced with new deionized $\mathrm{H}_{2} \mathrm{O}$. Each washed sample was placed in a glass petri dish and dried in an oven at $398 \mathrm{~K}$ for 22 hours. Samples were then placed in a dessicator. All other sorbents were used asreceived.

We summarize some of our findings. The kinetics for cesium sorption onto these materials shows that the uptake of cesium from solution onto crystalline silicotitanate (CST), illite, vermiculite (Grace $\mathrm{Co}$.), $\mathrm{SiO}_{2}$, and chabazite is rather quick in deionized water (Fig. 17), nearly reaching equilibrium within 10 minutes. Cesium binds very favorably in deionized water to all sorbents, with $>85 \%$ cesium sorbed. Interestingly, cesium begins to desorb from chabazite after approximately 10 minutes. KNiFC reaches equilibrium in less than a few hours for the smallest particle size (>100 mesh). 


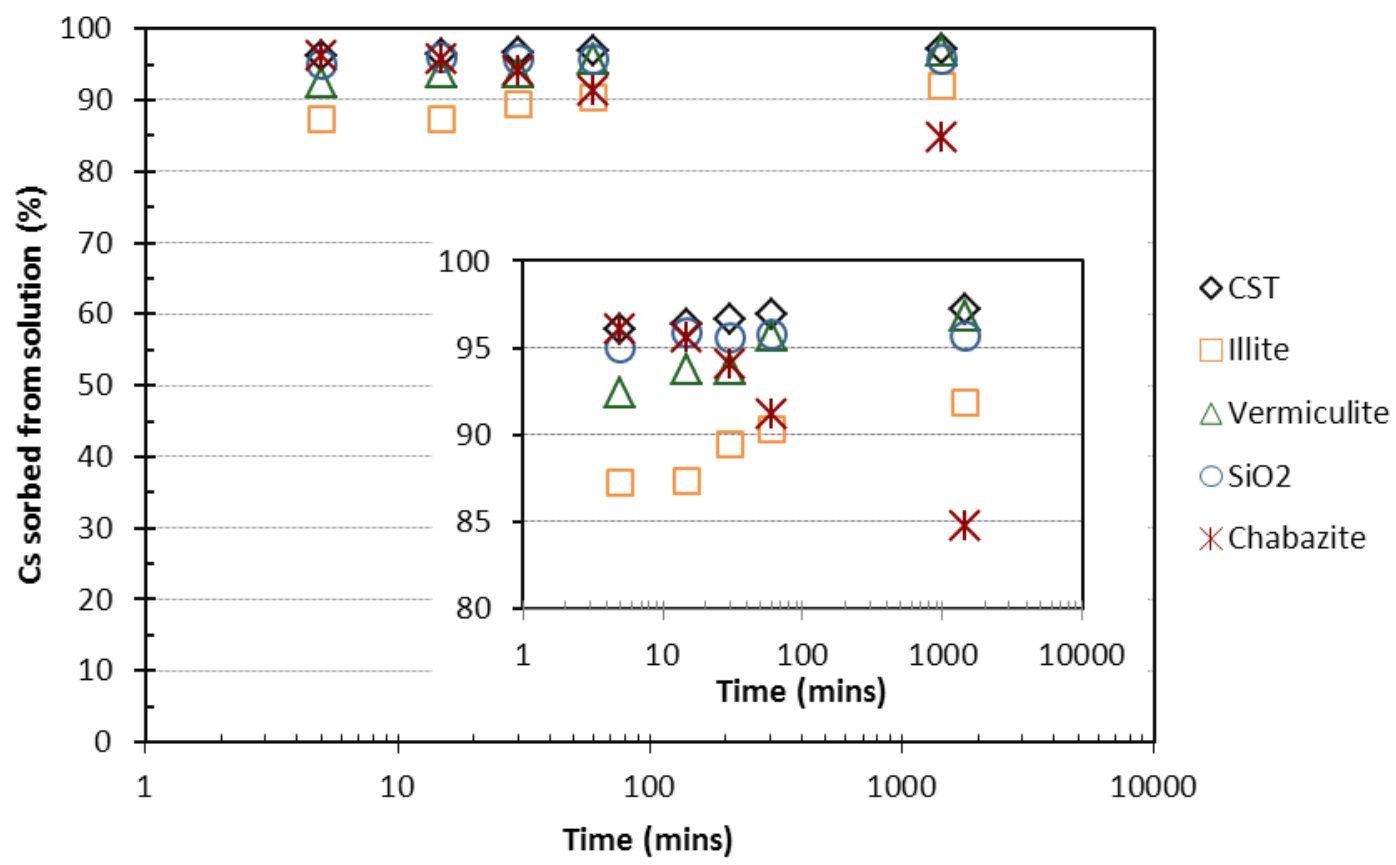

Figure 17. Kinetics of cesium sorption from deionized water onto the solid sequestering agent candidates $(10 \mathrm{mg}$ solid in $1 \mathrm{~mL}$ water. Tests in triplicate and samples counted in duplicate. Standard deviation $<1 \%$ for all tests).

But, with the presence of competing salts (alkali metal and alkali earth), even at very low concentrations, we observe a dramatic effect on the sorption and sorption kinetics. In tap water $\left(\sim 1.7 \mathrm{mmol}\right.$ salt per liter $\left.^{1}\right)$ the kinetics are slower for the three montmorillonite and two vermiculite clays we tested (Fig. 18). In addition, the $K_{d}$ values are noticeably depressed from their values in deionized water. Of the montmorillonites tested, the $\mathrm{K} 10\left(\mathrm{~K}_{\mathrm{d}}=3300 \mathrm{~mL} / \mathrm{g}\right)$ was least affected by the low concentrations of salt in the tap water and the $K_{d}$ of the vermiculites $\left(K_{d}=4800 \mathrm{~mL} / \mathrm{g}\right)$ were of the same magnitude as $\mathrm{K} 10$ (these tests used a slurry concentration of $1 \mathrm{mg} / \mathrm{mL}$ instead of $10 \mathrm{mg} / \mathrm{mL}$; thus the lower \% removals).

\footnotetext{
${ }^{1}$ Tap water in the City of Chicago has a typical content of $32.7 \mathrm{mg} / \mathrm{L} \mathrm{Ca}(0.8 \mathrm{mmol} / \mathrm{L}), 12.1 \mathrm{mg} / \mathrm{L} \mathrm{Mg}$ $(0.5 \mathrm{mmol} / \mathrm{L}), 1.51 \mathrm{mg} / \mathrm{L} \mathrm{K}(0.039 \mathrm{mmol} / \mathrm{L}), 8.47 \mathrm{mg} / \mathrm{L} \mathrm{Na}(0.37 \mathrm{mmol} / \mathrm{g})$.
} 

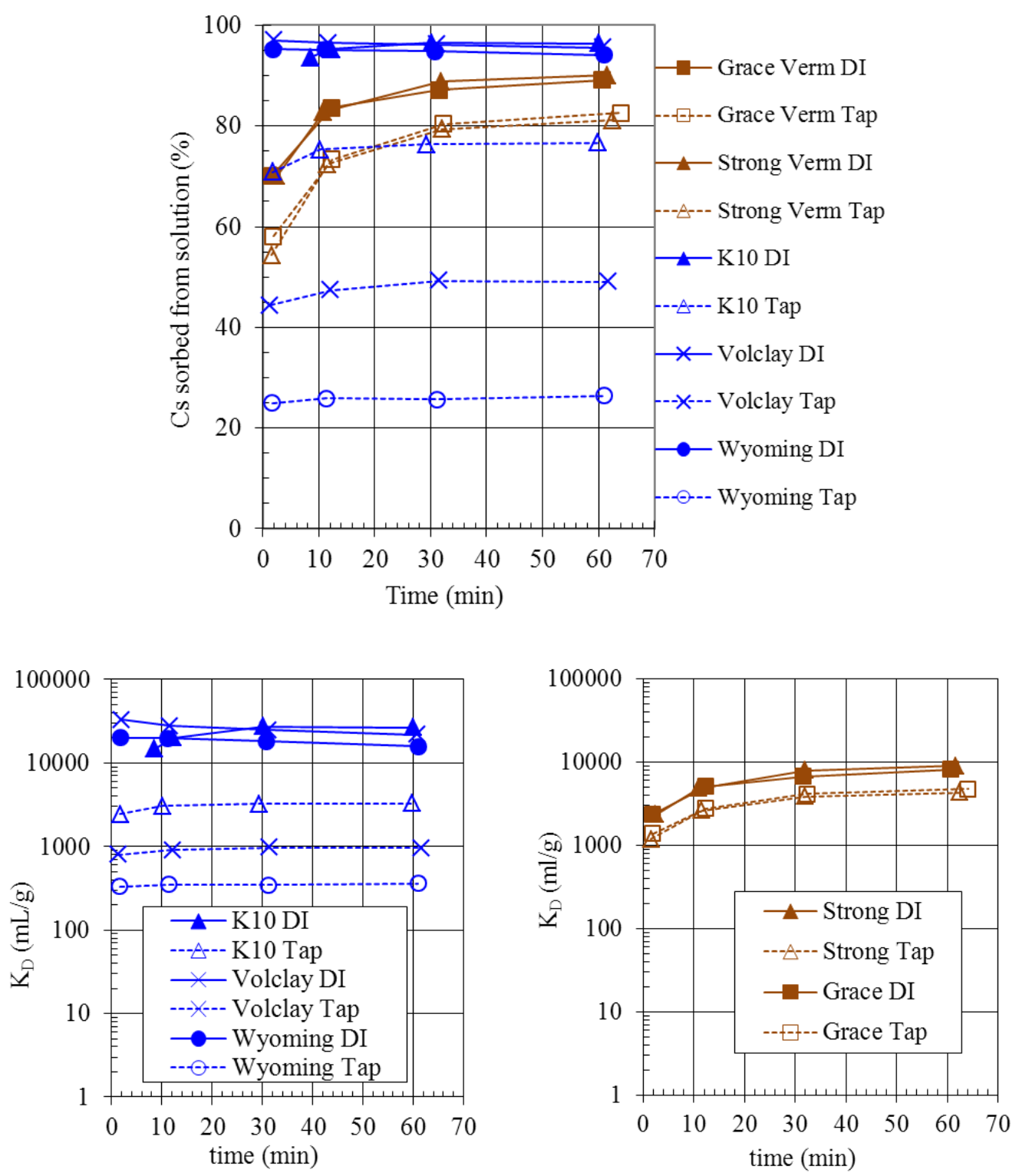

Figure 18. Sorption of Cs-137 from deionized water (DI) and Chicago tap water (Tap) onto montmorillonite (K10, Volclay, and the Wyoming clay BARA-KADE ${ }^{\circledR}$ ) and vermiculite clays (Strong Co. and Grace Co). Even though $\mathrm{K}_{\mathrm{d}}$ is plotted as a function of time, it is strictly an equilibrium value so only the value at 60 minutes should be quoted. (Tests run at a slurry concentration of $1 \mathrm{mg} / \mathrm{mL}$. Duplicate tests with single samples for counting.)

As we increased the salt concentration by adding ammonium chloride sorption is depressed further (Fig. 19). Sorption onto K10 drops below $65 \%$ at $0.1 \mathrm{mM}$ of ammonium in tap water to $30 \%$ in $1 \mathrm{mM}$ ammonium in tap water. However, the vermiculites are less affected and display slightly better sorption as ammonium concentration increases to $1 \mathrm{mM}$ in tap water. 


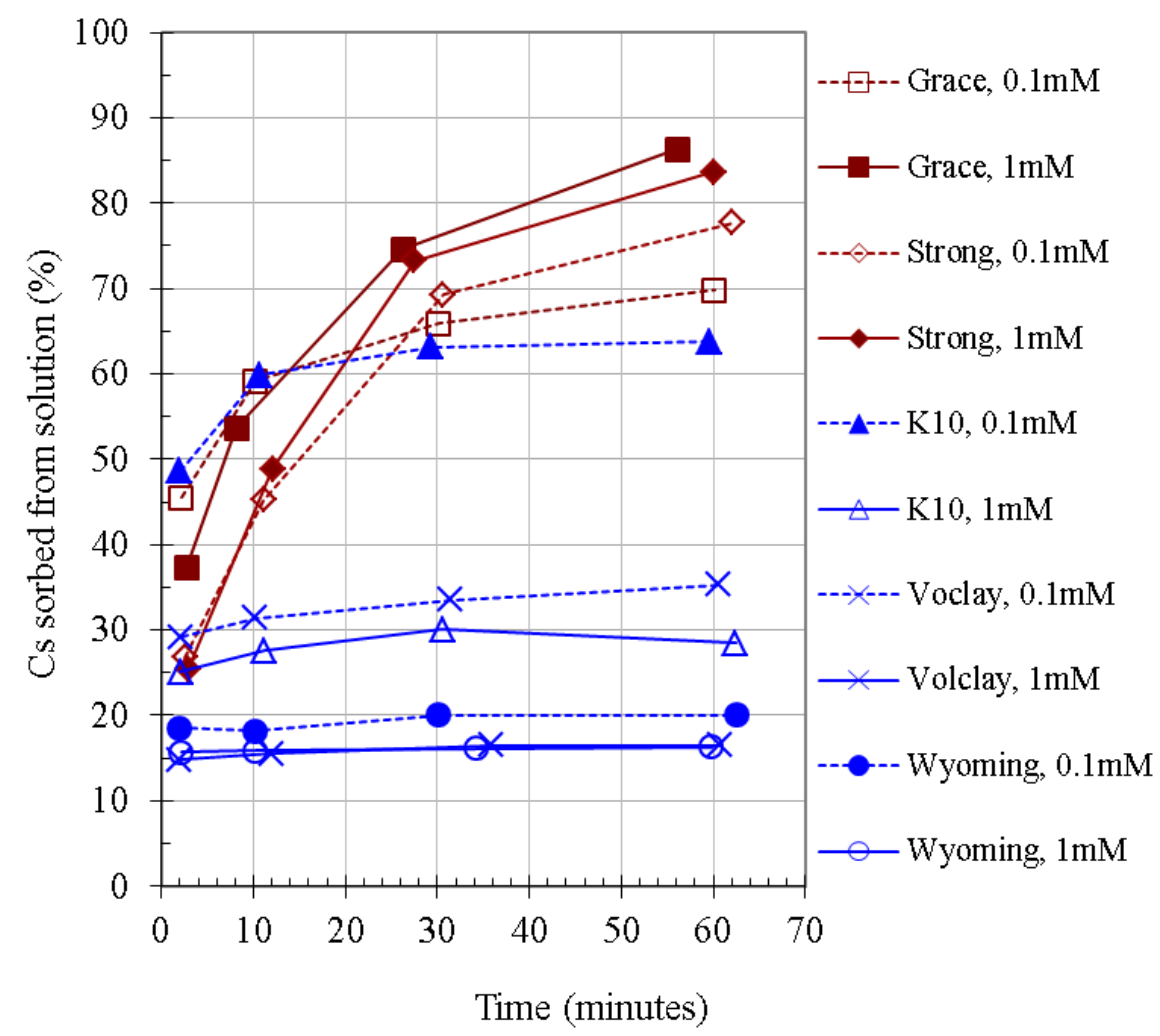

Figure 19. Sorption of Cs-137 from Chicago tap water (Tap) with additional ammonium chloride $(0.1$ or $1 \mathrm{mM})$ onto montmorillonite (K10, Volclay, and the Wyoming clay BARA-KADE $^{\circledR}$ ) and vermiculite clays (Strong Co. and Grace Co). (Tests run at a slurry concentration of $1 \mathrm{mg} / \mathrm{mL}$. Duplicate tests with single samples for counting.)

Using a higher slurry concentration of $10 \mathrm{mg} / \mathrm{mL}$, we ran similar tests in solution containing up to $200 \mathrm{mM}$ ammonium chloride in tap water (Fig. 20). First, at the lowest ammonium concentration in tap water the K10 removed $>94 \%$ of the cesium and the vermiculites $>95 \%$. Increasing the ammonium concentration progressively lowered sorption onto K10 montmorillonite. In contrast, as in Fig. 19, increasing the ammonium concentration in tap water improved sorption of cesium onto montmorillonite (Grace Co.) up to $10 \mathrm{mM}$ ammonium. Increases in salt thereafter depressed sorption, as observed with the K10 clay. 


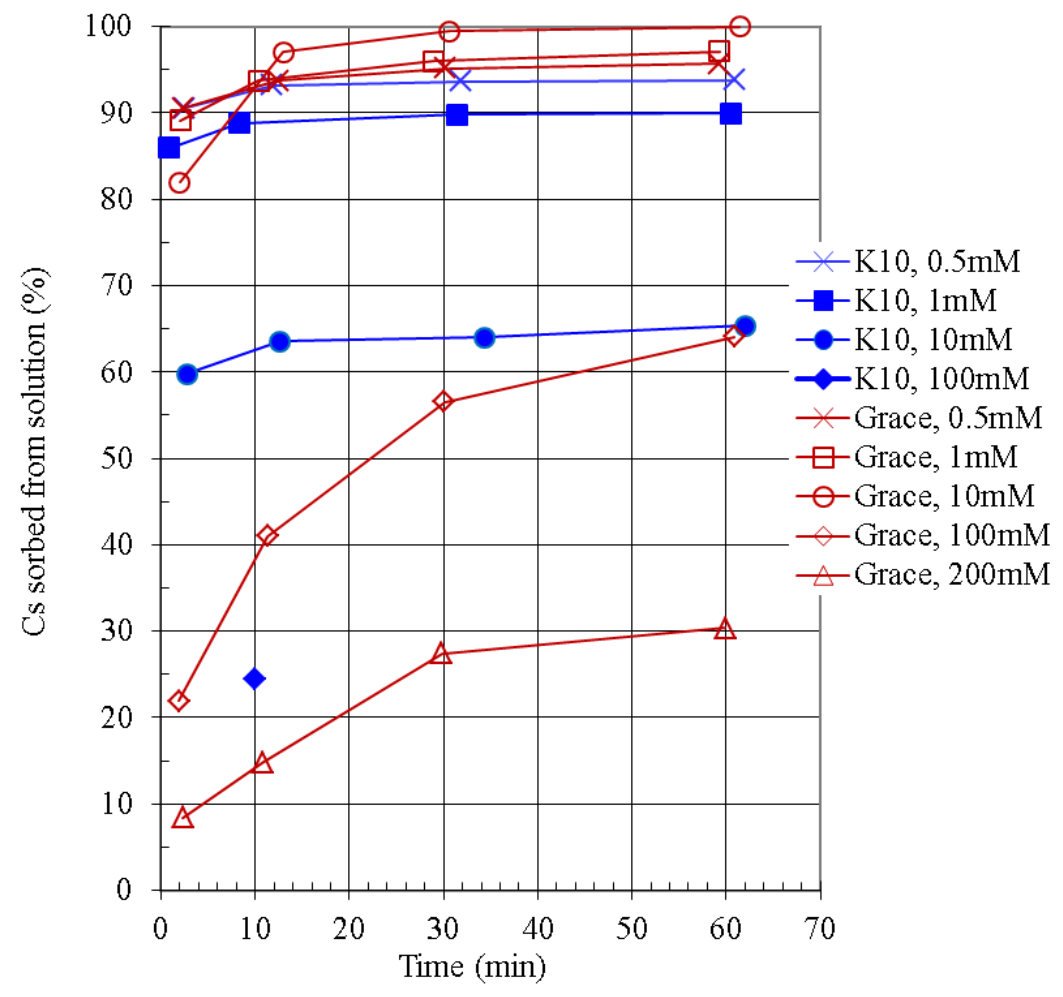

Figure 20. Kinetics of cesium sorption from $\mathrm{NH}_{4} \mathrm{Cl}$ solutions $(0.5-200 \mathrm{mM})$ onto the several montmorillonite and vermiculite solid sequestering agent candidates. (Tests run at a slurry concentration of $10 \mathrm{mg} / \mathrm{mL}$. Duplicate tests with single samples for counting.)

Various sorbents were tested further in the presence of different pure salts (in deionized water) and a range of concentrations $(0.1 \mathrm{mM}-500 \mathrm{mM})$. From $\mathrm{NH}_{4} \mathrm{Cl}$ solutions (Fig. 21), illite and $\mathrm{SiO}_{2}$ sorb cesium poorly except at the lowest salt concentration. Salt $>0.1 \mathrm{M}$ decreased sorption significantly among the other agents with CST also performing poorly at $0.5 \mathrm{M}$. In ammonium, the best solid was chabazite followed by vermiculite, but with $\mathrm{K}_{\mathrm{d}}$ 's $<100 \mathrm{~mL} / \mathrm{g}$ at $0.5 \mathrm{M} \mathrm{NH}_{4}{ }^{+}$. $\mathrm{KNiFC}$ has a large $\mathrm{K}_{\mathrm{d}}$ in high ammonium solutions. Regarding the $\mathrm{KNiFC}$, at $1 \mathrm{M} \mathrm{NH}_{4}{ }^{+}$, Mimura reports [Mimura-1997] a $\mathrm{K}_{\mathrm{d}}>7000 \mathrm{~mL} / \mathrm{g}$ and $>10,000 \mathrm{~mL} / \mathrm{g}$ at $0.5 \mathrm{M} \mathrm{NH}_{4}{ }^{+}$. 

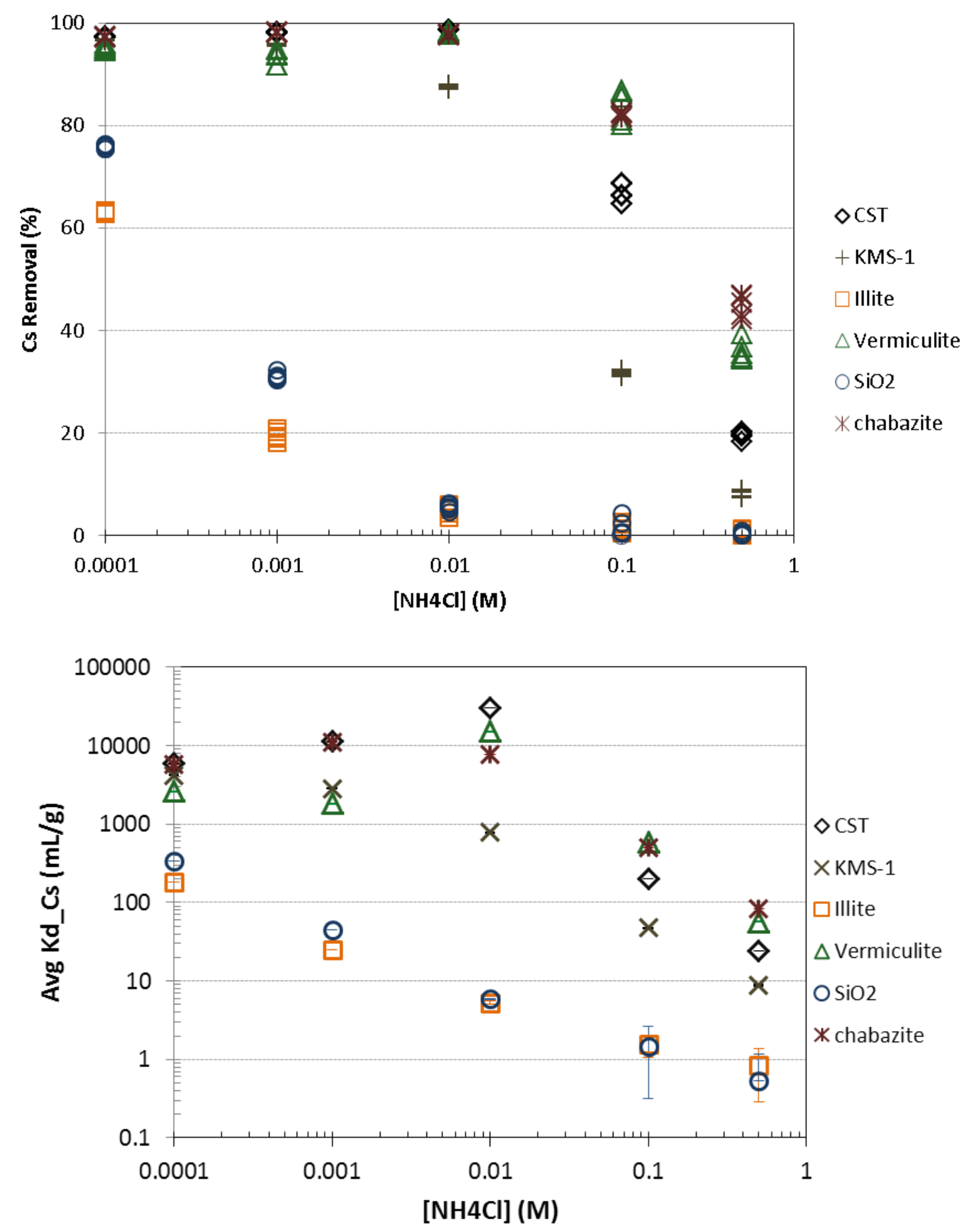

Figure 21. Sorption of cesium onto sequestering agent candidates as a function of $\mathrm{NH}_{4} \mathrm{Cl}$ concentration in solution $(10 \mathrm{mg}$ solid in $1 \mathrm{~mL}$ solution. Tests in triplicate and samples counted in duplicate. The standard deviation between samples was $<5 \%$ for most tests except those with very low sorption). 
Next we tested sorption in $\mathrm{KCl}$. Again, illite sorbed cesium poorly at all but the lowest salt concentrations, similarly to the $\mathrm{SiO}_{2}$ negative control (Fig. 22). With the others we saw a significant reduction in cesium sorption above $0.01 \mathrm{M} \mathrm{KCl}$ with $\mathrm{K}_{\mathrm{d}}=50$ $\mathrm{mL} / \mathrm{g}$ for chabazite and $34 \mathrm{~mL} / \mathrm{g}$ for vermiculite at $0.5 \mathrm{M} \mathrm{KCl}$. At this concentration, CST did well $\left(\mathrm{K}_{\mathrm{d}}=860 \mathrm{~mL} / \mathrm{g}\right)$. Regarding the $\mathrm{KNiFC}$, at $1 \mathrm{M} \mathrm{K}^{+}$, Mimura reports [Mimura1997] a $\mathrm{K}_{\mathrm{d}}>40,000 \mathrm{~mL} / \mathrm{g}$ and $>100,000 \mathrm{~mL} / \mathrm{g}$ at $0.5 \mathrm{M} \mathrm{K}^{+}$.
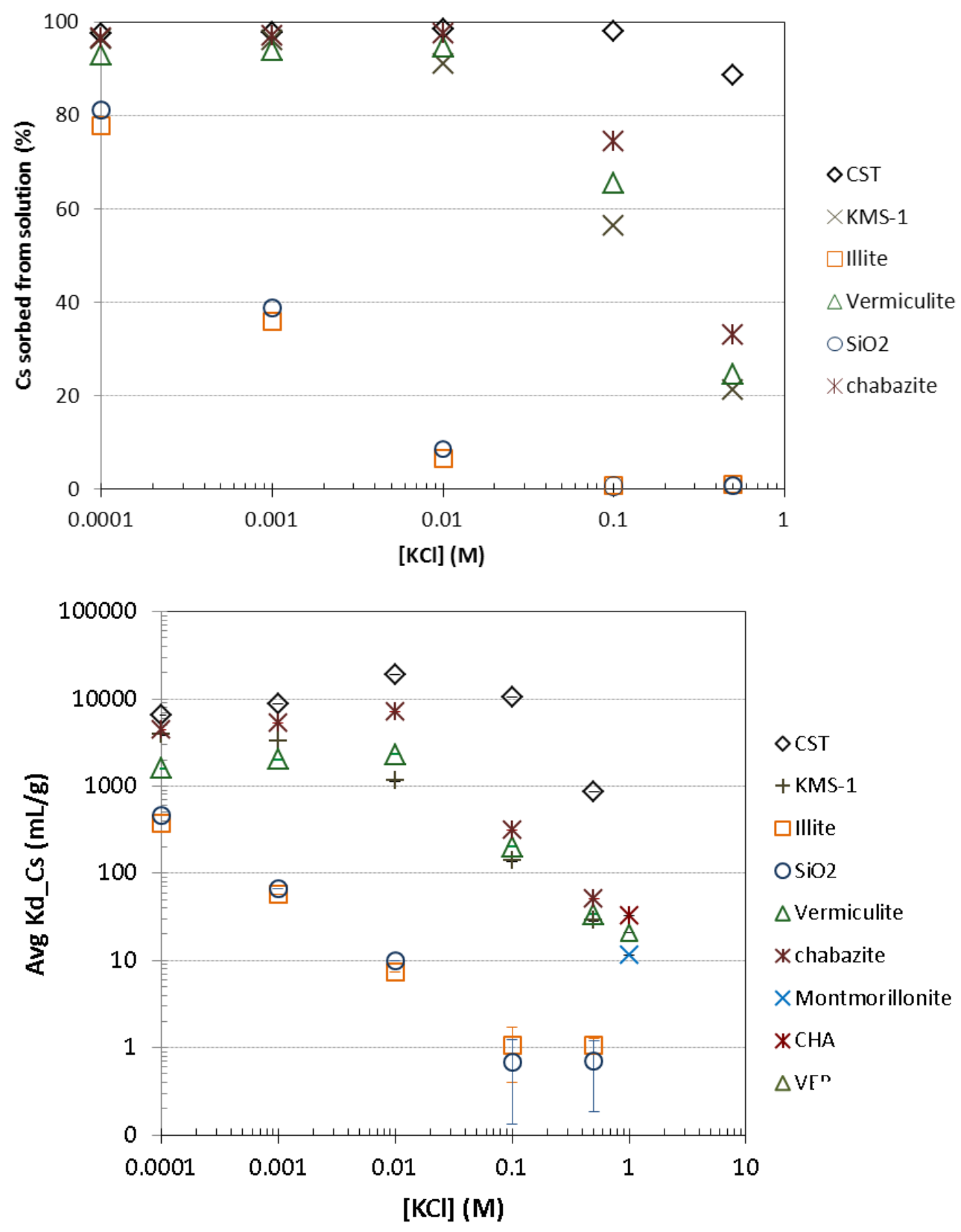

Figure 22. Sorption of cesium onto sequestering agent candidates as a function of $\mathrm{KCl}$ concentration in solution $(10 \mathrm{mg}$ solid in $1 \mathrm{~mL}$ solution. Tests in triplicate and samples counted in duplicate. The standard deviation between samples was $<5 \%$ for most tests except those with very low sorption). 
In the presence of sodium (Fig. 23), in the form of sodium carbonate $\mathrm{Na}_{2} \mathrm{CO}_{3}$, the sorption of cesium onto CST and chabazite was unaffected by high salt concentrations and vermiculite was less affected by high salt up to $1.0 \mathrm{M}$ sodium $\left(0.5 \mathrm{M} \mathrm{Na}_{2} \mathrm{CO}_{3}\right)$ than with other cationic salts. Sorption onto illite and $\mathrm{SiO}_{2}$ progressively worsened with increasing sodium concentration. Regarding the $\mathrm{KNiFC}$, in $\mathrm{Na}^{+}$, Mimura reports [Mimura-1997] a $\mathrm{K}_{\mathrm{d}}>100,000 \mathrm{~mL} / \mathrm{g}$ with little dependence on sodium concentration.
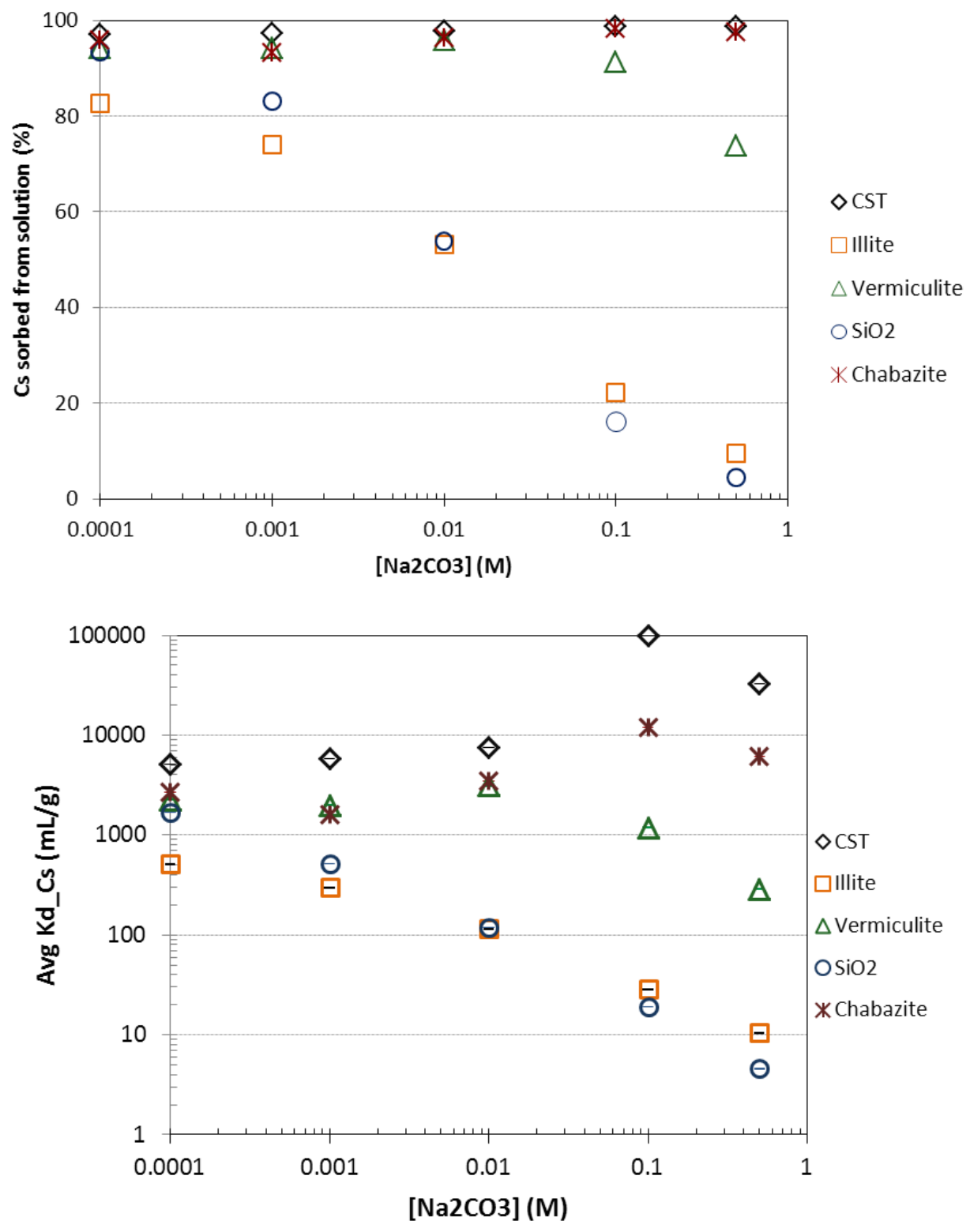

Figure 23. Sorption of cesium onto sequestering agent candidates as a function of $\mathrm{Na}_{2} \mathrm{CO}_{3}$ concentration in solution $(10 \mathrm{mg}$ solid in $1 \mathrm{~mL}$ solution. Tests in triplicate and samples counted in duplicate. The standard deviation between samples was $<5 \%$ for most tests except those with very low sorption). 
To understand the effect of slurry concentration on cesium sorption, we increased the slurry concentration at constant salt concentration of $0.5 \mathrm{M}$, since this was our target salt concentration for radiation mitigation. First, considering kinetics (Fig. 24), the vermiculite (Grace Co.) approached equilibrium after 60 minutes, similar to what we observed at lower salt concentrations. The K10 montmorillonite reached equilibrium by the first sampling at 10 minutes. We also note that there is no benefit to increasing the clay slurry concentration above $100 \mathrm{mg} / \mathrm{mL}$ for both clays; vermiculite removes $90 \%$ of the cesium while $\mathrm{K} 10$ montmorillonite removes slightly more than $40 \%$ in $0.5 \mathrm{M} \mathrm{NH}_{4} \mathrm{Cl}$ at both 100 and $125 \mathrm{mg} / \mathrm{mL}$.
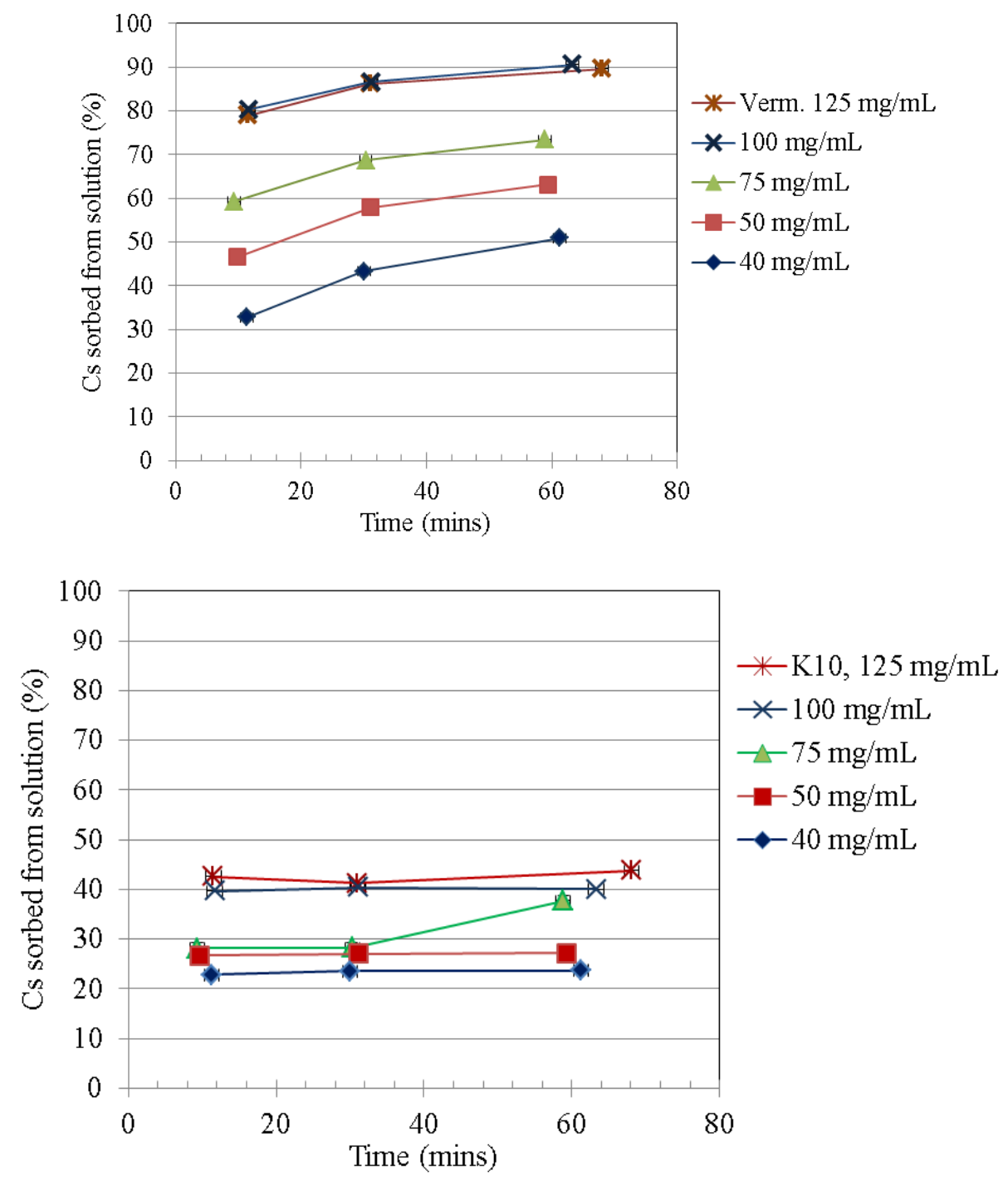

Figure 24. Kinetics for cesium sorption from $0.5 \mathrm{M} \mathrm{NH}_{4} \mathrm{Cl}$ solution onto vermiculite (Grace Co.) and montmorillonite (K10) as a function of clay slurry concentration. (Tests run at a slurry concentration of $10 \mathrm{mg} / \mathrm{mL}$. Triplicate tests with duplicate samples for counting. Standard deviations were $<5 \%$ except for vermiculite data at $75 \mathrm{mg} / \mathrm{mL}$ where standard deviations were $14 \%$ between duplicate counting samples.) 
In $\mathrm{KCl}$ (Fig. 25), the montmorillonite sorbs $80 \%$ cesium at $120 \mathrm{mg} / \mathrm{mL}$ while vermiculite sorbs slightly less than $60 \%$ cesium at this slurry concentration. We did observe an incremental benefit to increasing the slurry concentration above $100 \mathrm{mg} / \mathrm{mL}$.

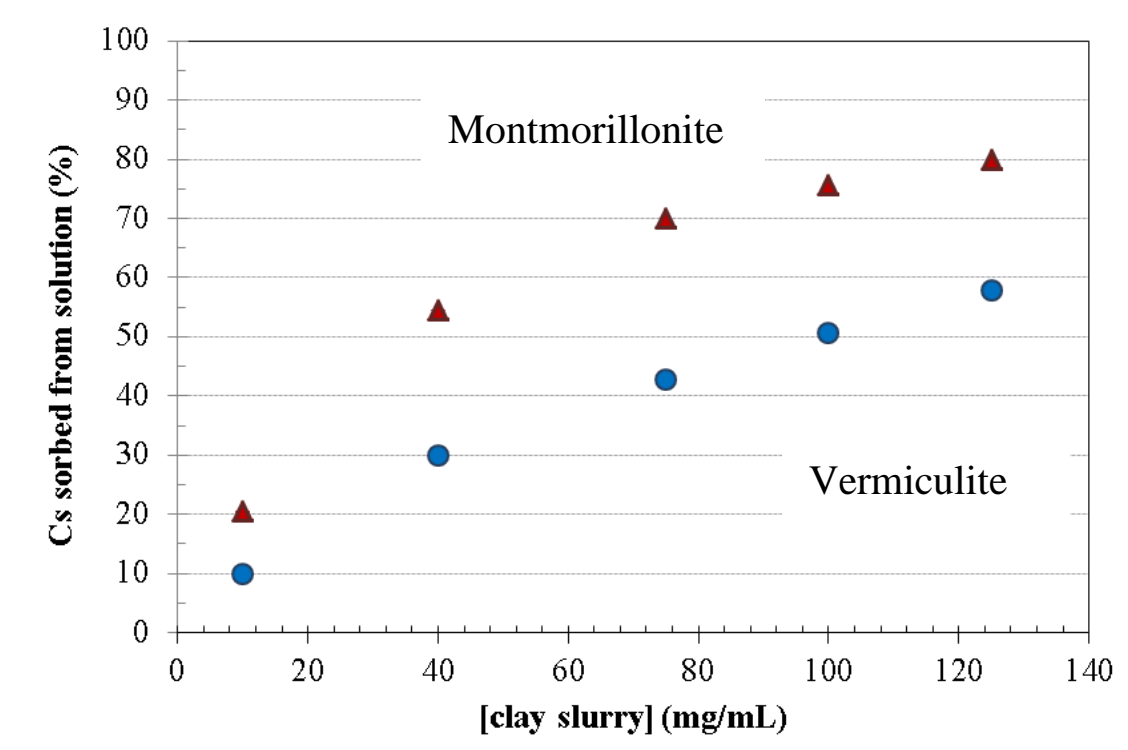

Figure 25. Effect of clay slurry concentration and time on Cs sorption in $0.5 \mathrm{M} \mathrm{KCl}$.

\subsubsection{Sequestering Agent Availability and Pricing}

The vermiculite clay can be obtained from several suppliers around the country. The largest are Grace Co. (VCX vermiculite concentrate, Specialty Vermiculite Corp, 62 Whittemore Ave., Cambridge, MA 02140, 1 (800) 342-2017, WWW.Grace.com) and The Strong Co., Inc. (4505 Emmett Sanders Road, Pine Bluff, AR 61601, 1 (870) 5357617 , www.strongseal.com). Typical properties of the vermiculite are in Tables 4-6.

Table 4. Typical Properties of VCX Vermiculite

\begin{tabular}{|ll|}
\hline \multicolumn{1}{|c|}{ Property } & \multicolumn{1}{c|}{ Typical Value } \\
\hline Color & Dark greenish brown to golden brown \\
\hline Shape & Flake \\
\hline Solubility & Insoluble in water \\
\hline Aspect Ratio & $20-40$ \\
\hline Surface Area (a) & $0.5-1.0\left(\mathrm{~m}^{2} / \mathrm{gm}\right)$ \\
\hline Mohs Hardness & $1.5-2.0($ Nonabrasive $)$ \\
\hline Specific Gravity & $2.4-2.8$ \\
\hline Bulk Density & $40-66(\mathrm{lbs} / \mathrm{ft})$ \\
& $640-1.041(\mathrm{~kg} / \mathrm{m})$ \\
\hline
\end{tabular}




\begin{tabular}{|ll|}
\hline \multicolumn{1}{|c|}{ Property } & \multicolumn{1}{c|}{ Typical Value } \\
\hline Moisture Content & $6.5 \%$ (heated to $\left.250^{\circ} \mathrm{F}, 110^{\circ} \mathrm{C}\right)$ \\
\hline Total Ignition Loss & $8.0-20.0 \%$ \\
\hline $\mathrm{pH}$ (in water) & $6-8$ \\
\hline Expansion & $10 \mathrm{X}($ Volume Change) \\
\hline Expansion Temperature & $1100-1800^{\circ} \mathrm{F}\left(580-970^{\circ} \mathrm{C}\right)$ \\
\hline Sintering Temperature & $2100-2200^{\circ} \mathrm{F}\left(1200-1300^{\circ} \mathrm{C}\right)$ \\
\hline Fusion Point & $2200-2400^{\circ} \mathrm{F}\left(1200-1300^{\circ} \mathrm{C}\right)$ \\
Cation Exchange Capacity & $50-100($ meq./100g) \\
\hline
\end{tabular}

Table 5. Typical Chemical Analysis of VCX vermiculite $\left[\left(\mathrm{Mg}, \mathrm{Ca}, \mathrm{K}, \mathrm{Fe}^{2+}\right)_{3}\left(\mathrm{Si}, \mathrm{Al}, \mathrm{Fe}^{3+}\right)_{4} 0_{10}(\mathrm{OH})_{2} \cdot 4 \mathrm{H}_{2} \mathrm{O}\right]$

\begin{tabular}{|c|c|}
\hline Element & \% by Weight \\
\hline $\mathrm{SiO}_{2}$ & $36-46$ \\
\hline $\mathrm{MgO}$ & $16-24$ \\
\hline $\mathrm{Al}_{2} \mathrm{O}_{3}$ & $11-16$ \\
\hline $\mathrm{Fe}_{2} \mathrm{O}_{3}$ & $8-13$ \\
\hline $\mathrm{K}_{2} \mathrm{O}$ & $4-6$ \\
\hline $\mathrm{CaO}$ & $1-3$ \\
\hline $\mathrm{TiO}$ & $1-3$ \\
\hline $\mathrm{MnO}$ & $0.1-0.2$ \\
\hline $\mathrm{Cr}_{2} \mathrm{O}$ & $0.05-0.2$ \\
\hline $\mathrm{Na}_{2} \mathrm{O}$ & $0.1-0.3$ \\
\hline $\mathrm{Other}$ & $0.0-0.5$ \\
\hline
\end{tabular}

(b) Elements are expressed as oxides

Table 6. Typical VCXTM Particle Size (Cumulative \% Weight Retained)

\begin{tabular}{|c|c|c|c|c|c|}
\hline U.S. Screens & $\mathbf{m m}$ & VCX 203 & VCX 204 & VCX 294 & VCX 205 \\
\hline 8 & 2.38 & $0-2.0$ & & & \\
\hline 20 & 0.84 & & $0-2.0$ & & \\
\hline 30 & 0.59 & $85.0-93.0$ & $0-15.0$ & $1.0-10.0$ & $0-1$ \\
\hline 50 & 0.297 & & & & $0-20$ \\
\hline 70 & 0.21 & $95.0-100.0$ & $85.0-95.0$ & & \\
\hline 100 & 0.149 & & $90.0-100.0$ & $45.0-100.0$ & $30-76$ \\
\hline
\end{tabular}


We obtained bulk pricing from Specialty Vermiculite Corp. (see below). Prices of bulk (tons) units are $\$ 130$ per ton and $3000 \mathrm{lb}$ totes are $\$ 212$.

Table 7. Bulk pricing of VCX 205 vermiculite ore (price does not include shipping) as of August 2012.

$\begin{array}{llll}\begin{array}{llll}\text { Products } \\ \text { Bulk Shipments: }\end{array} & \begin{array}{l}\text { Unit of } \\ \text { Sale }\end{array} & \begin{array}{l}\text { Price Per } \\ \text { Unit }\end{array} & \begin{array}{l}\text { Price Per } \\ \text { Ton }\end{array} \\ \begin{array}{l}\text { VCX 205 Bulk } \\ \text { Packaged Goods: }\end{array} & \text { Ton } & \$ 130.20 & \$ 130.20 \\ \text { VCX 205 50\# Bags (60/Pallet) } & \text { Bag } & \$ 4.17 & \$ 166.80 \\ \text { VCX 205 3000\# Tote } & \text { Tote } & \$ 267.02 & \$ 178.01\end{array}$

K10 Montmorillonite can be obtained from Fisher via ACROS Organics, LLC. Its general properties are in Tables $8-9$. Bulk pricing is $\$ 9.0$ and $\$ 10.0 / \mathrm{kg}$ for $5(\$ 8000 /$ ton $)$ and 10 tons (\$9000/ton), respectively (March 3, 2012 price quote).

Table 8. K10 Montmorillonite Product Specifications

\begin{tabular}{|c|c|}
\hline Property & Typical Value \\
\hline Appearance & beige to grey powder \\
\hline apparent bulk density: & $370 \mathrm{~g} / \mathrm{l}$ \\
\hline free moisture $\left(110^{\circ} \mathrm{C}, 2 \mathrm{hrs}.\right)$ & $:<3 \%$ \\
\hline loss on ignition $\left(1000^{\circ} \mathrm{C}, 2 \mathrm{hrs}.\right):$ & $6 \%$ \\
\hline $\mathrm{pH}$ of a $10 \%$ suspension (filtered): & 3.5 \\
\hline sieve analysis of the dry powder: & $>63 \mathrm{um}:<25 \%$ \\
\hline surface area: & $240 \mathrm{~m}^{2} / \mathrm{g}$ \\
\hline$:$ & 0 to $80 \mathrm{~nm}: 0.36 \mathrm{ml} / \mathrm{g}$ \\
\hline & 0 to $24 \mathrm{~nm}: 0.30 \mathrm{ml} / \mathrm{g}$ \\
\hline & 0 to $14 \mathrm{~nm}: 0.26 \mathrm{ml} / \mathrm{g}$ \\
\hline micropore volume & \\
\hline
\end{tabular}

Table 9. Typical Chemical Composition of K10 Montmorillonite

\begin{tabular}{|c|c|}
\hline Element & (dried at 110 $\mathbf{C}, \mathbf{2}$ hrs) \\
\hline $\mathrm{SiO}_{2}$ & $73.0 \%$ \\
\hline $\mathrm{Al}_{2} \mathrm{O}_{3}$ & $14.0 \%$ \\
\hline $\mathrm{Fe}_{2} \mathrm{O}_{3}$ & $2.7 \%$ \\
\hline $\mathrm{CaO}$ & $0.2 \%$ \\
\hline $\mathrm{MgO}$ & $1.1 \%$ \\
\hline $\mathrm{Na}_{2} \mathrm{O}$ & $0.6 \%$ \\
\hline $\mathrm{K}_{2} \mathrm{O}$ & $1.9 \%$ \\
\hline
\end{tabular}


Natural chabazite can be obtained from St. Cloud Mining (Winston, NM, (575) 743-5215, http://www.stcloudmining.com) from their mine in Arizona. The bulk price quoted was $\sim \$ 2.00$ per pound (\$4000/ton) depending on particle size and packaging. Tonnage quantities can be obtained within 20 business days.

An engineered form of chabazite is available through UOP (Des Plaines, IL, (800) 877-6184, www.uop.com) under the trade name IONSIV ${ }^{\mathrm{TM}}$ R9160. The bulk pricing was $\$ 34.75 / \mathrm{kg}$ ( $\$ 31,000 /$ ton) for 10 tons $(9,070 \mathrm{~kg}$ ) shipped free on board (FOB) from Mobile, AL with a lead time of 90 days.

Crystalline silicotitanate is solely supplied by UOP and formerly known as IONSIVTM IE 911. This material has recently been returned as an off-the-shelf item and renamed R9120-B. It is deployed at Fukushima to treat contaminated seawater. The lead time for these products is approximately two-months for domestic shipping (FOB Mobile, AL). It is orders of magnitude more expensive than the clay (Table 10).

Table 10. Estimated prices for IONSIVTM IE-911 as of February 2013

\begin{tabular}{|c|c|c|c|}
\hline & $100 \mathrm{~kg}$ & $500 \mathrm{~kg}$ & $1000 \mathrm{~kg}(1.12$ tons $)$ \\
\hline $\mathrm{R} 9120-\mathrm{B}$ & $\$ 218,900$ & $\$ 893,200$ & $\$ 1,786,400$ \\
\hline
\end{tabular}

Hexacyanoferrates also have been used successfully to decontaminate cesium from contaminated seawater related to the cleanup activities by TEPCO at the Fukushima-Daiichi reactor site. This material is offered under the trade name CsTreat ${ }^{\mathrm{TM}}$ and we were informed by the supplier (Fortum) that it can be supplied in bulk of $1-5 \mathrm{~m}^{3}$ within two to three weeks. Larger volumes would require a delivery estimate in a quotation from the company. Normal delivery is from Finland. The company would not provide exact pricing, but estimated that their product was three times higher than the IONSIVTM IE-911 from UOP.

\subsubsection{Choosing the Sequestering Agents}

With the information in the previous section, we can propose options for sequestering agents depending on the particular application and function. First, let us summarize the results of the previous section.

- In waters that contain very low concentrations of salts $(<1 \mathrm{mM})$, many different types of natural and synthetic materials will effectively sorb cesium. However, the target concentration of ammonium and potassium salts is $\sim 0.5$ M. At $0.5 \mathrm{M}$ salt, most of the sequestering agents are ineffective, thus requiring large quantities of solid, except for the $\mathrm{KNiFC}$.

- In $0.5 \mathrm{M} \mathrm{KCl}$, in terms of the $\mathrm{K}_{\mathrm{d}}$, the order of preferred sequestering agents is $\mathrm{KNiFeCN}>\mathrm{CST}>>$ chabazite $>\mathrm{K} 10$ montmorillonite>vermiculite.

- In $0.5 \mathrm{M} \mathrm{NH}_{4} \mathrm{Cl}$, in terms of the $\mathrm{K}_{\mathrm{d}}$, the order of preferred sequestering agents is $\mathrm{KNiFeCN}>>$ chabazite>vermiculite $>\mathrm{CST}$ but the $\mathrm{K}_{\mathrm{d}}$ is $<100 \mathrm{~mL} / \mathrm{g}$ for each. 
- In $0.5 \mathrm{M} \mathrm{Na}^{+}$, in terms of the $\mathrm{K}_{\mathrm{d}}$, the order of preferred sequestering agents is $\mathrm{KNiFeCN}=\mathrm{CST}>>$ chabazite $>>$ vermiculite.

- In terms of the available supply, vermiculite is preferred since all the others are not available in bulk as off-the-shelf items. The only possible exception is K10 montmorillonite, but the price of the K10 is $\$ 9000 /$ ton while VCX205 is $\$ 130 /$ ton).

- When a large mass of sequestering agent is not necessary (e.g., for final clarification of a depleted source term), $\mathrm{KNiFeCN}$ and crystalline silicotitanate is the most effective sequestering agent for cleaning $\mathrm{KCl}$ solutions while chabazite and vermiculite are most effective for cleaning ammonium solutions.

- The slurry concentration should be $\sim 100 \mathrm{~g} / \mathrm{L}$ for maximal removal $(90 \%$ cesium removed onto vermiculite in $0.5 \mathrm{M} \mathrm{NH}_{4} \mathrm{Cl}$ ) in a single step. However, if multiple steps (stages) can be designed, then the slurry concentration can be lowered accordingly. For instance, to achieve $90 \%$ removal in two stages [ $(1-$ $0.9)^{1 / 2}=0.3$, then $(1-0.3)=0.7$ or $70 \%$ removed per stage], only $75 \mathrm{~g} / \mathrm{L}$ of vermiculite is needed (see Fig. 24). With 10 stages, $<<10 \mathrm{mg} / \mathrm{mL}$ of vermiculite is

needed $[(1-0.9) 1 / 10=0.79$, then $(1-0.79)=0.2$ or $20 \%$ removed per stage] (see Fig. 21 ).

- It might be possible to perform an initial separation of cesium from the wash waters for the purpose of reusing wash water. Then, once mitigation operations are complete, the wash water can be decontaminated for unrestricted disposal. In this case, a specialty sequestration agent like $\mathrm{KNiFeCN}$ or CST operating in a column like those deployed at Fukushima might be prudent. A single column may be sufficient to treat the entire bulk of water even up to many millions of gallons.

\subsection{Distributing the Clay}

Once shipped to the location, the sequestering agent would need to be distributed across the floor of the berm, within the berm, and still be accessible for any mixing and separations units. Dump trucks, front loaders, bulldozers and similar earth-moving equipment can be used to cover the floor of the reservoir, fill the berm, build ramps to permit vehicles to move in and out of the berm, and stockpile supplies of the sequestering material for use.

\subsection{Containing the Contaminated Water for Filtration and Reuse}

Although we have discussed the chemical composition of the wash water, the utility of the clay as a sequestering agent for dissolved radioactive cesium, and the method of preparing the wash water for dissemination, we have not addressed the method of collecting and capturing the wash waters as they are generated and the method of treating such waters for reuse and/or disposal. These topics will be addressed here. 
Because of the potential volume of water, tens of thousands of gallons to millions of gallons, we cannot expect collapsible tanks to be sufficiently large and available to capture the wash waters until they can be processed and discharged. Instead, we searched for methods of creating reservoirs at the mitigation site to prepare and contain voluminous wash waters.

\subsubsection{The Network of Sewer Lines as a Reservoir}

One of the first solutions we considered was to allow the sewer lines to collect the wash waters. By plugging the sewer lines (Figs. 26 and 27) around a perimeter of the affected zone, one could contain the waters under the street level for eventual treatment. However, the risk of contaminated wash waters "backing up" into the drains of buildings in the affected area, the small volume of actual water capacity in the sewer lines, and the complexity of performing the operation made this option unattractive. The only method that seemed reasonable was to create reservoirs using collapsible berms as is the industry standard for containing flood waters.

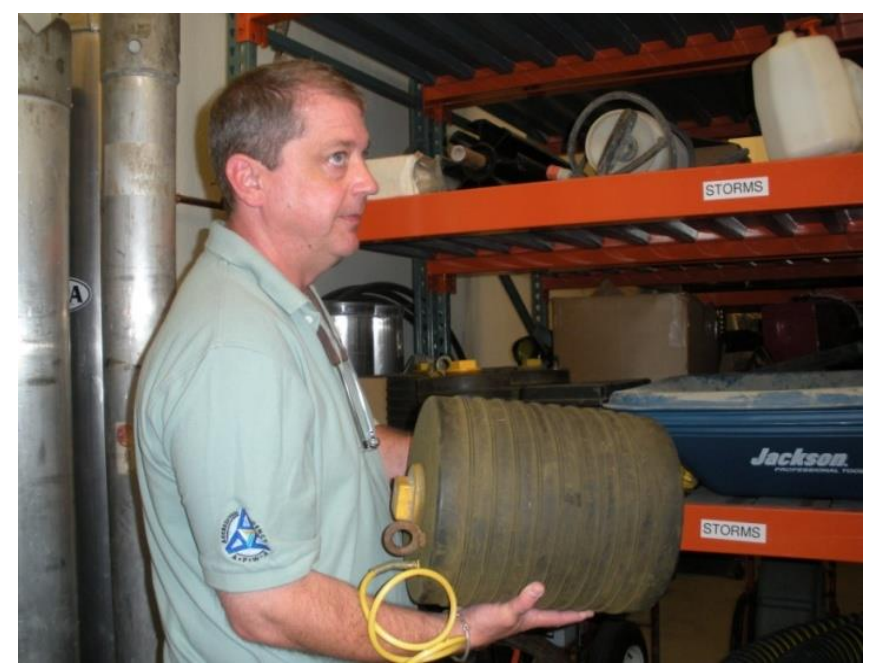

Figure 26. Inflatable rubber plugs, like the one being held, are used to isolate catch basins and inlets during maintenance. The yellow line connected to the left side of the plug is connected to an air supply to expand the plug in the pipe. 


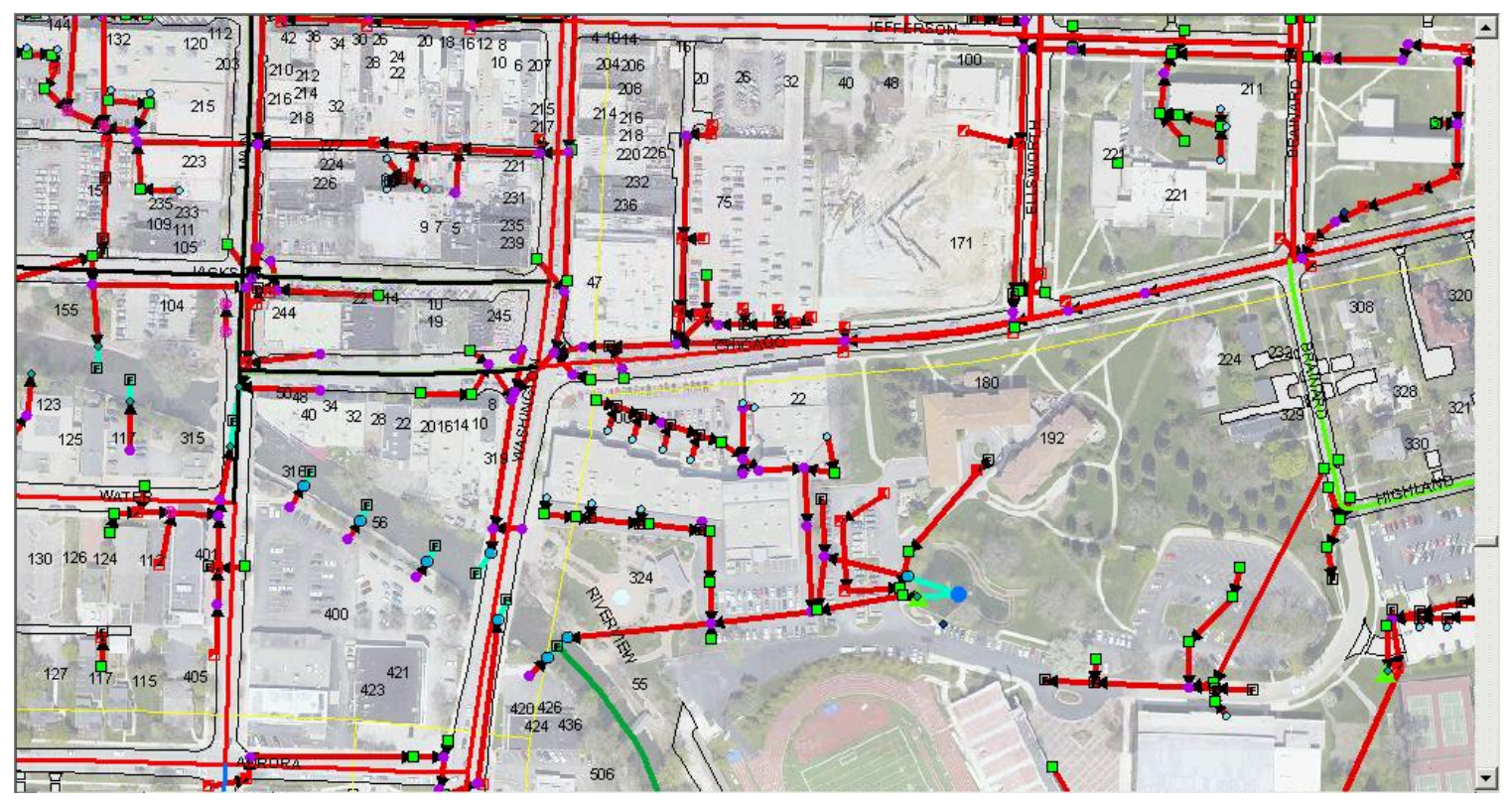

Figure 27. Storm and sanitary sewer maps like this can be used to plan the positions of sewer line plugs to isolate sewer lines in the affected zone, thus preventing the contamination of the entire sewer system and permitting the use of the sewers as a temporary reservoir for contaminated waters.

\subsubsection{Collapsible Berms}

In a previous report [USEPA-2012a], we described several types of collapsible berm concepts. These products are superior to sandbagging because miles of berm can be filled in a much shorter period than sandbags, once berm units arrive on-site. The containers are pre-fabricated and opened accordion style to create a long section in a short period of time. Large sections can be setup and filled with material available immediate to the site such as sand or dirt. Unlike sandbagging, fewer man-hours are required to fill open containers with material since heavy equipment can perform the work.

Several suppliers are available [USEPA-2012a]. Because they are worldwide suppliers of berm units, their units are off-the-shelf, and they are the preferred suppliers of material to the U.S. Army Corp of Engineers (USACE) and the U.S. Department of Defense (DOD), we asked HESCO USA to consult with us to develop a berm system for the containment of wash waters. HESCO USA also routinely deploys their personnel into areas containing hazardous materials so they are proficient with the personal protective equipment and procedures for working in such areas and handling hazardous materials. Their U.S. technical field representative suggested that training for work with radioactive materials would be within their capabilities, although this statement has not been confirmed officially with the company.

HESCO offers a variety of off-the-shelf unit sizes, liner material, and basket designs to fit their common applications. A typical basket section (Fig. 28) is $2 \mathrm{ft}(2 \times 2 \times$ 2 in. cells as a 5 cell section $10 \mathrm{ft}$ long), $3 \mathrm{ft}$ ( $3 \times 3 \times 3$ in. cells as a 5 cell section $15 \mathrm{in}$. 
long), or $4 \mathrm{ft}(4 \times 3 \times 3$ in. cells as a 5 cell section $15 \mathrm{ft}$ long or $5 \mathrm{ft}$ units). Militaryspecific units can be much longer. An interesting option with their design is to substitute the impermeable geotextile liner with a permeable liner. A permeable liner would allow us to use the berm as a reactive barrier, much like the in situ reactive barriers used in environmental management of groundwater contamination [Naftz-2002].

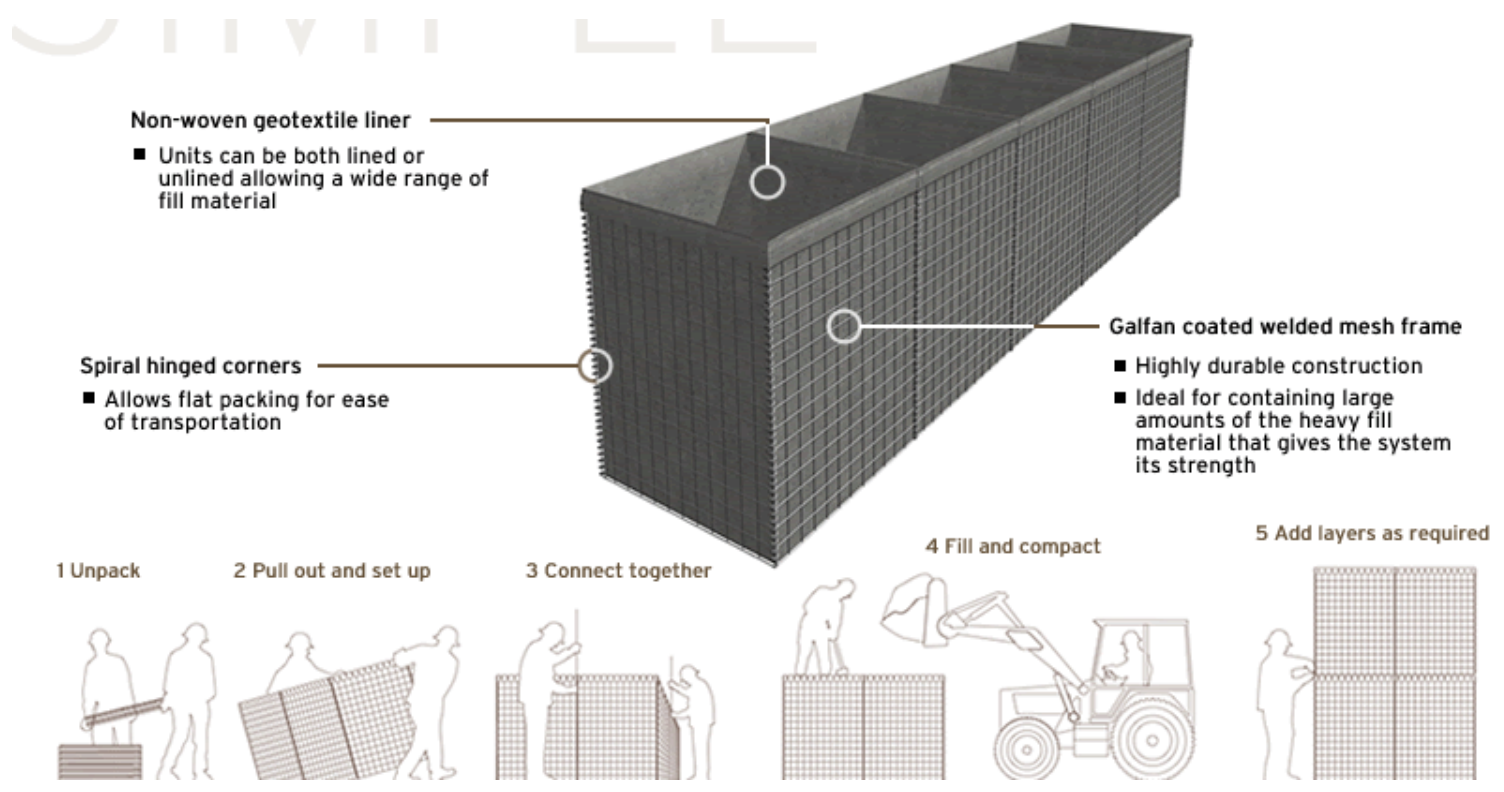

Figure 28. HESCO wire-reinforced geotextile containers for quickly establishing protective walls against flood waters. Units are shipped in collapsed form, unpacked accordion style, and filled with material to create hundreds of feet or miles of protective barriers.

They are shipped as five basket sections, where five individual rectangular containers (baskets) are connected accordion style as a single section. They also supply a much longer, integrated section (accordion style) that is used for military applications to setup very long (100's of feet) sections quickly. Galvanized steel pins are provided in the package to connect all the containers together as a continuous unit. The fabric liners are preinstalled in the baskets. Figure 28 provides a sketch description of the setup process. Front loaders or specialized hopper systems (Fig. 29) can be used to fill the containers. 

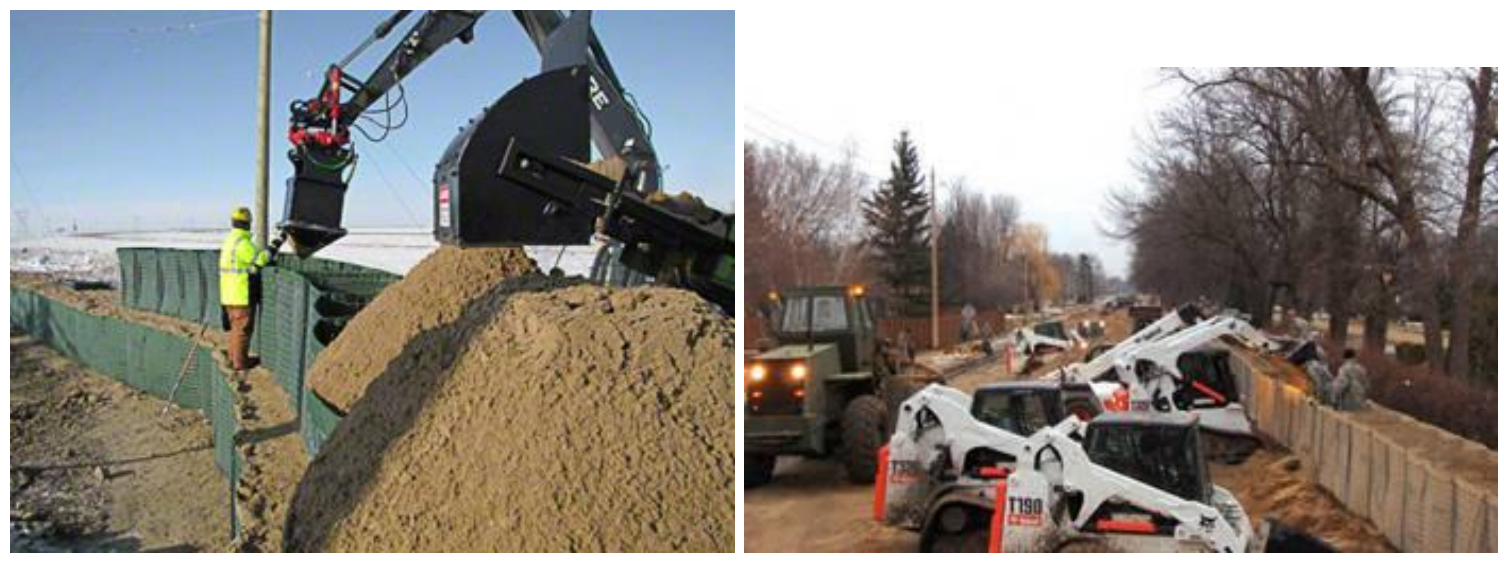

Figure 29. For the HESCO standard container systems a skid loader (bobcat) is used or they have a specialized hopper system with conveyers that directly feed material into the bags.

Once the mission is complete, the baskets are removed quite easily using a bobcat or a front loader. First, the connector pins are removed from between the container sections. Then, a chain with hooks is attached to the front of the bobcat shovel and connected to the ends of a container section. When the shovel is lifted, it pulls the container baskets upward dispensing the fill material on the ground. The baskets are then collapsed back into flat sections and disposed or reused. The fill material is shoveled into a dump truck for disposal or left in place depending on the application.

For our system, the HESCO containers are assumed to be contaminated as lowlevel radioactive waste as is the fill material. HESCO and other vendors provide a polydiaper liner that sits underneath the containers so that when the containers are removed the fill material is contained in the poly-diaper liner. The liner can then be wrapped around the fill material and lifted into a suitable transport vehicle. HESCO also has another system that requires a crane lift to remove an entire $15-\mathrm{ft}$ section in a few minutes.

A key aspect of the HESCO container design is ensuring proper density of the container units to withstand the force of water against the inner wall. Earth material is generally sufficiently dense to prevent the movement of the HESCO units against a reservoir of water. However, the vermiculite clay material has unusually low density. Therefore, HESCO suggested that either the clay material fill the container to a level much higher than the anticipated water level or we choose a partitioned container design known as the Rockface ${ }^{\circledR}$ product (Fig. 30). This product line has dual compartments so that the front face can be filled with the reactive sequestering agent while the rear compartment is filled with available earth material to increase the density. 


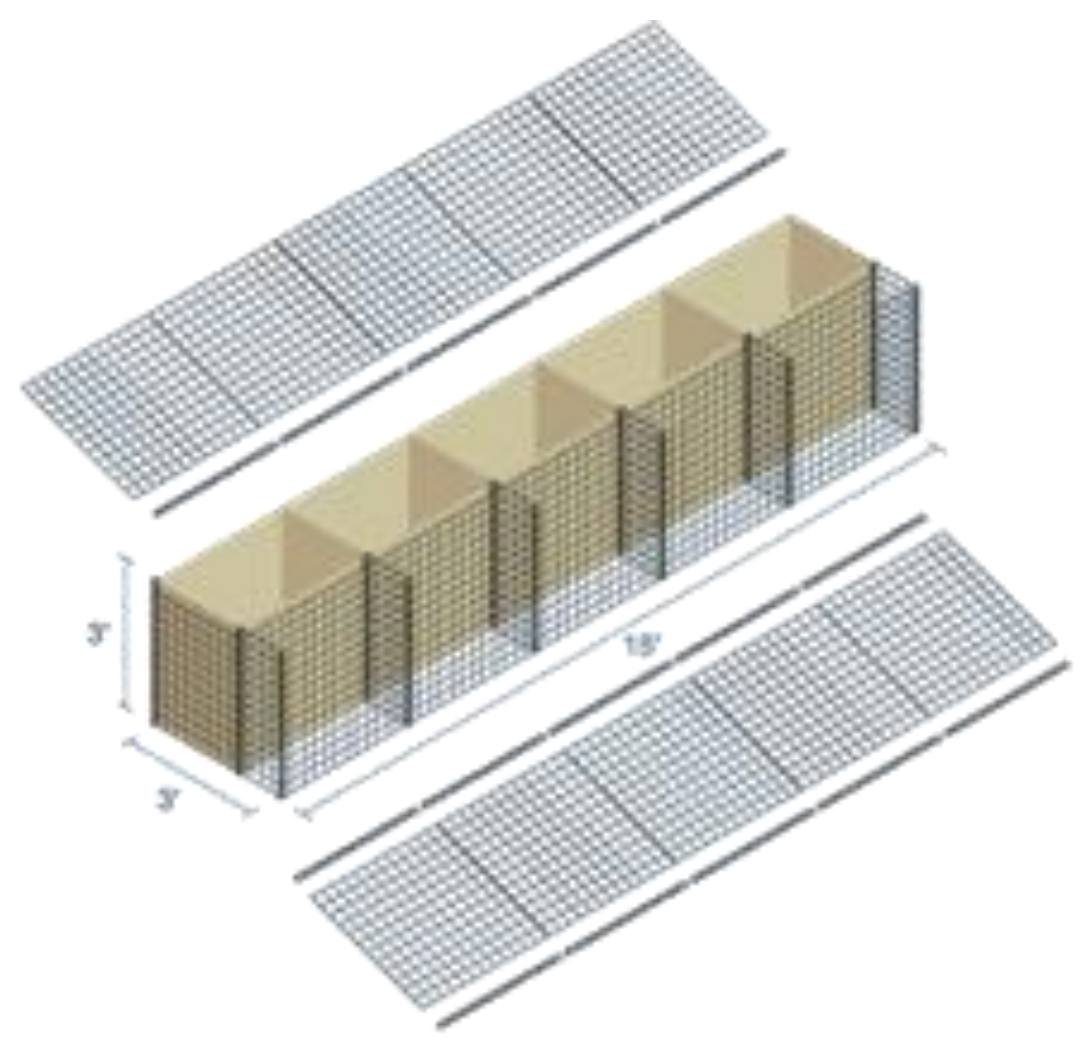

Figure 30. HESCO USA's Rockface ${ }^{\circledR}$ design is a five-basket unit with dual compartments. The rear compartment $(\tan )$ can be used for general fill material while the front face can be filled with the reactive sequestering agent to prevent spread of contaminated waters.

\subsubsection{Cost of HESCO Containers}

HESCO USA provided us with an estimate of the cost for deploying various HESCO container units for the purpose of radiation mitigation. The scenario was to deploy barriers sufficient to contain wash waters generated during the washing of an entire city block (we used the downtown Chicago financial district as our model). Using aerial maps (Fig. 31 and see Appendix A), we assumed that the façades of three city blocks would be washed requiring approximately 1500 linear feet of barriers to circle the perimeter (84 ft wide by $665 \mathrm{ft}$ long filled with an assumed capacity of $75 \%$ of fill height). ${ }^{2}$ The estimate of material and setup costs does not include the added costs of performing the work under radioactively-contaminated conditions.

In the first scenario, we assumed a one-foot tall barrier would be sufficient to contain the wash water. This would require the smallest HESCO container ( 2 foot) at a cost of $\$ 34,500$ and would require 112 cubic yards of sequestering agent or general fill material. Approximately 30 man-hours would be needed to complete the berm under nonradioactively contaminated work conditions. In the second scenario, we assumed a two-

\footnotetext{
${ }^{2}$ The specific details on where to position the barriers to prevent water invasion into the buildings within the affected zone has not been described in the current work.
} 
foot tall barrier would be required to contain the wash water. The same HESCO barriers apply, but would require 224 cubic yards of fill and 45 man-hours. In the third scenario, a 3 -foot barrier is required. One-hundred of the larger 3-foot Concertainer ${ }^{\circledR}$ units would be required at a total cost of $\$ 35,000,650$ cubic yards of fill material, and 60 man-hours. Adding a polymer underlayment to permit hauling the units whole for transport would add an additional $20 \%$ to the costs.

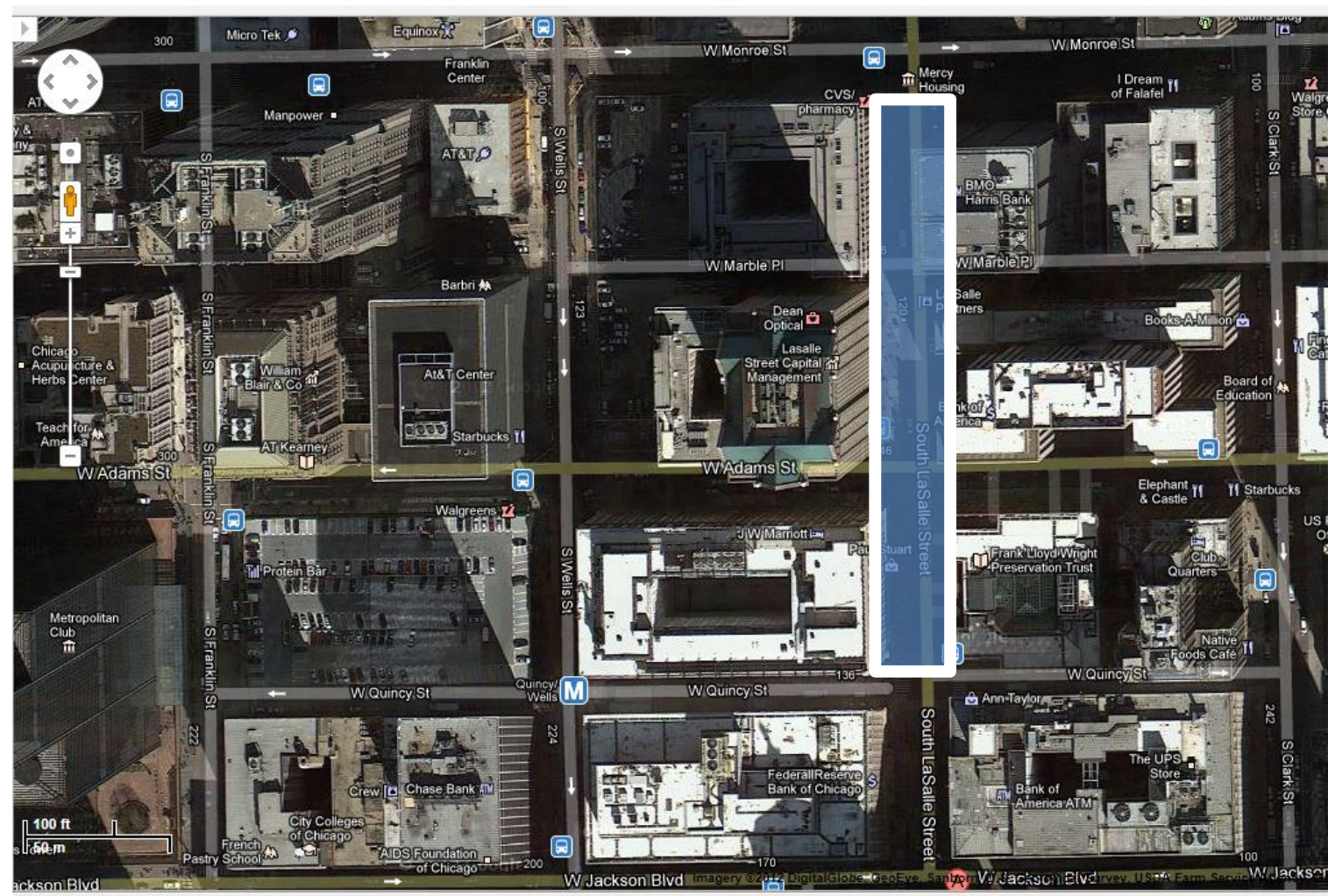

Figure 31. Aerial view of part of the Chicago financial district showing where berms could be placed to capture wash waters during mitigation operations on the façades of buildings along three city blocks (1500 linear feet).

Table 11. Cost estimate for cost of material and assisted deployment of HESCO Concertainers ${ }^{\mathrm{TM}}$ sufficient to cover 1500 linear feet.

\begin{tabular}{|l|l|}
\hline \multicolumn{1}{|c|}{ Berm Conditions } & \multicolumn{2}{|c|}{ Notes and Costs } \\
\hline 1) 1 foot tall x 2 feet deep, 1500 linear feet, & $\begin{array}{l}\text { Use a C2210 Unit but only fill to 1 inch. } \\
\text { porous. }\end{array}$ \\
& This would require 150 Units at \\
approximately \$230 ea. or \$34,500 of \\
HESCO material and 112 CYD of clay and \\
30 man-hours.
\end{tabular}




\begin{tabular}{|l|l|}
\hline \multicolumn{1}{|c|}{ Berm Conditions } & \multicolumn{1}{|c|}{ Notes and Costs } \\
\hline $\begin{array}{l}\text { 2) } 2 \text { foot tall x 2 feet deep, 1500 linear feet, } \\
\text { porous. }\end{array}$ & $\begin{array}{l}\text { Use a C2210 Unit. This would require 150 } \\
\text { Units at approximately \$230 ea. or \$34,500 } \\
\text { of HESCO material and 224 CYD of clay } \\
\text { and 45 man-hours. }\end{array}$ \\
\hline $\begin{array}{l}\text { 3) } 3 \text { foot tall x 3 feet deep, 1500 linear feet, } \\
\text { porous. }\end{array}$ & $\begin{array}{l}\text { Use a C3315 Unit. This would require 100 } \\
\text { Units at approximately \$350 each or } \\
\text { \$35,000 of HESCO material and 650 CYD } \\
\text { of clay and 60 man-hours. }\end{array}$ \\
\hline $\begin{array}{l}\text { 4) Same as 1) but with poly-diaper liner } \\
\text { under units so that they can be removed } \\
\text { whole and hauled. }\end{array}$ & $\begin{array}{l}\text { Add 20\% for a total of \$41,400 of HESCO } \\
\text { material and clay remains 112 CYD and 30 } \\
\text { man-hours. }\end{array}$ \\
\hline $\begin{array}{l}\text { 5) Same as 2) but with poly-diaper liner } \\
\text { under units so that they can be removed } \\
\text { whole and hauled. }\end{array}$ & $\begin{array}{l}\text { Add 20\% for a total of \$41,400 of HESCO } \\
\text { material and clay remains 224 CYD and 45 } \\
\text { man-hours. }\end{array}$ \\
\hline $\begin{array}{l}\text { 6) Same as 3) but with poly-diaper liner } \\
\text { under units so that they can be removed } \\
\text { whole and hauled. }\end{array}$ & $\begin{array}{l}\text { Add 20\% for a total of \$42,000 of HESCO } \\
\text { material and clay remains 650 CYD and } 60 \\
\text { man-hours. }\end{array}$ \\
\hline
\end{tabular}

\subsubsection{Multi-Stage Separations to Produce Radioactively-Free Wash Waters}

Within the reservoir itself, the wash water will be mixing to a varying degree with the clay sequestering agent as the waters accumulate during the wash mitigation procedure. The question becomes, "What do we do with the radioactive waters now?" As we showed in Figs. 24 and 25, we can only expect 80-90\% of the cesium to be sorbed onto the solid sequestering material under the best conditions (providing $100 \mathrm{~g} / \mathrm{L}$ of clay into the wash with sufficient mixing). Therefore, we expect the wash water to retain dissolved cesium without further treatment. As a consequence, we can neither reuse the waters for mitigation operations nor dispose of them as non-radioactive waters. The wash waters will require further treatment or multiple stages of separation. How do we design the system for multi-stage separations in an emergency operation?

We assume that the reservoir will contain a slurry of contaminated wash water and contaminated sequestering agent. We have a couple general options for treatment.

1) Pump the slurry into a filter to separate the solids from the liquid. Collect the solid for disposal or, if possible, reuse. Collect the liquid and treat this further to reduce radioactive concentrations (and possibly salt and surfactant concentrations) to below regulatory limits set for emergency operations. Reuse these recycled waters or discharge to the sewer.

2) Allow the slurry to settle and pump the clarified wash waters into a filter to separate the remaining solids from the liquid. Collect the liquid and treat this further to reduce radioactive concentrations (and possibly salt and surfactant concentrations) to below regulatory limits set for emergency operations. Reuse these recycled waters or discharge to the sewer. Allow solids to remain in the reservoir until their sorption capacity has been reached and then pump 
this material in concentrated form into a tank for transport and disposal or pump the slurry as outlined in 1).

These general options are being considered, but need to be evaluated more thoroughly in terms of technical feasibility, logistical feasibility, and cost. The brevity of the list hides the many details that would need to be considered before deciding on which method would work best for a particular scenario. For instance, how exactly do we design the reservoir footprint with pumps and mixers? How do we pump the slurry from the reservoir? How do we permit settling of the wash water slurry? Into what do we pump the clarified waters for subsequent treatments for radioactive and chemical decontamination? Into what do we pump the fully decontaminated waters for reuse? What type of pumps and piping would we have available for this type of operation? Other questions are expected as we vet this process with other experts. The scope of this work did not include a full assessment of the potential treatment methods but should be a topic for future work. We will, however, address general methods of separating slurries later in this report (see "Slurry Collection and Filtration").

\subsection{Prevent/Minimize Infiltration through Manholes and Sewers}

One of the primary criteria of the technology is to prevent contamination of underground utility, telecommunications, and sewer lines by limiting the invasion of wash waters into manhole covers and sewer inlets and catch basins. This is a particularly difficult task to accomplish quantitatively because of the many inlet points along the city streets. Since we would have little control over access points within individual commercial and residential buildings, we concern ourselves with access at the street level. The berm system we described is the primary engineering control against such invasion outside the berm zone. However, we would expect that within a sizable berm zone that manhole covers would be present as illustrated by a view of one downtown street in Chicago (Fig. 32). One method is to cover the manhole covers, inlets and catch basins with an impermeable material. This can be as simple as placing sandbags or laying down an impermeable membrane like a plastic sheeting and covering with heavy material like sandbags. Individual berm containers may serve the same purpose and would presumably be present in the area if a berm system is used for containing wash waters. 


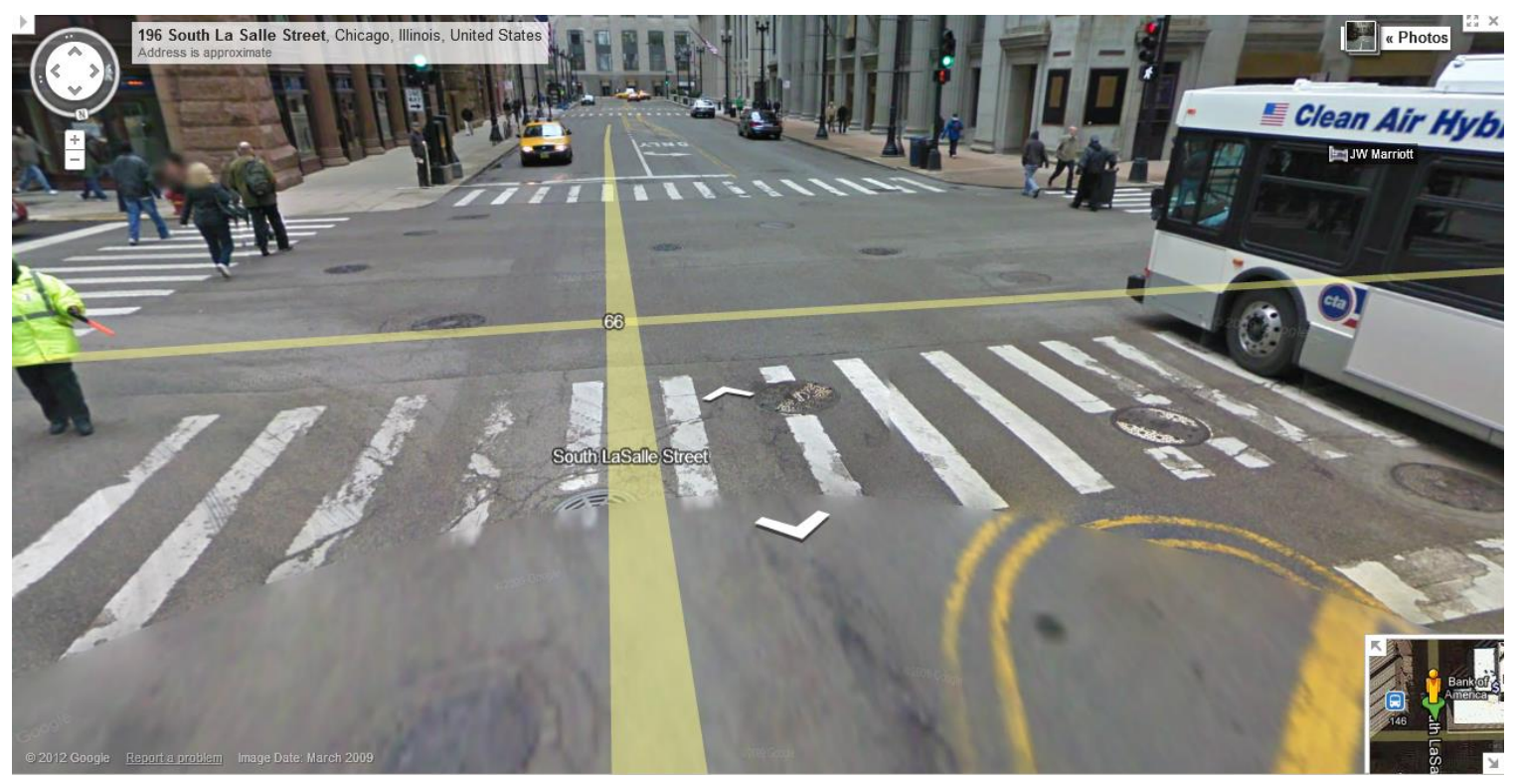

Figure 32. View of the corner of LaSalle St. and Adams St. in Chicago (Google Maps). There are approximately 20 manhole covers and sewer caps at or just off this corner. A significant number of these are not designed to prevent the entering of water at the street level.

We may also wish to provide secondary protection against water invasion to manhole covers and sewer inlets that are outside the berm zone. We may use the same impermeable covers described above or, since the water would be expected to be percolating runoff, we can simply isolate the inlet and manhole covers with impermeable booms (Fig. 33) used to contain water and oil spills or permeable woven logs (Fig. 34) that are designed to pass water and filter solids and are routinely used to control soil runoff.

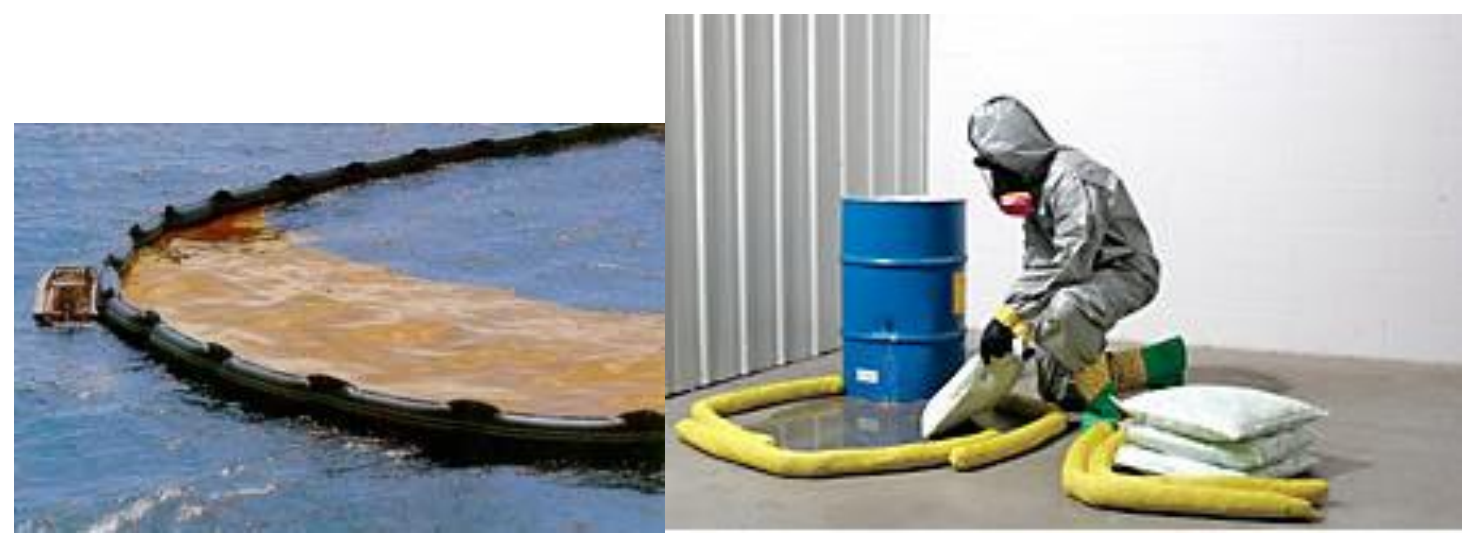

Figure 33. Impermeable socks are used to contain small water or oil spills. They may be used to prevent incidental invasion of potentially-contaminated waters from entering manhole covers or sewer inlets near the decontamination zone. 


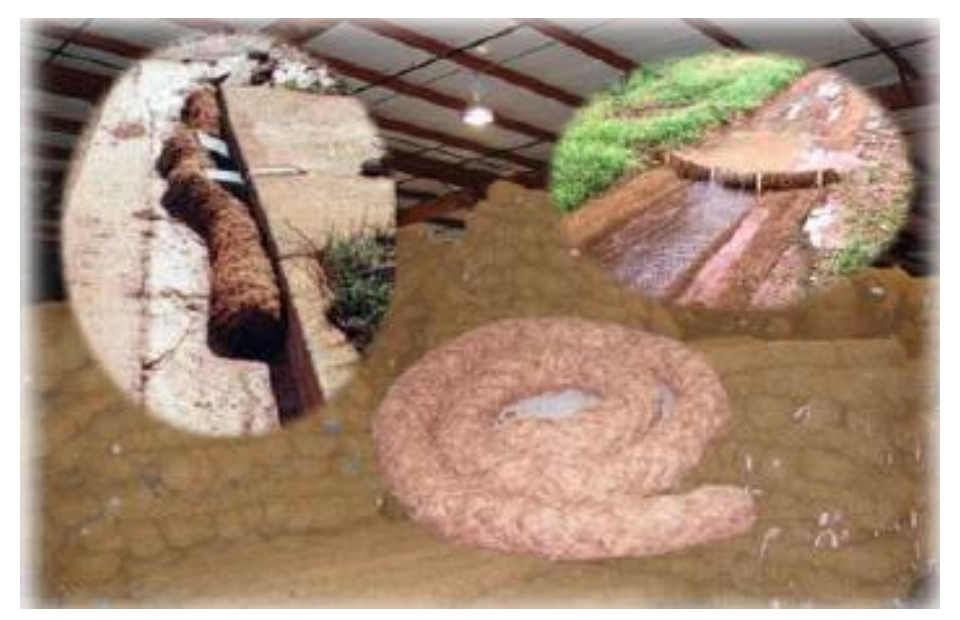

Figure 34. Permeable logs such as the RoLanka BioD-Watl coir logs are designed to control runoff and to prevent suspended soil from entering sewers. These may be used to prevent potentially-contaminated clay particles from entering manhole covers and sewer inlets. The BioD-Watt ${ }^{\mathrm{TM}}$ coir wattles are 6-12 in. diameter cylindrical shaped rolls. The knotted, high strength outer netting is made of machine spun bristle coir twines. They are lightly packed with cleaned mattress coir fiber in a uniform manner to filter sediment effectively. They come in $15 \mathrm{ft}$ long sections.

\subsection{Superabsorbers}

Superabsorbing polymers have an incredible ability to absorb water hundreds of times their weight. The superabsorbing polymer is one or a combination of acrylonitriles, acrylic acids, acrylamide, and polyvinyl alcohol. For electrolyte solutions, the polyacrylates and polyacrylamides are suitable where other superabsorbers lose their capacities for water in the presence of salts. The superabsorber is used in radioactive liquid disposal to convert the liquid waste into solid for facile disposal. For radiation contamination mitigation, it may prove to be useful to eliminate free liquids.

\subsection{Slurry Collection and Filtration}

If small quantities of waters are expected to be generated, then one may consider collecting the slurry directly into a tank for transport and further treatment prior to disposal. A variety of equipment is readily available to municipalities that could be used to collect the runoff. Two common types of equipment available to municipalities are street sweepers and vacuum truck vehicles.

The street sweeper commonly employed by municipalities (Fig. 35) is designed to draw low-density material from the street into the path of the vacuum units which hover approximately two inches above the pavement (Fig. 36). These units are not designed for heavy debris such as sediment but it can be cleared after several passes over the material. They are also not designed for chemicals since the off-gas system is not filtered except to remove large debris by in-line metal screens. In fact, when the unit is filled to capacity with water, the excess water is exhausted from the stack that sits behind the operator cab. 
These factors together may make the street sweeper a poor choice for many situations where the wash aid would be utilized, unless special precautions are taken to avoid overfilling the storage tank or drying of material and exhausting the dust.

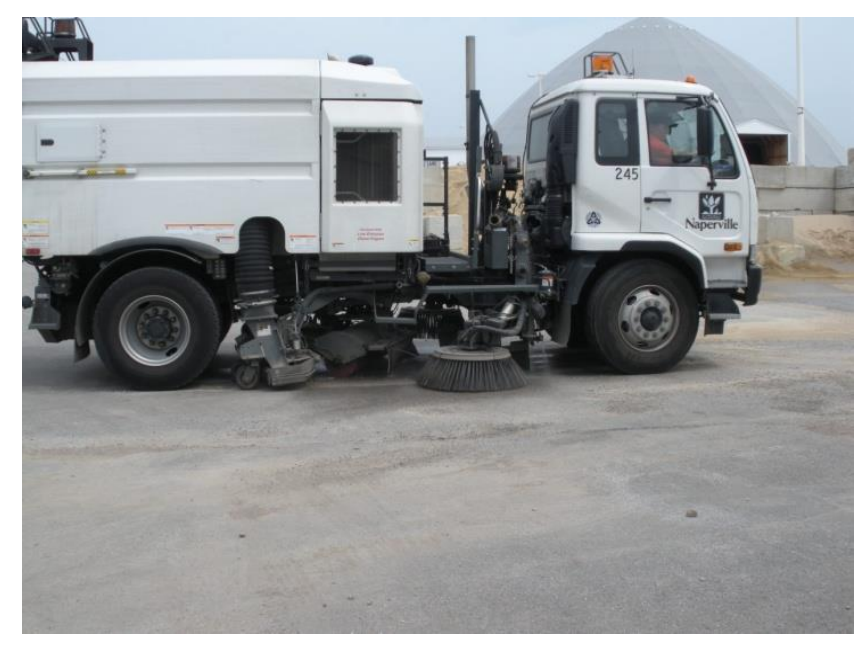

Figure 35. Street sweeper.

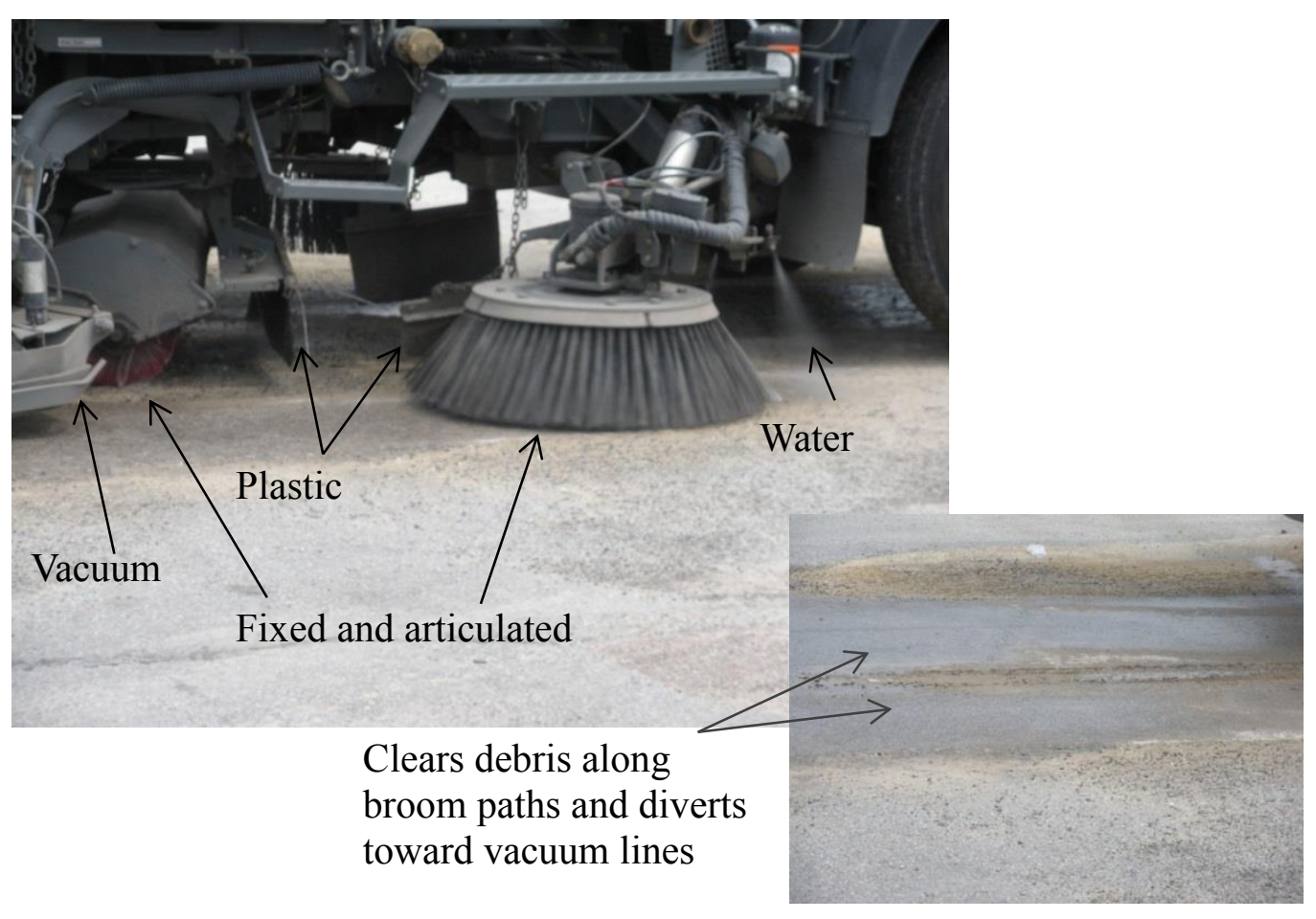

Figure 36. Close-up view of the plastic runners, water sprays, fixed and articulated brooms, and vacuum lines found on a typical street sweeper. 
One of the routine operations in municipalities is maintaining the catch basins and inlets to the storm sewer system. To clear them of debris such as leaves and sediment, vacuum trucks are employed (Fig. 37). These trucks are designed specifically for drawing higher density material but, similarly to the street sweepers, they do not employ high efficiency particulate arresting (HEPA) filters in their exhaust systems.
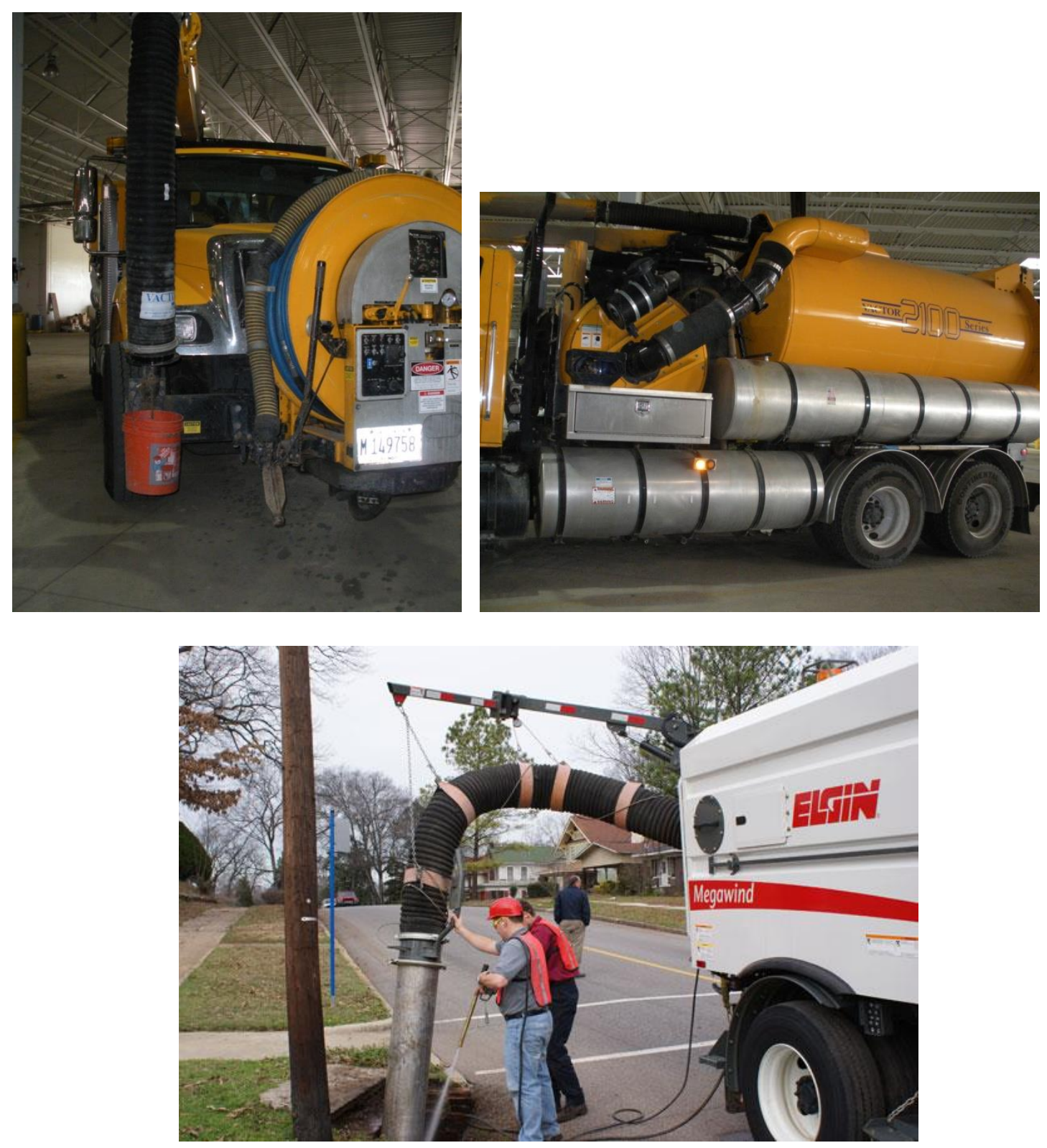

Figure 37. Vacuum trucks used by municipalities to clean out inlets and catch basins in the storm sewer system. 
Vacuum trucks have stronger vacuum systems than the street sweepers and hoses designed to reach the bottom of the sewers, and employ hydraulic excavation. Their tank capacity is similar to street sweepers at $<1500$ gallons.

In contrast to the vacuum trucks and street sweepers, industrial vacuum trucks are designed for hazardous material applications. These units (Fig. 38) have a series of inline filter systems to eliminate hazardous off-gas and include HEPA filters. They are typically not owned by the municipalities but are contracted by private companies. Their typical applications are to remove ash from coal plants and municipal waste incinerators. These units are prevalent around the country according to a national supplier contact from EJ Equipment (Eric LeSage, Regional Manager). These units have very strong vacuum systems (27 inches of vacuum) that are designed for stand-off operations that might run the vacuum hose hundreds of feet from the truck. The tank capacity is $12-16$ $\mathrm{yd}^{3}(2400-3200$ gallons).

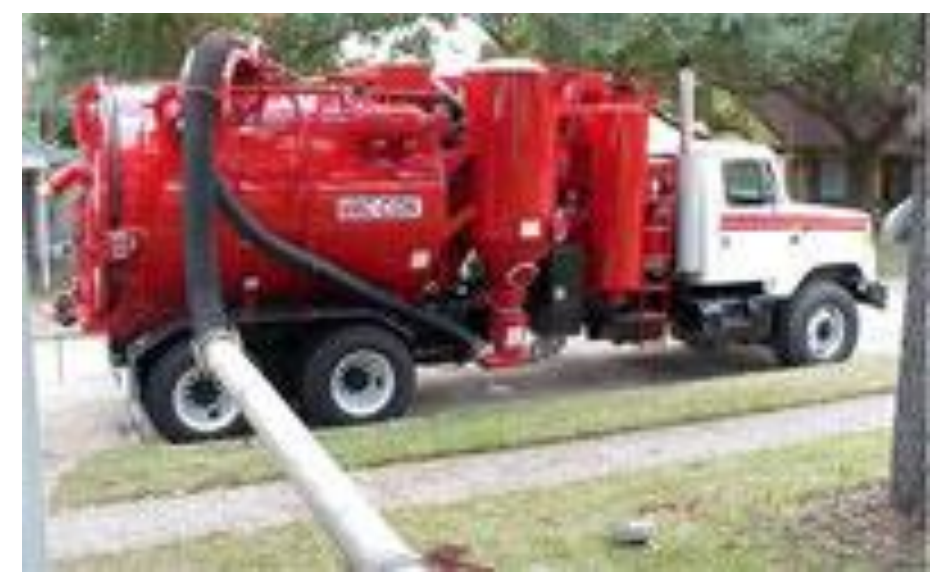

Figure 38. Industrial vacuum trucks are designed to handle hazardous solids and slurries and can operate 300-400 feet from the source material.

\subsection{Filtering the Contaminated Wash Water Slurry}

Assuming that the volume of slurry is too large for direct collection by one of the vehicles described in the previous section, or that these vehicles are deemed unsuitable for radiological operations, or that we wish to recycle the wash waters to reduce the volume of radioactive waters generated, then we need to consider methods of separating the wash water slurry collected. ${ }^{3}$ The two generic types of streams that we would need to treat are 1) wash water that is decanted or filtered through the clay that contains a much smaller percentage of clay plus the salt, surfactant, and radioactive cesium along with oils, particulate, and debris collected during the wash down activities

\footnotetext{
${ }^{3}$ In some locales, it is expected that the water would not just accumulate in the intentional reservoirs, but would also accumulate in various low lying areas, including portions of the wastewater collection system (i.e., sewer system), which have not been completely sealed (with the volumes of water involved, it will likely be impossible to make sure that none of the water enters the stormwater or sanitary collection system). Then, the truck units described in the previous section may prove useful.
} 
and 2) high slurry concentration wash water containing clay, salt, surfactant, and radioactive cesium along with oils, particulate, and debris collected during the wash down activities.

Ideally, the system for separating the contaminated slurry would be housed on a mobile filtration unit. Such mobile units (Fig. 39) are used to provide potable waters after disasters like floods, hurricanes, and tornadoes. Since they are designed to produce potable water, they often have a series of filter media and chemical additives to make the water safe for consumption. However, that is not our goal. We only strive to develop a system for reuse of wash water or at least removal of the radioactive component (i.e., the clay). We provided an overview of the types of mobile units available in our previous report [USEPA-2012a].

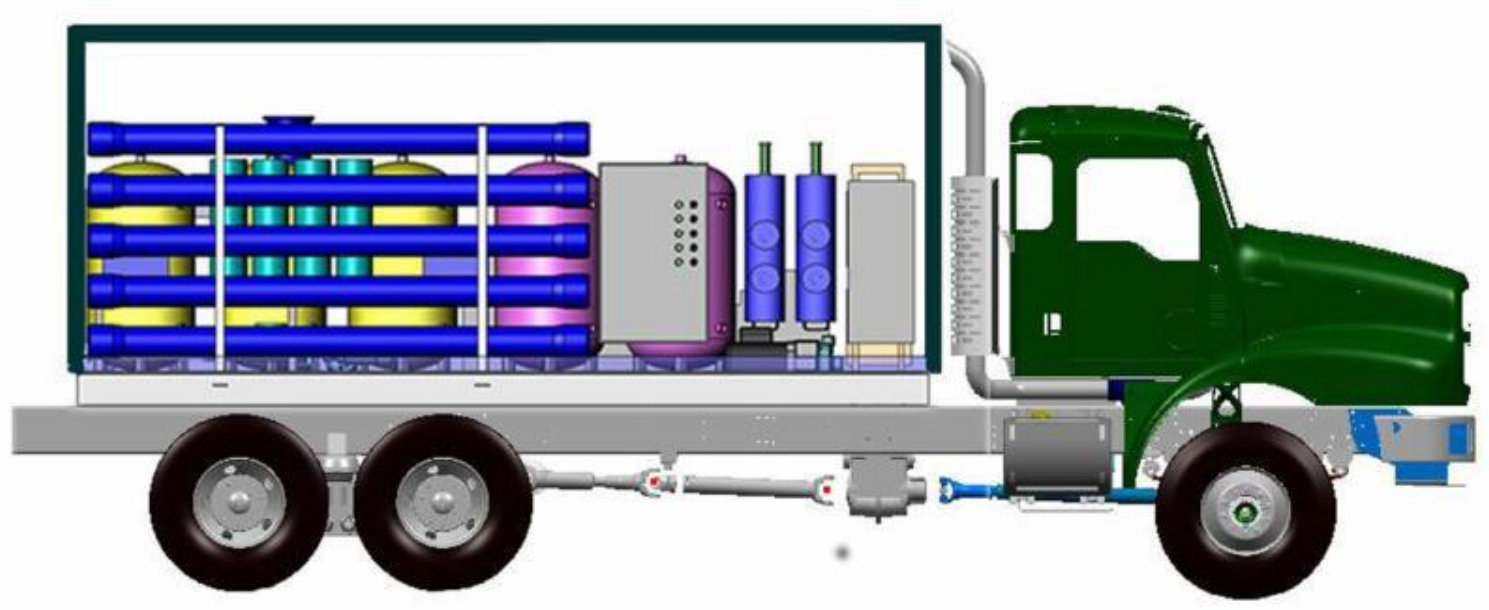

Figure 39. Generic mobile water filtration unit. Inbound water is subjected to particle strainers, chlorine injection, multimedia tanks (which remove large suspended solids and fine sand), carbon media tanks (which removes organic material), and three 25/1 gradient filters (for super fine silts); and is treated with an antiscalant and bio-inhibitor. The water then passes through a reverse osmosis unit. This particular unit has a capacity of 30,000 gallons per day.

However, since the input waters to these mobile filtration units do not contain a high percentage of solids, we must investigate an alternative means of reducing the slurry concentration before feeding it into one of these types of vehicles. Next, we describe methods of filtering solids at high volumetric throughput.

\subsubsection{Massive Throughput Filter Devices}

The various methods of mechanical separation are given in Fig. 40. Broadly, we can classify these into settling, filtration, and expression operations. For settling, waters can be separated into a more concentrated slurry (the settled material) and a liquid phase 
that may contain fine particles in low concentration. It is a good method to initially process large quantities of waters so that smaller operations can be used to handle the two product streams. For our purpose, we would need to separate potentially very large quantities of slurry composed of the clay and wash water. Of the five settling modalities - gravity, centrifugal force, heavy media, flotation, and magnetic forcegravity requires no additional equipment, but may require a large footprint to accommodate the settling beds. Settling operations employing centrifugal force are interesting because they can be made to process millions of gallons per day using relatively simple pieces of equipment.

Solid-liquid separation by screening is appropriate for some suspensions of coarse particles, but crossflow filtration units are usually more appropriate for finer particles like clay, since they tend to avoid large cake buildup and can be operated for longer periods before requiring a discharge of solids. In crossflow filtration, a suspension is passed at a moderate pressure drop, parallel to a semipermeable membrane. Solid particles are caught by the filter as the fluid moves freely through it. The velocity of the fluid tends to remove the solid cake to keep the filter operating longer, while the solids accumulate in the filter tank. Separation on filters is similar to crossflow filters except that the cake buildup may limit operations times compared to crossflow filters.

Separation by expression requires the use of presses to produce cakes with low water content. These pieces of equipment are highly specialized and may not be appropriate for emergency deployment.

General Separation Methods

\begin{tabular}{|c|c|c|}
\hline Settling & Filtration & Expression \\
\hline Gravity & Screens & Batch Presses \\
\hline $\begin{array}{l}\text { Centrifugal Force } \\
\text { Flotation }\end{array}$ & $\begin{array}{l}\text { Crossflow units (tubular, flat } \\
\text { sheet, or rotating filter } \\
\text { membranes) }\end{array}$ & Continuous Presses \\
\hline Magnetic Force & $\begin{array}{c}\text { Filters (gravity, pressure, } \\
\text { vacuum, or centrifugal } \\
\text { force-assisted) }\end{array}$ & \\
\hline
\end{tabular}

Figure 40. Decision tree for solids-liquid separations methods [Perry-1997].

For our purposes, we will require collection and filtration of the solid sequestering agent from the wash waters. The goal is to produce concentrated solids that can be pumped into a storage unit of some sort until they can be transported for treatment and 
disposal. The wash water would be intended for immediate reuse in decontamination operations and eventually for disposal, preferably by direct injection into the sewer system.

With the anticipated volume of wash water slurry and the need for equipment that can be quickly deployed in an emergency, we look toward operations that do not require specialized equipment and have high throughput. For such operations, we will look more closely at sedimentation operations, centrifugal separations, and crossflow/filter units.

\subsubsection{Sedimentation Operations}

A very simple method of separating a solid from a liquid is by sedimentation. Sedimentation basins or ponds (also called settling ponds or basins) are often used to control runoff at construction sites and mines, or for storm water control (Fig. 41). In simplified terms, the ponds operate according to the principle of Stokes' Law, which describes the settling of spherical particles in a fluid under laminar flow by the force of gravity.

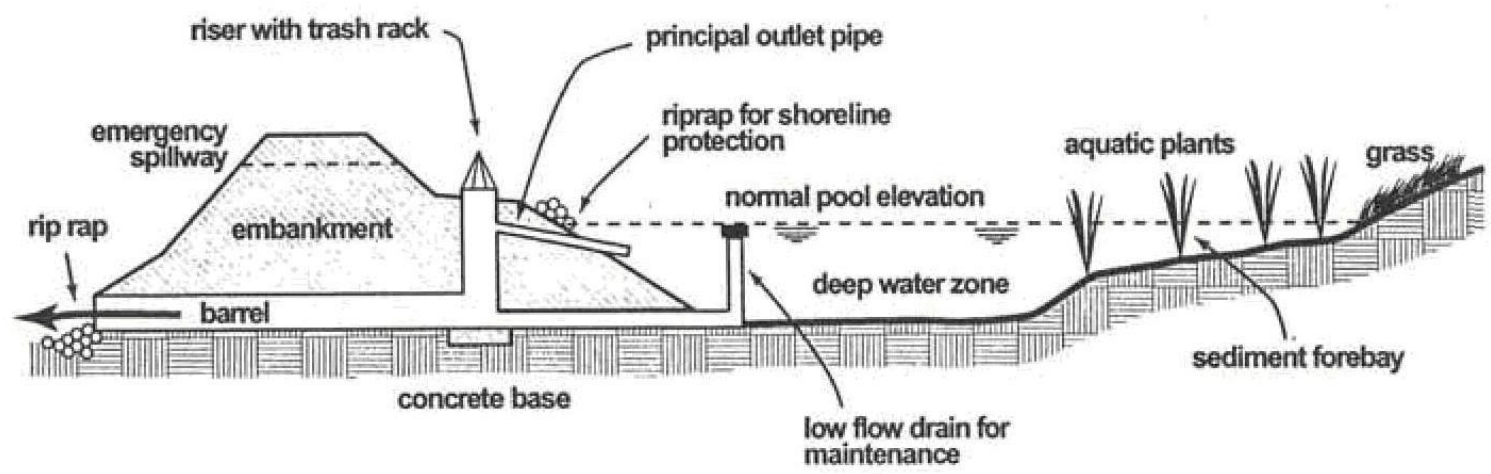

Figure 41. Sedimentation pond for storm water capture and clarification (from www.clemson.edu/extension/natural_resources/water/stormwater_ponds/construct_repair _dredge/).

From a balance of forces according to Newton's Second Law, the force on the particle is a result of gravity, buoyancy, and drag forces according to Eqn 2.

$$
F_{d}+F_{b}-F_{g}=m a
$$

Generically, the buoyancy force is simply the mass of displaced fluid times the acceleration due to gravity

$$
F_{b}=V_{p} \rho_{f} g
$$

and drag force is related to the velocity of the particle relative to the fluid 


$$
F_{D}=\frac{C_{D} A_{p} \rho_{f} v^{2}}{2}
$$

So we have for the downward acceleration of a particle in a fluid due to gravity,

$$
\frac{C_{D} A_{p} \rho_{f} v^{2}}{2}+V_{p} \rho_{f} g-m_{p} g=m_{p} a
$$

For a particle at terminal velocity the buoyancy and drag forces balance the gravitational force to constant velocity and we can solve for velocity as

$$
v=\sqrt{\frac{2\left(m_{p} g-V_{p} \rho_{f} g\right)}{C_{D} A_{p} \rho_{f}}}
$$

Substituting $\frac{m_{p}}{\rho_{p}}=V_{p}$, we get

$$
v=\sqrt{\frac{2 m_{p} g\left(\rho_{p}-\rho_{f}\right)}{C_{D} A_{p} \rho_{f} \rho_{p}}}
$$

For the special case of a spherical particle,

$$
m_{p}=\frac{\pi D_{p}^{3}}{6} \rho_{p}
$$

and

$$
A_{p}=\frac{\pi D_{p}^{2}}{4}
$$

Then, Eqn. 7 simplifies to

$$
v=\sqrt{\frac{4 D_{p} g\left(\rho_{p}-\rho_{f}\right)}{3 C_{D} \rho_{f}}}
$$

where the drag coefficient at low Reynolds number $\left(N_{R e}<0.1\right)$ is

$$
C_{D}=\frac{24}{N_{R e}}
$$

and the Reynolds number can be computed from

$$
N_{R e}=\frac{\rho_{f} v D}{\mu}
$$

which corresponds to Stokes' law and simplifies the drag force for a spherical particle to 


$$
F_{D}=\frac{C_{D} A_{p} \rho_{f} v^{2}}{2}=\frac{24 A_{p} \rho_{f} v^{2}}{2 N_{R e}}=3 \pi \mu v D
$$

Then Eqn. 2 becomes

$$
3 \pi \mu v D_{p}+\frac{\pi D_{p}^{3}}{6} \rho_{f} g=\frac{\pi D_{p}^{3}}{6} \rho_{p} g
$$

Rearranging to solve for the terminal velocity $v_{t}$, we have

$$
v_{t}=\frac{D_{p}^{2} g\left(\rho_{p}-\rho_{f}\right)}{18 \mu}
$$

From this we can compute that a sphere with diameter $150 \mu \mathrm{m}(\sim 100$ mesh) with density of $2.4 \mathrm{~g} / \mathrm{cm}^{3}$ has a terminal velocity under low Reynolds number in a solution of density $1.03 \mathrm{~g} / \mathrm{cm}^{3}$ of $18.6 \mathrm{~mm} / \mathrm{s}$. The time needed to settle to a depth of $1 \mathrm{ft}(0.3048 \mathrm{~m})$ is 16 seconds. When we compare this number to that plotted in engineering manuals (Fig. 42), we obtain $\sim 0.04 \mathrm{ft} / \mathrm{s}(12.2 \mathrm{~mm} / \mathrm{s})$ or 25 seconds to settle one foot in depth. 


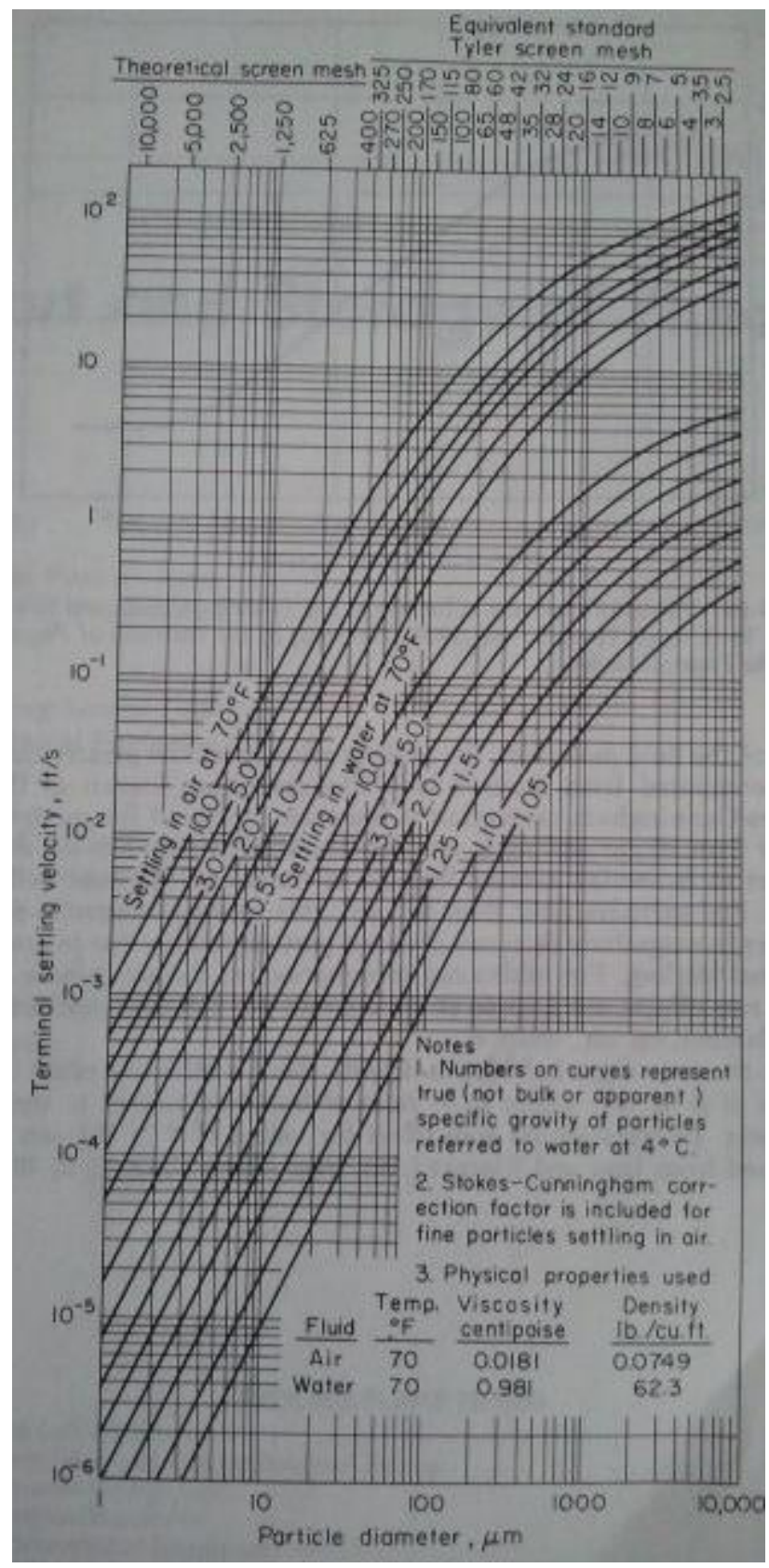

Figure 42. The terminal velocity of rigid spheres of different densities in air and water at $70^{\circ} \mathrm{F}$.

For the case of rigid, non-spherical particles, the expression for the terminal velocity is corrected. For axisymmetric particles (such as discs) in axial motion the above equation can be modified according to Bowen and Masliyah [Bowen-1973],

where

$$
v=\frac{V_{p s}}{K} \frac{D_{s}^{2} g\left(\rho_{p}-\rho_{f}\right)}{18 \mu}
$$

$$
K=0.244+1.035 \Sigma-0.712 \Sigma^{2}+0.441 \Sigma^{3}
$$


where $V_{p s}$ is the ratio of particle volume to volume of sphere with diameter $D_{s} ; \Sigma$ is the ratio of surface area of particle to that of a sphere with diameter $D_{s}=$ diameter of sphere with perimeter equal to the maximum particle projected perimeter parallel to the direction of flow. For a flattened disc with diameter equal to $100 \mu \mathrm{m}$ and thickness of $5 \mu \mathrm{m}(\Sigma=$ $0.533, D_{s}=100 \mu \mathrm{m}, K=0.660$ ), the terminal velocity is expected to be $1.41 \mathrm{~mm} / \mathrm{s}$, more than an order of magnitude lower than for the $100 \mu \mathrm{m}$ diameter sphere. The theoretical time required to descend $1 \mathrm{ft}(0.3 \mathrm{~m})$ is now 3.6 minutes. For flattened discs of thickness $30 \mu \mathrm{m}$, the terminal velocity is $7.2 \mathrm{~mm} / \mathrm{s}$ or 42 seconds needed to settle to a depth of one foot.

For concentrated particles, the terminal velocity is modified due to changes in the apparent suspension viscosity and density. For spheres of uniform size, the modified terminal velocity $v_{t s}$ is

$$
v_{t s}=v_{t}(1-c)^{n}
$$

where $c$ is the volume fraction of solid in the suspension and $n$ is a function of the Reynolds number and is 4.65 for the Stokes'-law regime $\left(N_{R e}<0.3\right)$ and 2.33 for the Newton's-law regime $\left(N_{R e}>1000\right)$ and varies smoothly in the intermediate regime. This equation also applies well to polydisperse particles in suspension, but the concentration effect is greater than computed here for nonspherical and angular particles than for spheres. Applying it to our flattened discs in a $10 \%$ by mass slurry $(c=0.05$ by volume), the hindered flow reduces the terminal velocity to $1.14 \mathrm{~mm} / \mathrm{s}$ and 4.5 minutes to settle one foot in depth.

The advantage of sedimentation ponds is that they are easy to construct, have few, if any, moving parts, and they can handle a large volume of water. The disadvantage is that they require a large footprint and require dredging to remove accumulated solids. The berm and reservoir system that we described earlier could operate like a sedimentation pond. In fact, the vermiculite clay particles settle from solution quite readily so we could design the reservoir to collect water as in a sedimentation pond allowing us to decant the settled wash water, ensure the removal of dissolved radionuclides, perform a final clarification, and reuse the wash water.

\subsubsection{Continuous Centrifugal Filters}

Of the centrifugal separators on the market, the tubular designs by LAKOS $^{\circledR}$ are most interesting (Fig. 43) and perhaps appropriate for our application. The LAKOS ${ }^{\circledR}$ centrifugal filters employ no moving parts and can separate $>10 \%$ solids in water. A single separator is designed to treat $7500 \mathrm{ppm}$ solid loading (0.75\%). Designed for very large irrigation projects also, the capacities of continuously operating systems are > 1,000,000 gallons per day (694 gallons per minute) (Table 12) and can be configured in series or in parallel for higher throughput or higher percent solids. A key piece of equipment that is required for the LAKOS ${ }^{\circledR}$ systems is a properly-sized pump to achieve the pressure drops necessary across the LAKOS unit to effect the centrifugal force. 


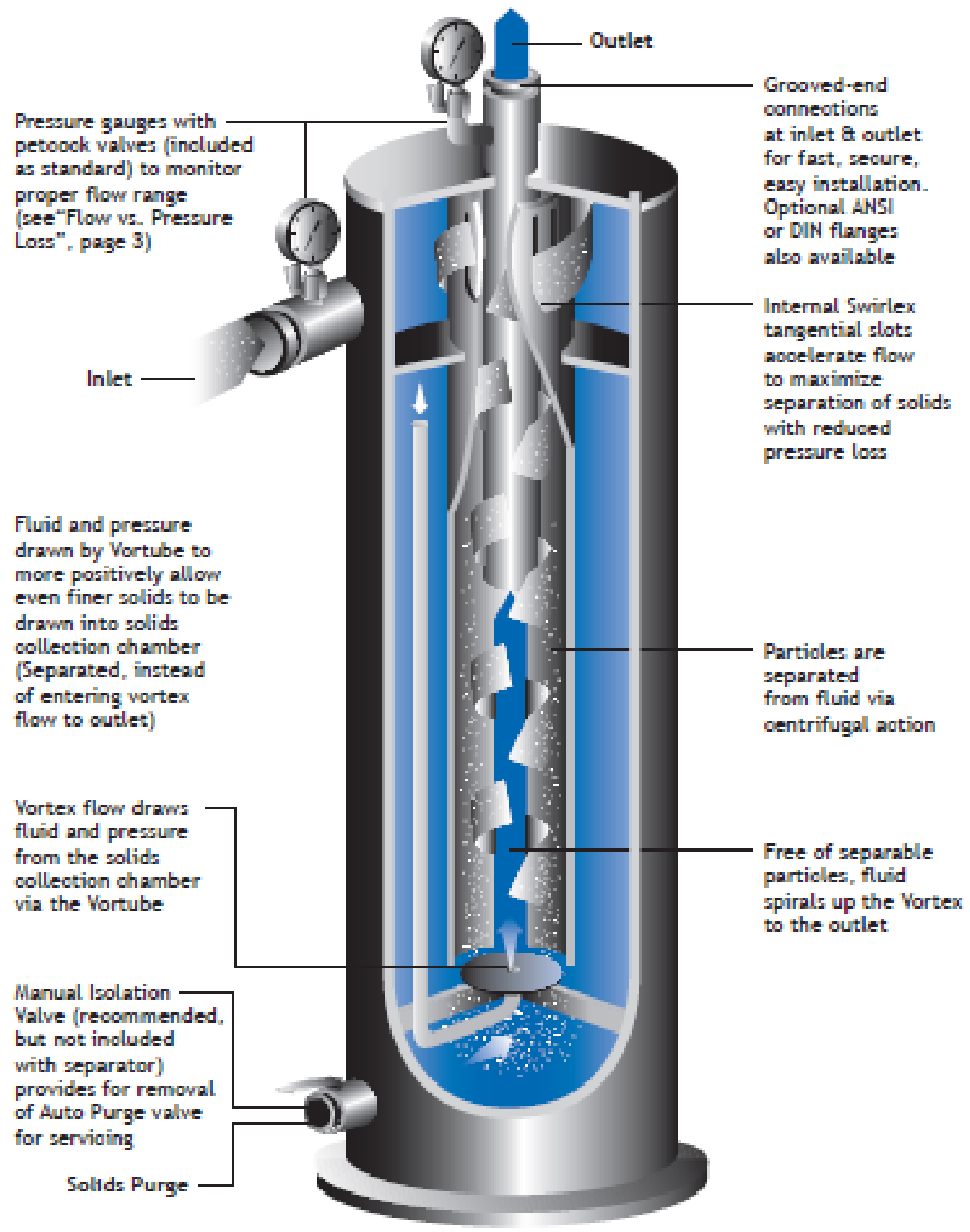

Figure 43. Schematic representation of the LAKOS $^{\circledR}$ centrifugal separator (from the LAKOS $^{\circledR}$ JPX system brochure). 
Table 12. Design specification for various LAKOS units (from the LAKOS ${ }^{\circledR}$ JPX system brochure).

\begin{tabular}{|c|c|c|c|c|c|c|c|c|c|c|}
\hline \multirow[t]{2}{*}{ Model $^{*}$} & \multicolumn{2}{|c|}{ Flow Range } & \multirow[t]{2}{*}{$\begin{array}{l}\text { Inlet/Outlet } \\
\text { Grooved } \\
\text { Coupling }\end{array}$} & \multirow{2}{*}{$\begin{array}{l}\text { Purge size } \\
\text { Male N.P.T. }\end{array}$} & \multicolumn{2}{|c|}{$\begin{array}{c}\text { Collection } \\
\text { Chamber Capacity }\end{array}$} & \multicolumn{2}{|c|}{$\begin{array}{l}\text { Weight } \\
\text { Empty }\end{array}$} & \multicolumn{2}{|c|}{$\begin{array}{l}\text { Weight } \\
\text { with Water }\end{array}$} \\
\hline & U.S. gpm & $\mathrm{m}^{3} / \mathrm{hr}$ & & & gal & liters & lbs. & $\mathrm{kg}$ & lbs. & $\mathrm{kg}$ \\
\hline JPX-0004 & $4-10$ & $1-2.5$ & $1 / 2^{a} \mathrm{NPT}^{\mathrm{tt}}$ & $1^{a}$ & 0.09 & 0.3 & 23 & 10.4 & 37 & 16.8 \\
\hline JPX-0010 & $10 \cdot 20$ & $2.5-4.5$ & $3 / 4^{a} \mathrm{NPT}^{t+}$ & $1^{a}$ & 0.11 & 0.4 & 48 & 21.8 & 61 & 27.7 \\
\hline JPX-0016 & $16-30$ & $4-7$ & $1^{*}$ & $1^{n}$ & 0.15 & 0.6 & 53 & 24.0 & 68 & 30.8 \\
\hline JPX-0028 & $28-45$ & $7-10$ & $1-1 / 4^{2}$ & $1-1 / 2^{*}$ & 0.27 & 1.0 & 84 & 38.1 & 101 & 45.8 \\
\hline JPX-0038 & $38-65$ & $9-15$ & $1-1 / 2^{2}$ & $1-1 / 2^{2}$ & 0.4 & 1.5 & 107 & 48.5 & 140 & 63.5 \\
\hline JPX-0060 & $60-100$ & $14-23$ & $2^{n}$ & $1-1 / 2^{2}$ & 0.8 & 3.0 & 188 & 85.3 & 259 & 117.5 \\
\hline JPX-0085 & $85-145$ & $19-33$ & $2-1 / 2^{2}$ & $1-1 / 2^{\mathrm{E}}$ & 0.8 & 3.0 & 229 & 103.9 & 313 & 142.0 \\
\hline JPX-0130 & $130-225$ & $30-51$ & $3^{*}$ & $1-1 / 2^{\mathrm{E}}$ & 0.8 & 3.0 & 241 & 109.3 & 329 & 149.2 \\
\hline $\begin{array}{l}J P X-0200-L \\
\text { JPX-0200-V }\end{array}$ & $200-325$ & $45-74$ & $4^{\prime \prime}$ & $1-1 / 2^{\mathrm{E}}$ & $\begin{array}{l}1.6 \\
4.4 \\
\end{array}$ & $\begin{array}{c}6.1 \\
16.7 \\
\end{array}$ & $\begin{array}{l}448 \\
384 \\
\end{array}$ & $\begin{array}{l}203.2 \\
174.2 \\
\end{array}$ & $\begin{array}{l}640 \\
605\end{array}$ & $\begin{array}{l}290.3 \\
274.4 \\
\end{array}$ \\
\hline $\begin{array}{l}J P X-0285-L \\
J P X-0285-V\end{array}$ & $285-525$ & $65-120$ & $4^{n}$ & $1-1 / 2^{n}$ & $\begin{array}{l}2.1 \\
5.4\end{array}$ & $\begin{array}{c}7.9 \\
20.5\end{array}$ & $\begin{array}{l}579 \\
488\end{array}$ & $\begin{array}{l}262.6 \\
221.4\end{array}$ & $\begin{array}{l}898 \\
781\end{array}$ & $\begin{array}{l}407.3 \\
354.3\end{array}$ \\
\hline $\begin{array}{l}J P X-0450-L \\
\text { JPX-0450-V }\end{array}$ & $450-825$ & $102-187$ & $6^{2}$ & $1-1 / 2^{n}$ & $\begin{array}{l}2.8 \\
6.7 \\
\end{array}$ & $\begin{array}{l}10.6 \\
25.4 \\
\end{array}$ & $\begin{array}{l}763 \\
690 \\
\end{array}$ & $\begin{array}{l}346.1 \\
313.0 \\
\end{array}$ & $\begin{array}{l}1203 \\
1132 \\
\end{array}$ & $\begin{array}{l}545.7 \\
513.5 \\
\end{array}$ \\
\hline $\begin{array}{l}J P X-0650-L \\
J P X-0650-V\end{array}$ & $650-1200$ & $150-275$ & $6^{2}$ & $1-1 / 2^{n}$ & $\begin{array}{c}4.3 \\
10.4 \\
\end{array}$ & $\begin{array}{l}16.3 \\
39.4 \\
\end{array}$ & $\begin{array}{l}966 \\
921 \\
\end{array}$ & $\begin{array}{l}438.2 \\
417.8 \\
\end{array}$ & $\begin{array}{l}1664 \\
1578 \\
\end{array}$ & $\begin{array}{l}754.8 \\
715.8 \\
\end{array}$ \\
\hline $\begin{array}{l}J P X-1160-L \\
\text { JPX-1160-V }\end{array}$ & $1160-2150$ & $265-490$ & $8^{2}$ & $1-1 / 2^{n}$ & $\begin{array}{r}8.6 \\
20.5 \\
\end{array}$ & $\begin{array}{l}32.6 \\
77.6 \\
\end{array}$ & $\begin{array}{l}1388 \\
1378 \\
\end{array}$ & $\begin{array}{l}629.6 \\
622.3 \\
\end{array}$ & $\begin{array}{l}2704 \\
2627 \\
\end{array}$ & $\begin{array}{l}1226.5 \\
1191.6 \\
\end{array}$ \\
\hline $\begin{array}{l}J P X-1850-L \\
J P X-1850-V\end{array}$ & $1850-3400$ & $420-775$ & $10^{n}$ & $2^{*}$ & $\begin{array}{l}15.0 \\
31.5\end{array}$ & $\begin{array}{c}56.8 \\
119.2\end{array}$ & $\begin{array}{l}2141 \\
2255\end{array}$ & $\begin{array}{c}971.1 \\
1022.9\end{array}$ & $\begin{array}{l}4008 \\
3977\end{array}$ & $\begin{array}{l}1818.0 \\
1803.9\end{array}$ \\
\hline $\begin{array}{l}J P X-2650-L \\
\text { JPX-2650-V }\end{array}$ & $2650-4900$ & $600-1115$ & $12^{n}$ & $2^{2}$ & $\begin{array}{l}23.5 \\
51.1 \\
\end{array}$ & $\begin{array}{c}89.0 \\
193.4 \\
\end{array}$ & $\begin{array}{l}3664 \\
3186 \\
\end{array}$ & $\begin{array}{l}1662.0 \\
1445.1 \\
\end{array}$ & $\begin{array}{l}7732 \\
6532 \\
\end{array}$ & $\begin{array}{l}3507.2 \\
2962.9 \\
\end{array}$ \\
\hline $\begin{array}{l}J P X-4200-L \\
J P X-4200-V\end{array}$ & $4200-7800$ & $950-1775$ & $16^{n}$ & $3^{n}$ & $\begin{array}{l}52.2 \\
99.3\end{array}$ & $\begin{array}{l}197.6 \\
375.9 \\
\end{array}$ & $\begin{array}{l}6024 \\
5761 \\
\end{array}$ & $\begin{array}{l}2732.4 \\
2613.1\end{array}$ & $\begin{array}{l}13102 \\
12867 \\
\end{array}$ & $\begin{array}{l}5942.9 \\
5836.3 \\
\end{array}$ \\
\hline $\begin{array}{l}J P X-6700-L \\
J P X-6700-V\end{array}$ & $6700-12750$ & $1520-2895$ & $20^{n}$ & $3^{n}$ & $\begin{array}{r}81.0 \\
162.3\end{array}$ & $\begin{array}{l}306.6 \\
614.4\end{array}$ & $\begin{array}{l}8476 \\
8092\end{array}$ & $\begin{array}{l}3844.6 \\
3670.5\end{array}$ & $\begin{array}{l}19612 \\
19339\end{array}$ & $\begin{array}{l}8895.8 \\
8772.0\end{array}$ \\
\hline
\end{tabular}

* Models ending with " $L$ ' are low profile; " $\mathrm{V}$ " for vertical profile

*t Inlet/Outlet may also be specified with ANSI flanges or DIN flanges; JPX-0004 and JPX-0010 are

standard male, N.P.T. (BSP or JIS threads available); other models also available with optional threading

Maximum pressure rating: 150 psi (10.3 bar); consult factory for higher pressure requirements

Pressure loss range: 3 - 12 psi (.2-.8 bar)

Maximum temperature rating: $180^{\circ} \mathrm{F}\left(82.2^{\circ} \mathrm{C}\right)$ Consult factory for higher temperatures

Maximum particle size: JPX-0016 and smaller - .25 inch $(6 \mathrm{~mm})$; all other models - .375 inch $(9 \mathrm{~mm})$

Material (standard carbon steel): Domes - A 285C/516 GR70, .25 inch (6 mm) minimum thickness

Other parts - A-36, A-53B or other quality grade, .25 inch $(6 \mathrm{~mm})$ minimum thickness; special

coatings and other materials available - consult factory

Assuming we would remove vermiculite clay from the wash water, we can estimate the separation efficiency using Fig. 44. Using a specific gravity of 2.4-2.8 and a particle size primarily less than $148 \mu \mathrm{m}$, we might expect a single pass LAKOS system to remove $>90 \%$ of solids. 


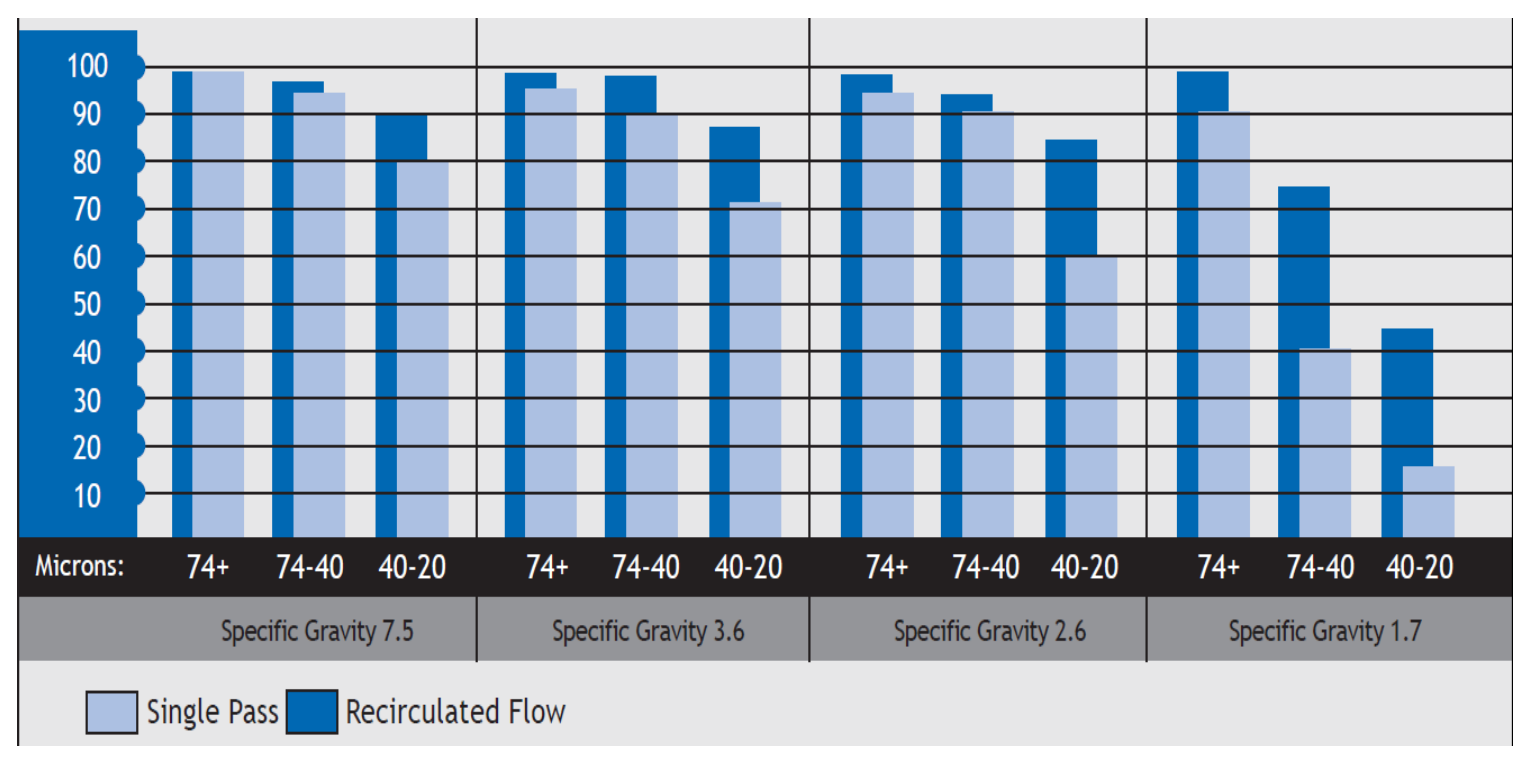

Figure 44. Percent of solids removed as a function of particle size and specific gravity for a single pass LAKOS system and for recirculated flow designs (from the LAKOS $^{\circledR}$ JPX system brochure).

For clays, we can expect a percentage of fines that might require better clarification. One option that is suggested by LAKOS is to operate a dual separator system (Fig. 45). With this design, the first-stage separator will remove most effectively the larger solids, which describes the bulk of material. The finer material will then be better removed in the second separator. The manufacturer reports that when the particle geometry is flakes, rods, and/or irregular shapes, "two-stage separators have been utilized to successfully increase overall particle-removal." 


\section{JPX Low Profile}
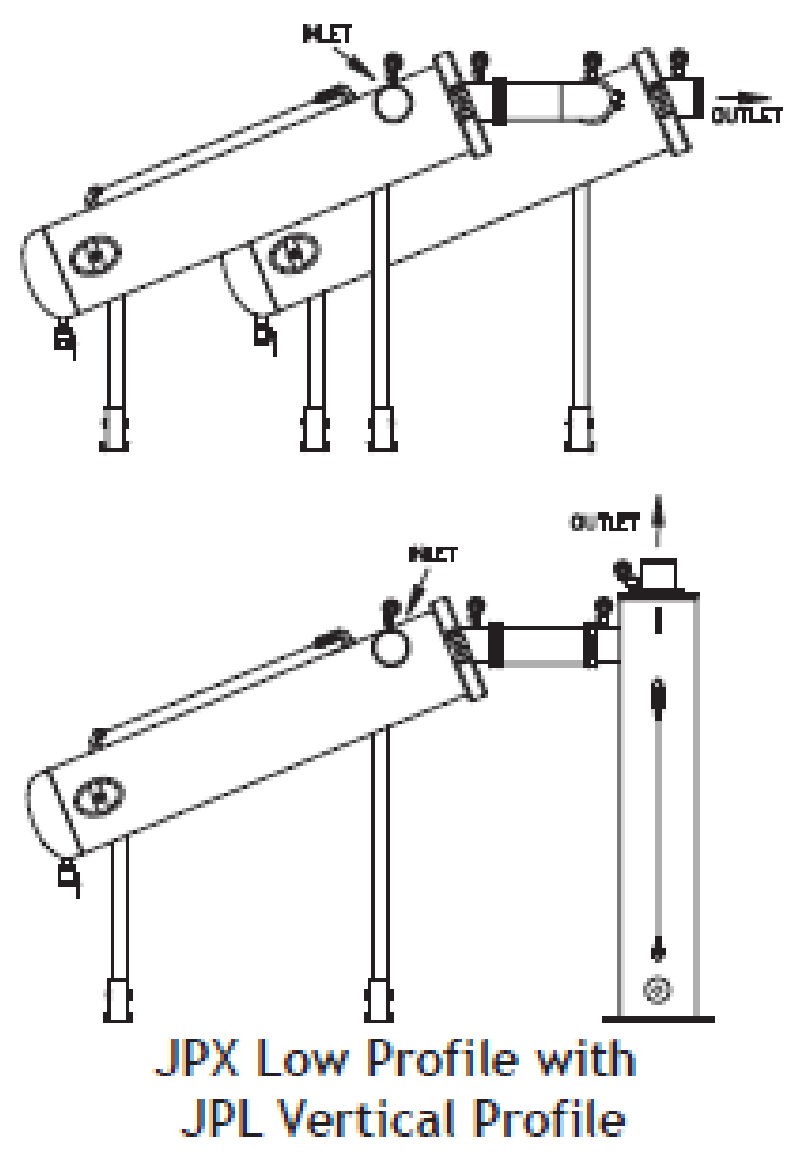

Figure 45. Combining LAKOS Separators to better remove higher solids content, finer solids, or irregularly shaped solids.

To evaluate initially, whether the vermiculite clay has the proper settling characteristics to be amenable to centrifugal separation by the LAKOS units, the supplier recommended conducting a settling test. According to the local distributor of LAKOS units, material that settles by gravity from a dispersed slurry within 3 minutes can be separated by a properly functioning LAKOS separator. We placed $0.1 \mathrm{~g}$ of sieved vermiculite (VCX 205 Grace Co.) into a $20 \mathrm{~mL}$ glass vial and added $10 \mathrm{~mL}$ of $0.5 \mathrm{M}$ $\mathrm{KCl}$. After shaking by vortex mixer briefly, the vial was held by a clamp and permitted to settle. Pictures were taken every 15 seconds to monitor settling (Fig. 46). Since we observed cloudiness in the supernatant after 3 minutes, we expect less than quantitative separation of the vermiculite in the LAKOS unit, but the loss is expected to be low. To quantify our settling tests, the test above was repeated and, after settling for 3 minutes, the entire supernatant was withdrawn and discarded. To the settled slurry, we added $10 \mathrm{~mL}$ of deionized water and centrifuged for 3 minutes at $3000 \mathrm{rpm}$, discarding the supernatant and repeating for a total of three washes. Then $1.2 \mathrm{~mL}$ of absolute ethanol 
was added and centrifuged as before, discarding the supernatant. The contents were allowed to dry. Within the errors of the test, there was no discernible loss of mass from the original mass of clay. With our optical results and quantitative measurements of the settled material, we concluded that the LAKOS centrifugal separator will perform according to specifications.

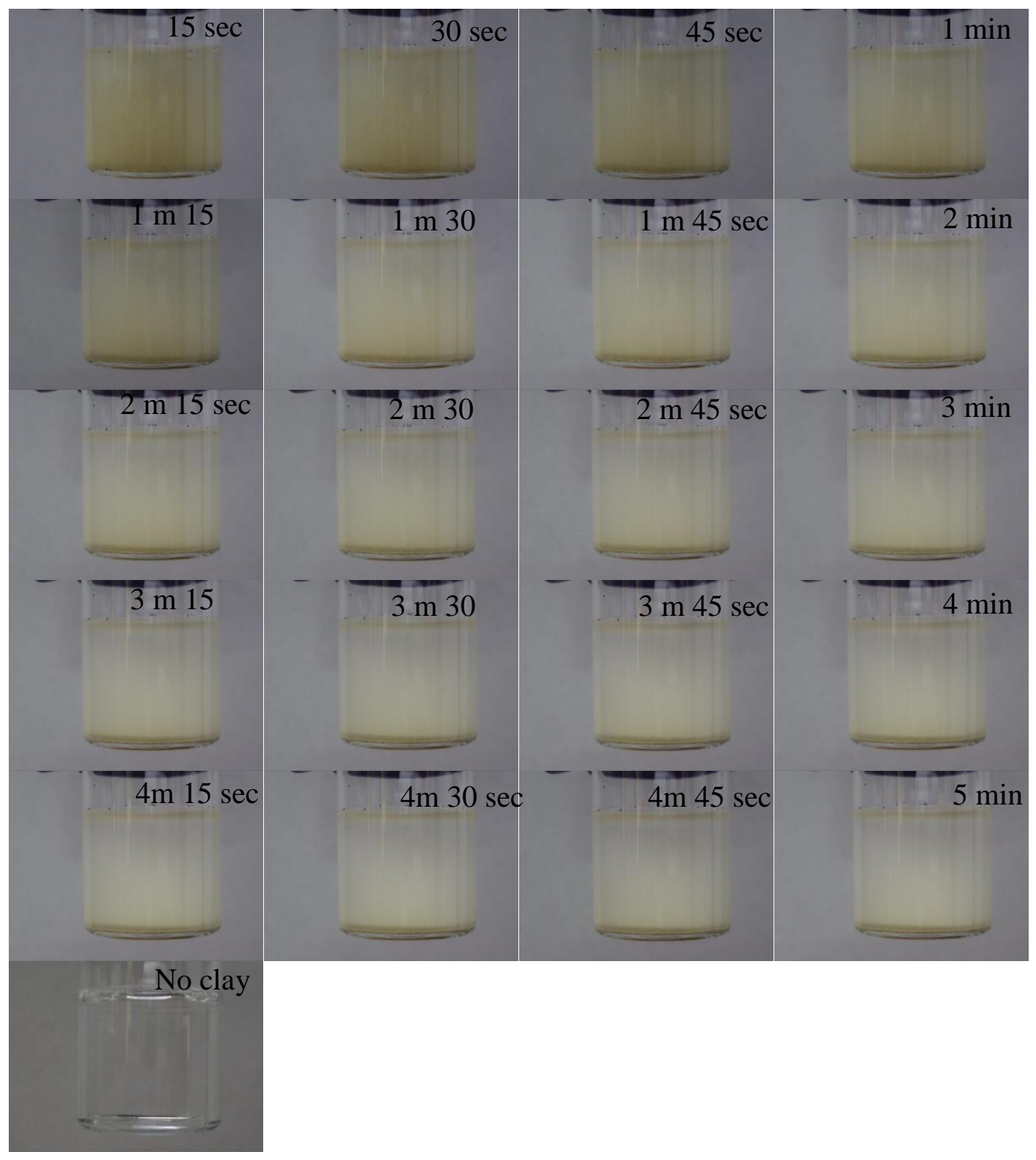

Figure 46. Vermiculite clay settling test shows that gravity settling can remove most of the clay from suspension within 1 minute. Only very fine material is left after 3 minutes. The bottom picture shows a clear vial of water. 


\subsubsection{Membrane Filter Systems}

Bag or cartridge membrane filters are simple systems for producing a filtered water (Fig. 47). However, they are not used on high slurry feeds because the filters clog quickly as material accumulates (cakes) on them. Since these are designed to remove very low concentration of solids in suspension, we explore them in more detail as a method of producing waters for recycle or disposal. Crossflow filter systems, as we discussed earlier, are more appropriate to maintaining operation without clogging or requiring a purge of the filter cake. A summary of secondary filters or final clarifier options was provided in a previous report [USEPA-2012a].
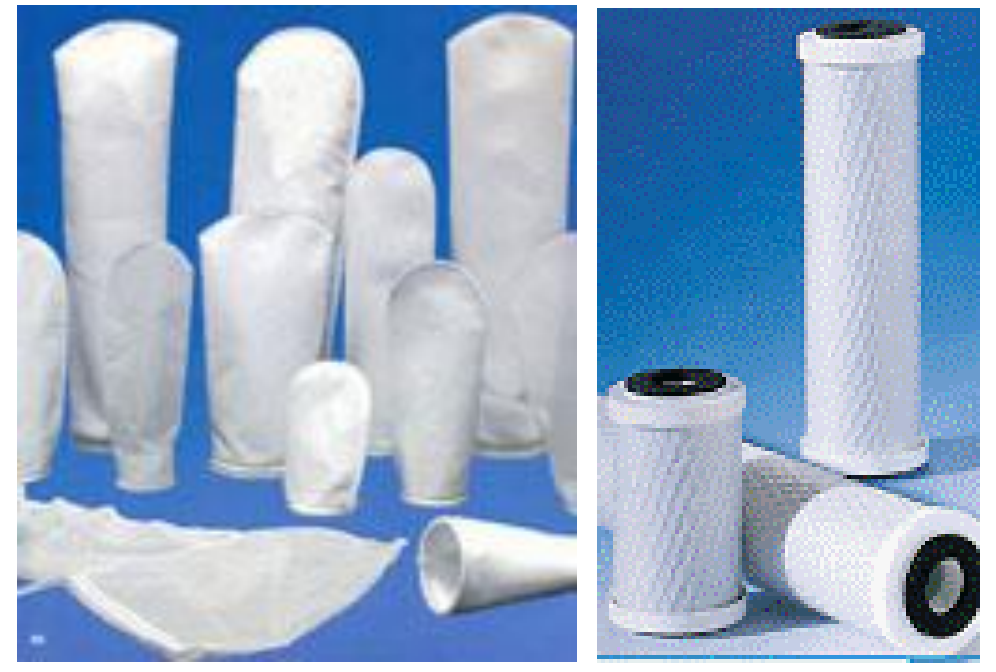

Figure 47. Bag (left) and cartridge (right) filter media tend to clog quickly in high slurry feeds.

A membrane filter system that employs a combination of a crossflow filter design and a settling tank is the system designed by Separmatic ${ }^{\mathrm{TM}}$ Systems (Menomonee Falls, WI). They offer two skid-based filtration units (Figs. 48-52) developed to produce drinking waters during emergencies or as a simplified treatment of well waters. These are vacuum-filtration or pressure filtration. Working in conjunction with a primary settling bed and/or centrifugal filter system, the Separmatic design is well-suited for ensuring no solids enter the recycled water or water intended for final treatment and disposition.

Both of their systems offer the ability to mix a fresh sequestering agent with the wash waters to reduce contamination levels further, before performing a final solids separation. This is because they employ a mixing tank intended as a reservoir to inject the diatomaceous earth onto the filter membrane. ${ }^{4}$

\footnotetext{
${ }^{4}$ The Separmatic ${ }^{\text {TM }}$ filter system employs diatomaceous earth as a filter cake on their membranes. The diatomaceous earth is the active primary filter of microorganisms and other pollutants to produce potable water.
} 


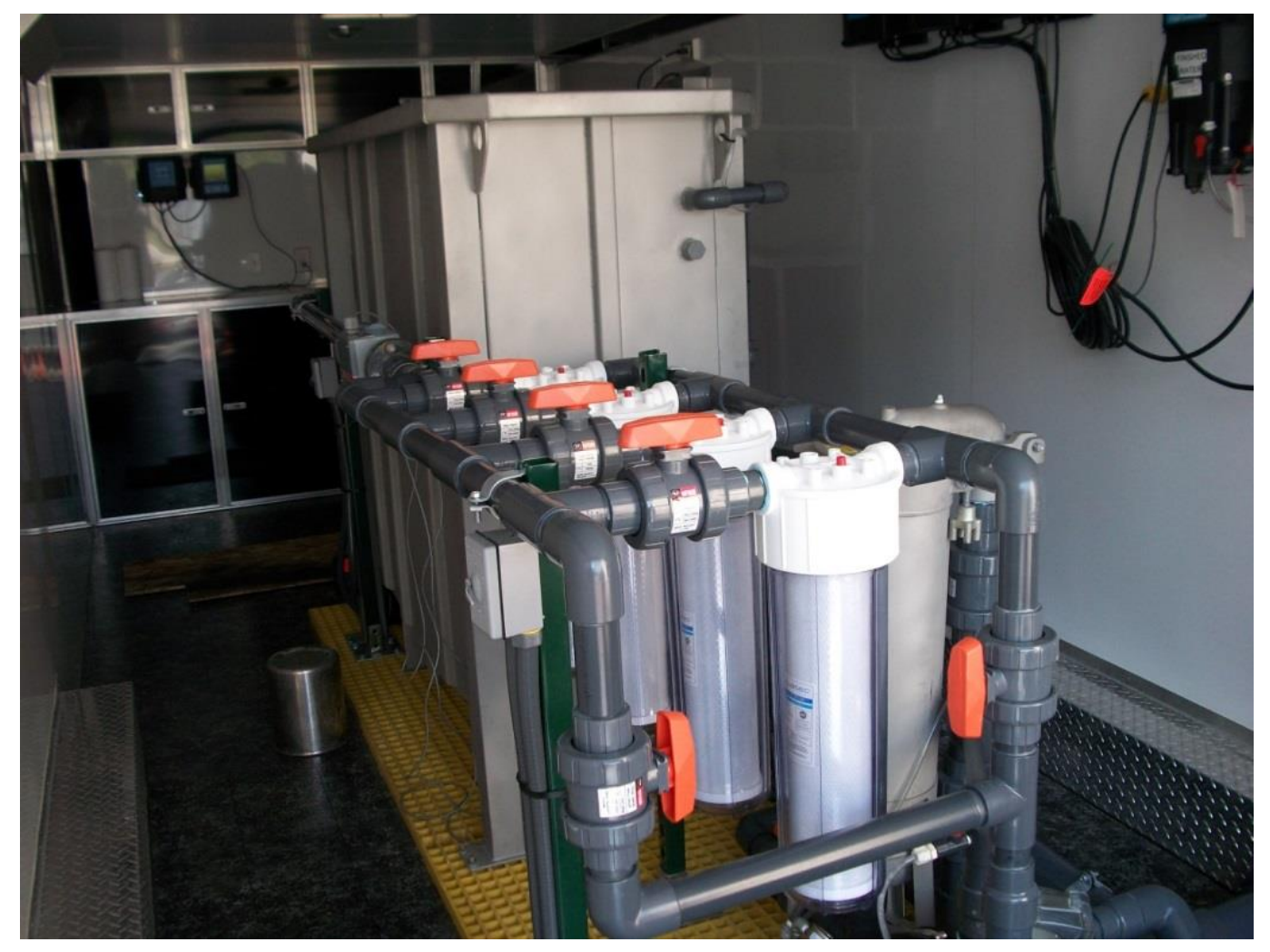

Figure 48. Separmatic ${ }^{\mathrm{TM}}$ Systems vacuum filtration unit. Smaller cartridge filters in the foreground are designed to pretreat the water before it enters final filtration in the vertical tank at the rear of the trailer. Such prefilter systems may contain much more selective sequestering agents (and more expensive) to produce water for discharge or reuse. 


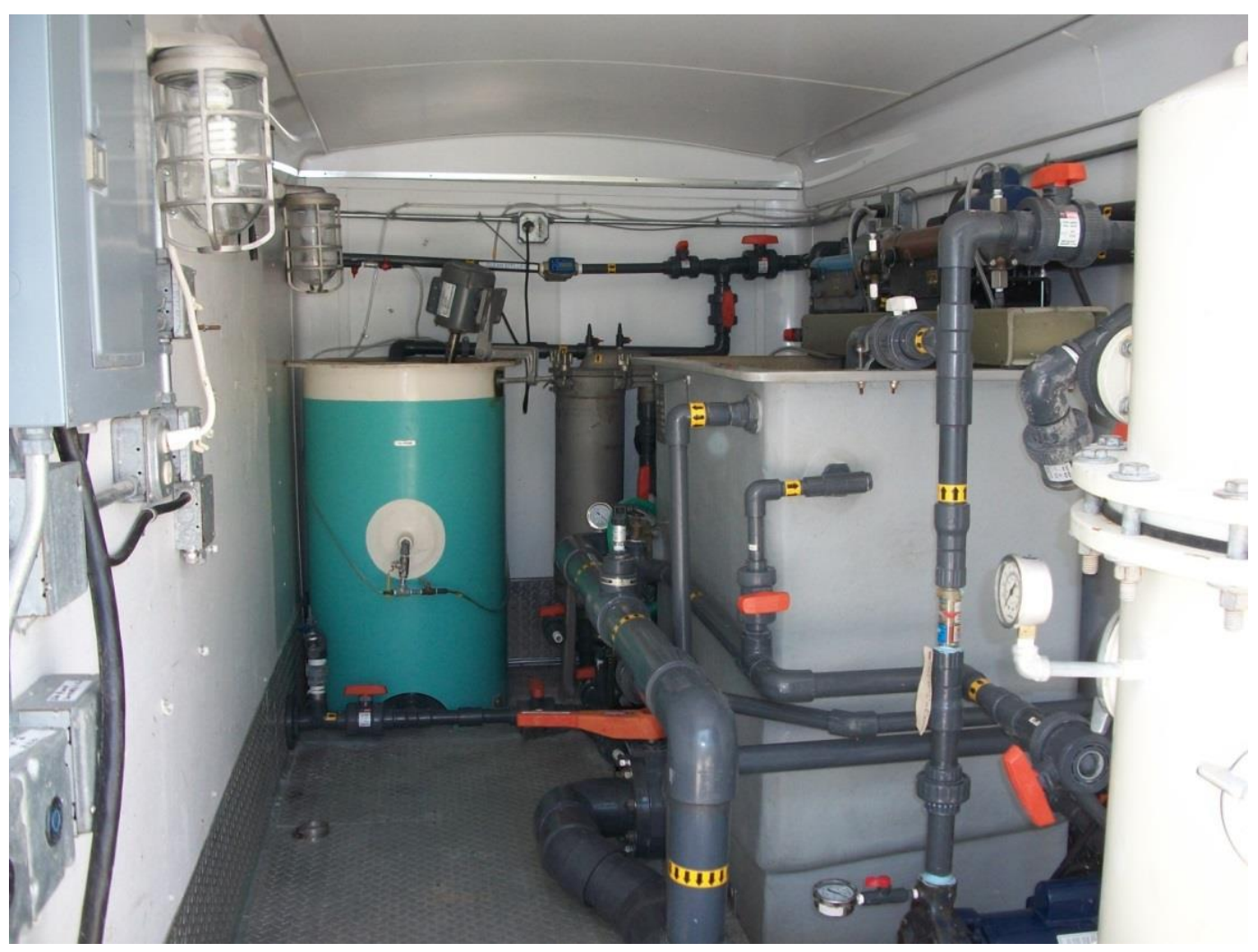

Figure 49. Separmatic ${ }^{\mathrm{TM}}$ Systems vacuum filtration unit. This unit can automatically charge the filter membrane with diatomaceous earth, which is used to remove very fine particulate and microorganisms from the drinking water. The mixing tank is in the rear, at the left and the vacuum filter tank is to the right. See Fig. 50 for a view inside the vacuum filter tank. 


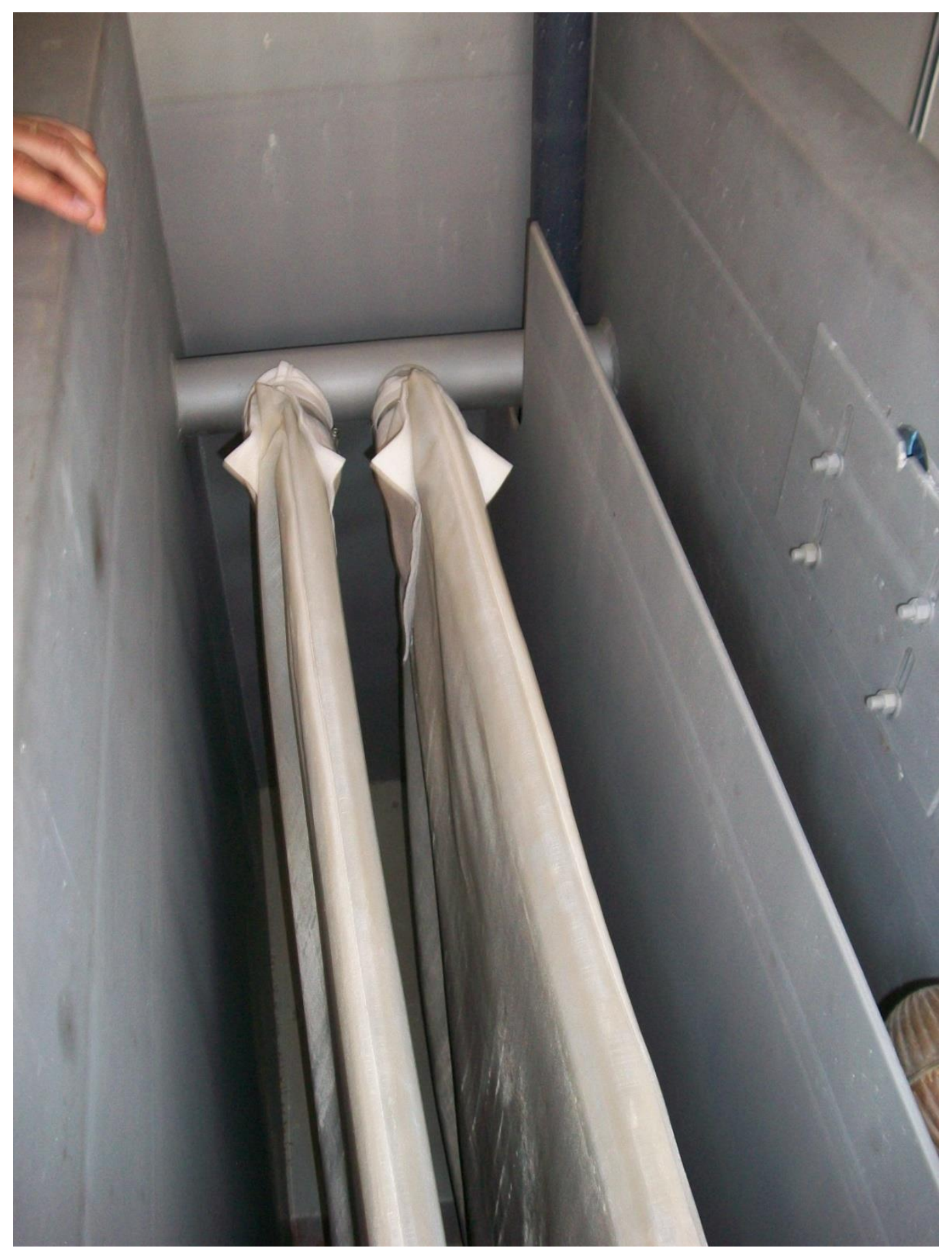

Figure 50. Separmatic ${ }^{\mathrm{TM}}$ Systems vacuum filtration unit. This view shows the membranes draped over the outlet manifold in the vacuum filter tank. During operation, solids will settle to the bottom of the tank and may accumulate up the membrane before requiring purging to remove the concentrated solids via a bottom purge valve. Automated sprayers help to dislodge any cake on the filters out the purge. 


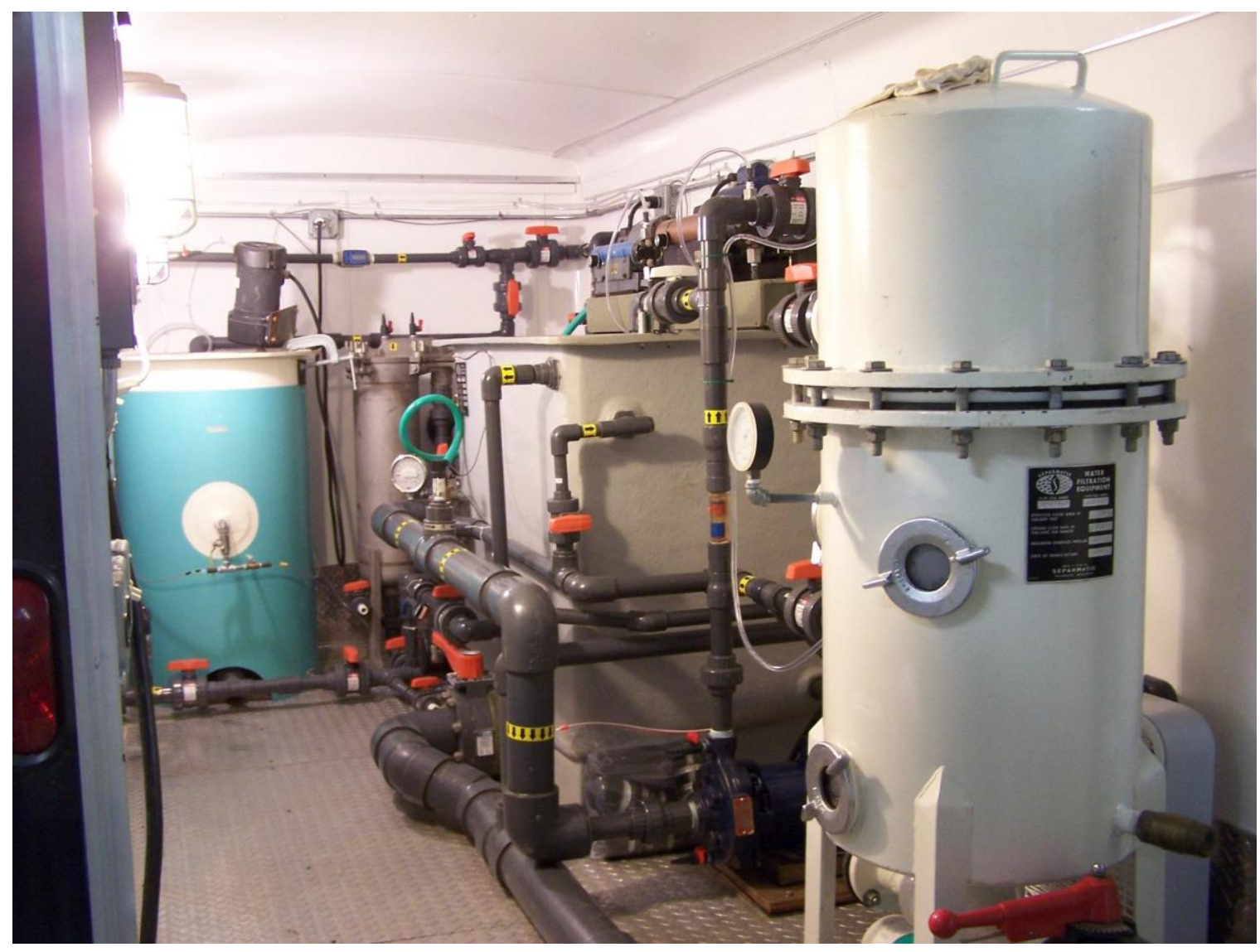

Figure 51. Skid-mounted pressure vessel filter design by Separmatic ${ }^{\mathrm{TM}}$ System. The pressurized filter tank is in the foreground. Note the viewports used to monitor cake buildup. 


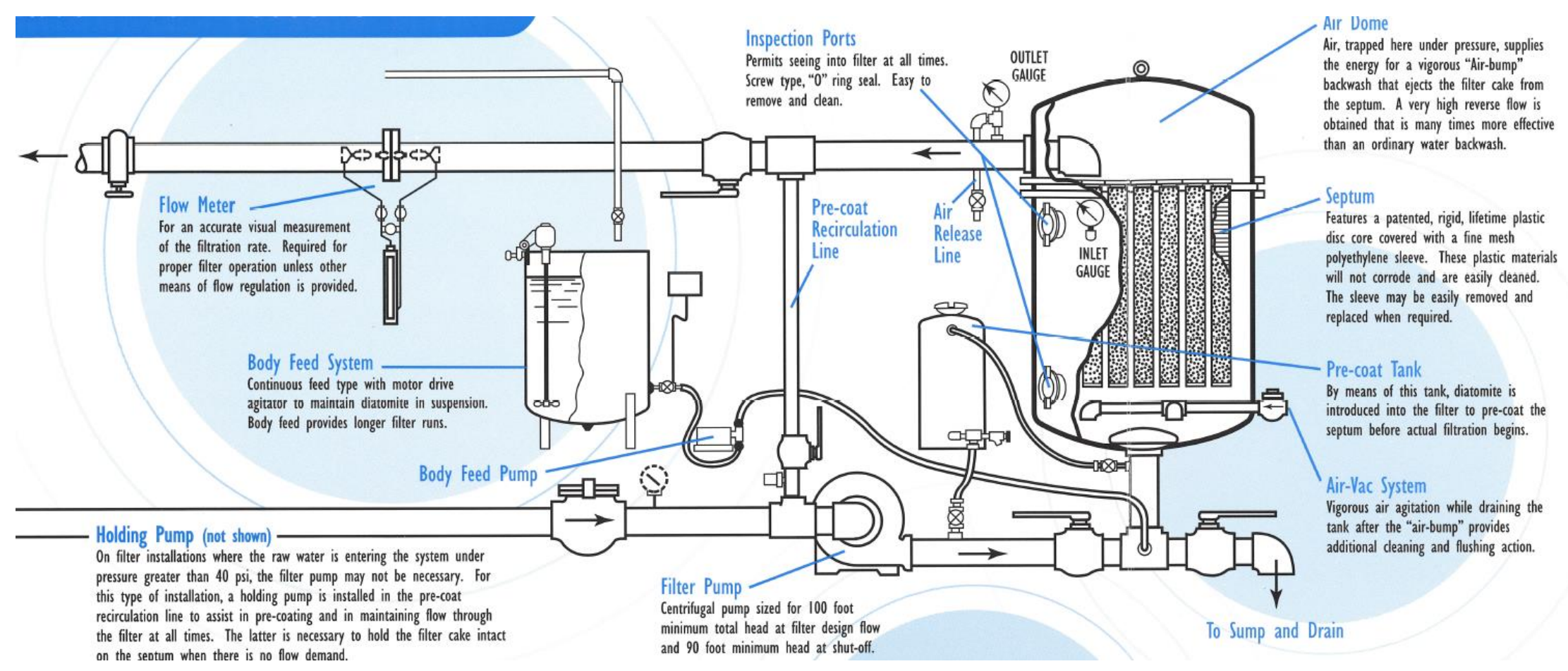

Figure 52. Pressure filter design showing how the tanks are used to mix and introduce solids into the feed water. This type of design may be used to mix selective sequestering agents into the wash water to remove the trace levels of radioactivity. 
The specifications on the fabric installed in Separmatic units for drinking water for both vacuum and pressure units are as follows:

$\begin{array}{ll}\text { Fiber } & \text { Polyethylene } \\ \text { Weave } & \text { Plain } \\ \text { Thread Count } & 109 \mathrm{x} 44 / \text { inch } \\ \text { Air Permeability } & 75-120 \text { cubic feet per minute } \\ \text { Weight } & 9.3 \mathrm{oz} / \mathrm{yd}^{2} \\ \text { Thread } & 8.75 \mathrm{mil}\end{array}$

\subsection{Disposal of Materials}

We consider the disposal of the material used to capture and decontaminate the wash waters. These include the berm containers (wire framing and pins, textile liner, and polymer liner), the fill material (earth materials like soil, sand, and rock) sequestering agents, and the decontaminated wash water containing the chemical (salt and surfactant) additives.

\subsubsection{Disposal of the Berm Containers}

Several commercial liners are available to dispose of the berm material and other dry materials suspected of contamination (Figs. 53 and 54). Examples include the PacTec packages and the Nautilus Bag ${ }^{\text {TM }}$. HESCO also provides liners that can be used to remove the container units using small cranes or skid loaders.
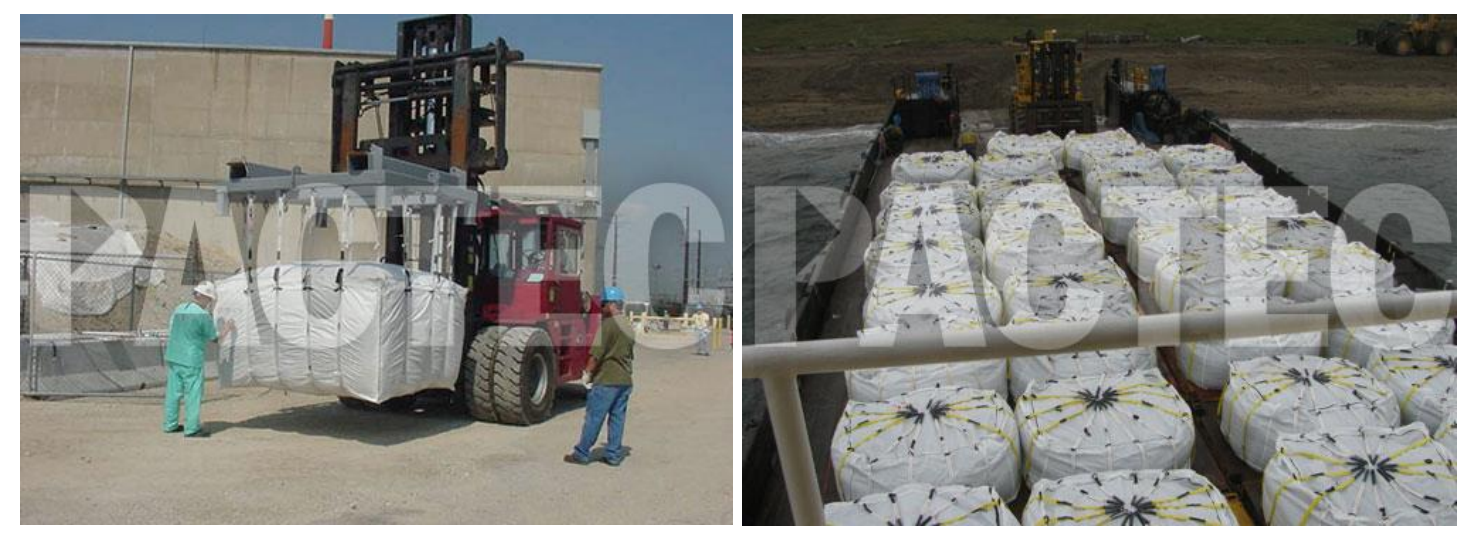

Figure 53. PacTec EPS (of PacTec Inc., USA, www.pactecinc.com/products/lift-bags) provides International Atomic Energy Agency- (IAEA) certified flexible packages for transportation, storage, and disposal of low-level waste (LLW). According to the manufacturer, "The LiftPac ${ }^{\circledR}$ is a U.S. Department of Transportation- (DOT) certified IP-1/IP-2 flexible container for flowable solids such as sand, soil, gravel, and construction debris. Manufactured from heavy-duty woven and non-woven polypropylene with patented zipper closures, the LiftPac gives users a safe and secure 
way to store, transport, and dispose of a variety of wastes. The LiftPac can be easily transported by rail, flatbed, dump truck, intermodal container, and barge."

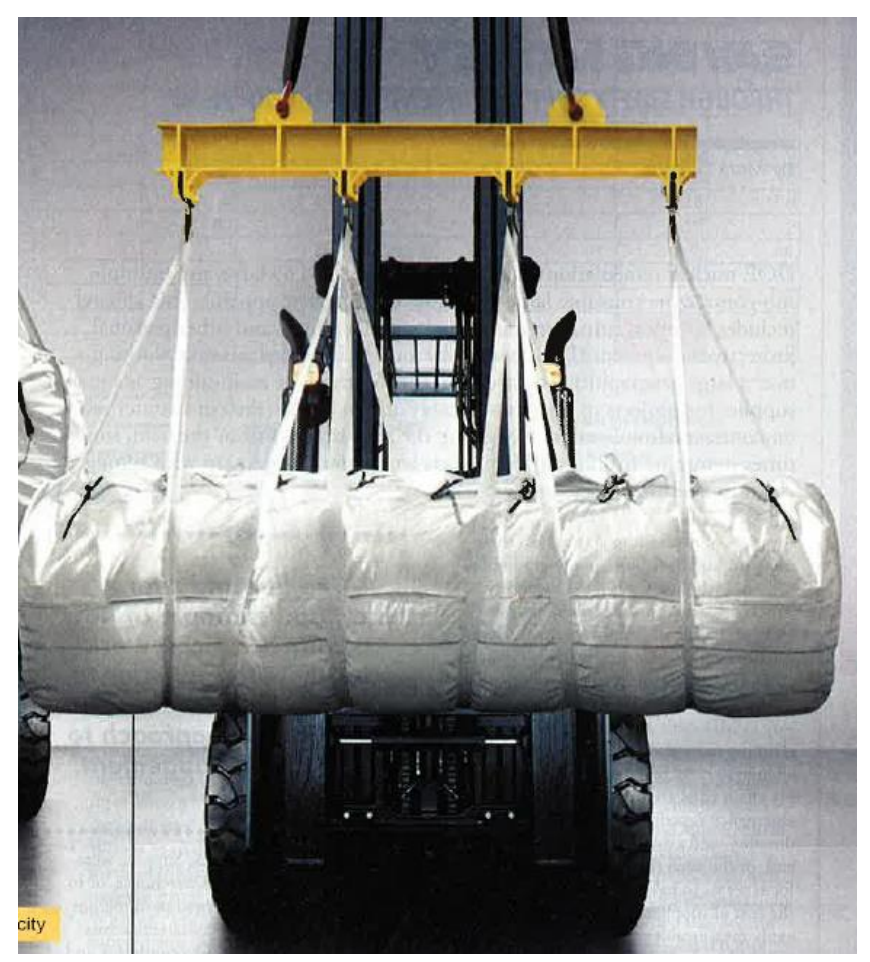

Figure 54. The Nautilus BagTM and the Truck BagTM are flexible packaging systems for transporting radioactive packages by Strategic Packaging Systems LLC. The $20 \mathrm{yd}^{3}$ (22 ton capacity) bag is shown. The Nautilus Bag was used to contain the demolition material from the Bevatron decontamination and decommissioning (D\&D) at Lawrence Berkeley National Laboratory.

\subsubsection{Disposal of the Fill Material and Sequestering Agents}

Regarding the fill and clay materials, and other sequestration agents, we must consider them in turn. If impermeable liners are used in the berm, then the fill material (clay, soil, rock rubble, etc.) may not require disposal as low-level radioactive waste. It is very likely that these can be screened for gross contamination and largely released to a landfill or reused as appropriate.

The solid material like the clays or soils or other sequestration agents that do come in direct contact with the contaminated wash waters will likely require disposal as low-level radioactive waste. On average, we expect the contamination levels to be very low. If we assume a $1000 \mathrm{Ci}$ release of $\mathrm{Cs}-137,50 \%$ of this activity goes from the affected zone into the wash water, and a total of 10 tons of sequestration agents are needed for its separation from the wash water. Then, we would produce $500 \mathrm{Ci} / 10$ tons or $60 \mathrm{Ci} / \mathrm{m}^{3}$ (assuming an average density of $1200 \mathrm{~kg} / \mathrm{m}^{3}$ for loose earth), which falls into 
the Class C limits. ${ }^{5}$ This is likely a conservative concentration since we would expect $>50$ tons of sequestering agent to be required for such a large release. Plus, we have not added the volume of ancillary material such as soils, building debris, demolition material, or materials resulting from other decontamination methods.

\subsubsection{Disposal of the Slurry or Wash Water}

The radioactive slurry and/or wash water can be pumped directly into a transport tanker with capacities that range from small mobile tankers holding less than 1000 gallons to large tank trucks used to distribute gasoline (cap. 5500-11,600 gal.).

For larger containment, we found a number of large flexible tank providers designed for containing drinking water, wastewater, chemicals and fuel, and oils (Figs. 55 and 56). These include Husky Portable Containment (Dewey, OK, www.huskyportable.com/index.php), Interstate Products, Inc. (Sarasota, FL www.interstateproducts.com), and Aero Tec Laboratories (Ramsey, NJ, www.atlinc.com). The largest containers had a 150,000 gallon capacity.

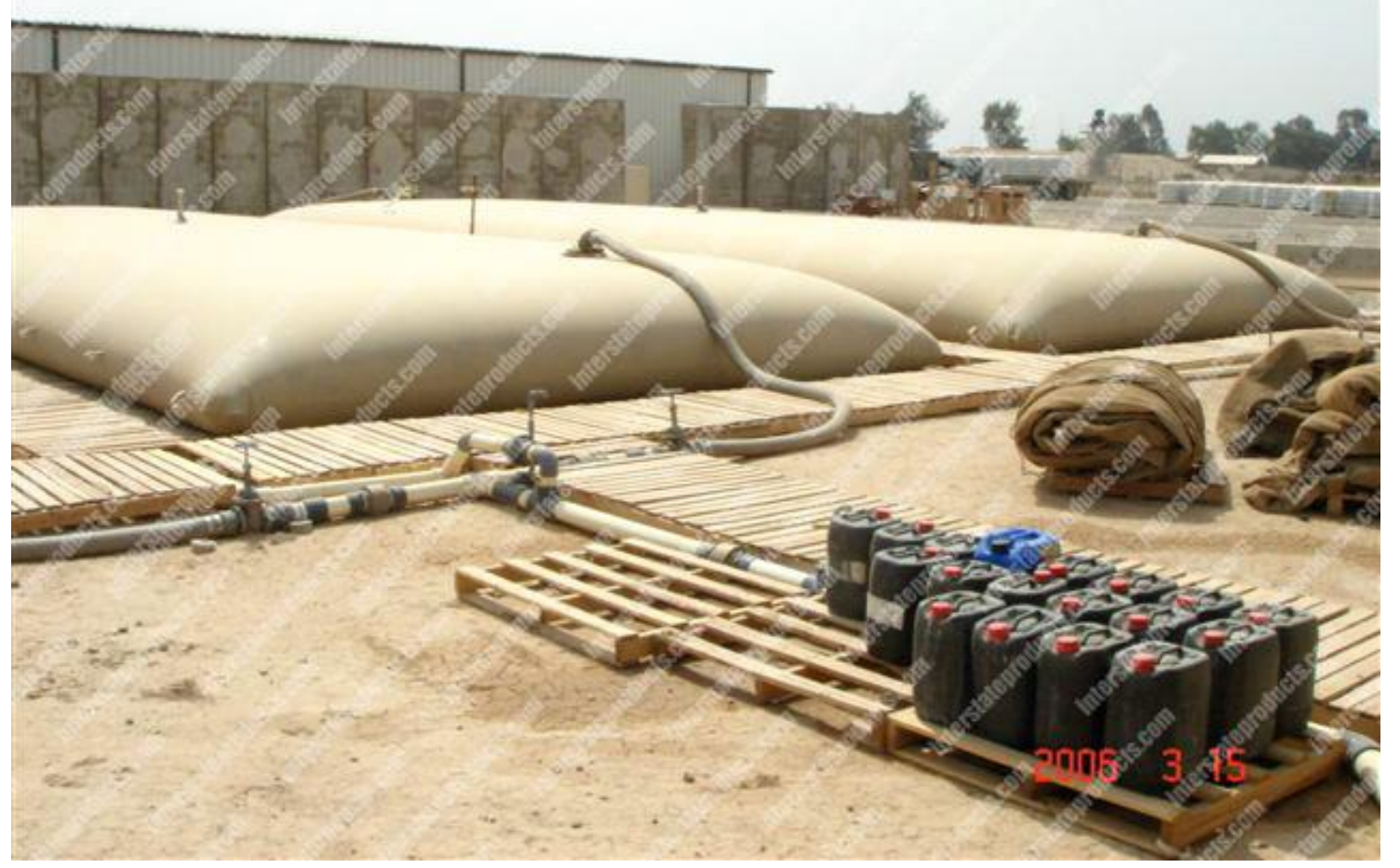

Figure 55. Large bladder tanks by Interstate Products designed for military fuel and water storage.

\footnotetext{
${ }^{5}$ Class A limits are $1 \mathrm{Ci} / \mathrm{m}^{3}$; Class B are $44 \mathrm{Ci} / \mathrm{m}^{3}$; Class C are $4600 \mathrm{Ci} / \mathrm{m}^{3}$.
} 

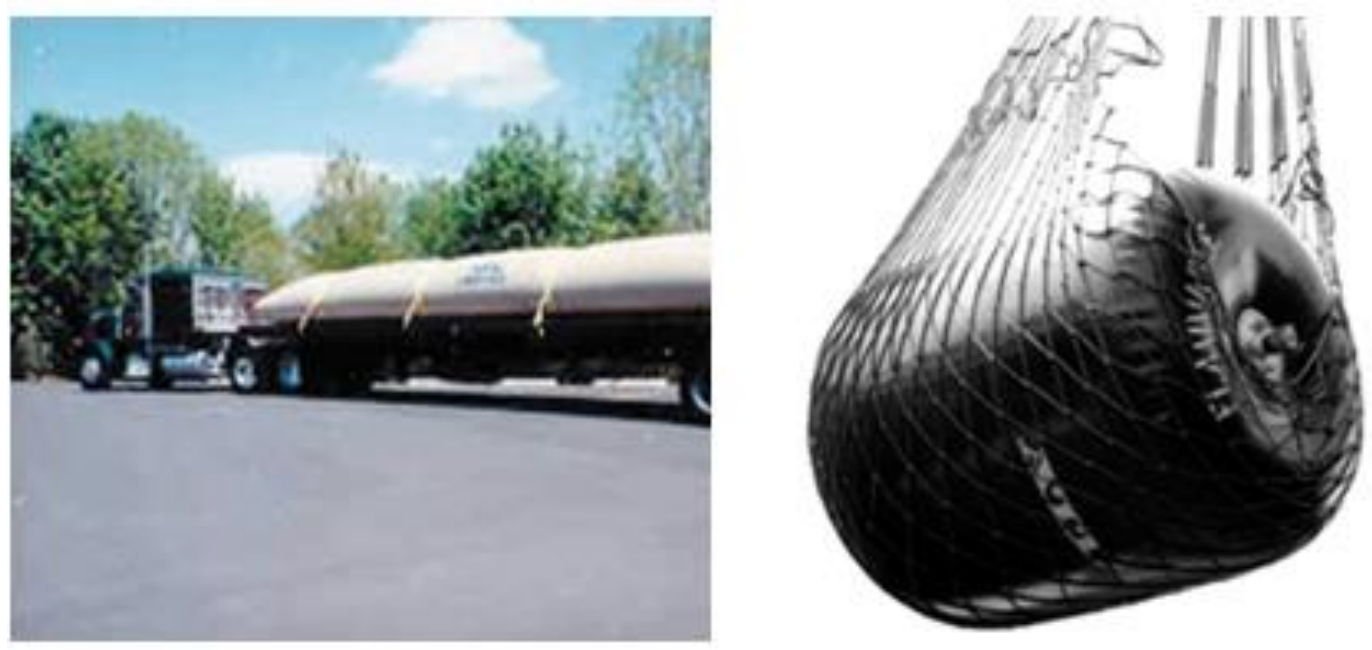

Figure 56. Aero Tec Laboratories (ATL) products provides a variety of inflatable bladder tanks in their Flex-Tank ${ }^{\mathrm{TM}}$ line.

Searching the Nuclear News April 2012 Buyers Guide for large flexible tanks approved for radioactive liquid and slurry wastes turned up ambiguous results. Mitsubishi Nuclear Energy Systems (VA) is listed as a supplier of rubber collapsible tanks, but there was no information available on their website indicating such products. JSM Protective, Inc. (NC) was also listed, but their website suggested that they deal in primarily small items such as individual personal protective equipment. Wright Industries (a Doerfer Company, SC) is listed as a provider of diaphragm tanks, but no information was available to confirm this product line on their website.

Small quantities of liquid slurry such as seepage from the berm or the final cleanup of the deconstructed berm zone can be removed using a common street sweeper or vacuum truck (Fig. 57). However, one must be mindful that these units are not designed to contain dust and fine particulate and measures must be taken to avoid filling these units above capacity since material then may be discharged from the stack.

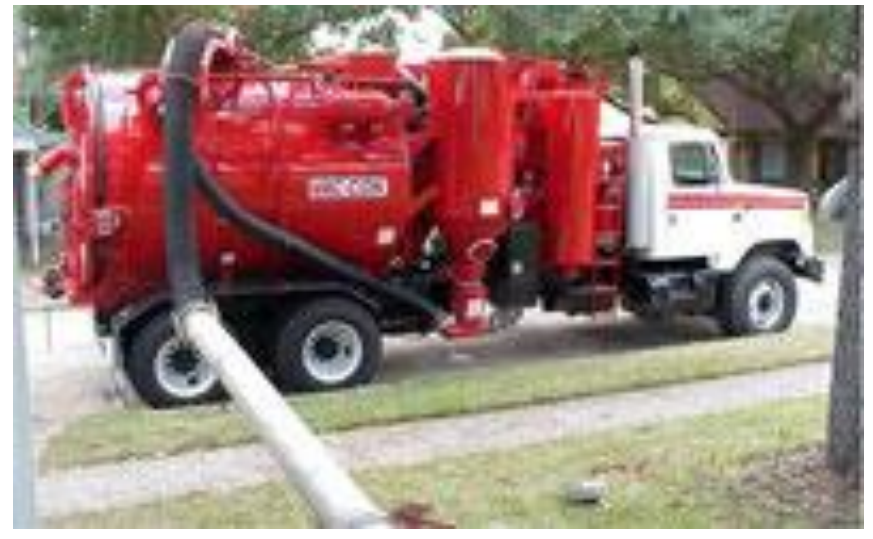

Figure 57. Vacuum truck employed to remove sediment and debris from catch basins and from the curbside. 


\subsection{Summary of COTS Selection Criteria and Recommendations}

We have discussed the technical data and bases for down-selecting individual systems to fulfill the overall operation of disseminating a wash solution and collecting it to treat and remove the radioactive components. We now summarize our results.

The Wash Solution consists of a salt solution with a surfactant additive to improve the wettability of asphalt and other hydrophobic surfaces. The surfactants are available worldwide. The salts that we found that work the best are potassium and ammonium. These are supplied worldwide as potassium chloride, potassium nitrate, ammonium nitrate, and ammonium chloride as well as in other forms. A Saturated Brine and Surfactant Can Be Created in smaller tanks and drawn into the firehose by the eductor system to achieve the desired salt concentration (>0.1 molarity and preferably $0.5 \mathrm{M}$ molarity and 1 millimolarity in surfactant). This concentrated brine is fed into the fire hose using COTS eductors employed by firefighter units. These eductors draw a secondary fluid into the main water line without the need for specialized pumps. In this manner, the need for extra equipment is minimal, since the small tanks (several thousand gallons) and eductors are already available locally.

The Solid Sequestering Agent has the function of binding the mobile radionuclides introduced into the salty wash waters. Based on Phase I studies and supplemented by Phase II experiments, the sequestering agents of choice are montmorillonite and vermiculite clay with vermiculite being preferred. Both are prevalent regionally, but the purity of the montmorillonite is important and can be a supply chain issue since the best purity is obtained overseas. CST or $\mathrm{KNiFC}$ are also very good, but the expense and availability of large quantities prevents their recommendation for emergency operations, unless stockpiled in advance.

The Clay is Distributed across the ground in the affected zone and within the artificial reservoirs setup downgrade from the wash activities. It can be simply dumped from a truck and spread using shovel trucks of any sort available. The idea is to have the wash waters run down from the buildings and roadways and come in immediate contact with the clay so that the now-mobile radionuclides are quickly bound.

We expect to Contain the Contaminated Water for Filtration and Reuse by deploying a system of berms to create reservoirs at the street level. The COTS system we chose is from HESCO Global. They are the prime suppliers of berm material for the military and flood zones across the U.S. Their systems of accordion-style mesh fabric or impermeable containers can be deployed rapidly and in hazardous conditions. The containers are filled with either the clay material or any available fill, like rocks, dirt, or sand. By encircling the perimeter of a contaminated zone, the wash waters will be contained. HESCO baskets can be placed atop catch basins, inlets, sewer caps, and utility manhole covers to prevent extensive intrusion of contaminated waters into the underground tunnels.

As the wash waters and clay material collect in the reservoirs, we will begin Slurry Collection and Filtration operations. From experiment, we expect up to $80 \%$ of the cesium to be bound within the clay sequestering agent within the reservoir. To permit release of the wash water for reuse or disposal, we must remove the remaining fraction of mobile cesium. This can be accomplished in several ways. But, first the original mass of 
sequestering agent must be separated from the wash water. To do this, we chose a series of COTS filters. The first is a centrifugal filter manufactured by LAKOS. The LAKOS units can operate at very high throughput (millions of gallons per day) on high slurry concentrations. There are no moving parts except for the pump that feeds the separator. Centrifugal action forces the solid material into the purge zone while the clarified product is fed to another unit for secondary or final clarification. Final clarification is achieved by a simple membrane filter. We chose the mobile transport design by Separmatic ${ }^{\mathrm{TM}}$ Systems because of its high throughput, simple operation, reliability, and reasonable cost. Their system removes all suspended material and can be purged automatically to avoid close contact with radioactive material. Additional mixing of clarified wash waters with clay to remove the remaining mobile cesium can be accomplished by transferring the product wash waters from either filtration unit to a small reservoir, mixing fresh clay into this reservoir, collecting this material, and separating the solids as before.

Disposal of Materials is a key aspect of the technology. By using the clay and filtration system, we can be reasonably assured that the wash waters will be suitable for direct disposal as treated waters (not low-level radioactive liquid waste). The presence of salt complicates its disposal since the salt would be prohibited from entering the water treatment facilities (based on our interaction with officials at the municipal water treatment facilities across the country). Therefore, a system would need to be emplaced to remove the salt. We are exploring options. The sequestering agents can be collected from the purge lines of the centrifugal and bag filter units directly into inflatable waste bladders provided by several U.S. suppliers and transported to a facility for low-level waste treatment. The berms can be wrapped in plastic (diaper-like wrap provided by HESCO as part of their container systems) and lifted onto trucks for transport and disposal. Or, if the contents are deemed clean, the HESCO container structure itself can be removed for low-level waste disposal and the fill material hauled away separately to a landfill or other suitable disposal site.

\section{ACKNOWLEDGMENTS}

The U.S. Environmental Protection Agency managed and collaborated in the research described in this presentation under Contract CB-CM3332. It has been subjected to the Agency's review and has been approved for publication. Note that approval does not signify that the contents necessarily reflect the views of the Agency. Mention of trade names, products, or services does not convey official EPA approval, endorsement, or recommendation. 


\section{REFERENCES}

Abe-1995. Abe, M., "Ion Exchange Selectivities of Inorganic Ion Exchangers," Chapter 9, in Ion Exchange and Solvent Extraction, Vol. 12, Marinsky and Marcus, eds., 381440, 1995.

Armand-2013.www.armandproducts.com/pdfs/POTCARB_price_list.pdf 2011.

Borai-2009. Borai, E.H., et al., "Efficient removal of cesium from low-level radioactive liquid waste using natural and impregnated zeolite minerals," Journal of Hazardous Materials 172, 416-422, 2009.

Bowen-1973. Bowen and Masliyah, "Drag force on isolated axisymmetric particles in stokes flow," Can. Chem. Eng. , 51, 8-15, 1973.

C\&S-2013. Personal communication with the engineers at C\&S Supply, 2013.

Choppin-1985. Choppin, G.R. and Allard, B., In Handbook on the Physics and Chemistry of the Actinides; Freeman, A.J. and Keller, C., eds., Elsevier Science Publishers: Amsterdam, the Netherlands, 407-429, 1985.

El-Kamash-2008. El-Kamash, A.M., "Evaluation of zeolite A for the sorptive removal of $\mathrm{Cs}^{+}$and $\mathrm{Sr}^{2+}$ ions from aqueous solutions using batch and fixed bed column operations," Journal of Hazardous Materials 151 (2-3) (2008) 432.

Hatch-1953. Hatch, L.P., Ultimate disposal of radioactive wastes. American Scientist, 41 3 (1953), pp. 410-421.

ICIS-2006. http://www.icis.com/chemicals/channel-info-chemicals-a-z/.

Kaminski-2008. Kaminski, M., C. Mertz, M. Finck, N. Kivenas, M. Kalensky, and J. Jerden, "Decontamination Of Cesium From Concrete Using A System of SuperAbsorbing Gels, Solid Adsorbents, And Ionic Solution: Program Summary Report," Report to Technical Support Working Group, November 2008.

Kaminski-2013. Kaminski, M., C., Mertz, M. Kalensky, and N. Kivenas, "Optimization of Radiological Decontamination Techniques For Tropical Environments," Report to Technical Support Working Group, October 2013.

Koyama-1997. Koyama, A. and K. Nishimaki, "Feasibility study of the applicability of the activated sludge process to treatment of radioactive organic liquid waste," Waste Management, Vol. 17, No. 1, pp. 47-52, 1997.

Livens-1991. Livens, F.R., Environ. Pollut. 70, 183-208, 1991.

Marešová-2001. Marešová, J., M. Horník, M. Pipíška, and J. Augustín, "Sorption of $\mathrm{Co} 2+, \mathrm{Zn} 2+, \mathrm{Cd} 2+$ and $\mathrm{Cs}+$ Ions by Activated Sludge of Sewage Treatment Plant, Nova Biotechnologica 10-1, 2010.

Mimura-1985. Mimura, H. and T. Kanno, "Distribution and fixation of cesium and strontium in zeolite A and chabazite," Journal of Nuclear Science and Technology 23, 281; 1985. 
Mimura-1997. Mimura, H., J. Lehto, and R. Harjula, "Ion exchange of cesium on potassium nickel hexacyanoferrate(II)s," J. Nucl. Sci. Techn., 34(5), 482-289, 1997.

Misaelides-2011. Misaelides, P., "Application of natural zeolites in environmental remediation A short review," Microporous Mesoporous Mater., 144(1), 15-18, 2011.

MWRD-2012. Personal communication with Anthony Quintanilla of the Water Reclamation District of Greater Chicago, 2012.

Naftz-2002. Naftz, D., et al., eds., Handbook of Groundwater Remediation using Permeable Reactive Barriers, Academic Press, San Diego, California, 2002.

Nease-2013. Personal communication with Nease Performance Chemicals, Cincinnati, Director of Technology Phil Benis, 2013.

Nisbet-2009. Nisbet, A., J. Brown, A. Jones, H. Rochford, D. Hammond, and T. Cabianca, "UK Recovery Handbooks for Radiation Incidents: 2009," Health Protection Agency, United Kingdom, HPA-RPD-064, November 2009.

NIST-2013. Solubility Database - International Union of Pure and Applied Chemistry / National Institute of Standards and Technology.Pashow-2013. Taylor-Pashow, K., T. Shehee, and D. Hobbs, "Advances in Inorganic and Hybrid Ion Exchangers," Solvent Extraction and Ion Exchange, 31, 122-170, 2013.

Pekarek-1972. Pekarek, V. and V. Vesely, "Synthetic Inorganic Ion Exchangers-II Salts of Heteropolyacids, Insoluble ferrocyanides, synthetic aluminosilicates and miscellaneous exchangers," Talanta, 19, 1245-1283, 1972.

Perry-1997. Perry's Chemical Engineers' Handbook, 7th ed., McGraw Hill, New York, pg. 18-131, 1997.

Shoumkova-2014. Shoumkova, A., "Zeolites for Water and Wastewater Treatment: An Overview," Australian Institute of High Energetic Materials, ABN: 68126426 917, available online at http://www.ausihem.org, last accessed 2014.

Song-1997. Song, K.C., H.K. Lee, H. Moon, and K.J. Lee, "Simultaneous removal of the radio-toxic nuclides cs-137 and I-129 from aqueous solution," Separation and Purification Technology 12, 215. 1997.

Tank Truck-2013. Wikipedia search of Tank Truck, 2013.U.S. Department of Homeland Security (DHS),-2003. "Top Officials (TOPOFF) Exercise Series: TOPOFF 2," U.S. Department of Homeland Security, http://www.dhs.gov/xlibrary/assets/T2_Report_Final_Public.doc.

U.S. Environmental Protection Agency (EPA)-2012a. Joint Environment Canada and USEPA Project: Scoping Report on Infrastructure Mitigation via Cs-137 Wash Aid, U.S. Environmental Protection Agency Office of Research and Development, March 15, 2012.

USEPA-2012b. "Nationally Significant Incident: Approach to RDD Response," U.S. Environmental Protection Agency, http://www.rrt9.org/go/doc/2763/495519, accessed March 2012. 
USEPA-2012c. "Liberty RadEX: National Tier 2 Full-Scale Radiological Dispersion Device Exercise, Philadelphia, Pennsylvania April 26-30, 2010," U.S. Environmental Protection Agency, http://www.epa.gov/libertyradex, accessed January 2012. 


\section{APPENDIX A. VIEWS OF ChICAGO FINANCIAL DISTRICT}

This section is intended to provide the reader with a view of a busy, urban corridor so that one may better picture the logistical challenges of setting up a decontamination zone during emergency operations. These are satellite and street view images of areas of the financial district in Chicago (Figs. A1-A21).

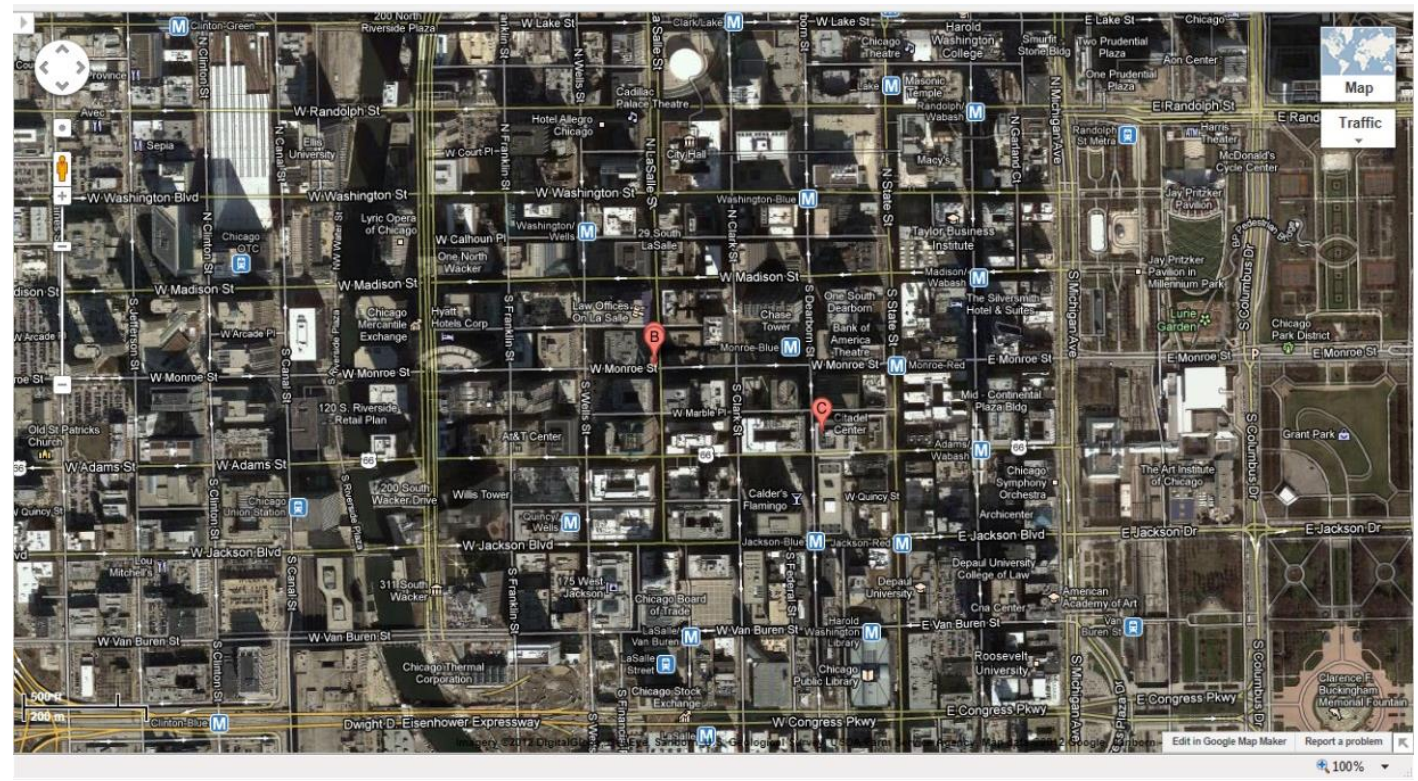

Figure A1. Wide area of view of the Chicago Loop.

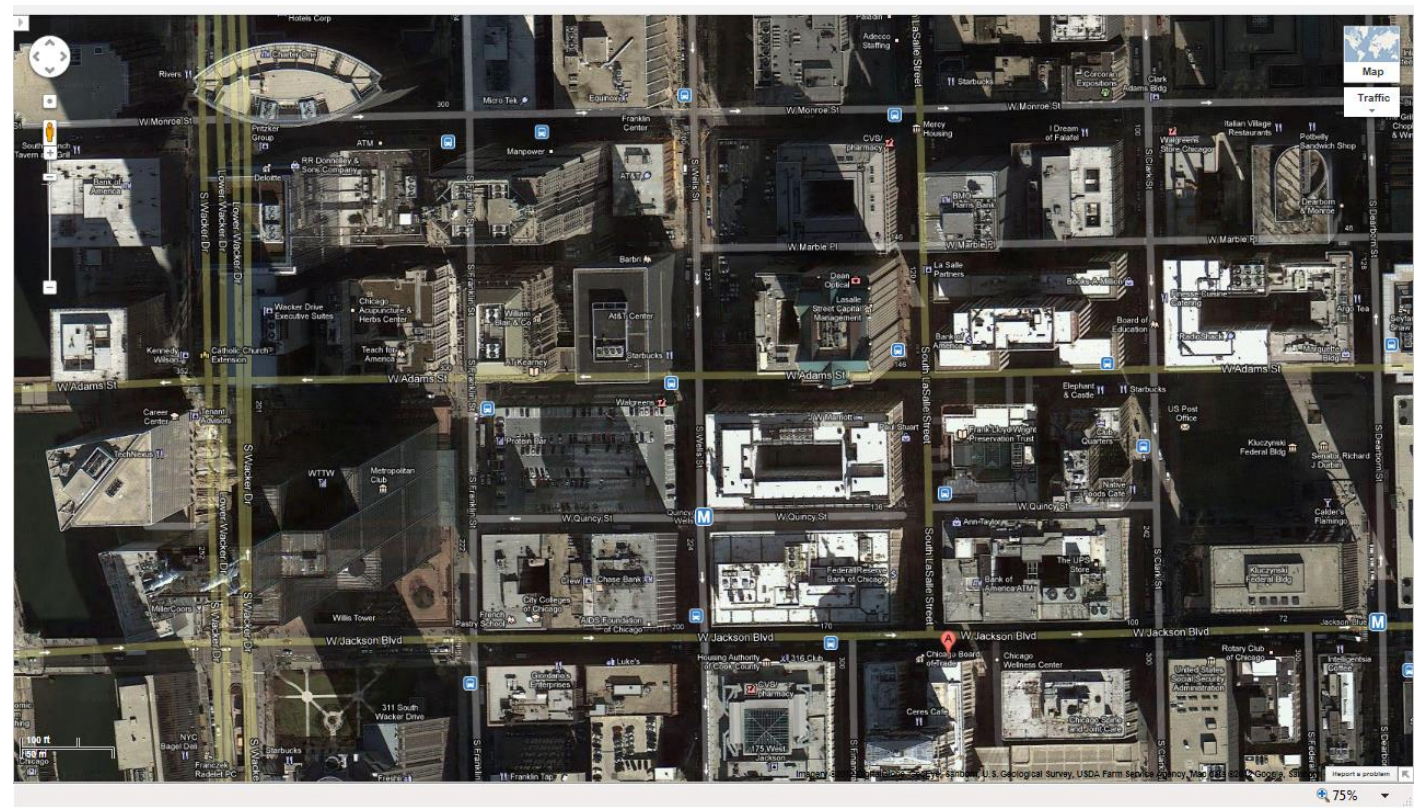

Figure A2. Closer view of the financial district of Chicago. 
We have assumed a release of radioactive cesium in the financial district of Chicago defined for this exercise as the area just north of the Chicago Board of Trade at the corner of Jackson Blvd. and LaSalle St. Mitigation operations will commence along LaSalle St. from Jackson Blvd. north four blocks to Monroe St. In establishing the bermed area to contain the wash waters, let us examine Figure A3. The length of Jackson Blvd. to Monroe St. in the figure is 2.8-3.0 in. (which scales to 270-290 m), depending on where the berms are set. A reservoir can be set along this section of the city to contain the wash waters generated within the bermed zone. The footprint is then approximately $290 \mathrm{~m} \times 20 \mathrm{~m}=5800 \mathrm{~m}^{2}$. The capacity for such a system, ignoring the pitch of the street, is calculated in Table A1.

The remaining pictures (Figs. A4-A21) provide different views of the flanking buildings, alleyways, catch basins, obstructions, and manhole and utility covers along this stretch of roadway. Logistical topics or questions remain, such as where exactly do we set up the berms (only at intersections or butted against the façades of the buildings around the entire perimeter shown in Fig. 3)? How do we prevent water from penetrating the manhole covers and catch basins? Where do we setup the tanks and separations equipment? The water that was initially treated with the clay will have residual cesium contamination and will likely require more than one treatment step before reuse, further treatment or storage, or injection into the sewer system. How do you clean the water more than once? Do we set up a series of ponds along one of the streets that allows water to be mixed with clay and then separated? Can we reuse the clay in these ponds as is practiced in banks of ion-exchange columns?

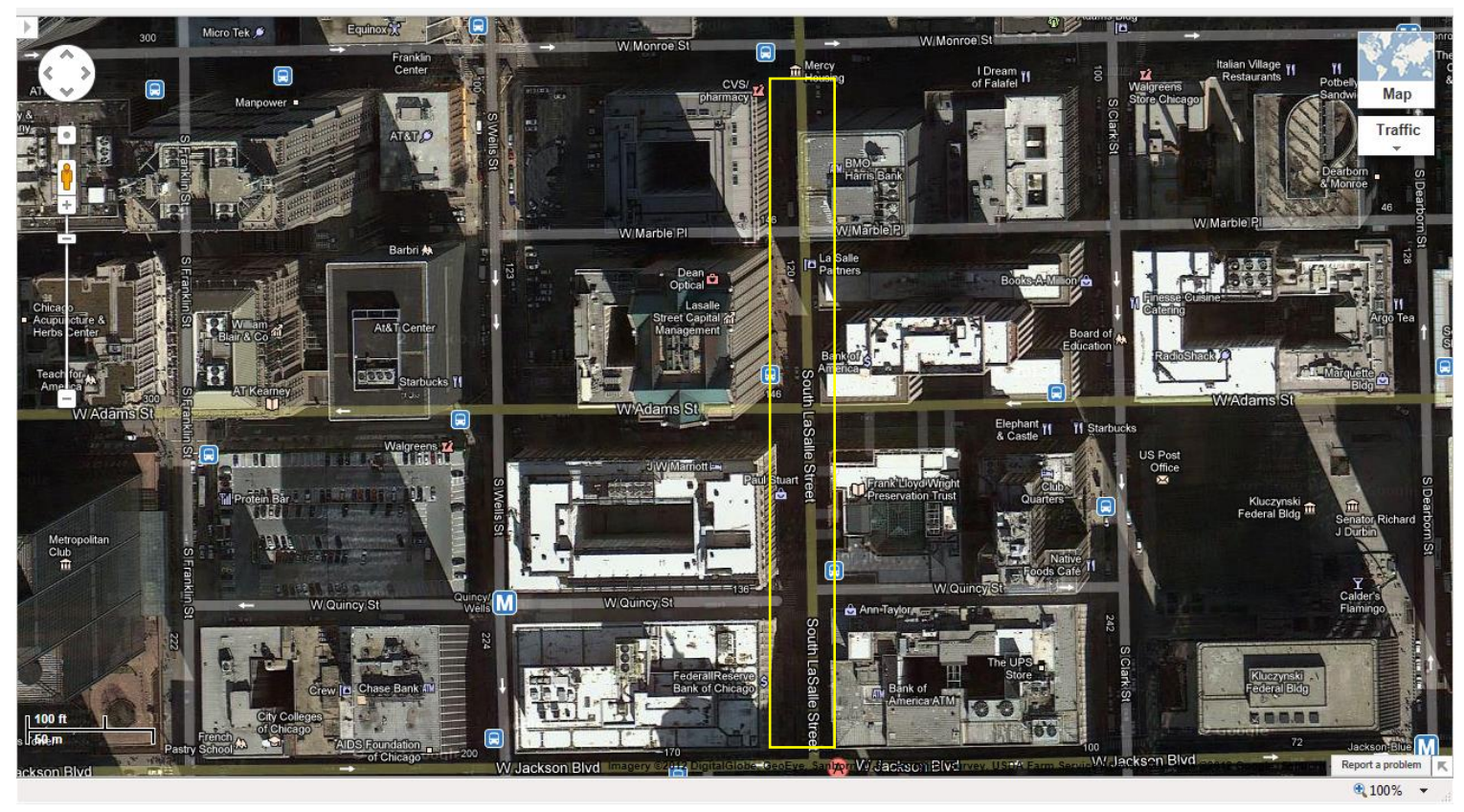

Figure A3. Outline of the hypothetical contamination mitigation zone. The scale is 0.52 in. per $50 \mathrm{~m}$ at the $45 \%$ scale for the original figure. 
Table A1. Simplified calculations of the size of the bermed area and capacity for wash water.

\begin{tabular}{ccc}
\hline $\begin{array}{c}\text { Average depth of } \\
\text { reservoir }(\mathbf{f t})\end{array}$ & $\begin{array}{c}\text { Volume of water } \\
\left.\mathbf{( m}^{\mathbf{3}}\right)\end{array}$ & $\begin{array}{c}\text { Volume of water } \\
\text { (gallons) }\end{array}$ \\
0.5 & 884 & 233,591 \\
1.0 & 1768 & 467,183 \\
1.5 & 2652 & 700,774 \\
2.0 & 3537 & 934,366 \\
3.0 & 5305 & $1,401,549$ \\
5.0 & 8841 & $2,335,915$ \\
\hline
\end{tabular}

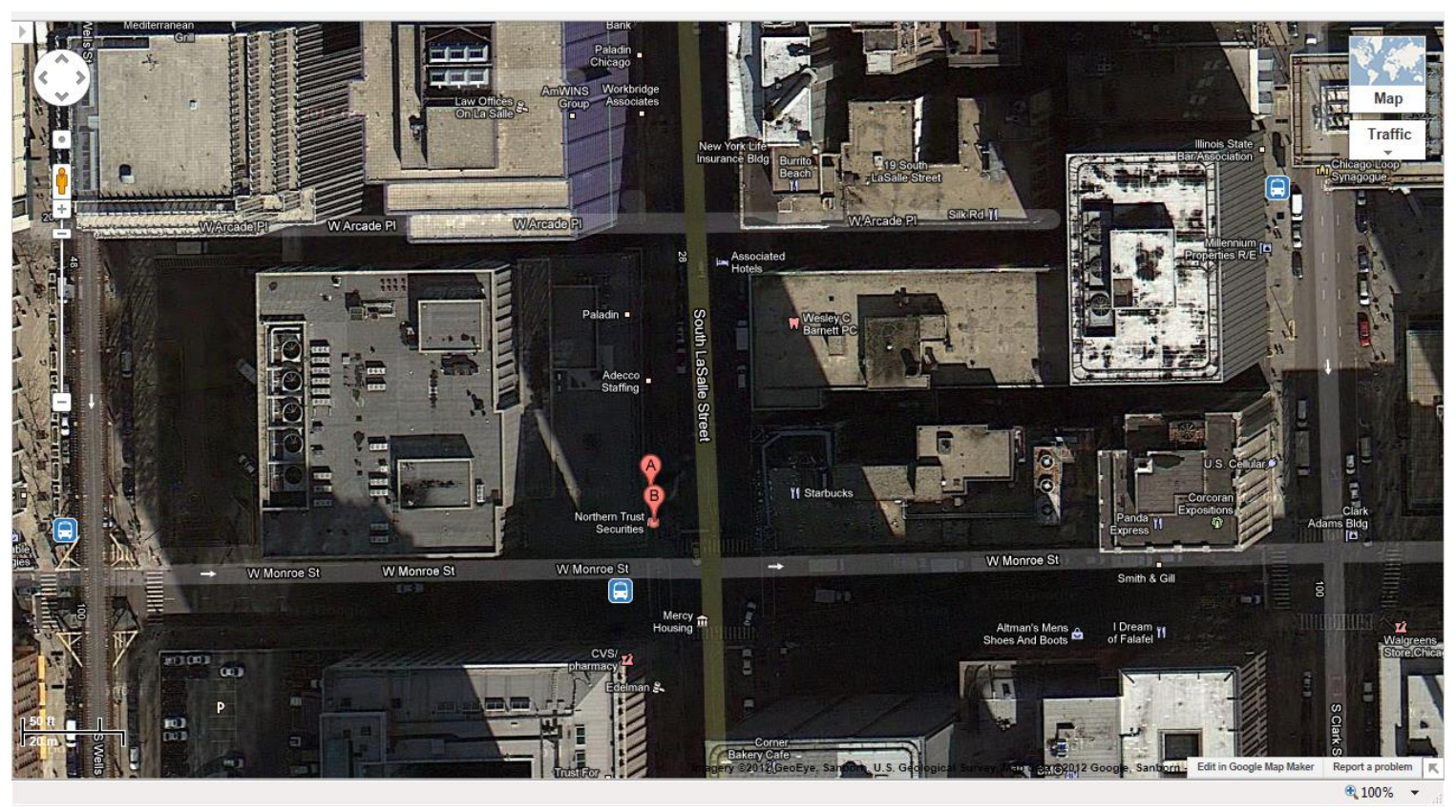

Figure A4. A barrier blocking S. LaSalle St. where it meets W. Monroe St. $(20 \mathrm{~m})$ and north crossing the side streets would provide a potential reservoir footprint of $5800 \mathrm{~m}^{2}$ (scale $20 \mathrm{~m}=0.42$ in.; side streets assumed 0.18 in. or $9 \mathrm{~m}$, major streets 0.42 in. or 20 $\mathrm{m})$. 


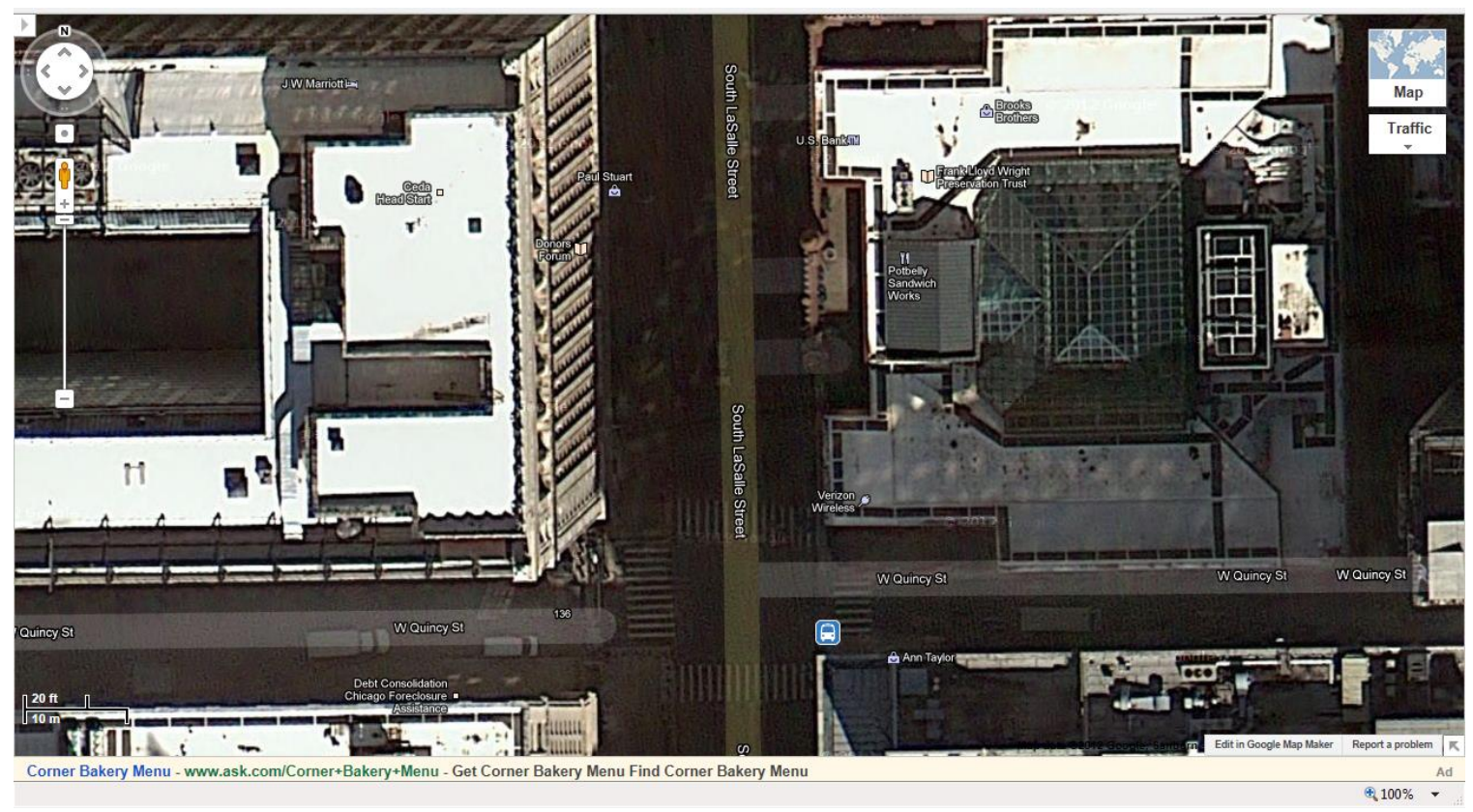

Figure A5. A closer look at the corner of W. Quincy St. and S. LaSalle St.

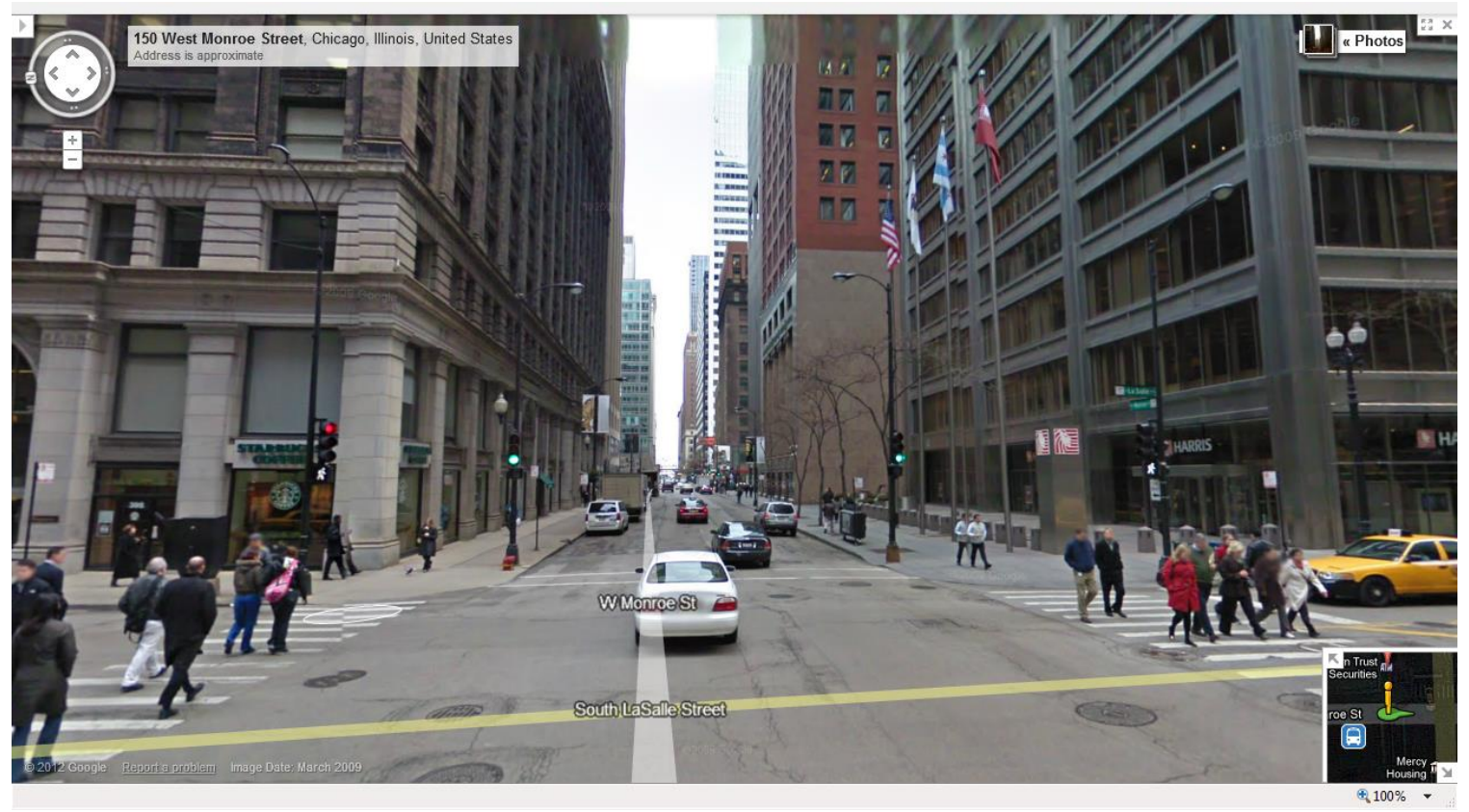

Figure A6. A view looking east down W. Monroe St. at the corner of S. LaSalle St. We must imagine setting up berms at the street level to collect the runoffs from the buildings. 


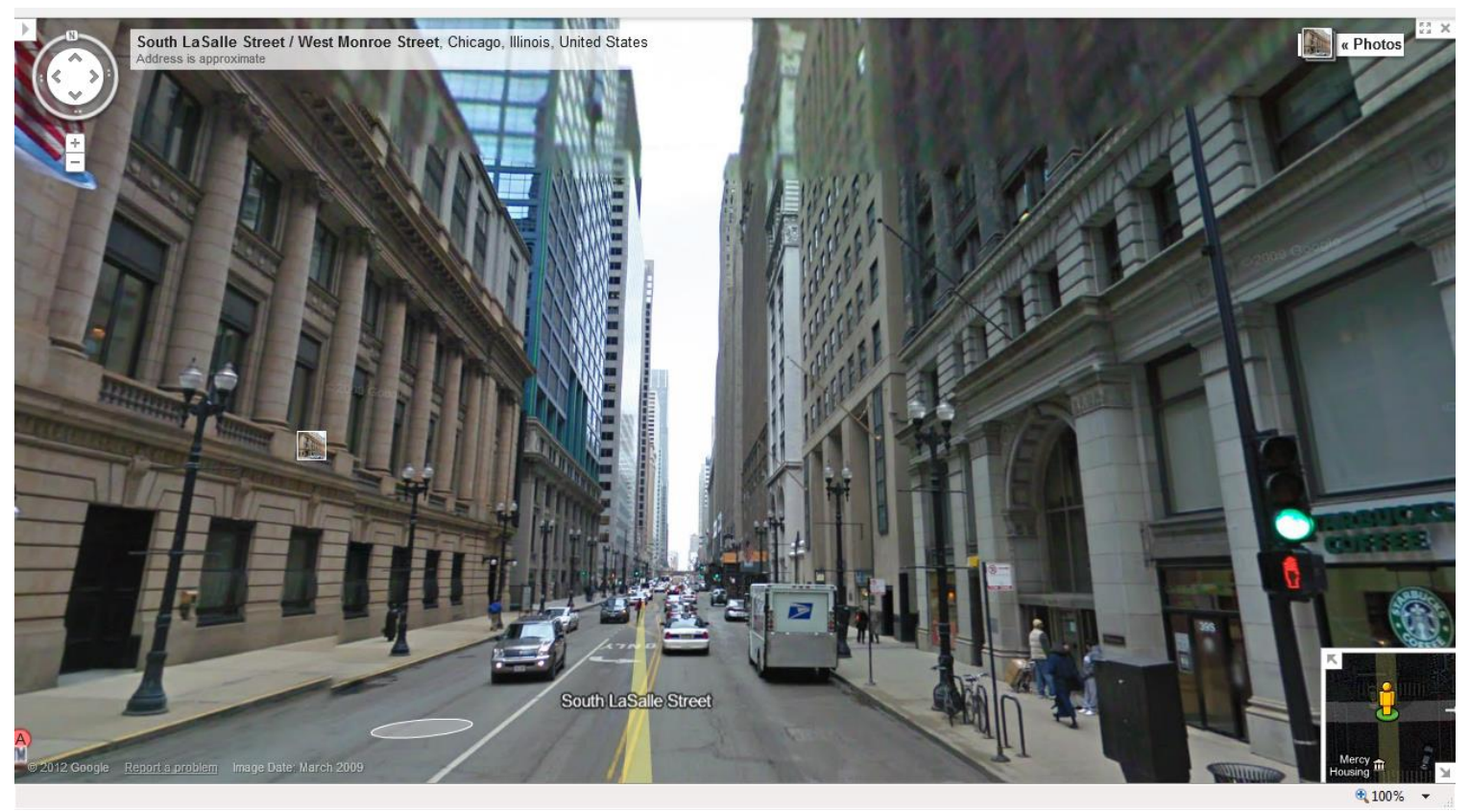

Figure A7. A view looking north down S. LaSalle St. at the corner of W. Monroe St.

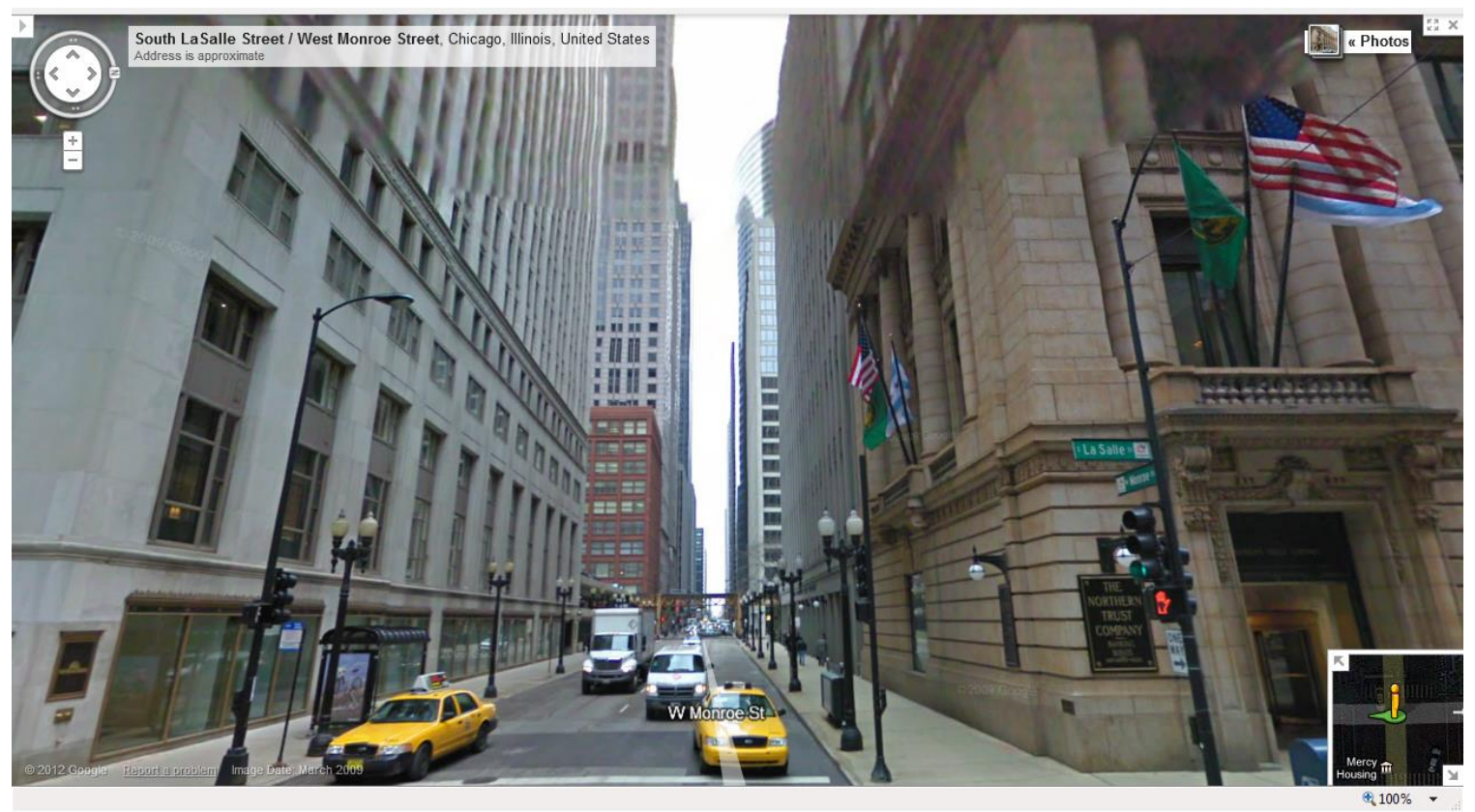

Figure A8. A view looking west down W. Monroe St. at the corner of S. LaSalle St. 


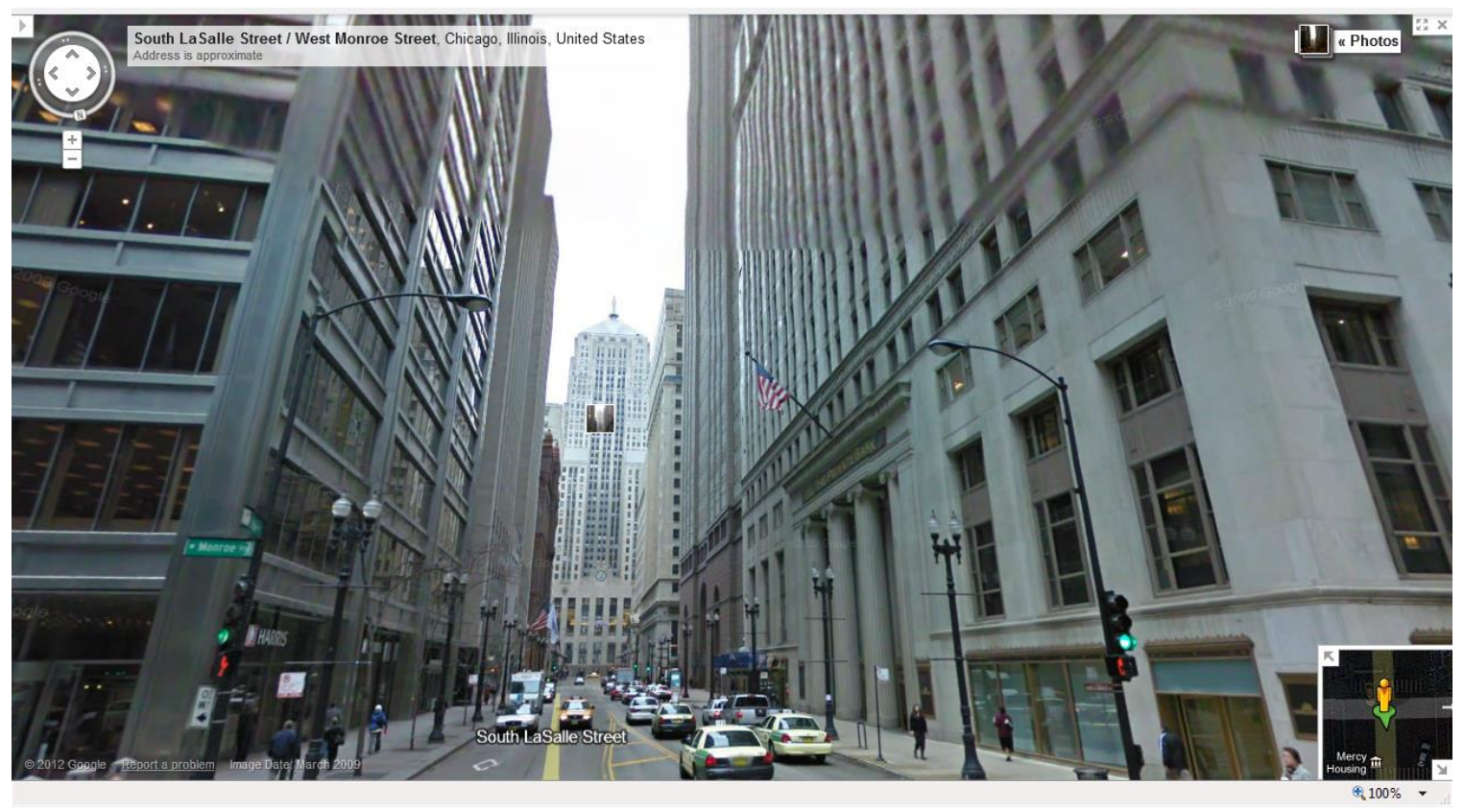

Figure A9. A view looking south down S. LaSalle St. toward W. Adams St.

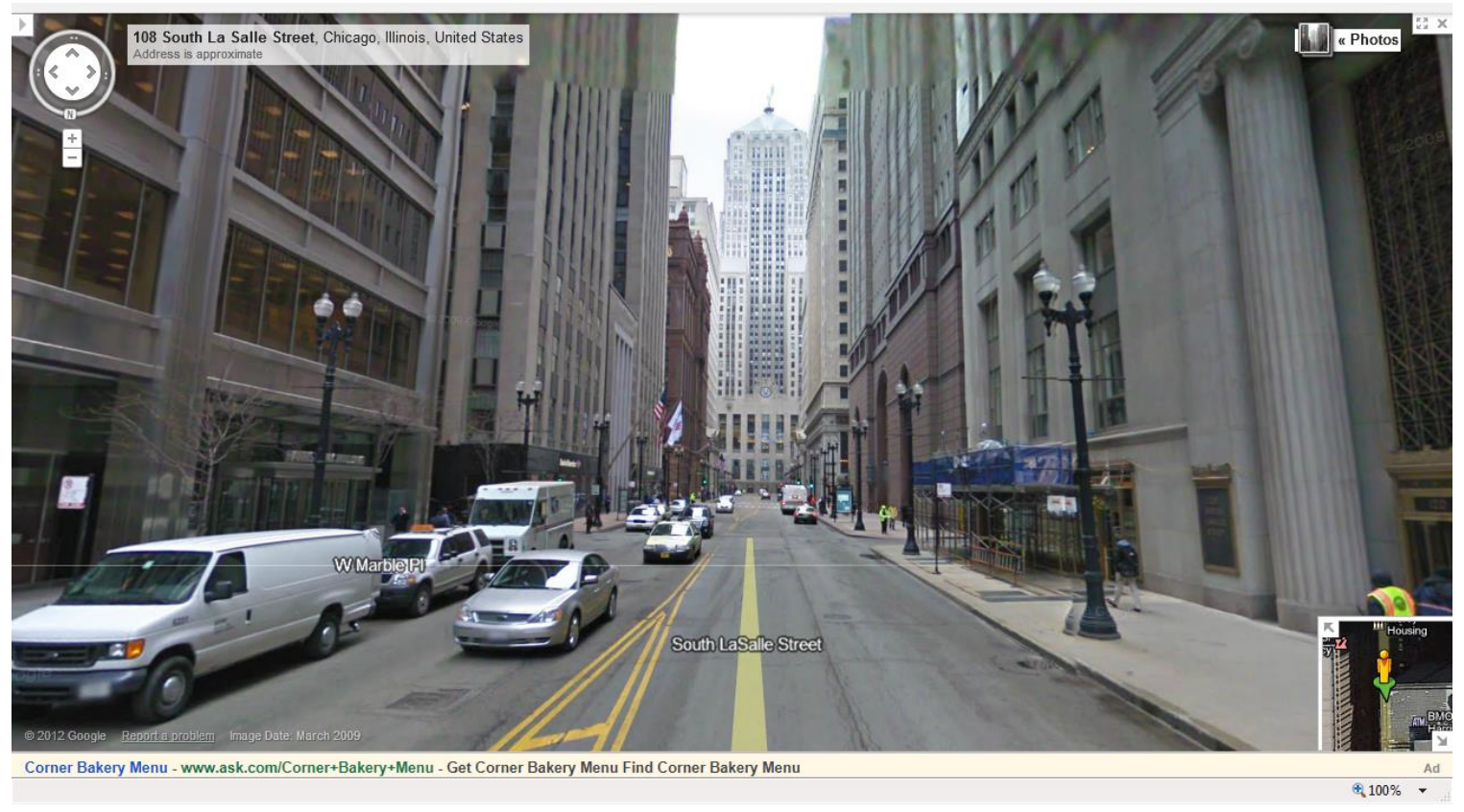

Figure A10. A view moving further south along S. LaSalle St. toward Jackson Blvd. 


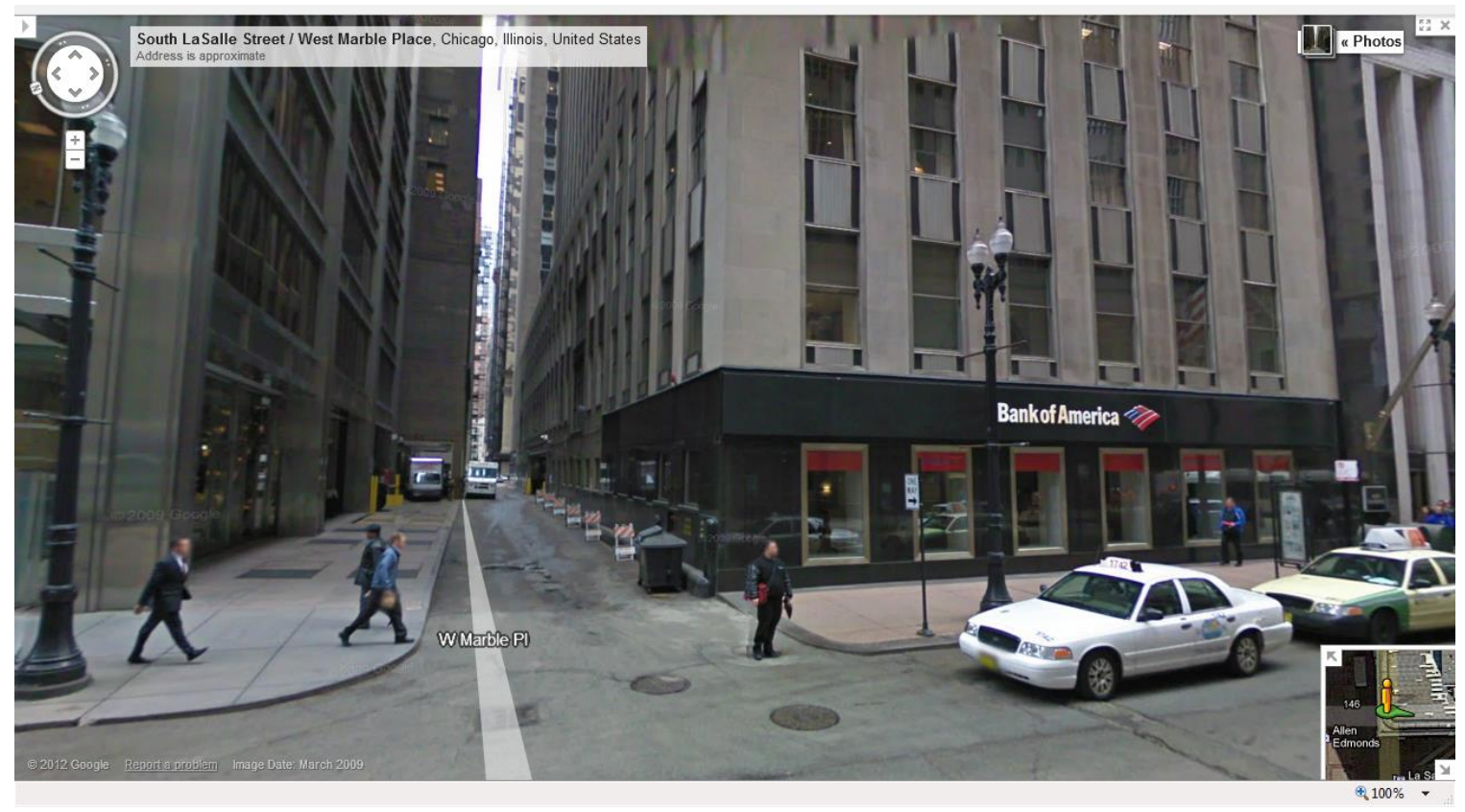

Figure A11. A view looking east down the $1^{\text {st }}$ alley at W. Marble Pl. and S. LaSalle in the financial district in Chicago.

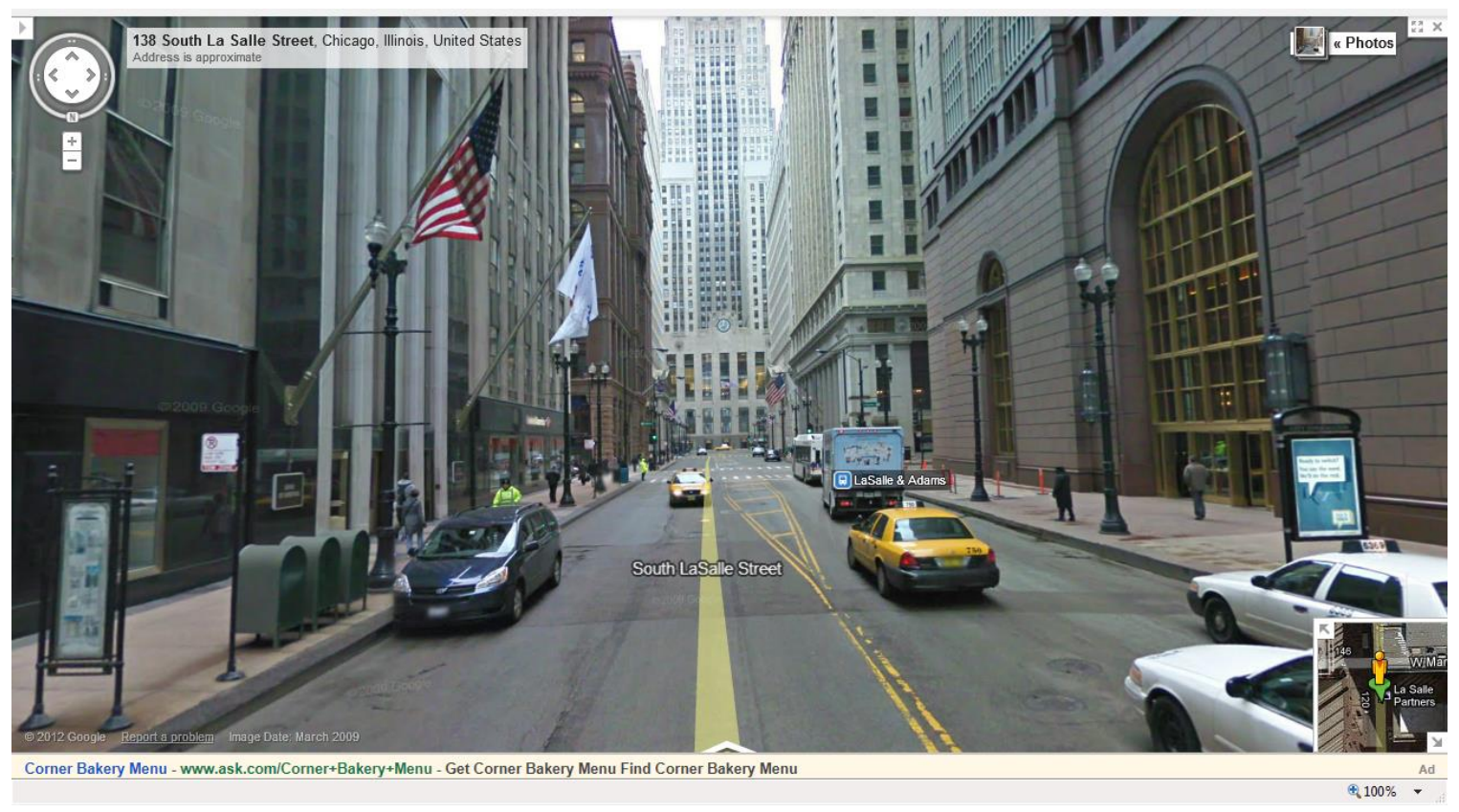

Figure A12. A view moving further south of W. Marble Pl. along S. LaSalle St. toward W. Adams St. 


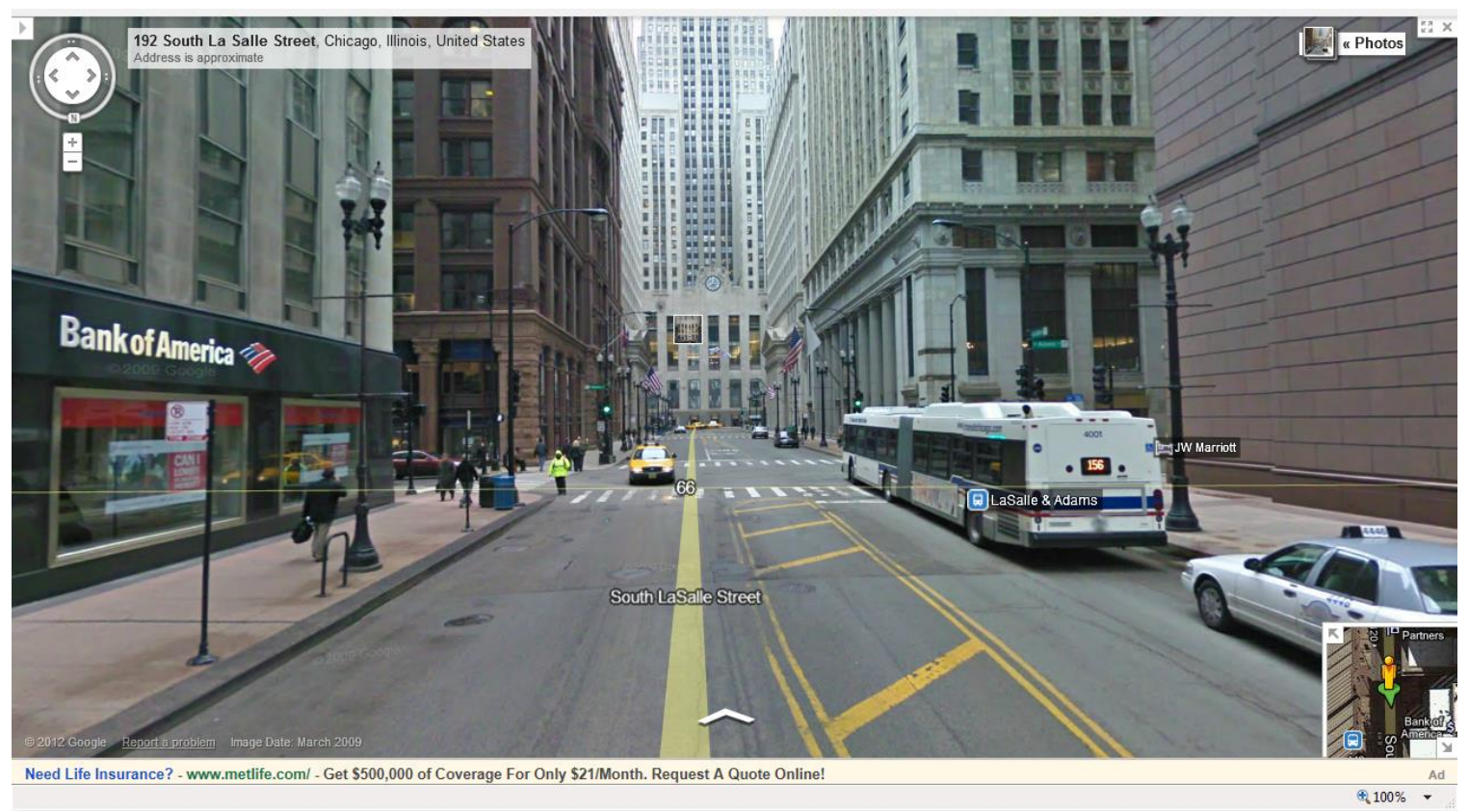

Figure A13. A view moving further south of W. Marble Pl. along S. LaSalle St. toward W. Adams St.

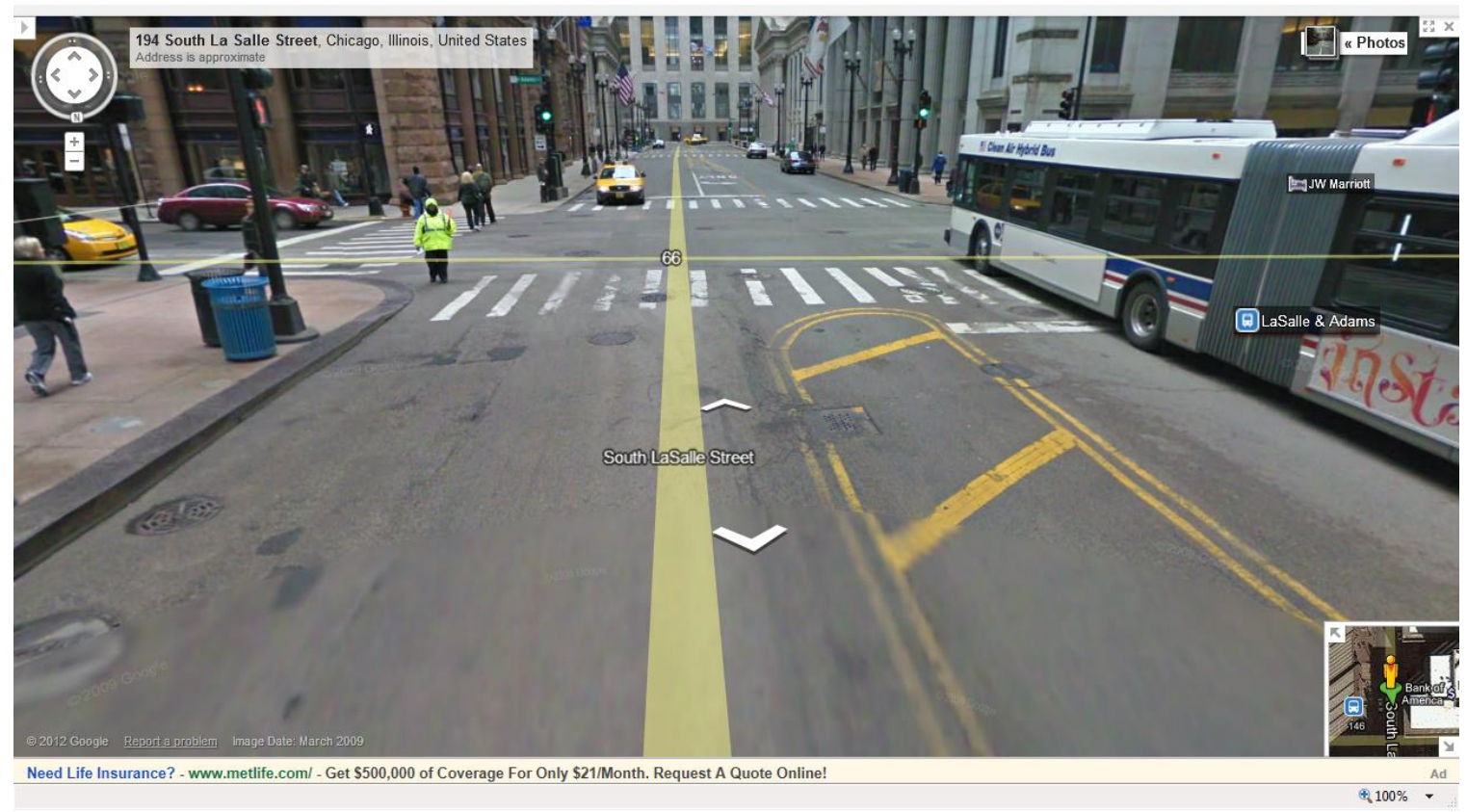

Figure A14. A view of approximately 20 sewer caps near and at the corner of S. LaSalle St. and W. Adams St. A significant number of these sewer caps are designed to allow water at the street level to enter. 


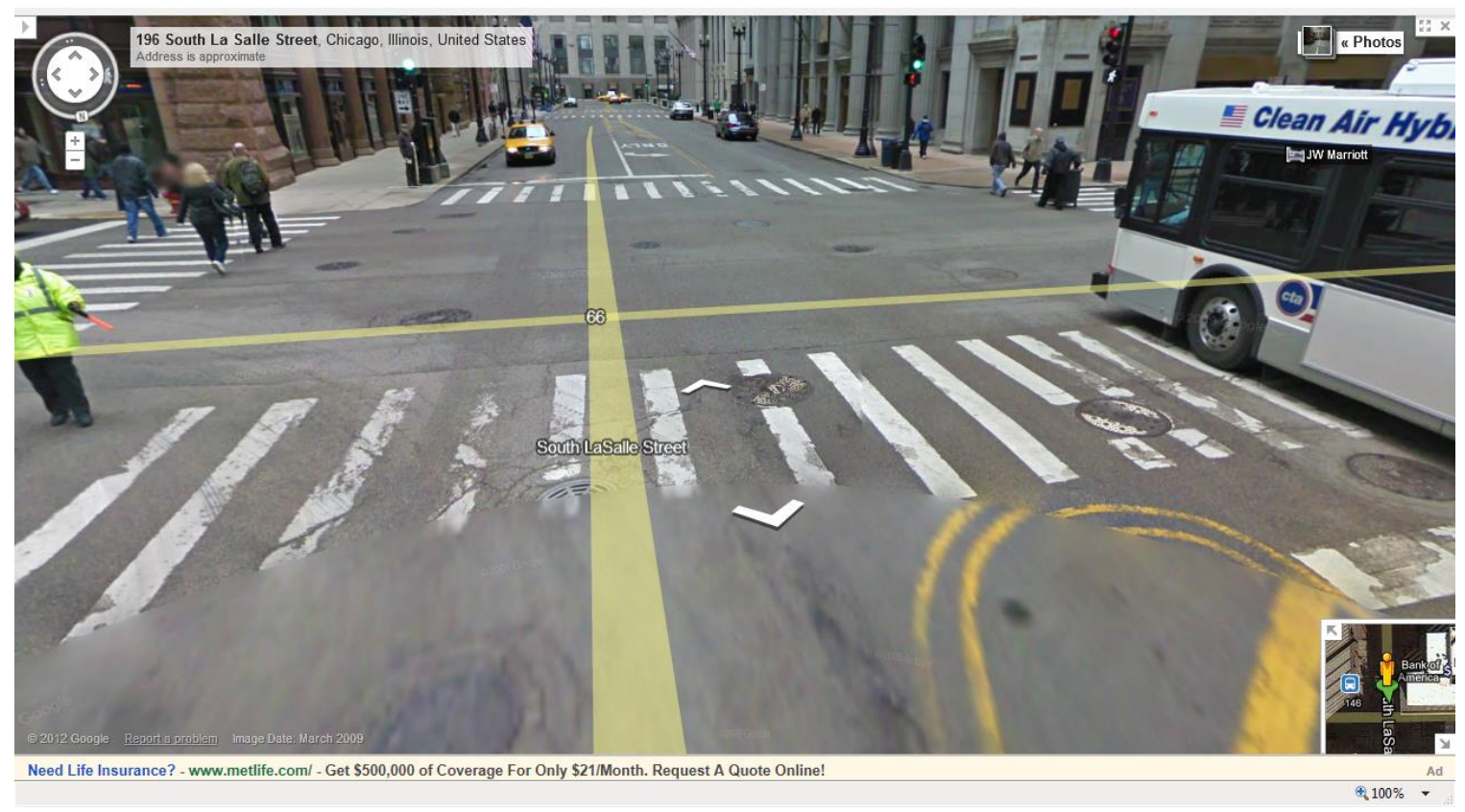

Figure A15. Another view of sewer caps at the corner of S. LaSalle St. and W. Adams St.

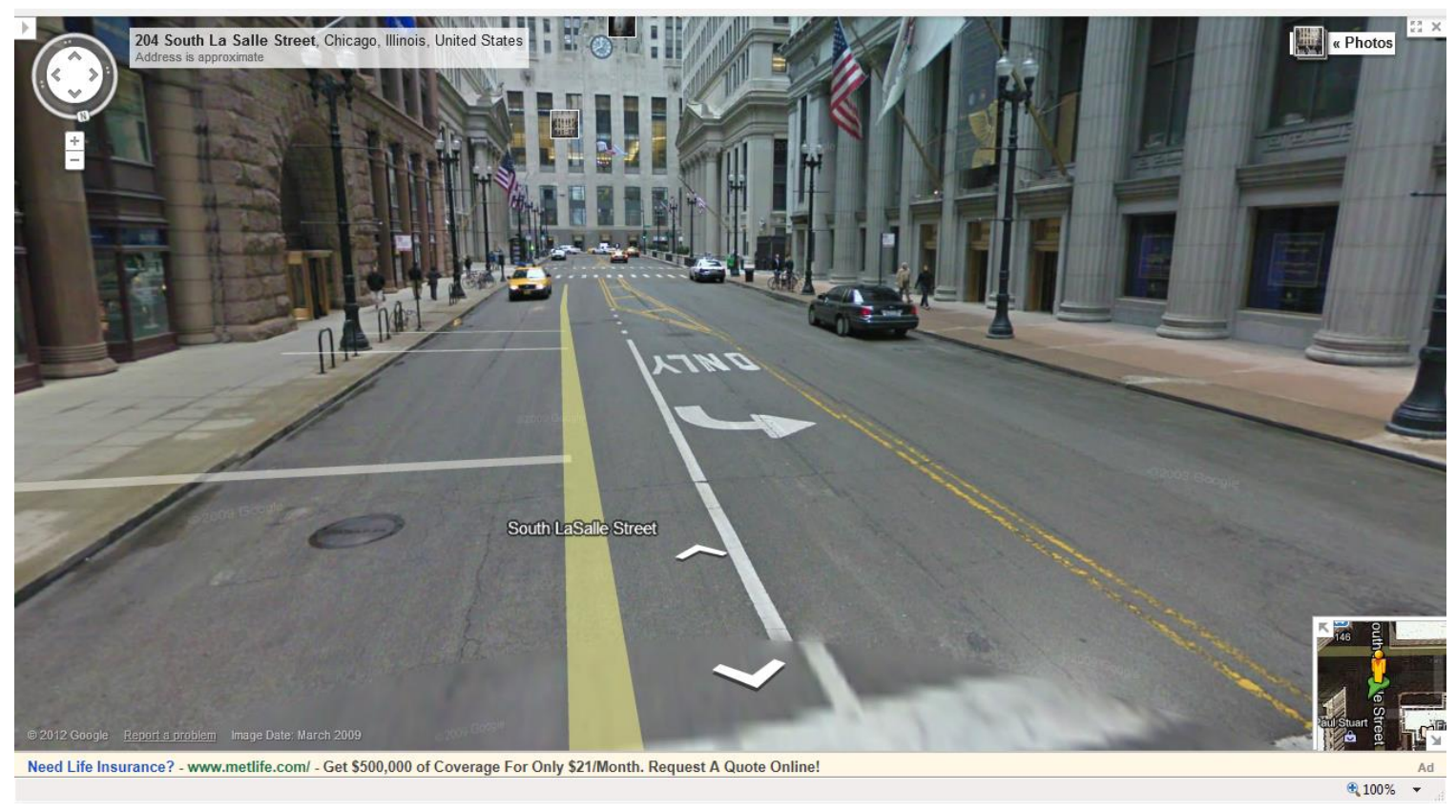

Figure A16. A view moving further south down S. LaSalle St. toward W. Quincy St. 


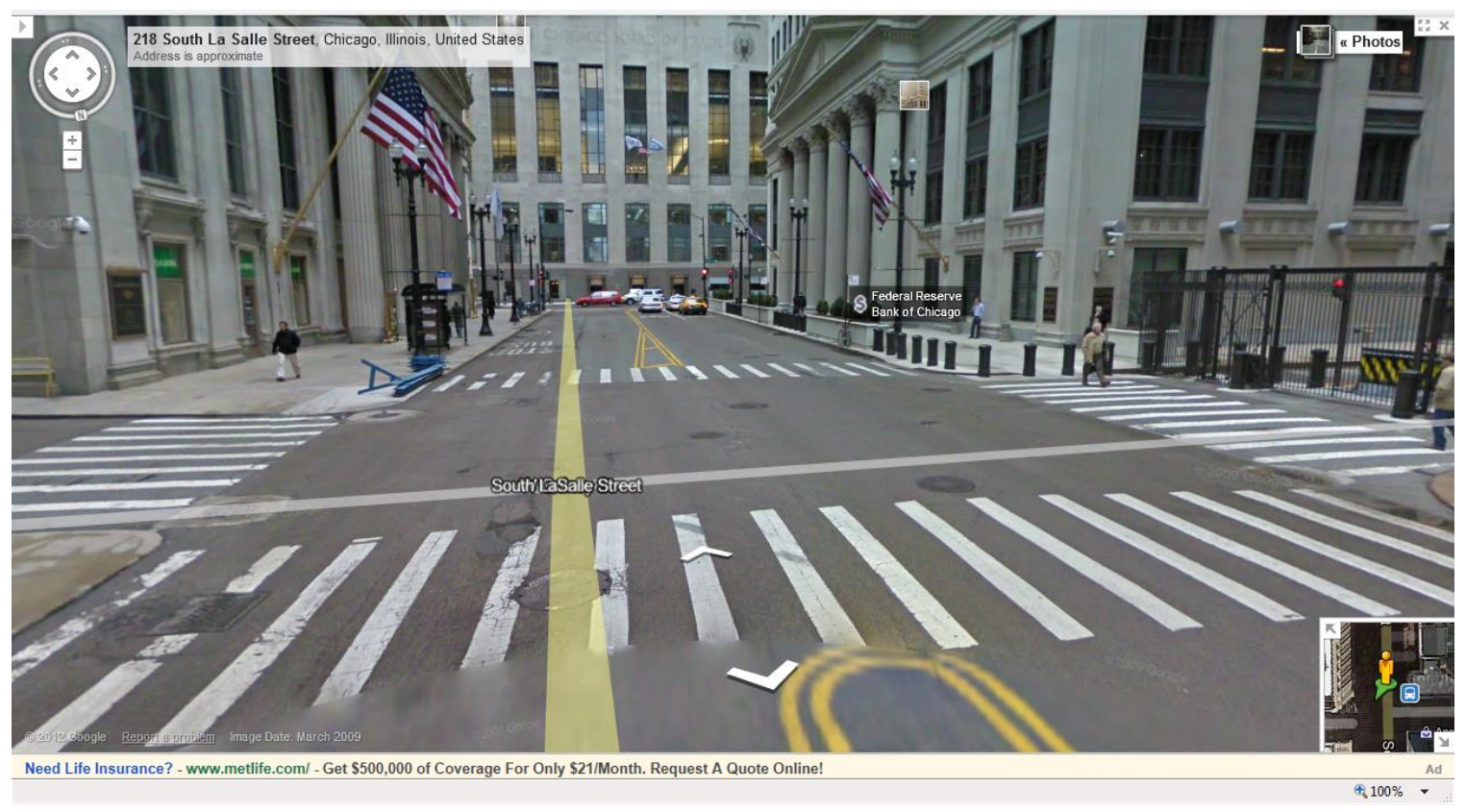

Figure A17. A view at the corner of W. Quincy St. and S. LaSalle St. looking south. Note the sewer caps.

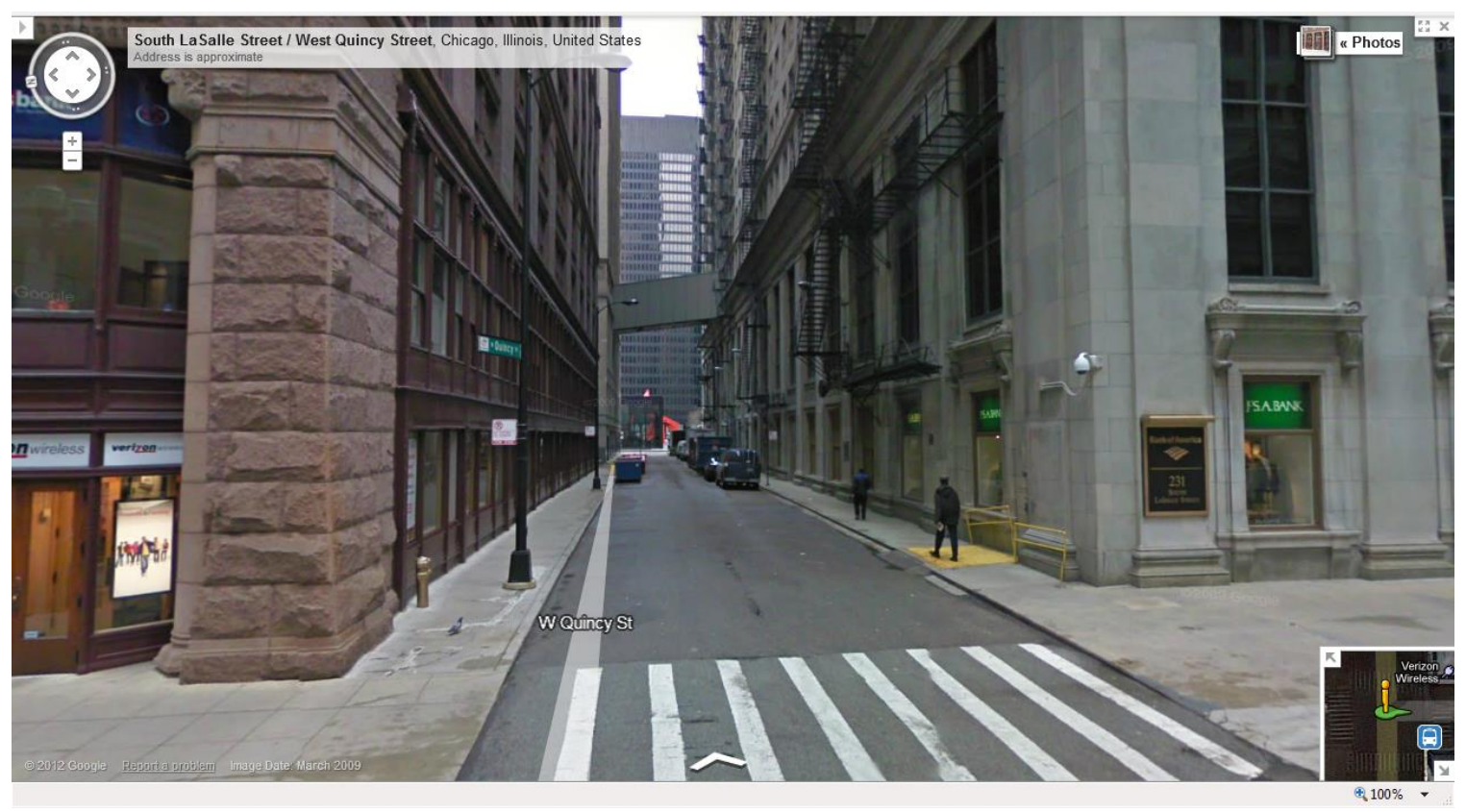

Figure A18. A view east down cross street (W. Quincy St.) off S. LaSalle St. 


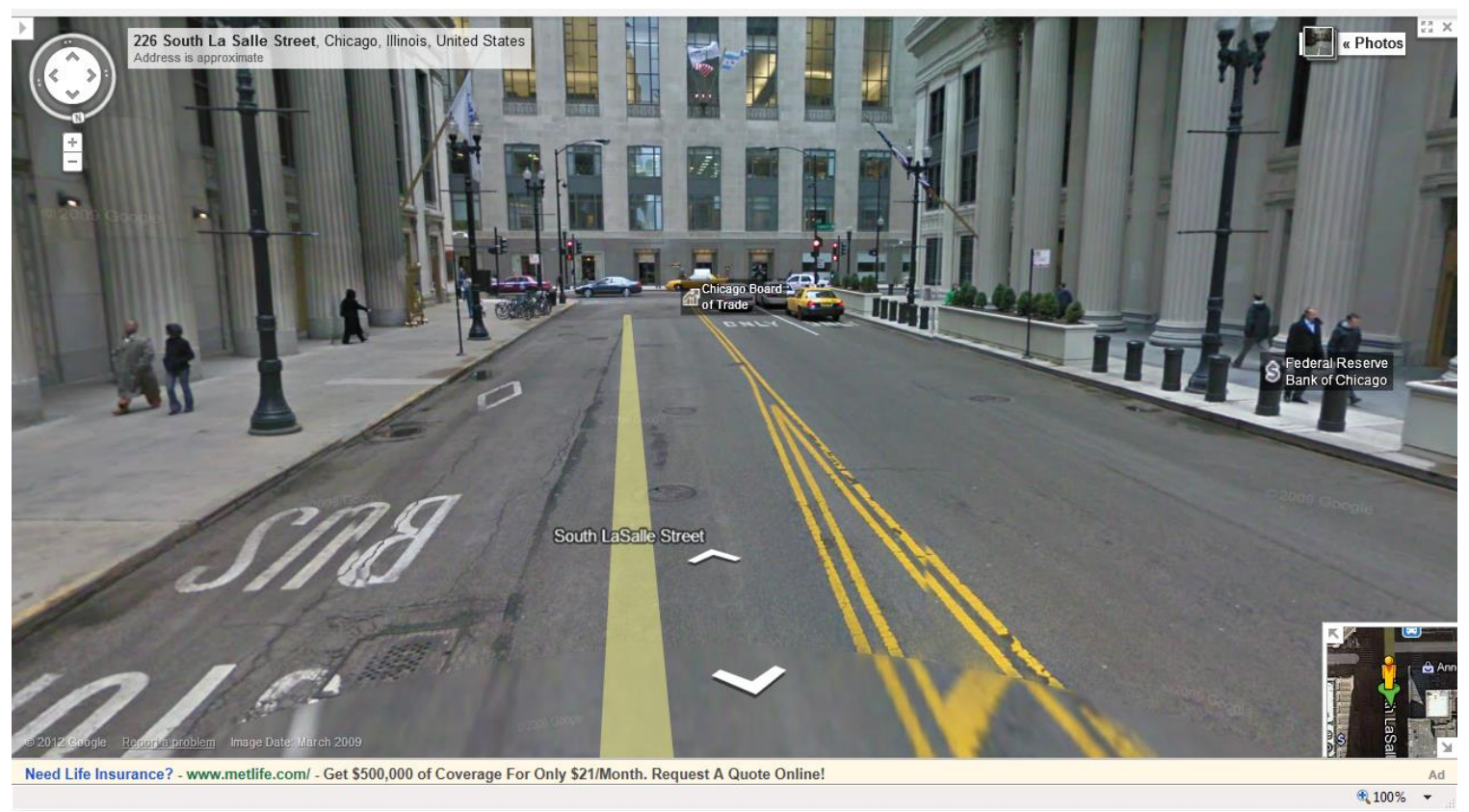

Figure A19. A view moving further south down S. LaSalle St. toward W. Jackson St.

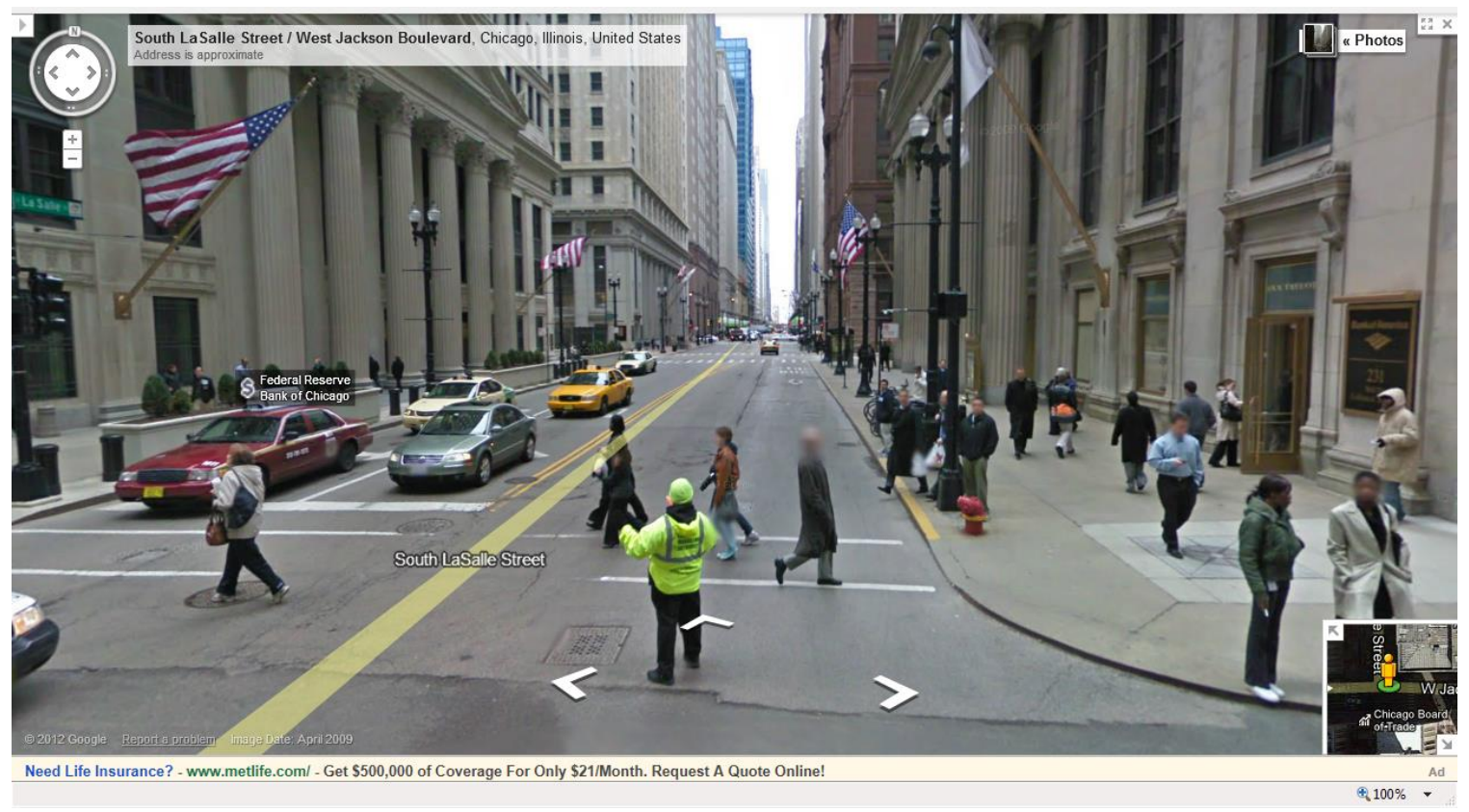

Figure A20. A view looking back north on S. LaSalle St. and W. Jackson Blvd. 


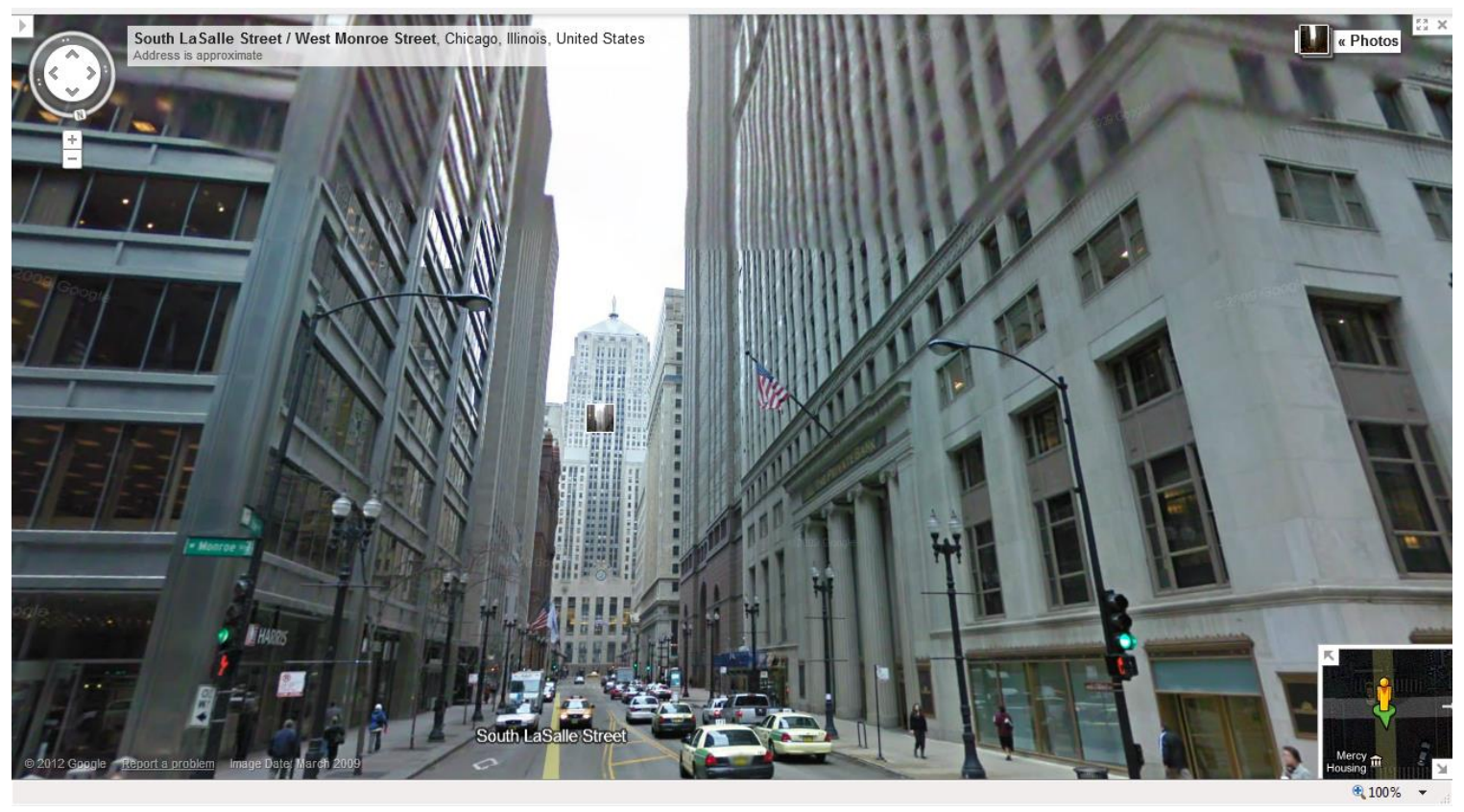

Figure A21. A view looking south down S. LaSalle St. toward W. Adams St. 


\section{APPENDIX B. SUMMARY OF DATA GATHERED ON POTENTIAL SEQUESTERING AGENTS FOR CESIUM FROM SALTY SOLUTION}

This table summarizes some of the sources we reviewed that describe solid sequestering agents for the removal of cesium from waters. These sources are just a fraction of the papers in the literature but represent those data relevant to sorption from salt solutions. Much of the impetus for performing such research in the past was to develop methods of removing cesium from high-level waste solutions at the Hanford Site and Savannah River Site. A key shortcoming to nearly all candidate sequestering agents is the intolerance to high salt solutions. Therefore, only a few agents cleared our downselection process. These are described in the body of this report. 


\begin{tabular}{|c|c|c|c|c|c|c|c|c|}
\hline Sorbent material & Element & $\begin{array}{c}\text { Concentration } \\
\text { of element }\end{array}$ & $\begin{array}{l}\mathrm{Kd} \mathrm{in} \mathrm{mL} / \mathrm{g} \text { (or other } \\
\text { units or \% sorbed) }\end{array}$ & $\begin{array}{c}\text { CEC (meq/ } \\
100 \mathrm{~g})\end{array}$ & $\begin{array}{l}\text { BET area }(\mathrm{m} 2 / \mathrm{g}) \\
\text { or Size (microns) }\end{array}$ & Solution Conditions & Reference & Notes \\
\hline $\begin{array}{l}\text { Magnetite, Goethite, Hematite, Limonite, } \\
\text { Ilmenite, Diaspore }(\mathrm{Al}(\mathrm{OH}) \mathrm{O}) \text {, Enstatite, } \\
\text { Quartz, Dolomite, bauxite called Mixed } \\
\text { Minerals (MM) }\end{array}$ & $\mathrm{Cs}(\mathrm{I})$ & $\begin{array}{l}\text { Tracer, } \\
\text { concentration } \\
\text { or activity not } \\
\text { stated }\end{array}$ & $\begin{array}{l}\text { Almost } 100 \% \\
\text { adsorption Cs and } \mathrm{Sr} \text { at } \\
200 \mathrm{mg} \text { solid loading } \\
\text { (no liq. Volume given) }\end{array}$ & $\begin{array}{c}35 \mathrm{~g} / \mathrm{kg} \mathrm{Cs} \\
(0.25 \mathrm{mmol}) \\
\text { loading capacity } \\
\text { and } 25 \mathrm{~g} / \mathrm{kg} \text { for } \\
\mathrm{Sr}(0.27 \mathrm{mmol} / \mathrm{g})\end{array}$ & $\begin{array}{c}80-100 \text { mesh }(0.044 \\
0.74 \text { mm) without } \\
\text { pretreatment }\end{array}$ & 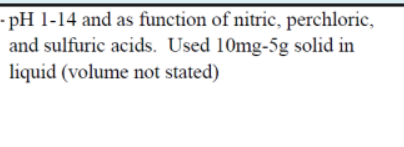 & Ahmad 1989 & $\begin{array}{l}\text { Adsorption of } 137 \mathrm{Cs} \text { and } 90 \mathrm{Sr} \text { radionuclides on MM from } \\
\text { aq. solns. is reported by describing the effect of } \\
\text { equilibration time. H ions, and adsorbent and adsorbate } \\
\text { concr. Optimum physicochem. conditions were identified. }\end{array}$ \\
\hline soil & $\mathrm{Cs}(\mathrm{I})$ & $?$ & $99 \%$ removal & & & & Spalding & $\begin{array}{l}\text { mix Cs } 137 \text { contaminated soil with chloride and heat }(800- \\
\left.1000^{\circ} \mathrm{C}\right) \text { for } 2 \mathrm{~h}\end{array}$ \\
\hline $\begin{array}{l}\text { askanite, gumbrin, nontronite, bentonite, } \\
\text { kaolin, phlogopite, biotite, muscorite, talcum, } \\
\text { vermiculite, glauconite, hydrophlogopite, } \\
\text { hydromuscovite, hydrogoethite, or virianite }\end{array}$ & $\mathrm{Cs}(\mathrm{I})$ & $\begin{array}{l}\text { details in } \\
\text { paper? }\end{array}$ & 66.5 to $99.9 \%$ & & & details in paper & Bakunov 1989 & $\begin{array}{l}\text { Increased sorption of } 137 \mathrm{Cs} \text { from } 37.1 \text { with only sand to } \\
\text { following with addition of } \sim 1 \text { wt } \% \text { minerals: } 99.9 \text {-askanite, } \\
\text { 99.9-gumbrin, } 99.9 \text {-nontronite, } 97.0 \text {-bentonite, } 95.6 \text {-kaolin, } \\
\text { 99.7-phlogopite, 97.3-biotite, } 94.5 \text {-muscorite, } 87.2 \text {-talcum, } \\
\text { 99.8-vermiculite, 98.3-glauconite, } 99.6 \text {-hydrophlogopite, } \\
\text { 88.9-hydromuscovite, 66.5-hydrogoethite, and } 98.9- \\
\text { virianite; } \text { NH4NO3, NaNO3, and Cs(NO3)2 also desorbed } \\
\text { 137Cs from minerals and the desorption increased as the } \\
\text { radius of the displacing ion approached the ionic radius of } \\
\text { 137Cs. }\end{array}$ \\
\hline $\begin{array}{l}\text { layered metal sulfides, KMS-1 (synthesized } \\
\text { material) }\end{array}$ & $\mathrm{Cs}(\mathrm{I})$ & $30-5 e 3 \mathrm{ppb}$ & 150 to 21,000 & $\begin{array}{l}226 \mathrm{mg} \mathrm{Cs} / \mathrm{g} \text { or } \\
1.7 \mathrm{mmol} \mathrm{Cs} / \mathrm{g}\end{array}$ & & $\begin{array}{l}\mathrm{t}=12 \mathrm{~h}, \mathrm{pH}=1-12, \mathrm{~V} / \mathrm{m}=50-1000 \mathrm{~mL} / \mathrm{g}, \mathrm{RT} \\
\text { molar ratios of } \mathrm{Na} / \mathrm{Cs}: 0-2 \mathrm{e} 4, \mathrm{Ca} / \mathrm{Cs}: 0-3 \mathrm{e} 3 \text { and } \\
\mathrm{Mg} / \mathrm{Cs}: 0-\mathrm{le} 3\end{array}$ & Manos 2009 & 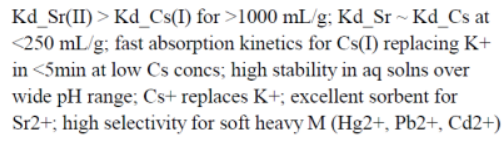 \\
\hline zeolites, sirconium-titanium silicates & & & & $\begin{array}{l}1.86 \text { to } 4.1 \\
\text { mmol Css }\end{array}$ & & & Manos 2009 & $\begin{array}{l}\text { most efficient Cs sorbents; refs therein [Moller et al. 2001, } \\
\text { J. Mater. Chem; Chang te al. } 1998 \text { Ind. Eng. Chem. Res.; } \\
\text { Bortun et al, 2000, Chem. Mater.; Clearfield et al. } 1998 \text { J. } \\
\text { Mol Struct } \text {. }\end{array}$ \\
\hline perlite & $\mathrm{Cs}(\mathrm{I})$ & & & & & & Rehspringer 2004 & $\begin{array}{l}\text { The present invention relates to treatment of chem. and } \\
\text { radioactive waste contg. cesium and or rubidium by } \\
\text { introducing it to the ceramic matrixes sintered contg. } \\
\text { expanded pearlite. The process includes primarily the } \\
\text { stages consisting in prepg. a soln. of salt of cesium and/or } \\
\text { rubidium; adding the expanded pearlite in desired quantity } \\
\text { in order to absorb the totality or near total of the prepd. } \\
\text { soln.; elimination solvent from the mass obtained; } \\
\text { precalcination the compd. of pearlite obtained to form the } \\
\text { powder of intermediate compd. prepd. at the preeceding } \\
\text { stages and carrying out the pearlite contg. cesium and or } \\
\text { rubidium. }\end{array}$ \\
\hline $\begin{array}{l}\text { bentonite clays (Na-form by treatmt w } \\
\text { Na2CO3, from Khakassiya deposit, Russia) }\end{array}$ & $\mathrm{Cs}(\mathrm{I})$ & $5.2 \mathrm{e}-5 \mathrm{M}$ & 15 to $90 \%$ & 27 & $\begin{array}{l}29 \mathrm{~m} 2 / \mathrm{g} ; 3.16 \mathrm{um}+ \\
50 \mathrm{~nm} \text { colloids }\end{array}$ & IS $=0.001$ to $0.1 \mathrm{M},[\mathrm{Cs}]=5.2 \mathrm{e}-5 \mathrm{M}, \mathrm{pH}=1.5$ to 10 & Sabodina 2006 & $\begin{array}{l}\text { Table } 1 \text { gives mineral composition of bentonite used }(70- \\
80 \% \text { montmorillonite) at } \mathrm{pH}>6 \text { and } \mathrm{I}=0.001 \mathrm{M},>90 \% \\
\text { sorbed; dec sorption at higher I and acidic conditions; } \\
\text { bentonite equilibrated soln: } 300 \mathrm{ppm} \mathrm{Na}+, 50 \mathrm{ppm} \\
\mathrm{CO} 3 \mathrm{HCO}, 45 \mathrm{ppm} \mathrm{SO} \text { (refer to Table } 2 \text { ), } \mathrm{NaClO} 4 \text { for I } \\
\text { adjustmt, } \mathrm{pH} \text { adjusted w } \mathrm{HCl} \text { or } \mathrm{NaOH} \text { sorption of } \mathrm{Cs} \\
\text { predominantly ion-exchg - strong dep on ionic strength; } \\
\text { also contains data for } \mathrm{Pu}\end{array}$ \\
\hline hydrous manganese oxide (synthesized matl) & $\mathrm{Cs}(\mathrm{I})$ & $\begin{array}{l}\text { le-2 to le- } 8 \mathrm{M} \\
+ \text { trace Cs134 }\end{array}$ & $1 e 3 \mathrm{~mL} / \mathrm{g}$ & & $120-170$ mesh & $0.1 \mathrm{~g}$ sorbent $10 \mathrm{~mL}$ soln, $\mathrm{t}=0-2 \mathrm{~h}, \mathrm{pH}=3.85$ & Mishra 2007 & \\
\hline hydrous stannic oxide (synthesized matl) & $\mathrm{Cs}(\mathrm{I})$ & 1e-2 to $1 \mathrm{e}-8 \mathrm{M}$ & $1 \mathrm{e} 3 \mathrm{~mL} / \mathrm{g}$ & & $120-170$ mesh & $0.1 \mathrm{~g}$ sorbent $10 \mathrm{~mL}$ soln, $\mathrm{t}=0-2 \mathrm{~h}, \mathrm{pH}=3.85$ & Mishra 2007 & \\
\hline
\end{tabular}




\begin{tabular}{|c|c|c|c|c|c|c|c|c|}
\hline Sorbent material & Element & $\begin{array}{l}\text { Concentration } \\
\text { of element }\end{array}$ & $\begin{array}{l}\mathrm{Kd} \text { in } \mathrm{mL} / \mathrm{g} \text { (or other } \\
\text { units or } \% \text { sorbed }\end{array}$ & CEC (meq/ & $\begin{array}{r}\text { BET area }(\mathrm{m} 2 / \mathrm{g}) \\
\text { or Size (microns) }\end{array}$ & Solution Conditions & Reference & Notes \\
\hline $\begin{array}{l}\text { bentonite (Na0.3(AlMg)2Si4O10(OH)2- } \\
\text { 4H2O) and pink granite }\end{array}$ & $\mathrm{Cs}(\mathrm{I})$ & $\begin{array}{l}\text { tracer to } 0.01 \mathrm{M} \\
\mathrm{Cs} \mathrm{Sr} \text { tracer to } \\
10^{0}-5 \mathrm{M} \mathrm{Am} .\end{array}$ & $\begin{array}{c}\mathrm{Kd}(\mathrm{Cs}- \\
\text { bentonite }=-600 \mathrm{~mL} / \mathrm{g} ; \\
\mathrm{Kd}(\mathrm{Cs}- \\
\text { granite })=24 \mathrm{~mL} / \mathrm{g} \text { at } \\
\mathrm{pH} 7-8, \text { increases at } \\
\mathrm{pH}>9 . \mathrm{Kd}(\mathrm{Am}- \\
\text { bentonite }=-4000 \mathrm{~mL} / \mathrm{g} \\
\text { at } \mathrm{pH} 7-8 . \mathrm{Kd}(\mathrm{Cs}- \\
\text { bentonite })=\sim 110 \mathrm{~mL} / \mathrm{g} \\
\text { at } 0.5 \mathrm{M} \mathrm{Na}+/ \mathrm{Ca} 2+.\end{array}$ & $\begin{array}{c}0.72 \text { and } 0.33 \\
\mathrm{mmol} / \mathrm{g} \text { for } \mathrm{Cs} \\
\text { and } \mathrm{Sr} \text { sorption } \\
\text { capacity by } \\
\text { Langmuir }\end{array}$ & $\begin{array}{l}\text { Bentonite fine } \\
\text { powder, granite } 70 \text { - } \\
100 \text { mesh }\end{array}$ & $\begin{array}{l}400: 1 \text { to } 20: 1 \text { volume to mass ratio for borehole } \\
\text { water with pH 2-10.0.01M to } 0.5 \mathrm{M} \text { salt }\end{array}$ & Murali 2002 & $\begin{array}{l}\text { Studied ability of backfill and host granite host rock to sorb } \\
\text { radionuclides. } 30 \mathrm{~min} \text { to reach equilirbium for bentonite } \\
\text { and Cs. } 60 \mathrm{~min} \text { for granite. }\end{array}$ \\
\hline cements & $\mathrm{Cs}(\mathrm{I})$ & & $0.1-100$ & & & & McKinley 1993 & reported Kd as $1 \mathrm{le}-4$ to $0.1 \mathrm{~m} 3 / \mathrm{kg}$ \\
\hline soil/surface sediments & $\mathrm{Cs}(\mathrm{I})$ & & 10,000 & & & & McKinley 1993 & reported $\mathrm{Kd}$ as $10 \mathrm{~m} 3 \mathrm{~kg}$ \\
\hline $\begin{array}{l}\text { montmorillonite, No. } 11 \text { (sodium saturated } \\
\text { form, Santa Rita, NM deposits) }\end{array}$ & $\mathrm{Cs}(\mathrm{I})$ & $\begin{array}{l}10^{-10}-0.1 \mathrm{~N}+ \\
\text { trace Css } 137\end{array}$ & $\begin{array}{l}50,000[\text { low Na+Cs }] \\
10[\text { hi Cs+Na] }\end{array}$ & 116 & $<100$ mesh & $\begin{array}{l}\mathrm{V} / \mathrm{m}=10 \mathrm{~mL} / \mathrm{g}, 100 \mathrm{mg} \text { clay } / 10 \mathrm{~mL},[\mathrm{Na}]=0.2- \\
0.002 \mathrm{~N}, \mathrm{t}=12 \mathrm{~h}, \mathrm{pH}=?\end{array}$ & Wahlberg 1962 & 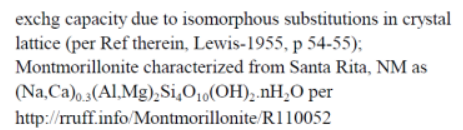 \\
\hline $\begin{array}{l}\text { montmorillonite, No. } 11 \text { (potassium saturated } \\
\text { form, Santa Rita, NM deposits) }\end{array}$ & $\mathrm{Cs}(\mathrm{I})$ & $\begin{array}{l}10^{-10}-0.1 \mathrm{~N}+ \\
\text { trace Css } 137\end{array}$ & $\begin{array}{l}30,000[\text { low Cs+K] } \\
10[\text { hi Cs+K] }\end{array}$ & 116 & $<100$ mesh & $100 \mathrm{mg}$ clay/ $10 \mathrm{~mL},[\mathrm{~K}]=0.2-0.002 \mathrm{~N}, \mathrm{t}=12 \mathrm{~h}$ & Wahlberg 1962 & $\begin{array}{l}\text { exchy capacity due to isomorphous substitutions in crystal } \\
\text { lattice (per Ref therein, Lewis-1955, p 54-55) }\end{array}$ \\
\hline $\begin{array}{l}\text { montmorillonite, No. } 11 \text { (Mg saturated form, } \\
\text { Santa Rita, NM deposits) }\end{array}$ & $\mathrm{Cs}(\mathrm{I})$ & $\begin{array}{l}10^{-10}-0.1 \mathrm{~N}+ \\
\text { trace Css137 }\end{array}$ & $\begin{array}{c}7,000[\text { low Cs+Mg] } \\
10[\text { hi Cs+Mg] }\end{array}$ & 116 & $<100$ mesh & $\begin{array}{l}\mathrm{V} / \mathrm{m}=100 \mathrm{~mL} / \mathrm{g}, 100 \mathrm{mg} \text { clay } / 10 \mathrm{~mL},[\mathrm{Mg}]=0.2- \\
0.002 \mathrm{~N}, \mathrm{t}=12 \mathrm{~h}\end{array}$ & Wahlberg 1962 & $\begin{array}{l}\text { exchg capacity due to isomorphous substitutions in crystal } \\
\text { lattice (per Ref therein, Lewis-1955, p } 54-55 \text { ) }\end{array}$ \\
\hline $\begin{array}{l}\text { montmorillonite, No. } 11 \text { (Ca saturated form, } \\
\text { Santa Rita, NM deposits) }\end{array}$ & $\operatorname{Cs}(\mathrm{I})$ & $\begin{array}{l}10^{-10}-0.1 \mathrm{~N}+ \\
\text { trace Cs } 137\end{array}$ & $\begin{array}{c}\text { 3,000 [low Cs+Ca] } 10 \\
{\left[\begin{array}{ll}\text { hi Cs+Ca] } \\
\text { Cs }\end{array}\right.}\end{array}$ & 116 & $<100$ mesh & $\begin{array}{l}\mathrm{V} / \mathrm{m}=100 \mathrm{~mL} / \mathrm{g}, 100 \mathrm{mg} \text { clay } / 10 \mathrm{~mL},[\mathrm{Ca}]=0.2- \\
0.002 \mathrm{~N}, \mathrm{t}=12 \mathrm{~h}\end{array}$ & Wahlberg 1962 & $\begin{array}{l}\text { exchg capacity due to isomorphous substitutions in crystal } \\
\text { lattice (per Ref therein, Lewis-1955, p 54-55) }\end{array}$ \\
\hline $\begin{array}{l}\text { montmorillonite, No. } 21 \text { (sodium saturated } \\
\text { form, Burns, MI deposits) }\end{array}$ & $\mathrm{Cs}(\mathrm{I})$ & $\begin{array}{l}10^{-10}-0.1 \mathrm{~N}+ \\
\text { trace Cs } 137\end{array}$ & $\begin{array}{c}20,000[\text { low Na+Cs }] 10 \\
{[\text { hi Na+Cs] }}\end{array}$ & 130 & $<100$ mesh & $\begin{array}{l}\mathrm{V} / \mathrm{m}=100 \mathrm{~mL} / \mathrm{g}, 100 \mathrm{mg} \text { clay } / 10 \mathrm{~mL},[\mathrm{Na}]=0.2- \\
0.002 \mathrm{~N}, \mathrm{t}=12 \mathrm{~h}\end{array}$ & Wahlberg 1962 & $\begin{array}{l}\text { exchg capacity due to isomorphous substitutions in crystal } \\
\text { lattice (per Ref therein, Lewis-1955, p 54-55) }\end{array}$ \\
\hline $\begin{array}{l}\text { montmorillonite, No. } 21 \text { (potassium saturated } \\
\text { form, Burns, MI deposits) }\end{array}$ & $\mathrm{Cs}(\mathrm{I})$ & $\begin{array}{l}10^{-10}-0.1 \mathrm{~N}+ \\
\text { trace Cs } 137\end{array}$ & $\begin{array}{c}30,000[\text { [low } \mathrm{Cs}+\mathrm{K}] \\
10[\mathrm{hi} \mathrm{Cs}+\mathrm{K}]\end{array}$ & 130 & $<100$ mesh & $100 \mathrm{mg}$ clay $/ 10 \mathrm{~mL},[\mathrm{~K}]=0.2-0.002 \mathrm{~N}, \mathrm{t}=12 \mathrm{~h}$ & Wahlberg 1962 & $\begin{array}{l}\text { exchg capacity due to isomorphous substitutions in crystal } \\
\text { lattice (per Ref therein, Lewis-1955, p 54-55) }\end{array}$ \\
\hline $\begin{array}{l}\text { montmorillonite, No, } 21 \text { (magnesium } \\
\text { saturated form, Burns, MI deposits) }\end{array}$ & $\mathrm{Cs}(\mathrm{I})$ & $\begin{array}{l}10^{-10}-0.1 \mathrm{~N}+ \\
\text { trace Cs137 }\end{array}$ & $\begin{array}{l}2,000[\text { low } \mathrm{Cs}+\mathrm{Mg}] \\
10[\mathrm{hi} \mathrm{Cs}+\mathrm{Mg}]\end{array}$ & 130 & $<100$ mesh & $\begin{array}{l}\mathrm{V} / \mathrm{m}=100 \mathrm{~mL} / \mathrm{g}, 100 \mathrm{mg} \text { clay } / 10 \mathrm{~mL},[\mathrm{Mg}]=0.2- \\
0.002 \mathrm{~N}, \mathrm{t}=12 \mathrm{~h}\end{array}$ & Wahlberg 1962 & $\begin{array}{l}\text { exchg capacity due to isomorphous substitutions in crystal } \\
\text { lattice (per Ref therein, Lewis-1955, p 54-55) }\end{array}$ \\
\hline $\begin{array}{l}\text { montmorillonite, No. } 21 \text { (calcium saturated } \\
\text { form, Burns, MI deposits) }\end{array}$ & $\mathrm{Cs}(\mathrm{I})$ & $\begin{array}{l}10^{-10}-0.1 \mathrm{~N}+ \\
\text { trace Cs } 137\end{array}$ & $\begin{array}{c}\text { 3,000[low Cs+Ca] } 10 \\
\quad[\text { hi Cs+Ca] }\end{array}$ & 130 & $<100$ mesh & $\begin{array}{l}\mathrm{V} / \mathrm{m}=100 \mathrm{~mL} / \mathrm{g}, 100 \mathrm{mg} \text { clay } / 10 \mathrm{~mL},[\mathrm{Ca}]=0.2- \\
0.002 \mathrm{~N}, \mathrm{t}=12 \mathrm{~h}\end{array}$ & Wahlberg 1962 & $\begin{array}{l}\text { exchg capacity due to isomorphous substitutions in crystal } \\
\text { lattice (per Ref therein, Lewis-1955, p 54-55) }\end{array}$ \\
\hline $\begin{array}{l}\text { illite, No. } 35 \text { (sodium saturated form, Fithian, } \\
\text { IL deposits) }\end{array}$ & $\mathrm{Cs}(\mathrm{I})$ & $\begin{array}{l}10^{-10}-0.1 \mathrm{~N}+ \\
\text { trace Css137 }\end{array}$ & $\begin{array}{c}200,000[\text { low Cs+Na] } 2 \\
{[\text { hi Cs+Na] }}\end{array}$ & 15 & $<100$ mesh & $\begin{array}{l}\mathrm{V} / \mathrm{m}=100 \mathrm{~mL} / \mathrm{g}, 100 \mathrm{mg} \text { clay } / 10 \mathrm{~mL},[\mathrm{Na}]=0.2- \\
0.002 \mathrm{~N}, \mathrm{t}=12 \mathrm{~h}\end{array}$ & Wahlberg 1962 & $\begin{array}{l}\text { exchy capacity due to isomorphous substitutions in the } \\
\text { crystal lattice and to broken bonds at edges of clay particles } \\
\text { (per Ref therein Grim-1953, 132-133) }\end{array}$ \\
\hline $\begin{array}{l}\text { illite, No. } 35 \text { (potassium saturated form, } \\
\text { Fithian, IL deposits) }\end{array}$ & $\mathrm{Cs}(\mathrm{I})$ & $\begin{array}{l}10^{-10}-0.1 \mathrm{~N}+ \\
\text { trace Cs137 }\end{array}$ & $\begin{array}{c}2,000[\text { low } \mathrm{Cs}+\mathrm{K}] \\
{[\mathrm{hi} \mathrm{Cs}+\mathrm{K}]}\end{array}$ & 15 & $<100$ mesh & $\begin{array}{l}\mathrm{V} / \mathrm{m}=100 \mathrm{~mL} / \mathrm{g}, 100 \mathrm{mg} \text { clay } / 10 \mathrm{~mL},[\mathrm{~K}]=0.2- \\
0.002 \mathrm{~N}, \mathrm{t}=12 \mathrm{~h}\end{array}$ & Wahlberg 1962 & $\begin{array}{l}\text { exchg capacity due to isomorphous substitutions in the } \\
\text { crystal lattice and to broken bonds at edges of clay particles } \\
\text { (per Ref therein Grim-1 } 1953.132-133 \text { ) }\end{array}$ \\
\hline $\begin{array}{l}\text { halloysite, No. } 12 \mathrm{~b} \text { (sodium saturated form, } \\
\text { Bedford, IN deposits) }\end{array}$ & $\mathrm{Cs}(\mathrm{I})$ & $\begin{array}{l}10^{-10}-0.1 \mathrm{IN}+ \\
\text { trace Css } 137\end{array}$ & $\begin{array}{c}150,000[\text { low } \mathrm{Cs}+\mathrm{Na}] 1 \\
\quad[\mathrm{hi} \mathrm{Cs}+\mathrm{Na}]\end{array}$ & 19 & $<100$ mesh & $\begin{array}{l}\mathrm{V} / \mathrm{m}=100 \mathrm{~mL} / \mathrm{g}, 100 \mathrm{mg} \text { clay } / 10 \mathrm{~mL},[\mathrm{Na}]=0.2- \\
0.002 \mathrm{~N}, \mathrm{t}=12 \mathrm{~h}\end{array}$ & Wahlberg 1962 & $\begin{array}{l}\text { exchg capacity due to dissociation of structural hydroxyl } \\
\text { groups at surface of crystals and to broken bonds at edges } \\
\text { of clay particles (per Ref therein, Grim-1953) }\end{array}$ \\
\hline $\begin{array}{l}\text { halloysite, No. } 12 \mathrm{~b} \text { (potassium saturated } \\
\text { form, Bedford, } \mathrm{IN} \text { deposits) }\end{array}$ & $\mathrm{Cs}(\mathrm{I})$ & $\begin{array}{l}10^{-10}-0.1 \mathrm{~N}+ \\
\text { trace Cs } 137\end{array}$ & $\begin{aligned} 400[\text { low } \mathrm{Cs}+\mathrm{K}] & 1 \\
{[\mathrm{hi} \mathrm{Cs}+\mathrm{K}] } & \end{aligned}$ & 19 & $<100$ mesh & $\begin{array}{l}\mathrm{V} / \mathrm{m}=100 \mathrm{~mL} / \mathrm{g}, 100 \mathrm{mg} \text { clay } / 10 \mathrm{~mL},[\mathrm{~K}]=0.2- \\
0.002 \mathrm{~N}, \mathrm{t}=12 \mathrm{~h}\end{array}$ & Wahlberg 1962 & $\begin{array}{l}\text { exchg capacity due to dissociation of structural hydroxyl } \\
\text { groups at surface of crystals and to broken bonds at edges } \\
\text { of clay particles (per Ref therein, Grim-1953) }\end{array}$ \\
\hline $\begin{array}{l}\text { halloysite, No. } 12 \mathrm{~b} \text { (magnesium saturated } \\
\text { form, Bedford, } \mathrm{N} \text { deposits) }\end{array}$ & $\mathrm{Cs}(\mathrm{I})$ & $\begin{array}{l}10^{-10}-0.1 \mathrm{~N}+ \\
\text { trace Cs } 137\end{array}$ & 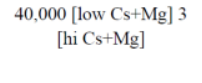 & 19 & $<100$ mesh & $\begin{array}{l}\mathrm{V} / \mathrm{m}=100 \mathrm{~mL} / \mathrm{g}, 100 \mathrm{mg} \text { clay } / 10 \mathrm{~mL},[\mathrm{Mg}]=0.2- \\
0.002 \mathrm{~N}, \mathrm{t}=12 \mathrm{~h}\end{array}$ & Wahlberg 1962 & $\begin{array}{l}\text { exchg capacity due to dissociation of structural hydroxyl } \\
\text { groups at surface of crystals and to broken bonds at edges } \\
\text { of clay particles (per Ref therenin, Grim-1953) }\end{array}$ \\
\hline $\begin{array}{l}\text { halloysite, No. } 12 \mathrm{~b} \text { (calcium saturaed form, } \\
\text { Bedford, IN deposits) }\end{array}$ & $\mathrm{Cs}(\mathrm{I})$ & $\begin{array}{l}10^{-10}-0.1 \mathrm{~N}+ \\
\text { trace Cs } 137\end{array}$ & $\begin{array}{c}30,000[\text { low Cs+Ca] } 1 \\
{[\text { hi Cs+Ca] }}\end{array}$ & 19 & $<100$ mesh & $\begin{array}{l}\mathrm{V} / \mathrm{m}=100 \mathrm{~mL} / \mathrm{g}, 100 \mathrm{mg} \text { clay } / 10 \mathrm{~mL},[\mathrm{Ca}]=0.2- \\
0.002 \mathrm{~N}, \mathrm{t}=12 \mathrm{~h}\end{array}$ & Wahlberg 1962 & $\begin{array}{l}\text { exchg capacity due to dissociation of structural hydroxyl } \\
\text { groups at surface of crystals and to broken bonds at edges } \\
\text { of clay particles (per Ref therein, Grim-1953) }\end{array}$ \\
\hline
\end{tabular}




\begin{tabular}{|c|c|c|c|c|c|c|c|c|c|}
\hline Sorbent material & Element & $\begin{array}{c}\text { Concentration } \\
\text { of element }\end{array}$ & $\begin{array}{l}\mathrm{Kd} \text { in } \mathrm{mL} / \mathrm{g} \text { (or othe } \\
\text { units or } \% \text { sorbedd }\end{array}$ & & $\begin{array}{c}\text { CEC (meq/ } \\
100 \mathrm{~g} \text { ) }\end{array}$ & $\begin{array}{l}\text { BET area }(\mathrm{m} 2 / \mathrm{g}) \\
\text { or Size (microns) }\end{array}$ & Solution Conditions & Reference & Notes \\
\hline $\begin{array}{l}\text { kaolinite, No } 4 \text { (sodium saturated form, } \\
\text { Macon, BA deposits) }\end{array}$ & $\mathrm{Cs}(\mathrm{I})$ & $\begin{array}{l}10^{-10}-0.1 \mathrm{~N}+ \\
\text { trace Csi37 }\end{array}$ & $\begin{array}{c}700[\text { low } \mathrm{Cs}+\mathrm{Na}] \\
{[\mathrm{hi} \mathrm{Cs}+\mathrm{Na}]}\end{array}$ & 1 & 10 & $<100$ mesh & $\begin{array}{l}\mathrm{V} / \mathrm{m}=100 \mathrm{~mL} / \mathrm{g}, 100 \mathrm{mg} \text { clay } / 10 \mathrm{~mL},[\mathrm{Na}]=0.2- \\
0.002 \mathrm{~N}, \mathrm{t}=12 \mathrm{~h}\end{array}$ & Wahlberg 1962 & $\begin{array}{l}\text { exchy capacity due to dissociation of structural hydroxyl } \\
\text { groups at surface of crystals and to broken bonds at edges } \\
\text { of clay particles (per Ref therein, Grim-1953) }\end{array}$ \\
\hline $\begin{array}{l}\text { kaolinite, No. } 4 \text { (potassium saturated form, } \\
\text { Macon, BA deposits) }\end{array}$ & $\mathrm{Cs}(\mathrm{I})$ & $\begin{array}{l}10^{-10}-0.1 \mathrm{~N}+ \\
\text { trace Css137 }\end{array}$ & $\begin{array}{r}700[\text { low Cs+K] } \\
{[\mathrm{hi} \mathrm{Cs}+\mathrm{K}]}\end{array}$ & 1 & 10 & $<100$ mesh & $\begin{array}{l}\mathrm{V} / \mathrm{m}=100 \mathrm{~mL} / \mathrm{g}, 100 \mathrm{mg} \text { clay } / 10 \mathrm{~mL},[\mathrm{~K}]=0.2- \\
0.002 \mathrm{~N}, \mathrm{t}=12 \mathrm{~h}\end{array}$ & Wahlberg 1962 & $\begin{array}{l}\text { exchy capacity due to dissociation of structural hydroxyl } \\
\text { groups at surface of crystals and to broken bonds at edges } \\
\text { of clay particles (per Ref therein, Grim-1953) }\end{array}$ \\
\hline $\begin{array}{l}\text { kaolinite, No. } 4 \text { (magnesium saturated form, } \\
\text { Macon, BA deposits) }\end{array}$ & $\mathrm{Cs}(\mathrm{I})$ & $\begin{array}{l}10^{-10}-0.1 \mathrm{~N}+ \\
\text { trace Css } 137\end{array}$ & $\begin{array}{c}400[\text { low } \mathrm{Cs}+\mathrm{Mg}] \\
{[\mathrm{hi} \mathrm{Cs}+\mathrm{Mg}]}\end{array}$ & 2 & 10 & $<100$ mesh & $\begin{array}{l}\mathrm{V} / \mathrm{m}=100 \mathrm{~mL} / \mathrm{g}, 100 \mathrm{mg} \text { clay } / 10 \mathrm{~mL}],[\mathrm{Mg}]=0.2- \\
0.002 \mathrm{~N}, \mathrm{t}=12 \mathrm{~h}\end{array}$ & Wahlberg 1962 & $\begin{array}{l}\text { exchy capacity due to dissociation of structural hydroxyl } \\
\text { groups at surface of crystals and to broken bonds at edges } \\
\text { of clay particles (per Ref therein, Grim-1953) }\end{array}$ \\
\hline $\begin{array}{l}\text { kaolinite, No. } 4 \text { (calium saturated form, } \\
\text { Macon, BA deposits) }\end{array}$ & $\mathrm{Cs}(\mathrm{I})$ & $\begin{array}{l}10^{-10}-0.1 \mathrm{~N}+ \\
\text { trace Css137 }\end{array}$ & $\begin{array}{r}400[\text { low } \mathrm{Cs}+\mathrm{Ca}] \\
{[\mathrm{hi} \mathrm{Cs}+\mathrm{Ca}]}\end{array}$ & 1 & 10 & $<100$ mesh & $\begin{array}{l}\mathrm{V} / \mathrm{m}=100 \mathrm{~mL} / \mathrm{g}, 100 \mathrm{mg} \text { clay } / 10 \mathrm{~mL},[\mathrm{Ca}]=0.2- \\
0.002 \mathrm{~N}, \mathrm{t}=12 \mathrm{~h}\end{array}$ & Wahlberg 1962 & $\begin{array}{l}\text { exchg capacity due to dissociation of structural hydroxyl } \\
\text { groups at surface of crystals and to broken bonds at edges } \\
\text { of clay particles (per Ref therein, Grim-1953) }\end{array}$ \\
\hline illite & $\mathrm{Cs}(\mathrm{I})$ & $\begin{array}{l}\text { details in } \\
\text { patent? }\end{array}$ & details in patent? & & & & details in patent? & Wendling 2004 & $\begin{array}{l}\text { Cesium uptake by plants depends on adsorption/desorption } \\
\text { reactions in the soil, as well as root uptake processes } \\
\text { controlled by the plant. In this study, sorption and } \\
\text { desorption of } \mathrm{Cs}+\text { on ref. illite (IMt-1) was investigated in } \\
\text { the presence of oxalate to gain understanding of } \\
\text { mechanisms by which plant root exudates may influence } \\
\mathrm{Cs}+\text { bioavailability in micaceous soils. Cesium sorption on } \\
\text { illite decreased significantly as oxalate concn. increased } \\
\text { from } 0.4 \text { to } 2 \mathrm{mM} \text {. Cesium desorption from illite increased } \\
\text { significantly with increasing oxalate concn. Desorption of } \\
\mathrm{Cs}+\text { by exchange with Na+, Ca2 } 2 \text { and } \mathrm{Mg} 2+\text { was } \\
\text { significantly enhanced in the presence of oxalate as } \\
\text { selectivity for } \mathrm{Cs}+\text { decreased with respect to these ions in } \\
\text { the presence of oxalate. On the other hand, oxalate had } \\
\text { little effect on the } \mathrm{Cs}+\mathrm{K}+\text { selectivity coeff. This suggests } \\
\text { that oxalate treatments increase the relative proportion of } \\
\text { exchange sites that are not hightly selective for } \mathrm{C}+\text { and } \mathrm{K}+\text {; } \\
\text { e.g. "planar" sites. The results indicate that oxalate plays an } \\
\text { important role in } \mathrm{Cs} \text { binding on illite and, therefore, plant } \\
\text { rhizosphere chem. is likely to alter } \mathrm{Cs}+\text { bioavailability in } \\
\text { micaceous soils. }\end{array}$ \\
\hline titanium silicate (synthesized using TiOSO4) & $\mathrm{Cs}(\mathrm{I})$ & $\begin{array}{c}2 \mathrm{e}-10 \text { and } 7 \mathrm{e}-5 \\
\mathrm{M}\end{array}$ & 6 to $4 \mathrm{e} 4 \mathrm{~mL} / \mathrm{g}$ & & & 120 to $726 \mathrm{~m} 2 / \mathrm{g}$ & $\mathrm{I}=0.1 \mathrm{M} \mathrm{Na}^{+}, \mathrm{t}=2 \mathrm{~h}, 1 / 100$ to $1 / 1000 \mathrm{~g} \mathrm{~mL}$ & Lujaniene 2009 & Ref therein $20,21 \mathrm{Cs}$ and $\mathrm{Sr}$ sorption onto crystalline TiSi \\
\hline $\begin{array}{l}\text { chazabite, clinoptilolite, } \mathrm{HTiSi}, \mathrm{KTiGe}, \\
\text { KTiSiGe, KTSgel, KTSsol, NaTi }\end{array}$ & $\mathrm{Cs}(\mathrm{I})$ & trace Cs-137? & le3 to $2 \mathrm{e} 5 \mathrm{~mL} / \mathrm{g}$ & & & & $\begin{array}{l}\mathrm{pH}=11,1: 200 \text { and } 1: 1000 \mathrm{~g} / \mathrm{mL}, \text { groundwater } \\
\text { simulant: [Na] }=3 \mathrm{e}-4 \mathrm{M},[\mathrm{Mg}=2 \mathrm{e}-4 \mathrm{M},[\mathrm{CO} 32- \\
]=1 \mathrm{e}-4 \mathrm{M},[\mathrm{OH}-]=2 \mathrm{e}-3 \mathrm{M},[\mathrm{NO}-\mathrm{-}-\mathrm{e}=2 \mathrm{e}-4 \mathrm{M}, \\
{[\mathrm{SO} 42-]=2 \mathrm{e}-4 \mathrm{M}}\end{array}$ & Behrens 1998 & $\begin{array}{l}\text { Table } 3 \text { summarizes Kd_Cs for sorbents, KTiSiGe }>\text { KTiGe } \\
\sim \text { HTiSi } \sim \text { KTSsol, lowest w NaTi }\end{array}$ \\
\hline $\begin{array}{l}\text { chazabite, clinoptilolite, HTiSi, KTiGe, } \\
\text { KTiSiGe, KTSgel, KTSsol, NaTi }\end{array}$ & $\mathrm{Cs}(\mathrm{I})$ & trace & 7 to $300 \mathrm{~mL} / \mathrm{g}$ & & & & $\begin{array}{l}\mathrm{pH}=14,1: 200 \mathrm{~g} / \mathrm{mL}, \text { defense waste simulants: } \\
{[\mathrm{Na}]=5 \mathrm{M},[\mathrm{Al}]=0.4 \mathrm{M},[\mathrm{K}]=0.03-0.1,[\mathrm{CO} 32-} \\
]=0.04-0.2 \mathrm{M},[\mathrm{OH}-]=2 \mathrm{M},[\mathrm{NO}-\mathrm{s}-]=2 \mathrm{M}\end{array}$ & Behrens 1998 & $\begin{array}{l}\text { Tables } 4 \text { and } 5 \text { summarizes Kd_Cs for sorbents, NaTi }> \\
\text { HTiSi }>\text { KTSgel }\end{array}$ \\
\hline $\begin{array}{l}\text { crystalline silicotitanate (CST, Ionsiv IE-910, } \\
\text { manufactured by UOP) }\end{array}$ & $\mathrm{Cs}(\mathrm{I})$ & $6 \mathrm{ug} / \mathrm{L}$ Cs-137 & $5 e 3$ to $9 \mathrm{e} 4 \mathrm{~mL} / \mathrm{g}$ & & & & 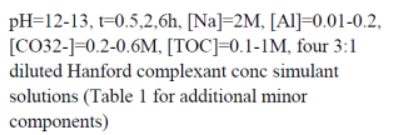 & Marsh 1995 & $\begin{array}{l}\text { Table } 6 \text { includes time dependency of Kd's for various } \\
\text { solutions; lower Kds with organic complexants (untreated } \\
\text { solutions) }\end{array}$ \\
\hline $\begin{array}{l}\text { potassium hexacyanoferrate crystals } \\
\text { (KCoFC, prepd at ORNL) and composite } \\
\text { (KCoFC-PAN, prepd by F. Sebesta, Czech } \\
\text { Techn. Univ.) }\end{array}$ & $\mathrm{Cs}(\mathrm{I})$ & $6 \mathrm{ug} / \mathrm{L}$ Cs-137 & $2 \mathrm{e} 2$ to $9 \mathrm{e} 4 \mathrm{~mL} / \mathrm{g}$ & & & $\begin{array}{l}150-600 \text { micron } \\
\text { crystals }\end{array}$ & 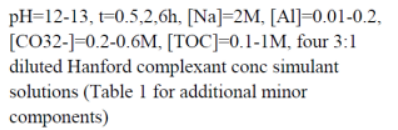 & Marsh 1995 & $\begin{array}{l}\text { Table } 6 \text { includes time dependency of Kd's for various } \\
\text { solutions; lower Kds with organic complexants (untreated } \\
\text { solutions) }\end{array}$ \\
\hline
\end{tabular}




\begin{tabular}{|c|c|c|c|c|c|c|c|c|}
\hline Sorbent material & Element & $\begin{array}{c}\text { Concentration } \\
\text { of element }\end{array}$ & $\begin{array}{l}\mathrm{Kd} \text { in } \mathrm{mL} / \mathrm{g} \text { (or other } \\
\text { units or \% sorbed) }\end{array}$ & $\begin{array}{c}\text { CEC (meq/ } \\
100 \mathrm{~g})\end{array}$ & $\begin{array}{l}\text { BET area }(\mathbf{m} 2 / \mathrm{g}) \\
\text { or Size (microns) }\end{array}$ & Solution Conditions & Reference & Notes \\
\hline $\begin{array}{l}\text { nickel hexacyanoferrate composite (NiFC- } \\
\text { PAN, prepd by F. Sebesta, Czech Techn. } \\
\text { Univ.) }\end{array}$ & $\mathrm{Cs}(\mathrm{I})$ & 6 ug $\mathrm{L}$ Cs-137 & $2 \mathrm{e} 2$ to $9 \mathrm{e} 4 \mathrm{~mL} / \mathrm{g}$ & & & $\begin{array}{l}\mathrm{pH}=12-13, \mathrm{t}=0.5,2,6 \mathrm{~h},[\mathrm{Na}]=2 \mathrm{M},[\mathrm{Al}]=0.01-0.2, \\
{[\mathrm{CO} 22-]=0.2-0.6 \mathrm{M},[\mathrm{TOCC}]=0.1-1 \mathrm{M} \text {, four } 3: 1} \\
\text { diluted Hanford complexant conc simulant } \\
\text { solutions (Table } 1 \text { for additional minor } \\
\text { components) }\end{array}$ & Marsh 1995 & $\begin{array}{l}\text { Table } 6 \text { includes time dependency of Kd's for various } \\
\text { solutions; lower Kds with organic complexants (untreated } \\
\text { solutions) }\end{array}$ \\
\hline $\begin{array}{l}\text { K-Ni hexacyanoferrate (KNiFC-CsTreat } \\
\text { prepd by Japan) }\end{array}$ & $\mathrm{Cs}(\mathrm{I})$ & 10ppm Cs-134 & $\begin{array}{l}\text { le4-1e6 depending on } \\
\text { solution }\end{array}$ & $\begin{array}{l}2.58 \mathrm{meq} / \mathrm{g} \mathrm{K} \\
\text { and } 3.34 \mathrm{meg} / \mathrm{g} \\
\quad \mathrm{Ni}\end{array}$ & $\begin{array}{l}<100 \text { mesh }(<149 \\
\text { um })\end{array}$ & $\begin{array}{l}10 \mathrm{mg} / \mathrm{mL} \text {. Effect of } \mathrm{pH}, \mathrm{Na}+, \mathrm{K}+, \mathrm{NH} 4+\text {, } \\
\text { Ca2+ ions, particle size, kinetics. Samples } \\
\text { equilibrated for } 5 \text { d for tests. }\end{array}$ & Mimura 1997 & 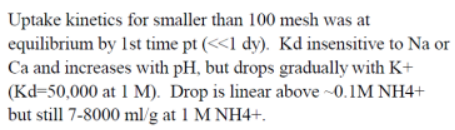 \\
\hline $\begin{array}{l}\text { resorcinol formaldehyde resin (BSC-210, } \\
\text { manufactured by Boulder Sci. Co., converted } \\
\text { to Na form) }\end{array}$ & $\mathrm{Cs}(\mathrm{I})$ & 6 ug/L Cs-137 & le3 to $7 e 3 \mathrm{~mL} / \mathrm{g}$ & & & $\begin{array}{l}\mathrm{pH}=12-13, \mathrm{t}=0.5,2,6 \mathrm{~h},[\mathrm{Na}]=2 \mathrm{M},[\mathrm{Al}]=0.01-0.2, \\
{[\mathrm{CO} 2 \mathrm{C}-\mathrm{e}]=0.2-0.6 \mathrm{M},[\mathrm{TOC}]=0.1-1 \mathrm{M}, \text { four } 3: 1} \\
\text { diluted Hanford complexant conc simulant } \\
\text { solutions (Table } 1 \text { for additional minor } \\
\text { components) }\end{array}$ & Marsh 1995 & $\begin{array}{l}\text { Table } 6 \text { includes time dependency of Kd's for various } \\
\text { solutions; lower Kds with organic complexants (untreated } \\
\text { solutions) }\end{array}$ \\
\hline $\begin{array}{l}\text { Superlig } 666 \text { (proprietary macrocycle, prepd } \\
\text { by IBC Adv. Technol., Inc.) }\end{array}$ & $\operatorname{Cs}(\mathrm{I})$ & 6 ug L Cs-137 & 30 to $4 \mathrm{e} 3 \mathrm{~mL} / \mathrm{g}$ & & & 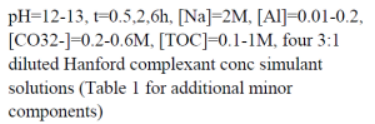 & Marsh 1995 & $\begin{array}{l}\text { Table } 6 \text { includes time dependency of Kd's for various } \\
\text { solutions; higher Kds with organic complexants (untreated } \\
\text { solutions) }\end{array}$ \\
\hline $\begin{array}{l}\text { SuperLig } 644 \text { (polymeric resin containing } \\
\text { poly (hydroxyarlyne) groups) } \\
\text { ligand }\end{array}$ & $\mathrm{Cs}(\mathrm{I})$ & $\begin{array}{l}\mathrm{Cs} 137=\sim 200 \\
\text { uCimL; } \\
6.7 \times 10^{-}-5 \mathrm{M} \\
\text { total Cs }\end{array}$ & $\begin{array}{l}400-2000 \mathrm{~mL} / \mathrm{g} \\
\text { depending on } \mathrm{Na} / \mathrm{Cs} \\
\text { ratio. }\end{array}$ & $\begin{array}{l}0.72 \text { to } 3.46 \\
\text { mmole } 9 \text { resin, } \\
\text { depending on } \\
\text { the Hanford } \\
\text { tank } \\
\text { composition }\end{array}$ & $\begin{array}{l}20-70 \text { mesh } \\
\text { granules and was } \\
\text { used received }\end{array}$ & $\begin{array}{l}\text { General composition was } 5 \mathrm{M} \mathrm{Na}+, \mathrm{K}(0.12 \mathrm{M}) \text {, } \\
\mathrm{Al}(0.7), \mathrm{NO} 3-(1.0 \mathrm{M}), \mathrm{NO} 2-(0.87 \mathrm{M}) \text {, and free } \\
\mathrm{OH}-(1.9 \mathrm{M}) \text { but varied between tank solutions. }\end{array}$ & Hassan 2002 & volumeresin mass ratio (phase ratio) was typically $\sim 100: 1$. \\
\hline $\begin{array}{l}\text { potassium hexacyanoferrate crystals } \\
\text { (KCoFC, prepd at ORNL) }\end{array}$ & $\mathrm{Cs}(\mathrm{I})$ & 6 ug/ Cs-137 & $7 e l$ to $9 e 4 \mathrm{~mL} / \mathrm{g}$ & & $150-600$ microns & $\begin{array}{l}\mathrm{pH}=14, \mathrm{t}=0.5,2,6 \mathrm{~h},[\mathrm{Na}]=4 \mathrm{M},[\mathrm{Al}]=0.4 \mathrm{M}, \\
{[\mathrm{CO} 2 \mathrm{C} 2]=2 \mathrm{M},[\mathrm{TOCC}]=0.1-1.7 \mathrm{M}, \text { four Hanford }} \\
\text { Tank 101-S simulant solutions (Table } 1 \text { for } \\
\text { additional minor components) }\end{array}$ & Marsh 1995 & $\begin{array}{l}\text { Table } 6 \text { includes time dependency of Kd's for various } \\
\text { solutions; lower Kds with organic complexants (untreated } \\
\text { solutions) }\end{array}$ \\
\hline $\begin{array}{l}\text { nickel hexacyanoferrate composite (NiFC- } \\
\text { PAN, prepd by F. Sebesta, Czech Techn. } \\
\text { Univ.) }\end{array}$ & $\mathrm{Cs}(\mathrm{I})$ & $6 \mathrm{ug} / \mathrm{Ls}-137$ & $3 e 1$ to $3 e 3 \mathrm{~mL} / \mathrm{g}$ & & & $\begin{array}{l}\mathrm{pH}=14, \mathrm{t}=0.5,2,6 \mathrm{~h},[\mathrm{Na}]=4 \mathrm{M},[\mathrm{Al}]=0.4 \mathrm{M}, \\
{[\mathrm{CO} 2-\mathrm{M} 2 \mathrm{=}, \mathrm{M},[\mathrm{TOCC}]=0.1-0.7 \mathrm{M}, \text { four Hanford }} \\
\text { Tank 101-S simulant solutions (Table } 1 \text { for } \\
\text { additional minor components) }\end{array}$ & Marsh 1995 & $\begin{array}{l}\text { Table } 6 \text { includes time dependency of Kd's for various } \\
\text { solutions; lower Kds with organic complexants (untreated } \\
\text { solutions) }\end{array}$ \\
\hline $\begin{array}{l}\text { Ammonium molybdophosphate- } \\
\text { polyacrylonitrile (AMP-PAN) composite } \\
\text { sorbents (prepd by F. Sebesta, Czech Techn. } \\
\text { Univ.) }\end{array}$ & $\mathrm{Cs}(\mathrm{I})$ & $\begin{array}{l}100 \mathrm{mg} \text { AMP- } \\
\text { PAN in } 15 \mathrm{mg} \mathrm{L} \\
\text { Cs in } 10 \mathrm{~mL} \\
\text { solution. }\end{array}$ & $\begin{array}{l}>10 \wedge 5 \mathrm{~mL} / \mathrm{g} \text { in } 1-2 \\
\text { HNO3 and or } 1-2 \mathrm{M} \\
\text { NaNO3; 4000mL } / \mathrm{g} \text { in } \\
0.5 \mathrm{M} \mathrm{KNO} 3 \text { and }\end{array}$ & $\begin{array}{l}22.5,19.8 \text { and } \\
19.6 \mathrm{mg} \mathrm{Cs} / \mathrm{g} \\
\text { sorbent for } 5 \text {, } \\
10 \text { and } 20\end{array}$ & $\begin{array}{c}0.3-0.6 \mathrm{~mm} \\
\text { diameter }\end{array}$ & & & $\begin{array}{l}\text { AMP-PAN SF02 sorbent was composed of } 85.7 \mathrm{w} \text { t\% AMP } \\
\text { and } 14.3 \mathrm{wt} \% \text { PAN. } 1.5 \mathrm{~cm} 3 \text { column BV at flowrates of } 5 \text {, } \\
10 \text { and } 20 \text { bed } \\
\text { volumes per hour }\end{array}$ \\
\hline $\begin{array}{l}\text { crystalline silicotitanate (Ionsiv IE-910, CST, } \\
\text { manufactured by UOP) }\end{array}$ & $\mathrm{Cs}(\mathrm{I})$ & 6 ug L Cs-137 & $2 \mathrm{e} 3$ to $4 \mathrm{e} 3 \mathrm{~mL} / \mathrm{g}$ & & & $\begin{array}{l}\mathrm{pH}=14, \mathrm{t}=0.5,2,6 \mathrm{~h},[\mathrm{Na}]=4 \mathrm{M},[\mathrm{Al}]=0.4 \mathrm{M}, \\
{[\mathrm{CO} 2-\mathrm{z}=2 \mathrm{M},[\mathrm{TOC}]=0.1-0.7 \mathrm{M}, \text { four Hanford }} \\
\text { Tank 101-SY simulant solutions (Table } 1 \text { for } \\
\text { additional minor components) }\end{array}$ & Marsh 1995 & $\begin{array}{l}\text { Table } 6 \text { includes time dependency of Kd's for various } \\
\text { solutions; slightly lower Kds with organic complexants } \\
\text { (untreated solutions) }\end{array}$ \\
\hline $\begin{array}{l}\text { resorcinol formaldehyde resin (BSC-210, } \\
\text { manufactured by Boulder Sci. Co., converted } \\
\text { to Na form) }\end{array}$ & $\mathrm{Cs}(\mathrm{I})$ & 6 ug L Cs-137 & $6 e 2$ to $3 e 3 \mathrm{~mL} / \mathrm{g}$ & & & $\begin{array}{l}\mathrm{pH}=14, \mathrm{t}=0.5,2,6 \mathrm{~h},[\mathrm{Na}]=4 \mathrm{M},[\mathrm{Al}]=0.4 \mathrm{M}, \\
{[\mathrm{CO} 2 \mathrm{2} 2]=2 \mathrm{M},[\mathrm{TOCC}]=0.1-0.7 \mathrm{M}, \text { four Hanford }} \\
\text { Tank 101-SY simulant solutions (Table } 1 \text { for } \\
\text { additional minor components) }\end{array}$ & Marsh 1995 & $\begin{array}{l}\text { Table } 6 \text { includes time dependency of Kd's for various } \\
\text { solutions; slightly lower Kds with organic complexants } \\
\text { (untreated solutions) }\end{array}$ \\
\hline $\begin{array}{l}\text { polymeric macrocycle (Superlig } 666, \\
\text { proprietary, prepd by IBC Adv. Technol., } \\
\text { Inc.) }\end{array}$ & $\mathrm{Cs}(\mathrm{I})$ & 6 ug L Cs-137 & $6 e 2$ to $4 \mathrm{e} 3 \mathrm{~mL} / \mathrm{g}$ & & & $\begin{array}{l}\mathrm{pH}=14, \mathrm{t}=0.5,2,6 \mathrm{~h},[\mathrm{Na}]=4 \mathrm{M},[\mathrm{Al}]=0.4 \mathrm{M}, \\
{[\mathrm{CO} 2 \mathrm{2}-\mathrm{e}=2 \mathrm{M},[\mathrm{TOC}]=0.1-0.7 \mathrm{M}, \text { four Hanford }} \\
\text { Tank 101-SY simulant solutions (Table } 1 \text { for } \\
\text { additional minor components) }\end{array}$ & Marsh 1995 & $\begin{array}{l}\text { Table } 6 \text { includes time dependency of Kd's for various } \\
\text { solutions; slightly lower Kds with organic complexants } \\
\text { (untreated solutions) }\end{array}$ \\
\hline silicotitanate (IONSIV IE-911, UOP) & $\mathrm{Cs}(\mathrm{I})$ & trace $\mathrm{Cs}-137$ & $710 \mathrm{~mL} / \mathrm{g}$ & & & $\begin{array}{l}\mathrm{pH}>14, \mathrm{t}=72 \mathrm{~h},[\mathrm{Na}]=5 \mathrm{M},[\mathrm{K}]=0.5 \mathrm{M}, \\
\mathrm{Na} / \mathrm{Cs}=8 \mathrm{e} 4 \text { (Attachment A for detailed contents } \\
\text { of DSSF waste simulant) }\end{array}$ & Brown 1996 & $\begin{array}{l}12-14 \% \text { increase in Cs loading with } 25 \text {-fold dilution of } \\
\text { waste }(5 \mathrm{M} \text { to } 0.2 \mathrm{M} \mathrm{Na})\end{array}$ \\
\hline $\begin{array}{l}\text { crystalline silicotitanate (IONSIV IE-910, } \\
\text { UOP) }\end{array}$ & $\mathrm{Cs}(\mathrm{I})$ & trace $\mathrm{Cs}-137$ & $910 \mathrm{~mL} / \mathrm{g}$ & & & $\begin{array}{l}\mathrm{pH}>14, \mathrm{t}=72 \mathrm{~h},[\mathrm{Na}]=5 \mathrm{M},[\mathrm{KK}]=0.5 \mathrm{M}, \\
\mathrm{Na} / \mathrm{Cs}=8 \mathrm{e} 4 \text { (Attachment A for detailed contents } \\
\text { of DSSF waste simulant) }\end{array}$ & Brown 1996 & $\begin{array}{l}\text { 12-14\% increase in Cs loading with } 25 \text {-fold dilution of } \\
\text { waste ( } 5 \mathrm{M} \text { to } 0.2 \mathrm{M} \text { Na) }\end{array}$ \\
\hline
\end{tabular}




\begin{tabular}{|c|c|c|c|c|c|c|c|c|}
\hline Sorbent material & Element & $\begin{array}{c}\text { Concentration } \\
\text { of element }\end{array}$ & $\begin{array}{l}\mathrm{Kd} \text { in } \mathrm{mL} / \mathrm{g} \text { (or other } \\
\text { units or \% sorbed) }\end{array}$ & $\begin{array}{c}\text { CEC (meq/ } \\
100 \mathrm{~g})\end{array}$ & $\begin{array}{l}\text { BET area (m2/g) } \\
\text { or Size (microns) }\end{array}$ & Solution Conditions & Reference & Notes \\
\hline $\begin{array}{l}\text { zeolite (aluminosilicate, IONSIV TIE-96, } \\
\text { UOP) }\end{array}$ & $\mathrm{Cs}(\mathrm{I})$ & trace Cs-137 & $21 \mathrm{~mL} / \mathrm{g}$ & & & $\begin{array}{l}\mathrm{pH}>14, \mathrm{t}=72 \mathrm{~h},[\mathrm{Na}]=5 \mathrm{M},[\mathrm{K}]=0.5 \mathrm{M}, \\
\mathrm{Na} / \mathrm{Cs}=8 \mathrm{e} 4 \text { (Attachment A for detailed contents } \\
\text { of DSSF waste simulant) }\end{array}$ & Brown 1996 & $\begin{array}{l}\text { double Cs loading with } 25 \text {-fold dilution of waste (5M to } \\
0.2 \mathrm{M} \mathrm{Na} \text { ) }\end{array}$ \\
\hline $\begin{array}{l}\text { polymeric macrocycle (SuperLig 644, IBC } \\
\text { Advanced Technol.) }\end{array}$ & $\mathrm{Cs}(\mathrm{I})$ & trace Cs-137 & $500 \mathrm{~mL} / \mathrm{g}$ & & & $\begin{array}{l}\mathrm{pH}>14, \mathrm{t}=72 \mathrm{~h},[\mathrm{Na}]=5 \mathrm{M},[\mathrm{K}]=0.5 \mathrm{M}, \\
\mathrm{Na} / \mathrm{Cs}=8 \mathrm{e} 4 \text { (Attachment A for detailed contents } \\
\text { of DSSF waste simulant) }\end{array}$ & Brown 1996 & $\begin{array}{l}40-45 \% \text { decrease in Cs loading with } 25 \text {-fold dilution of } \\
\text { waste ( } 5 \mathrm{M} \text { to } 0.2 \mathrm{M} \mathrm{Na} \text { ) }\end{array}$ \\
\hline $\begin{array}{l}\text { resorcinol-formaldehyde resin (BSC-187- } \\
210 \text {, Boulder Sci.) }\end{array}$ & $\operatorname{Cs}(\mathrm{I})$ & trace Cs-137 & $220 \mathrm{~mL} / \mathrm{g}$ & & & $\begin{array}{l}\mathrm{pH}>14, \mathrm{t}=72 \mathrm{~h},[\mathrm{Na}]=5 \mathrm{M},[\mathrm{K}]=0.5 \mathrm{M}, \\
\mathrm{Na} / \mathrm{Cs}=8 \mathrm{e} 4 \text { (Attachment } \mathrm{A} \text { for detailed contents } \\
\text { of DSSF waste simulant) }\end{array}$ & Brown 1996 & $\begin{array}{l}40-45 \% \text { decrease in } \mathrm{Cs} \text { loading with } 25 \text {-fold dilution of } \\
\text { waste }(5 \mathrm{M} \text { to } 0.2 \mathrm{M} \mathrm{Na})\end{array}$ \\
\hline $\begin{array}{l}\text { phenol-formaldehyde resin (Duolite CS-100, } \\
\text { Rohm \& Hass) }\end{array}$ & $\mathrm{Cs}(\mathrm{I})$ & trace $\mathrm{Cs}-137$ & $88 \mathrm{~mL} / \mathrm{g}$ & & & $\begin{array}{l}\mathrm{pH}>14, \mathrm{t}=72 \mathrm{~h},[\mathrm{Na}]=5 \mathrm{M},[\mathrm{K}]=0.5 \mathrm{M}, \\
\mathrm{Na} / \mathrm{Cs}=8 \mathrm{e} 4 \text { (Attachment A for detailed contents } \\
\text { of DSSF waste simulant) }\end{array}$ & Brown 1996 & $\begin{array}{l}40-45 \% \text { decrease in Cs loading with } 25 \text {-fold dilution of } \\
\text { waste ( } 5 \mathrm{M} \text { to } 0.2 \mathrm{M} \mathrm{Na} \text { ) }\end{array}$ \\
\hline kaolinite & $\mathrm{Cs}(\mathrm{I})$ & $1 \mathrm{kBq} / \mathrm{mL}$ & 3,287 & 170 & $2 u m$ & {$\left[\mathrm{CaCl}^{2}\right]=0.01 \mathrm{M}, \mathrm{pH} \sim 7, \mathrm{t}=24 \mathrm{~h}, \mathrm{~g}$ clay $\mathrm{L}$} & Bellenger (2008) & CEC in mol_ckg \\
\hline montmorillonite & $\mathrm{Cs}(\mathrm{I})$ & $1 \mathrm{kBq} / \mathrm{mL}$ & 4,514 & 940 & $2 u m$ & {$\left[\mathrm{CaCl}^{2}\right]=0.01 \mathrm{M}, \mathrm{pH} \sim 7, \mathrm{t}=24 \mathrm{~h}, 1 \mathrm{~g}$ clay $\mathrm{L}$} & Bellenger (2008) & CEC in mol_c $\mathrm{kg}$ \\
\hline illite & $\mathrm{Cs}(\mathrm{I})$ & $5 \mathrm{kBq} / \mathrm{mL}$ & 155,000 & 300 & $<\mathrm{um}$ & {$[\mathrm{CaCl} 2]=0.01 \mathrm{M}, \mathrm{pH} \sim 7, \mathrm{t}=24 \mathrm{~h}, 1 \mathrm{~g}$ clay $/ \mathrm{L}$} & Bellenger (2008) & CEC in mol_ckg \\
\hline quartz & $\mathrm{Cs}(\mathrm{I})$ & $1 \mathrm{kBq} / \mathrm{mL}$ & 0 & & $<200 \mathrm{um}$ & {$[\mathrm{CaCl} 2]=0.01 \mathrm{M}, \mathrm{pH} \sim 7, \mathrm{t}=24 \mathrm{~h}, 10 \mathrm{~g} / \mathrm{L}$} & Bellenger (2008) & CEC in mol_ckg \\
\hline calcium carbonate & $\mathrm{Cs}(\mathrm{I})$ & $1 \mathrm{kBq} / \mathrm{mL}$ & 33.8 & & & {$[\mathrm{CaCl} 2]=0.01 \mathrm{M}, \mathrm{pH} \sim 7, \mathrm{t}=24 \mathrm{~h}, 10 \mathrm{~g} / \mathrm{L}$} & Bellenger (2008) & CEC in mol_ckg \\
\hline
\end{tabular}




\section{References Cited in Appendix B}

Ahmad-1989. Ahmad, S. and I.H. Qureshi, "Separation of radionuclides from liquid waste using a mineral mixture,” Sep. Sci. Technol., 24(7-8), 569-579, 1989.

Bakunov-1989. Bakunov, N.A. and E.B. Yudintseva, "Decreased accumulation of Cs137 in plants following amendment of soils with natural sorbents," Agrokhimiya, 6, 90-96, 1989; in Russian.

Behrens-1998. Behrens, et al., "Assessment of a sodium nonatitanate and pharmacosiderite-type ion exchangers for $\mathrm{Sr}$ and $\mathrm{Cs}$ removal from DOE waste simulants,” Environ. Sci. Technol. 32, 101-107, 1998.

Bellenger-2008. Bellenger and Staunton, "Adsorption and desorption of 85Sr and 137Cs on reference minerals with and without inorganic and organic surface coatings," J. Environ. Radioactivity 99, 831-840, 2008.

Brown-1996. Brown, et al., "Comparison of Organic and inorganic ion exchangers for removal of $\mathrm{Cs}$ and $\mathrm{Sr}$ from simulated and actual Hanford 241-AW-101 DSSF tank waste," Pacific Northwest National Lab Report, PNNL-11120, 70 pgs., 1996.

Hassan-2002. Hassan, et al., "Ion exchange removal of cesium from Hanford tank waste supernates with SuperLig 644 resin," Journal of Radioanalytical and Nuclear Chemistry, 254, 1, 33-40, 2002.

Lujaniene-2009. Lujaniene, et al., "Application of inorganic sorbents for removal of Cs $\mathrm{Sr} \mathrm{Pu}$ and Am from contaminated solutions," J. Radioanl. Nucl. Chem. 282, 787-791, 2009.

Manos-2009. Manos, M.J. and M.G. Kanatzidis, JACS, 131 (18), 6599-6607, 2009.

Marsh-1995. Marsh, et al., "Effects of soluble organic complexants and their degradation products on the removal of selected radionuclides from high level waste, Part II" Los Alamos National Lab Report, LA-12943, 47 pgs., 1995.

Marsh-1995. Marsh, et al., "Effects of soluble organic complexants and their degradation products on the removal of selected radionuclides from high level waste, Part III" Los Alamos National Lab Report, LA-13000, 64 pgs., 1995.

McKinley-1993. McKinley, I.G. and A. Scholits, "A comparison of radionuclide sorption databases used in recent performance assessments," J. Contaminant Hydrology, 13, 347363, 1993. In Table 3.

McKinley-1993. McKinley, I.G. and A. Scholits, "A comparison of radionuclide sorption databases used in recent performance assessments," J. Contaminant Hydrology, 13, 347363, 1993. In Table 4.

Mimura-1997. Mimura, et al., "Ion Exchange of Cesium on Potassium Nickel Hexacyanoferrate(II)s,” J. Nucl. Sci. Techn., 34 (5) 484-489, 1997.

Mishra-2007. Mishra, S.P. and Vijaya, "Removal behavior of hydrous manganese oxide and hydrous stannic oxide for Cs(I) ions from aqueous solutions," Sep. Purif. Technol. 54, 10-17, 2007. 
Murali-2002. Murali, M.S. and J.N. Mathur, "Sorption characteristics of Am(III), Sr(II), and Cs(I) on bentonite and granite," J. Radioanal. Nucl. Chem., 254(1), 129-136, 2002.

Rehspringer-2004. Rehspringer, J-L., C. Estournes, and S. Vilminot, French Patent, "Process for containment of cesium and/or rubidium in fritted ceramic matrices based on expanded perlite," FR 2844913 A1 20040326, 2004.

Sabodina-2006. Sabodina, M.N., et al., "Neptunium, plutonium and 137Cs sorption by bentonite clays and their speciation in pore waters," J. Radioanal. Nucl. Chem., 2006.

Spalding. Spalding, B.P. and G.K. Jacobs, ORNL, ES Division.

Wahlberg-1962. Wahlberg and Fishman, "Adsorption of Cs on clay minerals," USGS Bulletin, Vol 1140-A., 1962.

Wendling-2004. Wendling, et al., "Cesium sorption to illite as affected by oxalate," Clays and Clay Minerals, 52(3), 375-381, 2004. 

Argonne

Nuclear Engineering Division

Argonne National Laboratory

9700 South Cass Avenue, Bldg. 205

Argonne, IL 60439-4854

www.anl.gov 